\title{
CARACTERIZACIÓN DE POLIMORFISMOS EN LOS GENES PPARG, CEBPA, LIPE, RXRA Y FABP4 ASOCIADOS A METABOLISMO LIPÍDICO EN RAZAS DE GANADO BOVINO
}

\section{Daniel Estanislao Goszczynski}

Trabajo de tesis para ser presentado como requisito parcial para optar al Título de DOCTOR en CIENCIAS VETERINARIAS

Área Genética y Producción Animal

PROGRAMA DE POSGRADO

EN CIENCIAS VETERINARIAS

FACULTAD DE CIENCIAS VETERINARIAS

UNIVERSIDAD NACIONAL DE LA PLATA

La Plata, Argentina

Diciembre, 2014 
A mis padres,

Graciela y Daniel 


\section{AGRADECIMIENTOS}

Quisiera expresar mi agradecimiento a aquellas personas que de alguna manera participaron en la realización del presente trabajo.

- Dr. Guillermo Giovambattista, director del trabajo de tesis, por haberme guiado a través de todo este trayecto. Por la atención, el tiempo, la disposición, el respeto y el buen humor brindados. También por ayudarme en la escritura, revisión y corrección del texto.

- Dra. María Verónica Ripoli, co-directora del trabajo de tesis, por el compromiso, la comprensión y la solidaridad, sobre todo en mis etapas más difíciles desde lo personal. También por ayudarme en la escritura, revisión y corrección del trabajo.

- Dra. Pilar Peral García, directora del IGEVET, por haberme permitido desarrollar mi trabajo en el instituto, y por la constante buena predisposición a atender mis inquietudes y necesidades.

- A todos los integrantes del IGEVET, que aportaron de maneras diversas al desarrollo de este trabajo y con quienes compartí gratos momentos.

- A mis amigos Ezequiel, Germán, Simona y Cristian por acompañarme en los buenos y malos momentos a lo largo de estos cinco años.

Especialmente, a mis padres Daniel y Graciela, y a mi hermana Sara, quienes me brindaron siempre su apoyo y realizaron esfuerzos gigantes para que yo siguiera adelante. 


\section{ÍNDICE}

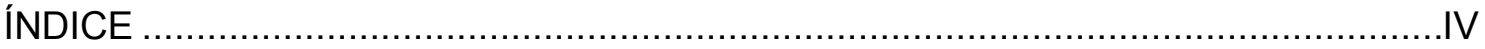

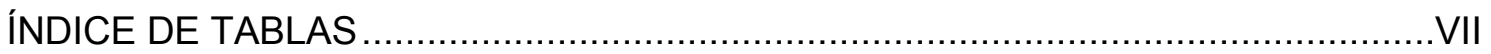

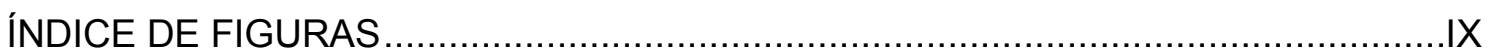

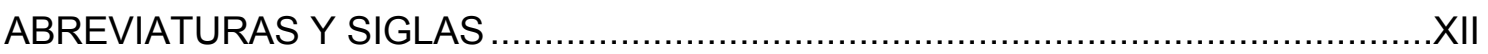

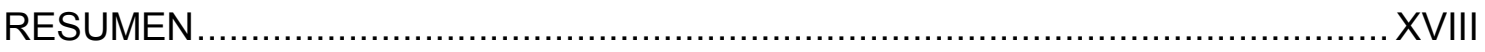

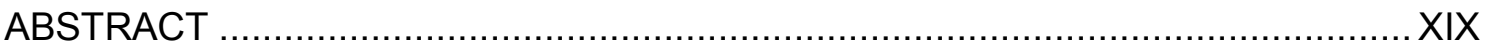

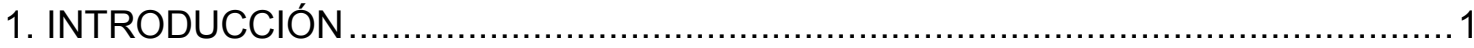

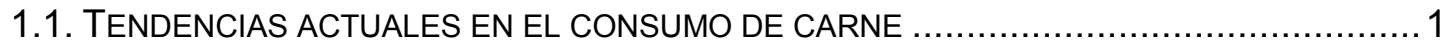

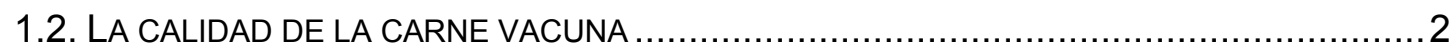

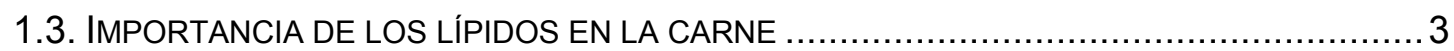

1.4. MEJORAMIENTO POR CONTROL DIETARIO .................................................. 4

1.5. MEJORAMIENTO POR CONTROL GENÉTICO ....................................................... 5

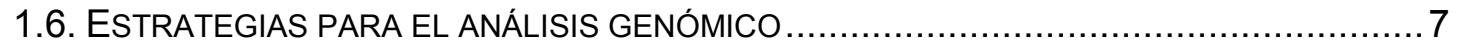

1.7. ADIPOGÉNESIS, LIPOGÉNESIS Y LIPÓLISIS ................................................. 8

1.8. GENES CANDIDATOS PARA LA DETERMINACIÓN DEL MARMOLEO ............................. 11

1.8.1. Receptor Gamma Activado por el Factor Proliferador de Peroxisomas

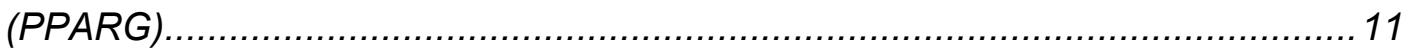

1.8.2. Proteína de Unión al Amplificador CCAAT Alpha (CEBPA)....................... 18

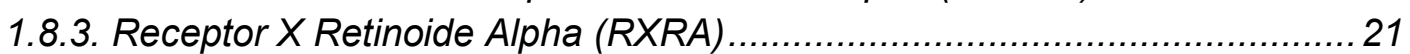

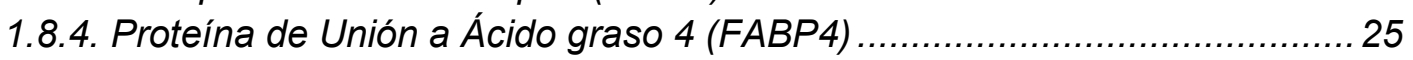

1.8.5. Lipasa Sensible a Hormona (LIPE) ................................................ 32

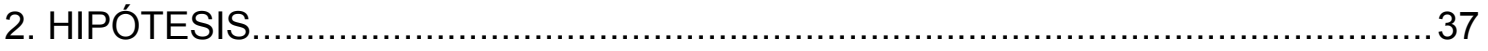

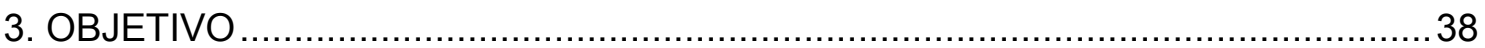

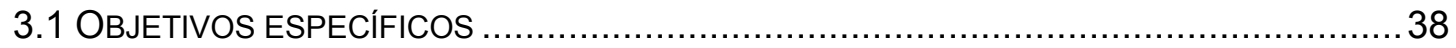

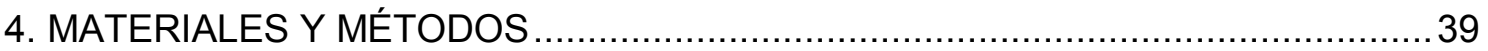

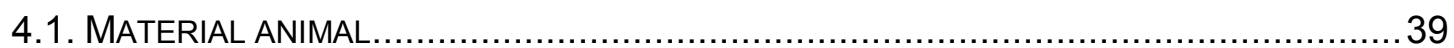

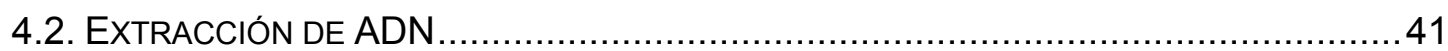

4.3. ESTUDIO DE RE-SECUENCIACIÓN: AMPLIFICACIÓN, SECUENCIACIÓN Y ANÁLISIS DE LAS

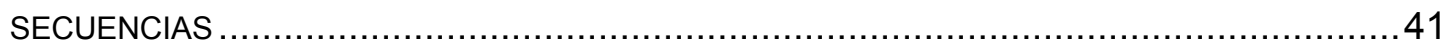

4.4. VALIDACIÓN POBLACIONAL DE POLIMORFISMOS: SELECCIÓN Y GENOTIPIFICACIÓN DE

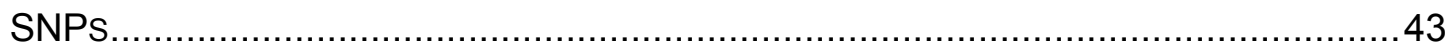

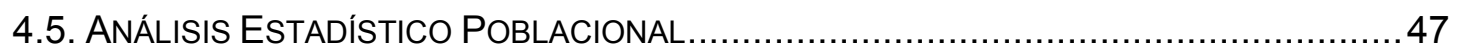

4.6. MEDICIÓN DE LAS VARIABLES FENOTÍPICAS DE CALIDAD DE CARNE $\ldots \ldots \ldots \ldots \ldots \ldots \ldots . . . . . . . . .47$

4.7. ANÁLISIS DE ASOCIACIÓN ENTRE LOS MARCADORES GENÉTICOSY LAS VARIABLES DE CONTENIDO Y COMPOSICIÓN DE GRASA DE LA CARNE .......................................... 48

4.8. MODELADO ESTRUCTURAL Y PREDICCIÓN DE EFECTOS ...................................... 48

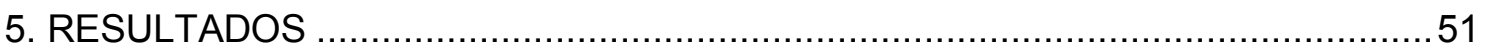

5.1. ESTUDIO DE RE-SECUENCIACIÓN DE GENES CANDIDATOS PARA CONTENIDO Y

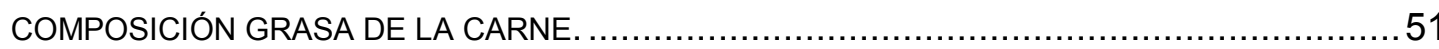

5.1.1. PPARG (Receptor Gamma Activado por el Proliferador de Peroxisomas) . 51 
5.1.2. CEBPA (Proteína de Unión al Amplificador CCAAT Alfa).........................5 54

5.1.3. LIPE (Lipasa Sensible a Hormona) ................................................... 55

5.1.4. FABP4 (Proteína de Unión a Ácidos Grasos 4) ......................................59

5.2. SELECCIÓN Y VALIDACIÓN DE SNPS A NIVEL POBLACIONAL ................................6. 62

5.2.1. PPARG (Receptor Gamma Activado por el Proliferador de Peroxisomas) . 62

5.2.2. CEBPA (Proteína de Unión al Amplificador CCAAT Alfa)..........................63 63

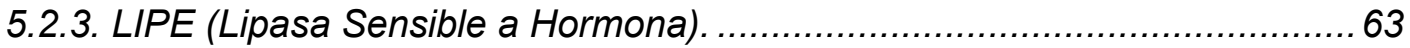

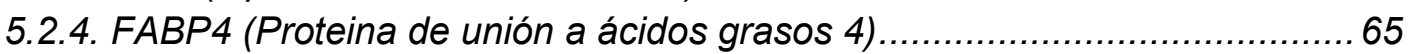

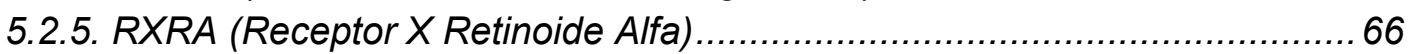

5.3. ANÁLISIS ESTADÍSTICO DE LOS POLIMORFISMOS ESTUDIADOS ............................67

5.3.1. Caracterización de los polimorfismos analizados en el gen PPARG

(Receptor Gamma Activado por el Proliferador de Peroxisomas) ......................6 67

5.3.2. Caracterización de los polimorfismos analizados en el gen CEBPA (Proteína de Unión al Amplificador CCAAT Alfa) ............................................................... 68

5.3.3. Caracterización de los polimorfismos analizados en el gen LIPE (Lipasa

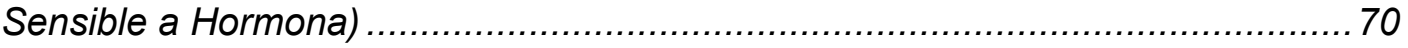

5.3.4. Caracterización de los polimorfismos analizados en el gen FABP4 (Proteína de Unión a Ácidos Grasos 4) .................................................................... 71

5.3.5. Caracterización de los polimorfismos analizados en el gen RXRA (Receptor

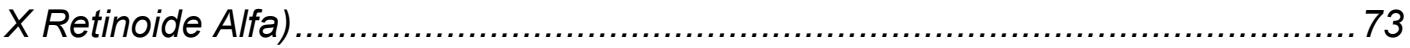

5.4. DETERMINACIÓN DE LOS HAPLOTIPOS PRESENTES EN LOS GENES ANALIZADOS ....... 75

5.4.1. Determinación de haplotipos del gen PPARG (Receptor Gamma Activado

por el Proliferador de Peroxisomas)............................................................. 75

5.4.2. Determinación de haplotipos del gen LIPE (Lipasa Sensible a Hormona).. 76

5.4.3. Determinación de haplotipos del gen FABP4 (Proteina de unión a ácidos

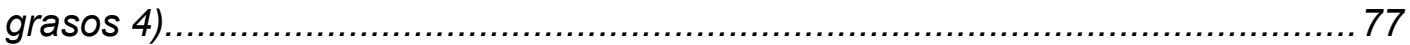

5.4.4. Determinación de haplotipos del gen RXRA (Receptor X Retinoide Alfa)... 78

5.5. ESTUDIOS DE ASOCIACIÓN ENTRE LOS SNPS ANALIZADOS Y CARACTERES DE

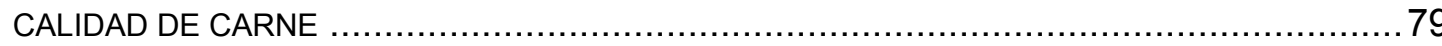

5.5.1. Asociación de los SNPs del gen PPARG con caracteres de calidad de carne

79

5.5.2. Asociación de los SNPs del gen CEBPA con caracteres de calidad de carne

5.5.3. Asociación de los SNPs del gen LIPE con caracteres de calidad de carne 81 5.5.4. Asociación de los SNPs del gen FABP4 con caracteres de calidad de carne

5.5.5. Asociación de los SNPs del gen RXRA con caracteres de calidad de carne

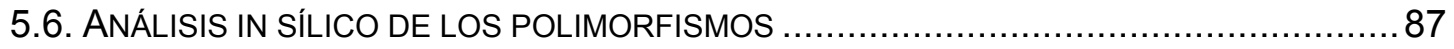

5.6.1. Análisis in sílico de los polimorfismos del gen PPARG........................... 87

5.6.2. Análisis in sílico del polimorfismo del gen CEBPA .................................... 91

5.6.3. Análisis in sílico de los polimorfismos del gen LIPE ............................... 92

5.6.4. Análisis in sílico de los polimorfismos del gen FABP4.............................. 94

5.6.5. Análisis in sílico de los polimorfismos del gen RXRA ................................99

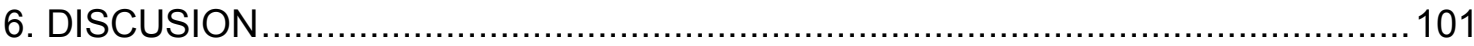

6.1. ANÁLISIS DE LA VARIABILIDAD PRESENTE EN LOS GENES ESTUDIADOS..................101 
6.2. ASOCIACIÓN ENTRE LOS SNPS SELECCIONADOS CON CARACTERES DE CALIDAD DE CARNE Y ESTUDIOS DE PREDICCIÓN.

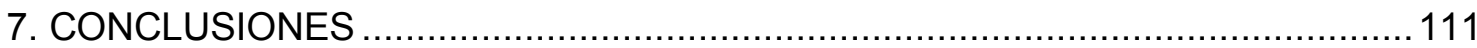

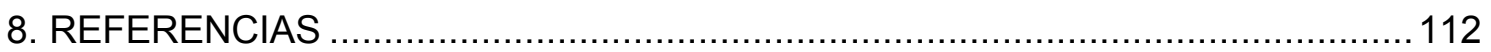

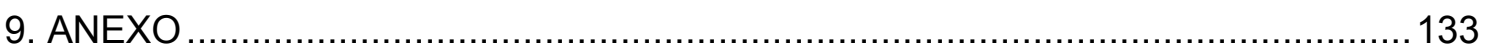

KIT DE PURIFICACIÓN DE ADN GENÓMICO WIZARD® (PROMEGA, MADISON, WI, USA) 133 EXTRACCIÓN DE ADN DE LAS MUESTRAS DE CARNE.................................. 134

PREPARACIÓN DE GELES DE POLIACRILAMIDA 6 \% ........................................ 134

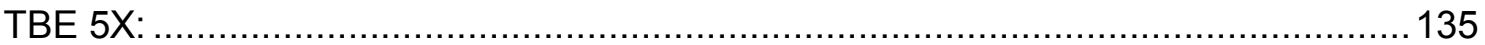

PREPARACIÓN DE LAS MUESTRAS PARA SU SIEMBRA .................................... 135

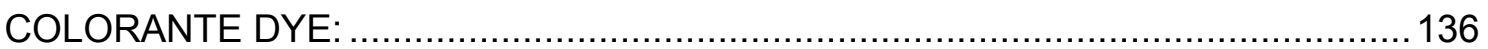

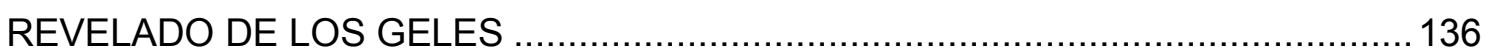

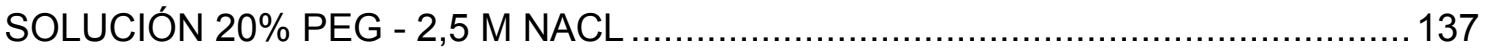

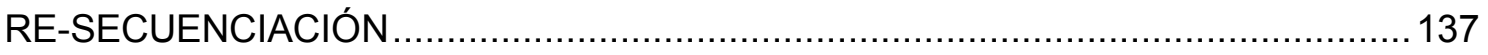

PROTOCOLO REACCIONES DE SECUENCIACIÓN .......................................... 139

PREPARADO DE MUESTRAS PARA PIROSECUENCIACIÓN ............................... 140

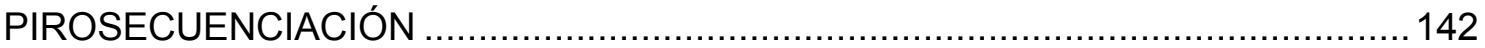

GENOTIPIFICACIÓN DE SNPS POR PIROSECUENCIACIÓN............................... 145

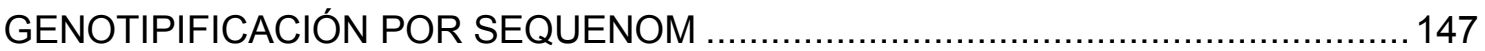




\section{ÍNDICE DE TABLAS}

TABLA 1. SNPS REPORTADOS EN LA BASE DE DATOS GENBANK PARA EL GEN

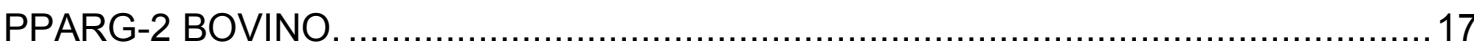

TABLA 2. POLIMORFISMOS REPORTADOS EN EL GEN BOVINO CEBPA. ...........21

TABLA 3. SNPS REPORTADOS PARA EL GEN BOVINO RXRA ..........................24

TABLA 4. SNPS REPORTADOS PARA EL GEN BOVINO FABP4 ........................... 31

TABLA 5. SNPS REPORTADOS EN LAS ZONAS CODIFICANTES DEL GEN

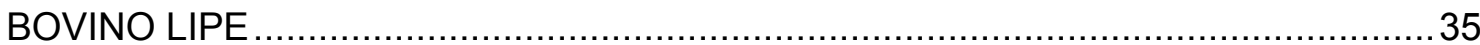

TABLA 6. ESTRUCTURA DEL PANEL MUESTREARIO “B” .....................................40

TABLA 7. CEBADORES DISEÑADOS PARA AMPLIFICAR LAS REGIONES CODIFICANTES DE LOS GENES PPARG, CEBPA, RXRA, LIPE Y FABP4

MEDIANTE PCR-SECUENCIACIÓN

TABLA 8- POLIMORFISMOS EN EL GEN BOVINO PPARG DETECTADOS POR RESECUENCIACIÓN EN EL PANEL "A".

TABLA 9. POLIMORFISMOS EN EL GEN CEBPA DETECTADOS POR RESECUENCIACIÓN EN LAS MUESTRAS DEL PANEL "A"...

TABLA 10. POLIMORFISMOS DETECTADOS POR RE-SECUENCIACIÓN DEL GEN BOVINO LIPE EN EL PANEL DE MUESTRAS "A".

TABLA 11. POLIMORFISMOS DETECTADOS POR RE-SECUENCIACIÓN DEL GEN BOVINO FABP4 EN EL PANEL DE MUESTRAS "A".

TABLA 12. FRECUENCIAS ALÉLICAS DE LOS POLIMORFISMOS

SELECCIONADOS DE PPARG TIPIFICADOS EN EL PANEL DE MUESTRAS "B"... 67

TABLA 13. HETEROCIGOSIDAD ESPERADA (HE), HETEROCIGOSIDAD OBSERVADA (HO) Y P-VALUE DEL EQUILIBRIO DE HARDY-WEINBERG (HWE) PARA LOS SNPS DE PPARG EN LAS SUBPOBLACIONES Y EN LA POBLACIÓN DEL PANEL "B".

TABLA 14. FRECUENCIAS ALÉLICAS DEL SNP RS210446561 DE CEBPA TIPIFICADO EN EL PANEL DE MUESTRAS "B".

TABLA 15. HETEROCIGOSIDAD ESPERADA (HE), HETEROCIGOSIDAD OBSERVADA (HO) Y P-VALUE DEL EQUILIBRIO DE HARDY-WEINBERG (HWE) PARA EL SNP RS210446561 DE CEBPA EN LAS SUBPOBLACIONES Y LA POBLACIÓN ENTERA DEL PANEL "B"

TABLA 16. FRECUENCIAS ALÉLICAS DE LOS POLIMORFISMOS SELECCIONADOS DE LIPE TIPIFICADOS EN EL PANEL "B"

TABLA 17. HETEROCIGOSIDAD ESPERADA (HE), HETEROCIGOSIDAD OBSERVADA (HO) Y P-VALUE DEL EQUILIBRIO DE HARDY-WEINBERG (HWE) PARA LOS SNPS DE LIPE EN LAS SUBPOBLACIONES Y LA POBLACIÓN ENTERA DEL PANEL "B" 
TABLA 18. FRECUENCIAS ALÉLICAS DE LOS POLIMORFISMOS

SELECCIONADOS DE FABP4 TIPIFICADOS EN EL PANEL DE MUESTRAS "B".... 72

TABLA 19. HETEROCIGOSIDAD ESPERADA (HE), HETEROCIGOSIDAD

OBSERVADA (HO) Y P-VALUE DEL EQUILIBRIO DE HARDY-WEINBERG (HWE)

PARA LOS SNPS DE FABP4 EN LAS SUBPOBLACIONES Y LA POBLACIÓN

ENTERA DEL PANEL "B".

TABLA 20. FRECUENCIAS ALÉLICAS DE LOS POLIMORFISMOS

SELECCIONADOS DE RXRA TIPIFICADOS EN EL PANEL DE MUESTRAS "B".....74

TABLA 21. HETEROCIGOSIDAD ESPERADA (HE), HETEROCIGOSIDAD

OBSERVADA (HO) Y P-VALUE DEL EQUILIBRIO DE HARDY-WEINBERG (HWE)

PARA LOS SNPS DE RXRA EN LAS SUBPOBLACIONES Y LA POBLACIÓN

ENTERA DEL PANEL "B"

TABLA 22. MEDIAS DE CUADRADOS MÍNIMOS DE LOS VALORES DE ÁCIDOS GRASOS Y ERROR ESTÁNDAR (ES) PARA LAS CLASES GENOTÍPICAS DE LOS POLIMORFISMOS RS207671117 Y RS42016945 DEL GEN BOVINO PPARG.

TABLA 23. MEDIAS DE CUADRADOS MÍNIMOS DE LOS VALORES DE ÁCIDOS GRASOS Y ERROR ESTÁNDAR (ES) PARA LAS CLASES GENOTÍPICAS DEL POLIMORFISMO RS210446561 DEL GEN BOVINO CEBPA..

TABLA 24. MEDIAS DE CUADRADOS MÍNIMOS DE LOS VALORES DE ÁCIDOS GRASOS Y ERROR ESTÁNDAR (ES) PARA LAS CLASES GENOTÍPICAS DE LOS POLIMORFISMOS RS109759779, RS109598915 Y RS41887406 DEL GEN BOVINO LIPE.

TABLA 25. MEDIAS DE CUADRADOS MÍNIMOS DE LOS VALORES DE ÁCIDOS GRASOS Y ERROR ESTÁNDAR (ES) PARA LAS CLASES GENOTÍPICAS DE LOS POLIMORFISMOS RS41729173, RS110757796, RS110652478, RS110383592 Y RS111014258 DEL GEN BOVINO FABP4.

TABLA 26. MEDIAS DE CUADRADOS MÍNIMOS DE LOS VALORES DE ÁCIDOS GRASOS Y ERROR ESTÁNDAR (ES) PARA LAS CLASES GENOTIIPICAS DE LOS POLIMORFISMOS RS133517803 Y RS207774429 DEL GEN BOVINO RXRA.

TABLA 27. VOLÚMENES DE REACTIVOS EMPLEADOS EN EL KIT DE EXTRACCIÓN DE ADN GENÓMICO WIZARD®. 


\section{ÍNDICE DE FIGURAS}

FIG. 1. GENES INVOLUCRADOS EN LA ADIPOGÉNESIS ................................ 9

FIG. 2. RUTA DE SEÑALIZACIÓN DE PPARS. .............................................. 12

FIG. 3. REPRESENTACIÓN ESQUEMÁTICA DEL PPARG Y SUS DOMINIOS..........13

FIG. 4. MODELO DE REGULACIÓN DE LA TRANSCRIPCIÓN POR EL MECANISMO

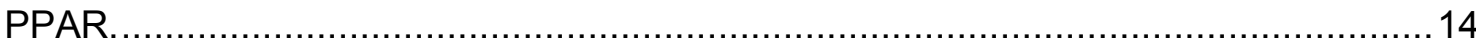

FIG. 5. ESTRUCTURAS CRISTALIZADAS DE PPARG VISUALIZADAS CON JMOL..

FIG. 6 ESTRUCTURA DEL DOMINIO BZIP DE CEBPA UNIDO A ADN................... 19

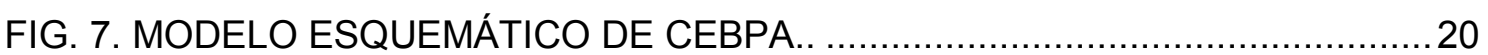

FIG. 8. ESTRUCTURA Y DOMINIOS DEL RXRA.............................................. 23

FIG. 9. ESTRUCTURA CRISTALOGRÁFICA DE FABP4 UNIDA A ÁCIDO OLEICO.. 26

FIG. 10. MODELO DE INTERACCIÓN ENTRE AMINOÁCIDOS ESPECÍFICOS DE

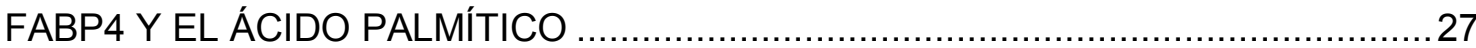

FIG. 11. ACTIVACIÓN DE PPARS POR INCORPORACIÓN DE ÁCIDOS GRASOS . 28

FIG. 12. MODELO ESQUEMÁTICO DEL TRANSPORTE DE ÁCIDOS GRASOS POR

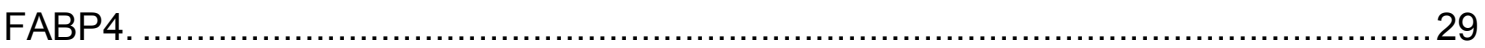

FIG. 13. DOMINIOS FUNCIONALES DE FABP4 ......................................... 29

FIG. 14. REPRESENTACIÓN ESQUEMÁTICA DE LA DEGRADACIÓN COORDINADA DE TRIGLICÉRIDO A DIACILGLICÉRIDO Y MONOGLICÉRIDO......33

FIG. 15. ESTRUCTURA DEL DOMINIO CATALÍTICO DE LIPE ................................ 33

FIG. 16. DISTRIBUCIÓN DE LOS CEBADORES PARA LA PIROSECUENCIACIÓN DEL SNP RS110757796 DEL EXÓN 2 DEL GEN FABP4.

FIG. 17. CEBADORES DISEÑADOS PARA LA TIPIFICACIÓN DEL SNP RS41610552

DEL GEN PPARG MEDIANTE LA TÉCNICA DE PIROSECUENCIACIÓN 46

FIG. 18. SECUENCIAS DE ADN OBTENIDAS MEDIANTE EL ANÁLISIS DE MUESTRAS DEL PANEL "A" DONDE SE OBSERVAN LOS DIFERENTES SNPS DETECTADOS EN EL GEN PPARG EN ESTADO HETEROCIGOTA.....

FIG. 19. HAPLOTIPOS Y BLOQUES DE LIGAMIENTO DETECTADOS POR RESECUENCIACIÓN DEL GEN BOVINO PPARG Y OBTENIDOS CON EL PROGRAMA HAPLOVIEW 3.31 CON LOS MÉTODOS DE CUATRO GAMETAS.

FIG. 20. SECUENCIAS DE ADN OBTENIDAS MEDIANTE EL ANÁLISIS DE MUESTRAS DEL PANEL "A" DONDE SE OBSERVAN LOS SNPS DETECTADOS EN EL GEN CEPBA EN ESTADO HETEROCIGOTA.

FIG. 21. POLIMORFISMOS DETECTADOS EN EL GEN BOVINO LIPE POR RESECUENCIACIÓN DE LAS MUESTRAS DEL PANEL "A". 
FIG. 22. HAPLOTIPOS Y BLOQUES DE LIGAMIENTO DETECTADOS EN EL GEN BOVINO LIPE A PARTIR DE LOS DATOS DEL ANÁLISIS DE RE-SECUENCIACIÓN Y OBTENIDOS POR MEDIO DEL PROGRAMA HAPLOVIEW 3.31.

FIG. 23. DISTRIBUCIÓN DE LOS SNPS DETECTADOS EN EL GEN BOVINO FABP4 POR RE-SECUENCIACIÓN..

FIG. 24. HAPLOTIPOS Y DESEQUILIBRIO DE LIGAMIENTO EN EL GEN BOVINO FABP4 OBTENIDOS POR RE-SECUENCIACIÓN Y CON EL PROGRAMA HAPLOVIEW 3.31.

FIG. 25. ANÁLISIS DE CONSERVACIÓN DE RESIDUOS A NIVEL EVOLUTIVO EN EL GEN BOVINO LIPE

FIG. 26. ANÁLISIS DE LIGAMIENTO Y HAPLOTIPOS ENTRE LOS SNPS SELECCIONADOS DEL GEN PPARG, OBTENIDOS MEDIANTE EL MÉTODO SÓLIDO IMPLEMENTADO EN EL PROGRAMA HAPLOVIEW 76

FIG. 27. ANÁLISIS DE LIGAMIENTO Y HAPLOTIPOS ENTRE LOS SNPS SELECCIONADOS DE LIPE, OBTENIDOS MEDIANTE EL MÉTODO SÓLIDO IMPLEMENTADO EN EL PROGRAMA HAPLOVIEW

FIG. 28. ESTUDIO DE LIGAMIENTO Y HAPLOTIPOS ENTRE LOS SNPS SELECCIONADOS DE FABP4, BLOQUES OBTENIDOS MEDIANTE EL MÉTODO SÓLIDO IMPLEMENTADO EN EL PROGRAMA HAPLOVIEW

FIG. 29. ESTUDIO DE LIGAMIENTO Y HAPLOTIPOS ENTRE LOS SNPS SELECCIONADOS DE RXRA, OBTENIDOS MEDIANTE EL MÉTODO SÓLIDO IMPLEMENTADO EN EL PROGRAMA HAPLOVIEW

FIG. 30. SECUENCIA UTR5' DE LA ISOFORMA 2 DE PPARG Y ALGUNOS DE SUS SITIOS DE UNIÓN A FACTORES DE UNIÓN A ARN

FIG. 31. ESTRUCTURA SECUNDARIA DE LA REGIÓN UTR 5' DE LA ISOFORMA 2 DEL GEN BOVINO PPARG PREDICHA CON MFOLD WEB SERVER.

FIG. 32. SECUENCIAS UTR5' DE LA ISOFORMA 1 DE PPARG Y ALGUNOS DE LOS SITIOS DE UNIÓN A FACTORES DE UNIÓN A ARN PREDICHOS POR RBPDB. ... 89

FIG. 33. ESTRUCTURA SECUNDARIA DE LA REGIÓN UTR 5' DEL TRANSCRIPTO ENSBTAT00000044042 DE LA ISOFORMA 1 DEL GEN BOVINO PPARG PREDICHA CON MFOLD WEB SERVER.

FIG. 34. ESTRUCTURA SECUNDARIA DE LA REGIÓN UTR 5' DEL TRANSCRIPTO ENSBTAT00000001760 DE LA ISOFORMA 1 DEL GEN BOVINO PPARG PREDICHA CON MFOLD WEB SERVER.

FIG. 35. MODELADO MOLECULAR DEL DOMINIO CATALÍTICO PUTATIVO DE LIPE

FIG. 36. POSIBLES EFECTOS DE LA MUTACIÓN RS110652478 (VAL110MET) SOBRE LA ESTRUCTURA PROTEICA DE FABP4, PREDICHA A PARTIR DE LA ESTRUCTURA DE FABP4 HUMANA POR HHPRED.

FIG. 37. EFECTOS DE LA MUTACIÓN RS110757796 (ILE74VAL) SOBRE LA ESTRUCTURA PROTEICA DE FABP4, PREDICHA A PARTIR DE LA ESTRUCTURA DE FABP4 HUMANA POR HHPRED.. 
FIG. 38. EFECTOS DE LA MUTACIÓN RS110757796 (ILE74VAL) SOBRE LOS AMINOÁCIDOS DE UNIÓN A LIGANDO DE FABP4, PREDICHA A PARTIR DE LA ESTRUCTURA DE FABP4 HUMANA POR HHPRED.

FIG. 39. SITIOS DE UNIÓN A LOS FACTORES DE TRANSCRIPCIÓN ESRRB,

TFAP2A, TFAP2C Y RUNX3 DETECTADOS EN LA REGIÓN PROMOTORA DE LA VARIANTE 3 DE RXRA

FIG. 40. REPRESENTACIÓN DE LA INTERACCIÓN ENTRE LOS RESIDUOS DE FABP4 Y EL ACIDO PALMITICO EN HUMANOS. 109

FIG 41. REPRESENTACIÓN ESQUEMÁTICA DE UN PROCESO DE SECUENCIACIÓN POR TERMINADORES FLUORESCENTES

FIG 42. REACCIONES INVOLUCRADAS EN LA GENERACIÓN DE LUZ. 142

FIG. 43. PASOS DE LA PIROSECUENCIACIÓN. 144

FIG. 44. PREPARADO DEL MOLDE EN FASE SÓLIDA. 145

FIG. 45. GENOTIPIFICACIÓN POR LA PLATAFORMA SEQUENOM 147 


\section{ABREVIATURAS Y SIGLAS}

50AH. Grupo genético media sangre Angus-Hereford

75A. Grupo genético 3/4 Angus 1/4 Hereford

75H: Grupo genético 3/4 Hereford 1/4 Angus

A: Angus

ACC: Acetil-CoA Carboxilasa

ACS: Acetil-CoA Sintetasa

ADN: Äcido desoxirribonucleico

AF-1: Dominio activador 1

AF-2: Dominio activador 2

AG: Äcidos grasos

AGI: Äcidos grasos insaturados

AGMI: Äcidos grasos monoinsaturados

AGPAT: 1-Acilglicerol-3-fosfato-O-aciltransferasa

AGPI: Äcidos grasos polinsaturados

AGS: Äcidos grasos saturados

$\mathrm{AH} x \mathrm{AH}$ : Cruza entre dos animales Angus-Hereford

ALBP: Proteína de Unión a Lípido de Adipocito

AMPc: Adenosín monofosfato cíclico

ARN: Ácido ribonucleico

ARNm: Ácido ribonucleico mensajero

ATGL: Triglicérido Lipasa de Adipocito

AxH: Cruza de Angus y Hereford 
BTA14: Cromosoma bovino 14

bZIP: Cierre básico de leucina

C14:0: Ácido mirístico

C14:1: Ácido miristoleico

C16:0: Ácido palmítico

C16:1: Ácido palmitoleico

C17:0: Ácido margárico

C18:0: Ácido esteárico

C18:1c9: Ácido oleico

C18:1c11: Ácido vaccénico

C18:2c912: Ácido linoleico

C18:2t912: Ácido linolelaídico

C18:3c91215: Ácido a-linolénico

C18:3c6912: Ácido y-linolénico

C20:0: Ácido araquídico

C20:1: Ácido eicosenoico

C20:2: Ácido eicosadienoico

C20:3c81114: Ácido eicosatriinoico

C20:3n-6: Ácido dohono-c-linolénico

C20:4n-6: Ácido araquidónico

C20:5n-3: Ácido eicosapentaenoico

C21:0: Ácido heneicosílico

C22:5n-3: Ácido docosapentaenoico

C22:6n-3: Ácido docosahexaenoico 
CEBPA: Proteína de Unión al amplificador CCAAT alfa

CEBPB: Proteína de Unión al amplificador CCAAT beta

CEBPD: Proteína de Unión al Amplificador CCAAT delta

CEBPE: Proteína de Unión al Amplificador CCAAT epsilon

CEBPG: Proteína de Unión al Amplificador CCAAT gamma

CEBPZ: Proteína de Unión al Amplificador CCAAT zeta

CICCRA: Cámara de la Industria y Comercio de Carnes de la República Argentina

CLA: Äcido linoleico conjugado

Ct-1: Fragmento carboxi-terminal 1

Ct-2: Fragmento carboxi-terminal 2

DBD: Dominio de unión a ADN

DG: Diglicérido

DGAT1: Diacilglicerol O-aciltransferasa 1

DMSO: Dimetilsulfóxido, DMSO, $\mathrm{CH} 3 \mathrm{SOCH} 3$

EBVs: Valores estimados de cría

EGD: Espesor de grasa dorsal

EGD_PRE: Espesor de grasa dorsal pre-faena

EGD_BIFE: Espesor de grasa dorsal del bife

EIF4-B: factor de iniciación de la traducción eucariota 4-B

EPDs: Diferencias esperadas de progenie

ESRRB: Estrogen Related Receptor Beta

F1: Filial 1

F2: Filial 2

FABP4: Proteina de unión a ácidos grasos - 4 
FAME: Metil-ésteres de ácidos grasos

FAS: Sintetasa de Ácidos Grasos

FDR: Índice de falsos descubrimientos

FT: Factor de transcripción

FUS: proteína fusionada en sarcoma

GH: Hormona de Crecimiento

GPAT: Glicerol-3-Fosfato aciltransferasa

GWAS: Estudios de asociación del genoma completo

H. Hereford

HAxHA: Cruza entre dos animales Hereford-Angus

HDAC: Histona deacetilasa

HSL: Lipasa Sensible a Hormona

HWE: Equilibrio de Hardy-Weinberg

INDEL: Inserción o deleción

INTA: Instituto Nacional de Tecnología Agropecuaria

IPCVA: Instituto de la Promoción de la Carne Vacuna Argentina

LBD: Dominio de unión a ligando

LX. Cruza de F1 con Limousin

LEP: Leptina

LIPE: Lipasa Sensible a Hormona (previamente HSL)

LPL: Lipoprotein Lipasa

LXRA: Receptor Hepático X Alfa

MAF: Frecuencia de alelo mínima

MALDI: Desorción/ionización mediante láser asistida por Matriz 
MBNL1: muscleblind-like Drosophila

MG: Monoglicérido

MGL: Monoglicérido Lipasa

$\mathrm{n}$ : Número de muestras

NCOA2: Coactivador 2 de Receptor Nuclear

NES: Señal de exportación nuclear

NLS: Señal de localización nuclear

NONO: Non-POU domain-containing octamer-binding protein

NPY: Neuropéptido Y

NR: Receptor nuclear de hormona tiroidea/esteroidea

Nt: Amino-terminal

OECD-FAO: Organización para la Cooperación y el Desarrollo EconómicoOrganización de las Naciones Unidas para la Alimentación y la Agricultura

PCR: Reacción en cadena de la polimerasa

PPAP: Fosfatasas del ácido fosfatídico

PPARA: Receptor Alfa Activado por el Factor Proliferador de Peroxisomas

PPARB/D: Receptor Beta/Delta Activado por el Factor Proliferador de

Peroxisomas

PPARG: Receptor Gamma Activado por el Proliferador de Peroxisomas

PPRE: Elemento de respuesta a PPARG

QTLs: Loci de caracteres cuantitativos

R: Módulo regulatorio de LIPE

RUNX3: Runt-related transcription factor 3

RXRA: Receptor X Retinoide Alfa

SCD: $\Delta^{9}$-estearoil-CoA Desaturasa 
SNP: Polimorfismo de nucleótido simple

SREBP: Proteínas de Unión a Elementos Regulatorios de Esterol

TFAP2A: Factor de Transcripción AP-2 Alfa

TFAP2G: Factor de Transcripción AP-2 Gamma

TG: Tiroglobulina

TGI: Triglicérido

TOF: Tiempo de vuelo

TZD: Tiazolidinediona

uORF: Marco de lectura abierto upstream

UTR5': Región no traducida 5'

UTR3': Región no traducida 3'

$\omega-6$ : Ácidos grasos omega-6

$\omega-3$ : Ácidos grasos omega-3

YTHDC1: proteína con dominioYTH 1 


\section{RESUMEN}

La calidad de la carne está determinada por cualidades como el marmoleo, el sabor, la terneza y la composición, entre otras. Estas cualidades están reguladas a distintos niveles, y uno de ellos es la genética. Hoy en día se conoce buena parte de las vías metabólicas que regulan estas características, y se han propuesto "genes candidatos" que codifican factores importantes dentro de estas vías. Los genes PPARG, CEBPA, FABP4, LIPE y RXRA son parte de las vías de diferenciación adipocítica y del metabolismo lipídico. El objetivo de este proyecto fue caracterizar la variabilidad genética en estos genes en razas bovinas con diferente calidad carnicera. Los datos se obtuvieron por medio de técnicas moleculares (reacción en cadena de la polimerasa, re-secuenciación) aplicadas a muestras de ADN extraídas de animales pertenecientes a diferentes razas criadas alrededor del mundo. Luego se realizaron una serie de análisis a través de programas bioinformáticos y herramientas web. Algunos de los polimorfismos detectados en los genes y otros disponibles en las bases de datos de internet fueron seleccionados para realizar estudios de validación a nivel poblacional y análisis estadísticos de asociación a caracteres de calidad carnicera en una población de ganado local. Los resultados fueron diversos: PPARG y CEBPA presentaron una variabilidad moderada, y FABP4 y LIPE presentaron una variabilidad alta. Algunos de los polimorfismos analizados sugieren una asociación a la composición lipídica de la carne y otros caracteres de engrasamiento, como espesor de grasa dorsal. Algunas de las posibles explicaciones biológicas para estas asociaciones fueron analizadas con diferentes herramientas bioinformáticas y se observaron algunos fenómenos interesantes. El conocimiento de la variabilidad existente en estos genes es de importancia para complementar los métodos de selección genética tradicionales y mejorar la calidad del ganado. 


\section{ABSTRACT}

The meat quality is determined by features such as marbling, flavor, tenderness and composition, among others. These qualities are regulated at different levels, and one of them is genetics. Nowadays, many of the metabolic pathways that regulate these features are known, and several genes that encode important factors within these pathways have been suggested as "candidate genes". The PPARG, CEBPA, FABP4, LIPE and RXRA genes are part of the routes of adipocyte differentiation and lipid metabolism. The objective of this project was to characterize the genetic variation in these genes in cattle breeds with different meat quality. The data were obtained by molecular techniques (Polymerase chain reaction, re-sequencing) applied to DNA samples obtained from animals of different breeds raised around the world. A series of analyzes by bioinformatics software and Web tools was then performed. Some of the detected polymorphisms and other SNPs available in internet databases were selected to perform validation studies in a local population and statistical association analyses with meat quality traits. The obtained results evidenced that PPARG and CEBPA had moderate variability, and FABP4 and LIPE had high variability. Some of the polymorphisms analyzed suggested an association to the lipid composition of meat and other traits, such as backfat thickness. Some possible biological explanations for these associations were analyzed with different bioinformatics tools, and interesting phenomena were observed. Knowledge of the variability in these genes is important to complement the traditional breeding methods and improve the quality of livestock. 


\section{INTRODUCCIÓN}

\subsection{Tendencias actuales en el consumo de carne}

Desde tiempos inmemoriales la carne ha formado parte de la dieta del ser humano, dado que es un alimento completo que posee proteínas, minerales, grasas, ácidos grasos, pequeñas cantidades de carbohidratos y otros componentes bioactivos.

El consumo de carnes en general, a nivel mundial, presenta un promedio de

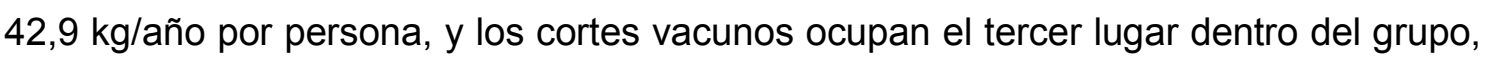
por debajo de las carnes de pollo y cerdo (OECD-FAO. Agricultural Outlook 20132022). En nuestro país en particular, se registra uno de los niveles más elevados de consumo de carne, siendo la carne vacuna la que presenta el mayor nivel, con un valor promedio actual de $59 \mathrm{~kg} / \mathrm{año}$ por persona (CICCRA, 2014). Este valor es aproximadamente cinco veces mayor que el nivel de consumo mundial.

Mientras en el mundo desarrollado el consumo de carne no registra importantes variaciones a lo largo de los últimos años, el consumo anual per cápita de carne en los países en desarrollo va aumentando notoriamente. El crecimiento demográfico, el incremento de los ingresos y de la información disponible, junto con los cambios en las preferencias alimentarias causados por estos factores, han producido un aumento de la demanda de productos pecuarios acompañado de mayores niveles de calidad sanitaria y nutricional, como así también de menor impacto ambiental en la obtención de estos productos. (FAO, 2013). Por esta razón, organismos internacionales como la Organización de las Naciones Unidas para la Alimentación y la Agricultura (FAO) plantean lineamientos que apuntan a generar una "dieta sostenible" a partir de la producción agropecuaria, es decir, generar alimentos con un mínimo uso de los recursos y un bajo costo ambiental, garantizando un estado nutricional saludable y permanente en los consumidores (FAO, 2013).

Considerando este contexto, y dados los valores de consumo de carne en Argentina, la industria de la carne debería comenzar a atender estos nuevos lineamientos basados en la calidad y el desarrollo sustentable de la ganadería. 


\subsection{La calidad de la carne vacuna}

La calidad de la carne se define por su composición, sus cualidades sensoriales y otros factores higiénicos y tecnológicos. La composición constituye el aspecto nutricional y es objetiva, mientras que las propiedades organolépticas como el sabor, color, terneza, marmoleo, jugosidad y aspecto son altamente subjetivas. También hay ciertos atributos externos que determinan calidad, como la marca, el origen e inocuidad alimentaria, entre otros (Warris, 2000).

La carne está compuesta por una cantidad abundante de proteínas, pero también contiene minerales, vitaminas, lípidos y una pequeña parte de carbohidratos (McRae et al., 2005; Nuernberg et al., 2005). Las carnes rojas presentan una gran diversidad de lípidos, y estos compuestos son responsables de buena parte de las propiedades que determinan su calidad, como el sabor, la jugosidad y el valor nutricional. Con respecto a esta última característica, la diversidad lipídica proporciona ventajas y desventajas para el consumo de carnes rojas en general. Por un lado, la carne vacuna es fuente de ácidos grasos (AG) esenciales, como el ácido linoleico, el linolénico y otros ácidos grasos poliinsaturados (AGPI), con propiedades benéficas para la salud. Por otro lado, es fuente de ácidos grasos saturados(AGS) y ácidos grasos "trans", los cuales son considerados factores de incidencia en la aparición de enfermedades cardiovasculares y cánceres (Eynard, 2006; García et al., 2008). Estas cualidades negativas hacen que los consumidores cuestionen el mérito real de la carne como alimento, motivo por el cual el estudio de su contenido y composición lipídica se ha vuelto un tema de interés para la comunidad científica.

La composición química de la carne es compleja y viene determinada por factores extrínsecos e intrínsecos. Se sabe que la composición de AG es afectada por la categoría del animal, el manejo, su constitución genética, el tipo de alimentación utilizado y diversos procesos bioquímicos como la digestión microbiana, la síntesis de novo, la desaturación in-situ y la transferencia de AG entre tejidos (Warriss, 2000; Eggen et al., 2003; Martínez Marín et al., 2010). En función de estos conocimientos, el objetivo principal de la industria de la carne vacuna debería estar enfocado en combinar de la manera más eficaz todos estos factores para obtener un producto de elevado valor nutricional y sensorial. 


\subsection{Importancia de los lípidos en la carne}

Los lípidos son un grupo heterogéneo de moléculas orgánicas que incluye a las grasas, ceras, esteroles, vitaminas liposolubles, monoglicéridos (MGs), diglicéridos (DGs), triglicéridos (TGls) y fosfolípidos entre otros. Conforman la principal reserva energética del organismo, están involucrados en la absorción de vitaminas y son componentes estructurales de las membranas celulares. También actúan como precursores en rutas metabólicas que regulan procesos fisiológicos, como la transmisión neuronal, el desarrollo, la visión (Valenzuela et al., 2008) y los procesos inflamatorios (Rodríguez-Cruz et al., 2005).

Los bovinos disponen principalmente de dos tipos de depósitos grasos que conforman la grasa visceral y la grasa de res. La grasa de res está compuesta por tejido adiposo subcutáneo, intermuscular e intramuscular (Fiems et al., 2000). El tejido adiposo subcutáneo tiene importantes implicancias productivas (Ulbrichtet al., 1991; Fiems et al., 2000) y repercute sobre diferentes características organolépticas de la carne durante el período post-mortem (May et al., 1992). Más allá de esto, la grasa subcutánea generalmente es separada de la carne y no se consume.

A diferencia de la grasa subcutánea, el tejido adiposo intramuscular es consumido como parte de la carne. En algunos países como Estados Unidos o Japón, un elevado contenido de grasa intramuscular es reconocido como un atributo favorable y genera valor agregado. Además, el contenido de grasa intramuscular determina parte de la terneza, puesto que la grasa actúa a modo de dilución sobre el número de fibras, las cuales ejercen la resistencia al corte (Warris, 2000). En Argentina se generan carnes con un contenido reducido de grasa intramuscular, con valores aproximados de $1 \%$ a $5 \%$ estimado como extracto etéreo, lo que responde en buena medida al rechazo por parte de los consumidores de un elevado contenido de grasa intramuscular (IPCVA, 2011). Esto hace que el objetivo de la producción para consumo local sea obtener una res con la mayor proporción de músculo, y la mínima cantidad de grasa subcutánea (espesor de grasa dorsal) requerida por el consumidor y necesaria para su correcta conservación (Mac Loughlin et al., 2011).

Como ya se ha mencionado en la sección 1.2, el perfil lipídico presente en este tejido es determinante para la calidad de la carne debido a las diferentes propiedades fisicoquímicas que presenta cada tipo de lípido. Por ejemplo, los AGS presentan puntos de fusión más altos que los ácidos grasos insaturados (AGI), por lo que un mayor contenido de AGS resultará en una mayor consistencia, lo que afectará a la 
textura y al sabor de la carne. El problema de los AGI es la propensión a la oxidación, la cual afecta la vida útil de la carne, acelerando su degradación. Otra de estas diferencias viene dada por la oxidación durante la cocción, donde se liberan distintos compuestos volátiles dependiendo del perfil de AG que tenga la carne (Warris, 2000). Con el pasar del tiempo, cada vez se conoce más acerca de las propiedades nutricionales y terapéuticas de los ácidos grasos. Nuevos estudios demuestran que el reemplazo de los AGS en la dieta por ácido oleico y otros AGI disminuye el riesgo de enfermedades cardiovasculares reduciendo los lípidos en sangre, particularmente el colesterol LDL (Lopez-Huertas, 2010). En años recientes, los investigadores y los productores han estado intentando desarrollar productos alimenticios, como la leche, con menor contenido de AGS y mayores proporciones de ácidos benéficos como el ácido oleico. También se ha demostrado que el ácido oleico tiene propiedades antitumorales, ya que juega un rol en la activación de diferentes procesos intracelulares involucrados en el desarrollo de carcinomas (Carrillo et al., 2012).

Todos estos factores y otros tantos hacen a la calidad general de la carne, pero es necesario establecer un balance adecuado entre ellos, de manera que se favorezcan tanto la parte nutricional como la sensorial.

\subsection{Mejoramiento por control dietario}

Numerosas investigaciones fueron llevadas a cabo para evaluar el efecto de la dieta sobre la composición de lípidos de la carne (Nuernberg et al., 2005; Warren et al., 2008; Alfaia et al., 2009). Fundamentalmente, estos estudios comparan dietas basadas en forrajes frescos (pasturas) con diferentes dietas de suplementación con granos. Una dieta de alto contenido energético y la ampliación de los períodos de tiempo de engorde incrementan el contenido de grasa intramuscular, la acumulación de tejido adiposo subcutáneo y de grasa abdominal (George, 2001).

También se conoce que la composición lipídica de la carne refleja, en parte, el perfil de ácidos grasos ingerido en la dieta (Scollan et al., 2006). Cuando se comparan las dietas a nivel nutricional, las dietas basadas en pasturas generan carnes con mayor contenido de AGPI, los cuales son, en su mayoría, beneficiosos para la salud, pero con menor contenido de AGMI, sobre todo ácido oleico, ya que este abunda en los granos (Daley et al., 2010).El manejo dietario para mejorar la composición de la carne vacuna es una opción viable, pero muchas veces no resulta de acuerdo a los esperado, ya que depende de algunos otros factores como los procesos de 
biohidrogenación que ocurren en el rumen (Scollan et al., 2006; Vasta et al., 2009) y la raza del animal, entre otros (Garcia et al., 2008). Surge así la necesidad de explorar el ámbito de la genética para complementar los métodos nutricionales de mejoramiento.

\subsection{Mejoramiento por control genético}

Tradicionalmente, la mejora de diversas variables de interés productivo ha sido llevada a cabo mediante programas de selección genética basados en la medición fenotípica de dichas variables con el objeto de estimar un "mérito" genético, propio a cada animal, en respuesta a determinados objetivos de selección. Sin embargo, estas estrategias tienen limitaciones en el caso de variables con baja heredabilidad, como es el caso de variables reproductivas, o en aquellas para las cuales su medición fenotípica es complicada, costosa y/o tardía dentro del ciclo productivo, como ocurre con el marmoleo y la composición de la carne en bovinos. En estos casos los programas de selección resultan limitados debido al tiempo y a los gastos que son necesarios para llevar a cabo las pruebas de progenie en toros seleccionados (Barendse et al., 2004). Muchas asociaciones de razas publican los Valores Estimados de Cría (EBVs, Estimated Breeding Values), o las Diferencias Esperadas de Progenie (EPD, Expected Progeny Difference) para marmoleo. Ambas medidas son equivalentes y se calculan combinando mediciones realizadas en los mataderos con datos obtenidos a partir del ultrasonido en la descendencia de toros con mérito genético. En este contexto, surge la necesidad de métodos rápidos que nos permitan acceder a la predisposición genética de los animales para depositar grasa en el músculo. Las pruebas de ADN con mérito predictivo para la propensión del marmoleo representan una herramienta muy útil para facilitar el incremento genético en dicha variable (Beuzen et al., 2000; Dekkers et al., 2004; Casas et al., 2007).

El contenido y la composición de lípidos son caracteres de variación continua, que responden a una red de procesos que dista de estar completamente dilucidada. A través de la utilización de herramientas genéticas se trata de identificar los genes y los polimorfismos causales de la variación cuantitativa y de caracterizar estos genes en las poblaciones de interés para evaluar su implementación en el mejoramiento (Hocquette et al., 2006). Para que todo este proceso se justifique debe existir variabilidad en las poblaciones bovinas para las variables de interés. Afortunadamente, la genética cuantitativa ha mostrado evidencias de variación de origen genético en el contenido y composición de lípidos de la carne. Se han reportado diferencias entre 
diversas razas en el contenido de $\mathrm{AGMI}$, ácido linolénico, ácido linoleico conjugado (CLA), entre otros (Lawless et al., 1999; Taniguchi et al., 2004a; Taniguchi et al., 2004b; Šubrt et al., 2006; Garcia et al., 2008; Kraft et al., 2008; Prado et al., 2008; Zapletal et al., 2009). Al comparar la composición de lípidos entre las sub-especies Bos indicus y Bos taurus, las diferencias son mucho más marcadas (Huerta-Leidenz et al., 1996; Prado et al., 2008). También se ha probadola existencia de variabilidad en el contenido de varios AG dentro de las razas (Casas et al., 2005; Hoashi et al., 2008; Zhang et al., 2008). Lo mismo sucede en el caso del marmoleo, dado que se ha comprobado que existe variabilidad entre y dentro de las razas (Casas et al., 2007).

Además de detectar variabilidad entre individuos, se debe considerar la heredabilidad de las variables objeto de selección, es decir, los individuos deben ser capaces de transmitir a su progenie los alelos favorables para una característica dada. Los valores de heredabilidad reportados para marmoleo están dentro de un rango muy amplio que abarca valores desde 0,01 (Lee et al., 2000), usando el peso como covariable, hasta 0,88 (Pariacote et al., 1998), usando la edad como covariable, pero la mayoría son valores de medios a altos, entre 0,30 y 0,57 (Benyshek et al., 1988; Lamb et al., 1990; Van Vleck et al., 1992; Gregory et al., 1995; Barkhouse et al., 1996; O'Connor et al., 1997; Devitt et al., 2001; Fernandes et al., 2002; Kemp et al., 2002; Splan et al., 2002; Yoon et al., 2002). En la fracción de triglicéridos presente en la carne vacuna, los contenidos de ácidos mirístico (C14:0), miristoleico (C14:1), palmítico (C16:0), palmitoleico (C16:1), AGS y AGMI-cis los valores de heredabilidad son de bajos a moderados $(0,14-0,27)$ en cruzas con Hereford (Pitchford et al., 2002); en cruzas diversas de bovinos para carne en pasturas los valores son medios a altos $(0,38$ - 0,55) (Kelly et al., 2013) y en bovinos de razas japonesas los valores son elevados $(0,65$ - 0,82) (Inoue et al., 2011). Sin embargo, en el caso de los AGPI se han registrado en general valores bajos de heredabilidad, lo cual sugiere que esta fracción es menos plausible de manipular por medio de la genética (Pitchford et al., 2002; Kelly et al., 2013). Además, debido a sus funciones fisiológicas y a los efectos sobre las propiedades organolépticas, su manipulación se torna difícil. Más allá de esta observación, las evidencias reportadas permitirían la aplicación de herramientas como la selección para mejorar el marmoleo y el perfil de los AG presentes en la carne vacuna. 


\subsection{Estrategias para el análisis genómico}

Existen diversas metodologías para identificar genes asociados a variables de interés productivo, las dos más utilizadas son los estudios de asociación del genoma completo (GWAS, Genome-Wide Association Study) y el análisis de genes candidatos. GWAS se basa en la detección de loci de caracteres cuantitativos (QTLs, Quantitative Trait Loci) a través del genoma, los cuales resultan asociados a la variable de interés productivo. La base de datos bovina presenta actualmente 11543 QTLs para diferentes características, de los cuales 2294 determinan calidad carnicera (Cattle QTLdb, 2014). Varios QTLs que afectan al depósito de grasa intramuscular se encuentran en el cromosoma bovino 14 (BTA14), lo cual sugiere que los genes ubicados sobre este cromosoma tendrían una fuerte influencia sobre el marmoleo. A diferencia de GWAS, los estudios de genes candidatos se enfocan en la caracterización de polimorfismos y la posterior asociación de genes que participan o están involucrados, de alguna manera, en las vías de regulación de las variables de interés, y no sobre el genoma total. Numerosos genes han sido identificados como candidatos reguladores de marmoleo y composición lipídica de res, tales como la enzima Diacilglicerol O-aciltransferasa1 (DGAT1), Tiroglobulina (TG), Hormona de Crecimiento $(\mathrm{GH})$, Leptina (LEP), Estearoil-coenzima A desaturasa (SCD) y Neuropéptido Y (NPY), entre otros (Barendse et al., 1999, 2004, 2006; Buchanan et al., 2002; Thaller et al., 2003; Nkrumah et al., 2004; Taniguchi et al., 2004; Sorensen et al., 2006; Wood et al., 2006; Sherman et al., 2008; Tatsuda et al., 2008). Las secuencias y polimorfismos reportados para estos genes se encuentran disponibles en la base de datos del Centro Nacional de Información sobre Biotecnología (National Center for Biotechnology Information, NCBI, USA), y en otras bases de datos alrededor del mundo. Esta información es de gran utilidad para seleccionar y estudiar polimorfismos de nucleótido simple (Single Nucleotide Polymorphisms, SNPs), es decir, cambios de una sola base en el ADN, a los que se pueda adjudicar las diferentes expresiones de la variable en estudio.

Los SNPs son la forma más frecuente de variación de ADN en los mamíferos. Son abundantes, normalmente bialélicos y fácilmente detectables por técnicas automáticas. En 2009, la base de datos de SNPs (dbSNP, http://www.ncbi.nlm.nih.gov/snp) contaba con algo más de dos millones de polimorfismos en bovinos, la gran mayoría provenientes del Proyecto Genoma y de la raza Hereford. Actualmente, el sitio cuenta con 73439640 polimorfismos, reportados por diferentes grupos de investigación en diferentes razas gracias al avance de las 
tecnologías de secuenciación. Sin embargo, la mayoría de estos SNPs aún no han sido validados a nivel poblacional, por lo que no se conoce su distribución y frecuencia en las diferentes razas bovinas (Van Eenennaam et al., 2012). Estos datos son de gran importancia para determinar el grado de información de estos polimorfismos para estudios de asociación o de identificación genética. Por lo tanto, la caracterización de genes relacionados con la adipogénesis y el metabolismo lipídico en diferentes razas bovinas resulta un tema de suma importancia para la comunidad académica y para la industria de la carne.

\subsection{Adipogénesis, lipogénesis y lipólisis}

Adipogénesis es un término inclusivo que describe la proliferación, diferenciación y conversión de pre-adipocitos en células asimiladoras de lípidos dentro del tejido adiposo (Hausman et al., 2001; Kokta et al., 2004; Novakofski, 2004; Fernyhough et al., 2007). Los procesos de adipogénesis y lipogénesis están gobernados por una vasta cantidad de enzimas que actúan al mismo tiempo y que dependen, a su vez, de hormonas y metabolitos. La diferenciación de los preadipocitos se da a través de una cascada de eventos controlados por reguladores de la transcripción, coactivadores, y otros controles del ciclo celular. El proceso entero está estrechamente regulado a nivel transcripcional y puede ser inducido in-vitro por medio de señales externas, como la insulina, los glucocorticoides y/o moléculas que incrementen el Adenosín monofosfato cíclico (AMPc) intracelular (Gregoire et al., 1998). Estas señales pueden disparar el comienzo de la cascada transcripcional compuesta por una red de proteínas que median el funcionamiento de los adipocitos.

El gen maestro regulador de la diferenciación adipocítica es el Receptor Gamma Activado por el Factor Proliferador de Peroxisomas (Peroxisome Proliferator Activated Receptor Gamma, PPARG), un miembro de la superfamilia de receptores nucleares que es indispensable y suficiente para que ocurra la adipogénesis (Rosen et al., 2002). Varias proteínas denominadas Proteínas de Unión al Amplificador CCAAT (CCAAT/Enhancer-Binding Proteins, CEBPs) son también importantes reguladores transcripcionales de la adipogénesis y la lipogénesis. Dichas proteínas forman parte de una cascada de eventos en la que la inducción temprana de los genes $C E B P B$ y $C E B P D$ lleva a la inducción de CEBPA, que es un trans-activador de PPARG. CEBPA y PPARG actúan en conjunto para promover la diferenciación adipocítica y se regulan recíprocamente (Wu et al., 1999; Rosen, 2005) (Fig. 1). 
Además de las CEBPs, las Proteínas de Unión a Elementos Regulatorios de Esterol (Sterol Regulatory Element-Binding Proteins, SREBPs) también están involucradas en la regulación de la expresión de PPARG, ya que este posee en su promotor un elemento de respuesta a esterol (Otto et al., 2005). El resultado de la activación in-vitro de PPARG en tejido adiposo bovino es la regulación positiva (aumento de expresión) de genes que permiten la diferenciación de los pre-adipocitos a adipocitos que son las células capaces de almacenar triglicéridos (Grant et al., 2008; Lengi et al., 2010).

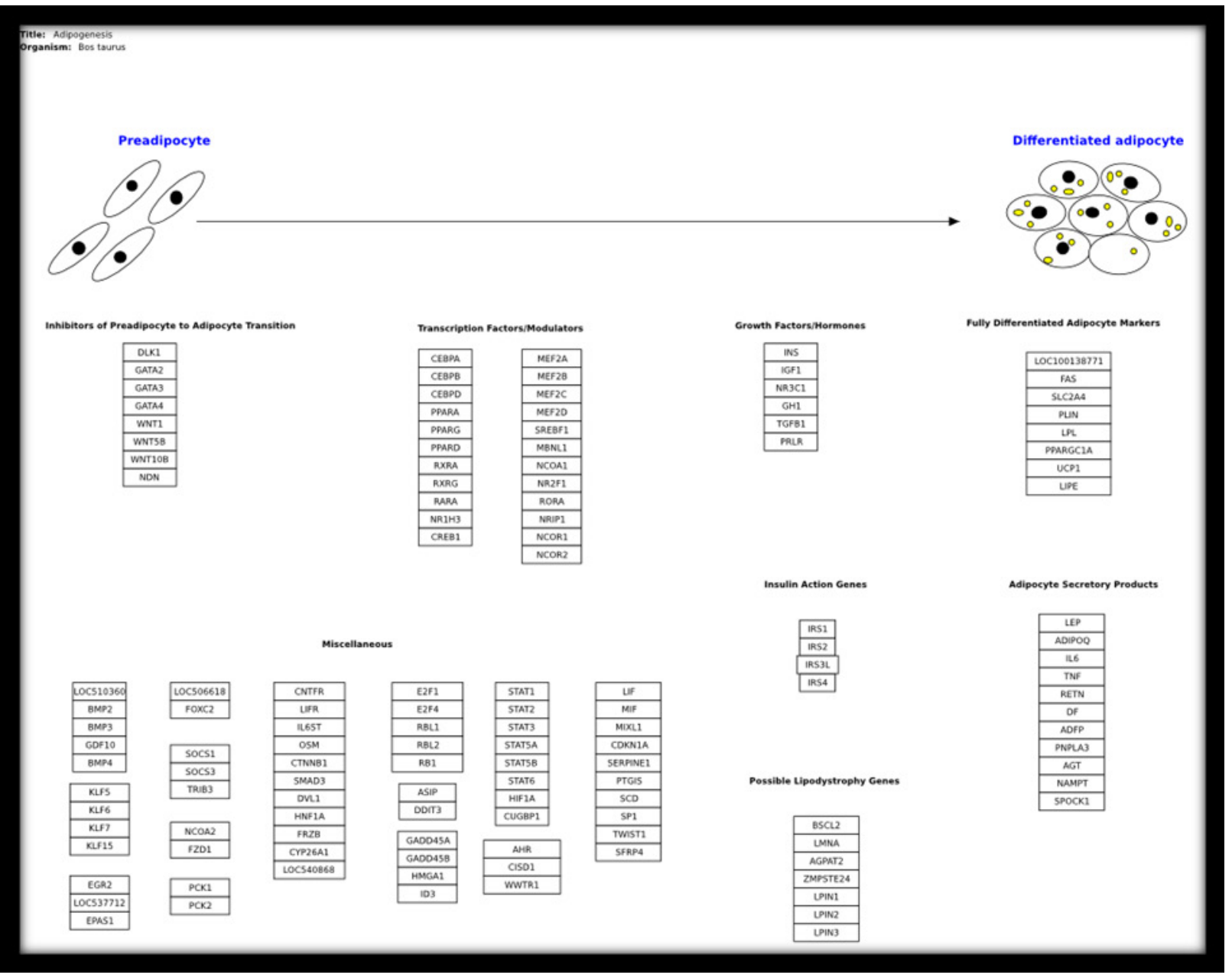

Fig. 1. Genes involucrados en la adipogénesis. (Extraído de WikiPathways, WP987) 
La lipogénesis comprende los procesos bioquímicos de síntesis de ácidos grasos y la posterior síntesis de triglicéridos a partir de la esterificación de los ácidos grasos con glicerol. Estos procesos ocurren en todas las células del organismo, pero principalmente en el tejido adiposo y en el hígado. Requiere una molécula de acetato, que es activado a acetil-CoA por una enzima Acetil-CoA Sintetasa (ACS) y posteriormente carboxilado por la enzima Acetil-CoA Carboxilasa (ACC) para formar malonil-CoA. A continuación, la elongación se realiza mediante reacciones sucesivas de condensación descarboxilativa de moléculas de acetil-CoA con la malonil-CoA. Todas las reacciones de síntesis de ácidos grasos están estrechamente reguladas por la enzima Sintetasa de Ácidos Grasos (Fatty Acid Synthetase, FAS), que posee múltiples actividades (Nguyen et al., 2008), y a la cual se podría considerar como el elemento clave de la síntesis. Los ácidos grasos resultantes, mayormente palmitato, pueden ser elongados 0 desaturados en las mitocondrias 0 en el retículo endoplásmico. La desaturación involucra tres enzimas acil-CoA desaturasas que tienen amplia especificidad y pueden desaturar en C5, C6 o C9: $\Delta^{5}$-eicosatrienoil-CoA Desaturasa, $\Delta^{6}$-oleoil (linolenoil)-CoA Desaturasa y $\Delta^{9}$-estearoil-CoA Desaturasa (SCD). Esta última cataliza el paso limitante y es la enzima clave de la biosíntesis de AGMI, principalmente ácido oleico (C18:1) y palmitoleico (C16:1).

La esterificación de los ácidos grasos para formar triglicéridos comprende varias reacciones. Primero, los ácidos grasos son activados por una Acil-CoA Sintetasa (ACS), y luego son acilados secuencialmente al esqueleto de glicerol-3fosfato, en sus tres posiciones, por las enzimas GPAT (sn-1), AGPAT (sn-2) y DGAT (sn-3). Previo a la acilación en sn-3, debe defosforilarse esta posición por fosfatasas del ácido fosfatídico (PPAP) como las Lipinas (Weiss et al., 1960). Tanto el ácido fosfatídico como el diacilglicerol son, además, precursores de otros importantes glicerolípidos: fosfatdilinositol, fosfatidilglicerol y cardiolipina, en el caso del ácido fosfatídico; y fosfatidilcolina, fosfatidilserina y fosfatidiletanolamina, en el caso del diacilglicerol. Todas las enzimas mencionadas representan una parte importante del proceso de biosíntesis.

Se entiende por lipólisis al conjunto de los procesos metabólicos mediante los cuales los lípidos son transformados en ácidos grasos y glicerol para cubrir los requerimientos energéticos del organismo. Mientras la síntesis de triglicéridos ocurre en múltiples tejidos, la lipólisis ocurre de manera predominante en el tejido adiposo y los ácidos grasos liberados son tomados por los otros órganos. Hasta hace poco, el modelo de lipólisis adipocítica consistía en que la Lipasa Sensible a Hormona 
(Hormone-Sensitive Lipase, HSL, ahora también llamada LIPE para no confundir con Homoserin Lactona), una enzima con amplia especificidad de sustrato, catalizaba la hidrólisis de ácidos grasos de las posiciones sn-1 y el sn-3 de triglicéridos y diglicéridos, generando 2-monoacil glicerol, el cual era luego hidrolizado por una monoglicérido-lipasa para obtener glicerol y ácidos grasos (Fredrikson et al., 1986; Holm et al., 2003). Según este modelo, LIPE era la enzima determinante y exclusiva de los procesos degradativos de triglicéridos. Sin embargo, nuevos estudios han sugerido la existencia de otras lipasas de triglicéridos, como la desnutrina (también llamada ATGL), y han propuesto que el rol más importante de LIPE es la hidrólisis de los diglicéridos (Haemmerleet al., 2002; Villena et al., 2004). También se cree que LIPE es la única o al menos la más importante hidrolasa de colesteril ester in-vivo (Fredrikson et al., 1981; Kraemer et al., 2002; Ben Ali et al., 2004).

\subsection{Genes candidatos para la determinación del marmoleo}

\subsubsection{Receptor Gamma Activado por el Factor Proliferador de Peroxisomas (PPARG)}

El Receptor Activado por el Factor Proliferador de Peroxisomas (PPAR) es un receptor nuclear de hormonas que forma un heterodímero con el Receptor $\mathrm{X}$ Retinoide (RXR) y actúa como factor de transcripción (Isseman et al., 1990). Hay tres subtipos de Receptores: PPARA, PPARB/D y PPARG. Este último presenta las isoformas PPARG1 y PPARG2, las cuales difieren solo en su extremo $\mathrm{N}$-terminal ya que la isoforma PPARG2 contiene 30 aminoácidos adicionales. PPARG2 es expresado principalmente en el tejido adiposo, donde juega importantes y diversos roles: i. inducir y controlar la diferenciación de fibroblastos o pre-adipocitos a adipocitos (Matsusue et al., 2004; Evans et al., 2004); ii.Afectar la sensibilidad a la insulina y regular la homeostasis de glucosa (Berger et al., 2002; Walczak et al., 2002);y iii. Controlar la incorporación, el transporte, el depósito y la disposición de lípidos (Schoonjans et al., 1996;Walczak et al., 2002). Esta variedad de roles es llevada a cabo por medio de la activación directa o indirecta de los genes del metabolismo lipídico, como la Proteína de Unión a Acidos Grasos (Fatty Acid-Binding Protein, FABP), Receptor Hepático X Alfa (Liver X Receptor Alpha, LXRA) y Lipoprotein Lipasa (LPL) (Frohnert et al., 1999; Escher et al., 2000; Evans et al., 2004; Rosen et al., 2006; Rosenson et al., 2007) (Fig. 2). PPARG1 se expresa de manera más amplia, en tejido adiposo, músculo esquelético, hígado, intestino y macrófagos. Ambas isoformas pueden inducir 
adipogénesis, pero PPARG2 parece ser más potente en esta función (Mueller et al., 2002).

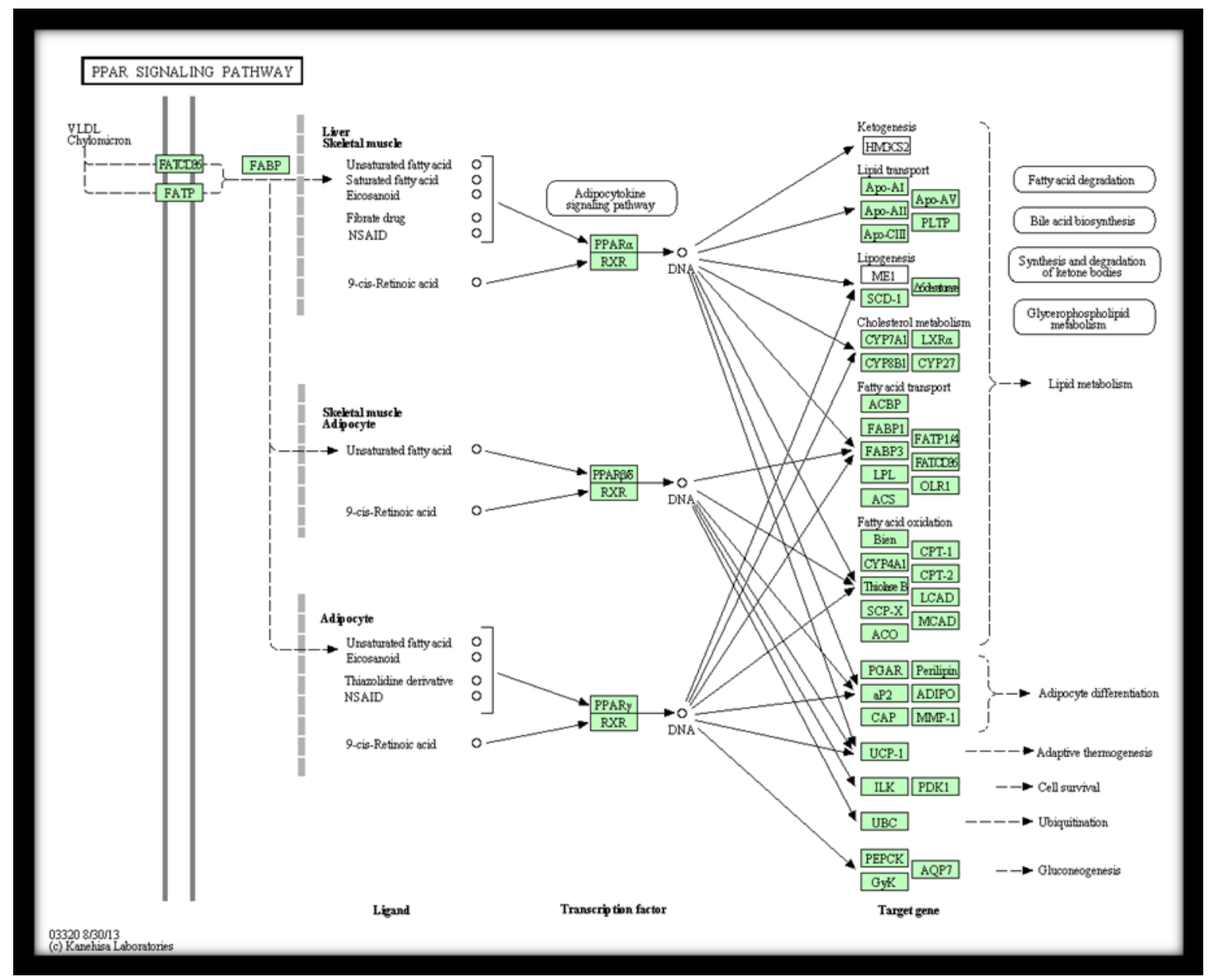

Fig.2. Ruta de señalización de PPARs (tomado de http://www.kegg.jp/pathway/bta03320).

El receptor está compuesto básicamente por cuatro regiones, la primera de ellas es una región $\mathrm{N}$-terminal, que está pobremente conservada y que contiene el dominio activador 1 (AF-1), cuya actividad puede ser regulada por modificaciones post traduccionales (van Beekum et al., 2009). El dominio de unión a ADN (DBD, DNA Binding Domain) está localizado en la porción central y está altamente conservado entre especies y entre los receptores nucleares. Ocho de los nueve residuos conservados de cisteína del dominio DBD están coordinados con iones zinc, lo que resulta en dos dedos de zinc que son esenciales para la estabilización de las estructuras secundarias y terciarias de la proteína y para la unión al ADN (Khorasanizadeh et al., 2001). La región de unión a ADN se conecta por medio de una región bisagra con el dominio de unión a ligando (LBD, Ligand Binding Domain). La región LBD está medianamente conservada y se encuentra involucrada también en la 
heterodimerización con RXRA. Además, contiene la región AF-2, la cual posee una poderosa función activadora que depende del tipo de ligando (Fig. 3).

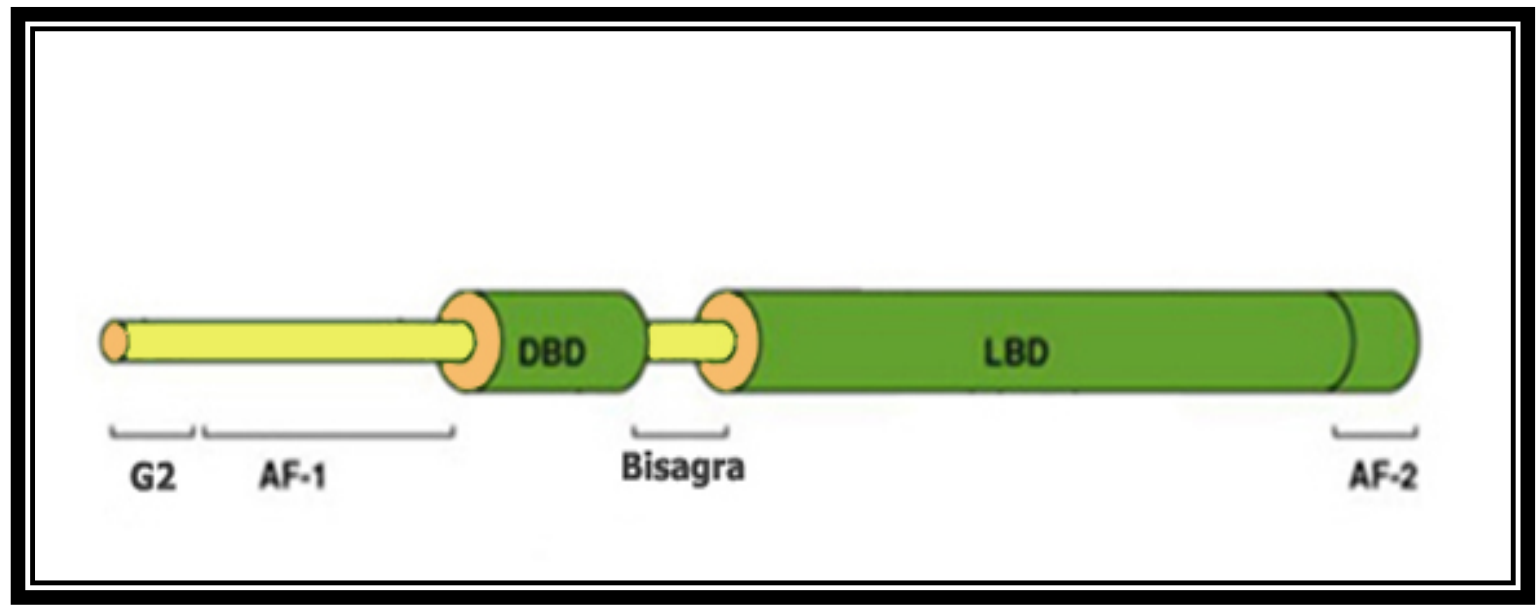

Fig. 3. Representación esquemática del PPARG y sus dominios. G2: región exclusiva de la isoforma 2. AF-1: primer dominio activador; DBD: dominio de unión a ADN. LBD: dominio de unión a ligando. AF-2: segundo dominio activador. (Adaptado de Jeninga et al., 2009).

La unión del ligando estabiliza la conformación activa del LBD, sirviendo como interruptor entre las funciones activadoras y represoras del receptor (Nolte et al., 1998). En los promotores de algunos genes diana, los PPARs sin ligando reclutan corepresores, como N-CoR y SMRT, que forman complejos multiproteicos con actividad histona deacetilasa (HDAC) y reprimen la transcripción (Guan et al., 2005). Cuando se une el ligando, estos complejos de co-represores son intercambiados por complejos co-activadores, como CBP y TRAP, que facilitan la transactivación (Perissi et al., 2005) (Fig. 4). 


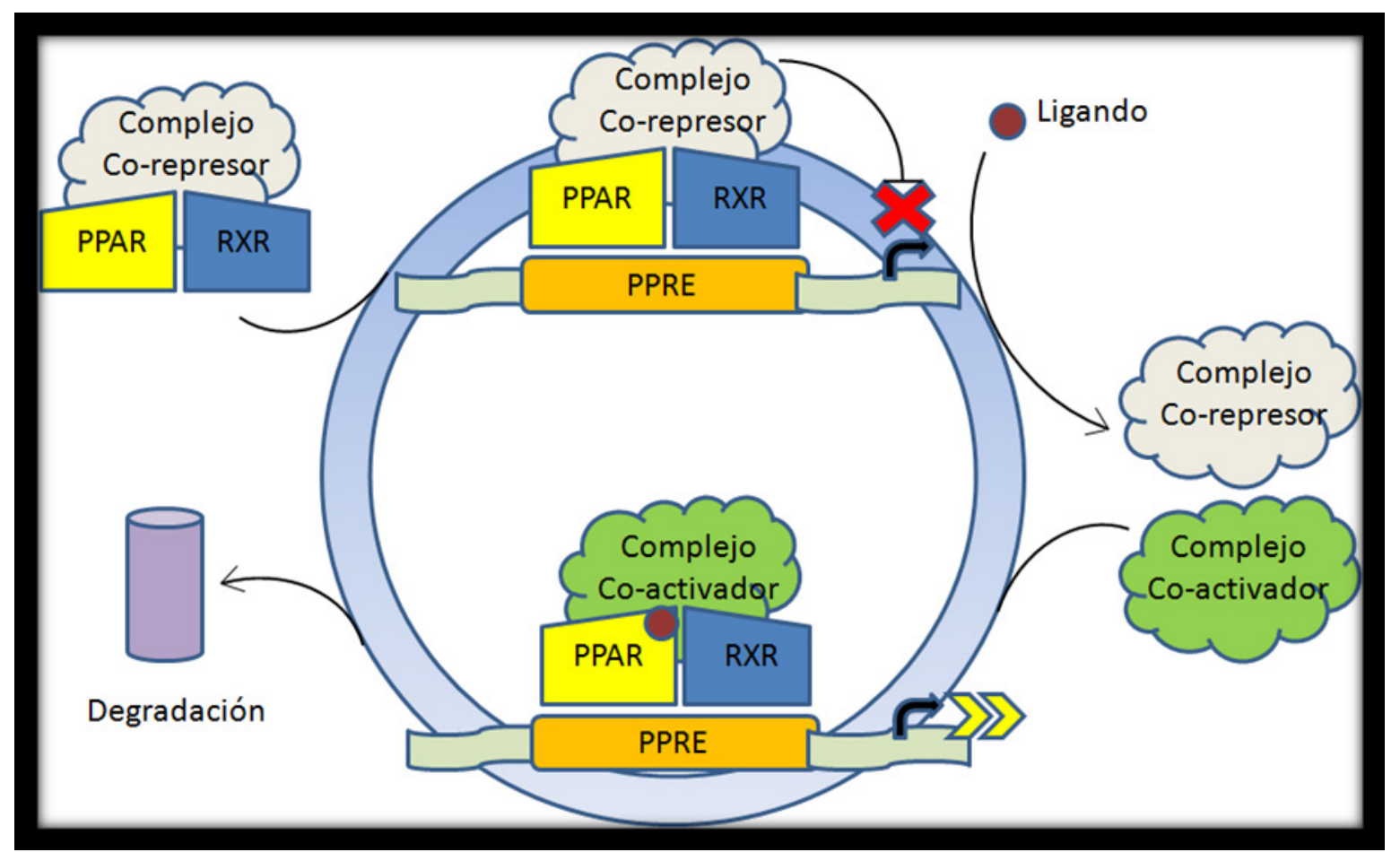

Fig. 4. Modelo de regulación de la transcripción por el mecanismo PPAR.

Varios ligandos endógenos han sido identificados para PPARG, entre estos están incluidos los ácidos grasos polinsaturados, eicosanoides y derivados de la prostaglandina J2 (Forman et al., 1995; Kreyet al., 1997). Los agonistas sintéticos incluyen a las tiazolidinedionas (TZDs) (Lehmannet al., 1995) y agonistas basados en tirosina (Henke et al., 1998), los cuales se ha probado que mejoran la sensibilidad a la insulina y disminuyen los niveles de glucosa en sangre en pacientes humanos con diabetes tipo 2.

Por medio de estudios de cristalografía se ha logrado obtener la estructura del dominio de unión a ligando, tanto en presencia de ligando (Nolte et al., 1998; Gampe et al., 2000; Itoh et al., 2008; Waku et al., 2009) como en forma de heterodímero con RXRA (Gampe et al., 2000) (Fig. 5). Estos estudios revelan 13 hélices alfa y una pequeña lámina $\beta$ de cuatro cadenas. El bolsillo de unión a ligando comprende los residuos de las hélices $3,5,11$ y 12 , mientras que los residuos involucrados en la heterodimerización con RXRA se encuentran en las hélices 9 y 10 y en el bucle entre las hélices 8 y 9 (Gampe et al., 2000). En la conformación unida a ligando, la hélice 12 y los residuos de las hélices 3,4 y 5 forman una abrazadera que interactúa con los coactivadores. Chandra et al. (2008) reportaron la estructura del heterodímero RXRAPPARG unido a ligando y a ADN, demostrando por primera vez como distintos dominios cooperan para modular las propiedades del receptor. Estos autores observaron que el LBD se localiza prominentemente en el centro del complejo, alrededor del cual se localizan todos los otros dominios. También se han identificado 
interacciones no esperadas entre el LBD y el DBD, las cuales involucran a los residuos R181 y H183 del DBD y a E455 del LBD (numerados de acuerdo a la isoforma 2). Además, el LBD de PPARG interactúa con la región DBD/bisagra de RXRA, por medio de la lámina $\beta$. Esto fue evidenciado por una mutación en una de las cadenas $\beta$, F375A, la cual redujo la capacidad de unión a ADN (Chandra et al., 2008). Otro descubrimiento importante es la interacción de la región bisagra de PPARG con la región 5' del elemento de respuesta a PPARG (PPRE), lo cual explica la orientación polar del heterodímero observada sobre la secuencia de ADN. En la Figura 5 se detallan los dominios del heterodímero PPARG-RXRA unido a ADN y a sus respectivos ligandos.

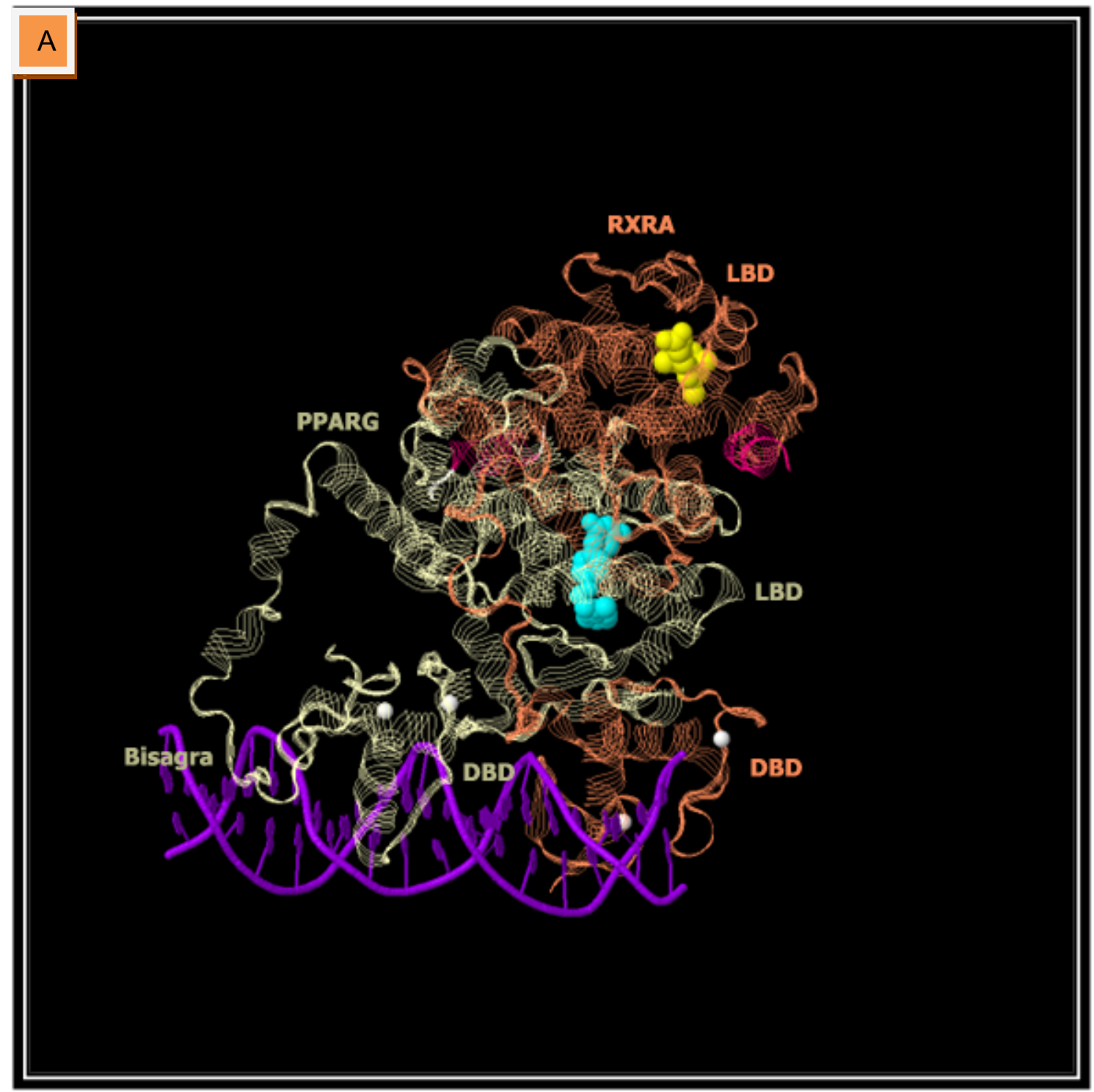




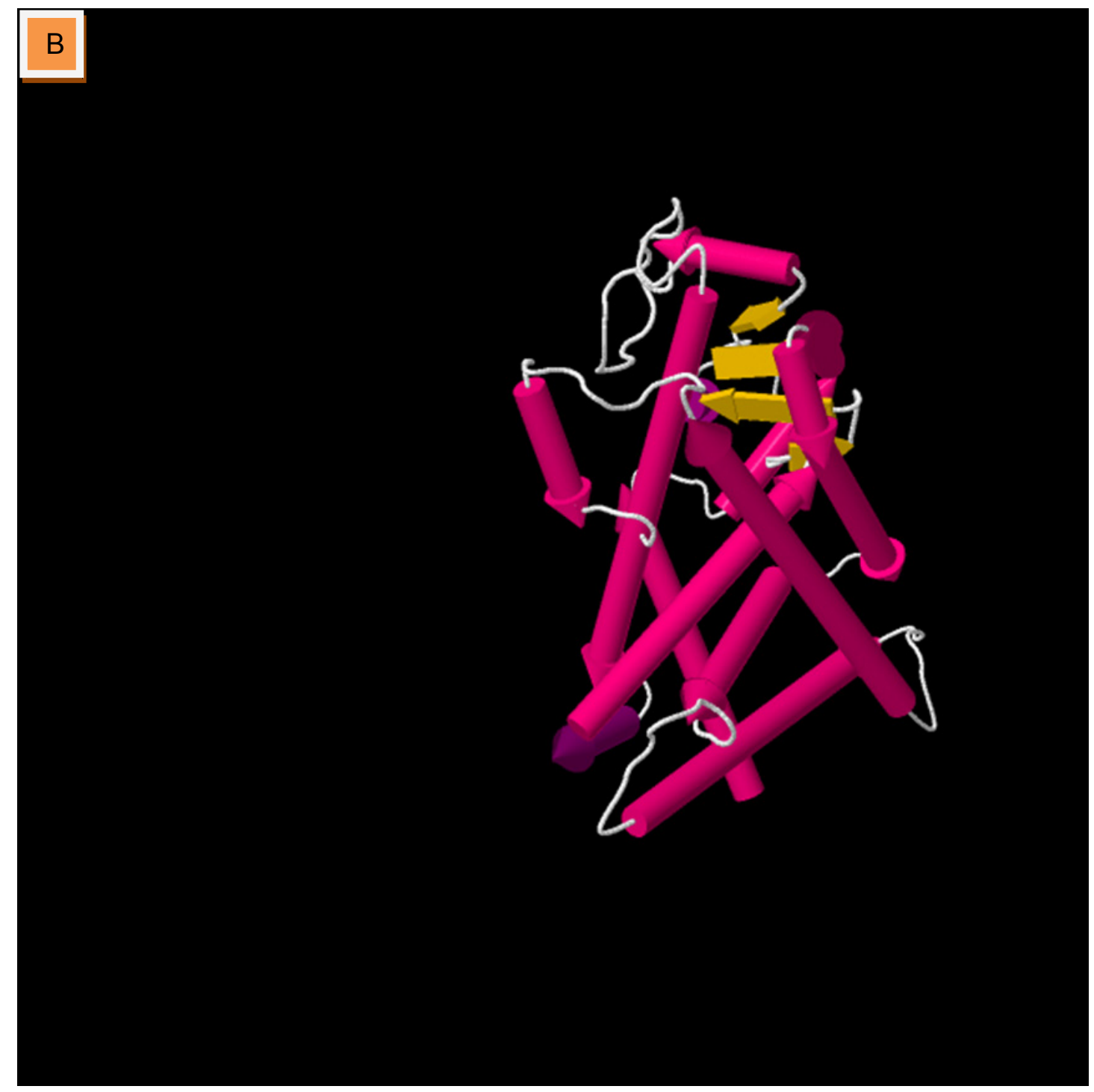

Fig. 5. Estructuras cristalizadas de PPARG visualizadas con Jmol. (A): Heterodímero PPARG (amarillo claro)-RXRA (naranja) unido a ADN (violeta), iones de zinc (blanco), dos péptidos coactivadores NCOA2 (rojo), y a los ligandos: 2,4-tiazolidiinediona, 5-[[4-[2-(metil-2-piridinilamino)etoxi]fenil]methil]-(9cl) (celeste) y ácido retinoico (amarillo oscuro). PDB-ID: 3DZY (B) Dominio de unión a ligando (LBD) de PPARG. PDBID:1FM6.

La isoforma 2 de PPARG está codificada en el gen PPARG (Gene ID: 281993), el cual se localiza en el cromosoma bovino 22. Este gen tiene un promotor de $597 \mathrm{pb}$ (GenBank: AF012874.1) y un ADNc constituido por aproximadamente 1827 pb. La lista de SNPs reportados para las regiones promotora-proximal y codificantes del gen bovino PPARG en el GenBank se detalla en la tabla 1. Cabe mencionar que los reportes no aclaran a qué razas pertenece cada uno y que solo una pequeña cantidad de ellos están validados a nivel poblacional. 


\begin{tabular}{|c|c|c|c|c|c|c|c|}
\hline Identificación & $\begin{array}{l}\text { Posición } \\
\text { (UMD 3.1) }\end{array}$ & $\begin{array}{c}\text { Evidenci } \\
\text { as }\end{array}$ & Alelos & Secuencia 5' & Secuencia 3' & Región* & Efecto \\
\hline rs210335442 & 57432370 & 1 & $\mathrm{C} / \mathrm{T}$ & aaagcagtgaacagccttatgacgcaacag & ttgtcacagctggtctctaacaggaggatg & Promotor & - \\
\hline rs209163323 & 57432343 & 1 & G/A & cagcttgtcacagctggtctctaacaggag & atgccagccagtccatccaggcctggtcct & Promotor & - \\
\hline rs207671117 & 57432251 & 3 & $\mathrm{G} / \mathrm{A}$ & ttggaaacggacgtcttgactcattggtgc & ttcccaagttttactgccatgcatcttttt & UTR5' & - \\
\hline rs209092270 & 57412899 & 1 & $\mathrm{C} / \mathrm{A}$ & ccactcccatgcctttgacatcaagccctt & accaccgttgacttctccagcatttccact & Exón 2 & Phe/Leu (65) \\
\hline rs110406459 & 57402478 & 5 & $\mathrm{~T} / \mathrm{C}$ & tgcttcttttctccetcgeccatattcctt & gtagggtttcttccggaggacaatcagatt & $\begin{array}{l}\text { Intrón (exón } \\
\text { 4)- Región } \\
\text { splicing }\end{array}$ & - \\
\hline rs132979274 & 57402368 & 1 & $\mathrm{C} / \mathrm{T}$ & agtagaaataaatgtcagtactgtcggttt & agaagtgccttgctgtggggatgtctcata & Exón 4 & Gln/STOP \\
\hline rs109613657 & 57367375 & 6 & $\mathrm{G} / \mathrm{T}$ & agacaatctgctgcaagccttggagctgca & ctcaagctgaaccaccccgagtcctcccag & Exón 7 & $\mathrm{GIn} / \mathrm{His}(448)$ \\
\hline rs211388309 & 57367181 & 2 & $\mathrm{~T} / \mathrm{A}$ & acttgtattagcagagaagtccgagttcac & gacagcatcttccttctcccaattgcacta & UTR3' & - \\
\hline
\end{tabular}

*Los paréntesis indican cercanía relativa

Tabla 1. SNPs reportados en la base de datos GenBank para el gen PPARG-2 bovino.

En total, y considerando todas las razas de bovinos, fueron reportados 8 SNPs entre el promotor y las zonas codificantes del gen, de los cuales dos se encuentran en la región promotora y solo 3 en zonas de traducción. Como se mencionó previamente, varios de estos SNPs, sobre todo los que no cuentan con observaciones múltiples, podrían en realidad ser artefactos, polimorfismos demuy baja frecuencia o específicos de raza.

En los últimos años, algunas de estas variantes genéticas presentes en el gen PPARG han sido asociadas a marmoleo, composición de ácidos grasos y cualidades carniceras, aunque los estudios fueron realizados en razas asiáticas, y en gran parte de los casos las mutaciones presentaban frecuencias génicas muy desbalanceadas. La mutación g 57396952 C>T (Bos_taurus_UMD_3.1) del intrón 6 fue asociada a terneza en la raza Qinchuan y la mutación rs109613657 del exón 7 (Q448H), fue asociada a espesor de grasa dorsal (EGD) y retención de agua (Fan et al., 2011). Esta última mutación también fue asociada por Oh et al. (2011) con composición de ácidos grasos, más específicamente con contenido de AGS y AGMI en razas coreanas. La variante rs42016945, ubicada en la zona UTR5' de PPARG1 fue asociada por Sevane et al. (2013) con la cantidad de varios ácidos grasos polinsaturados omega-3 en el músculo: ácido docosapentaenoico (C22:5n-3), ácido eicosapentaenoico (C20:5n-3)y ácido docosahexaenoico (C22:6n-3). El genotipo AA de este SNP evidenció incrementos de $9 \%, 15 \%$ y $18 \%$, respectivamente para AGPI comparado con el genotipo homocigota GG. Puesto que los AGPI omega-3 y sus metabolitos son ligandos naturales para PPARG (Edwards et al., 2008), la influencia de PPARG sobre 
los niveles de ácidos grasos omega-3 es consistente con sus roles fisiológicos conocidos.

\subsubsection{Proteína de Unión al Amplificador CCAAT Alpha (CEBPA)}

Las Proteínas de Uniónal Amplificador CCAAT (CCAAT/enhancer-binding proteins, C/EBPs) son factores de transcripción críticos para la regulación adipocítica. Las CEBPs tienen un dominio de cierre básico de leucina (bZIP) altamente conservado y una región $\mathrm{N}$-terminal variable, y hasta la fecha se conocen seis miembros: C/EBPA, C/EBPB, C/EBPD, C/EBPE, C/EBPG, y C/EBPZ (Williams et al., 1991; Lin et al., 1993; Lekstrom et al., 1998). Se sabe que dichas proteínas regulan la transcripción de genes que son importantes para el metabolismo, la diferenciación y la inflamación, entre ellos el PPARG (Hanson, 1998; Poli, 1998; Ramji et al., 2002; Zuo et al., 2006). Todas las isoformas de C/EBP comparten una alta identidad de secuencia entre los aminoácidos 277 - 340 de la región C-terminal, la cual contiene el dominio bZIP mencionado anteriormente. Este dominio consiste en una región de unión a ADN rica en aminoácidos básicos seguida por un motivo de dimerización "cierre de leucina" (Landschulz et al., 1989; Vinson et al., 1989; Cao et al., 1991; Hurst, 1995). La dimerización es un pre-requisito para la unión a ADN, la cual es mediada por la región básica que asume una estructura alfa-hélice (Vinson et al., 1989; Hurst, 1995). La región básica guarda una estrecha relación con el cierre de leucina ya que cambios en el espacio entre estas regiones llevan a una pérdida de la capacidad de unión (Agre et al., 1989). De acuerdo al modelo de unión a ADN por proteínas bZIP, el dímero forma una estructura de $Y$ invertida en la cual cada brazo de la $Y$ está formado por la región básica, los cuales se unen a la mitad de la secuencia palindrómica de reconocimiento en el surco mayor del ADN a modo de tenedor (Fig. 6). 


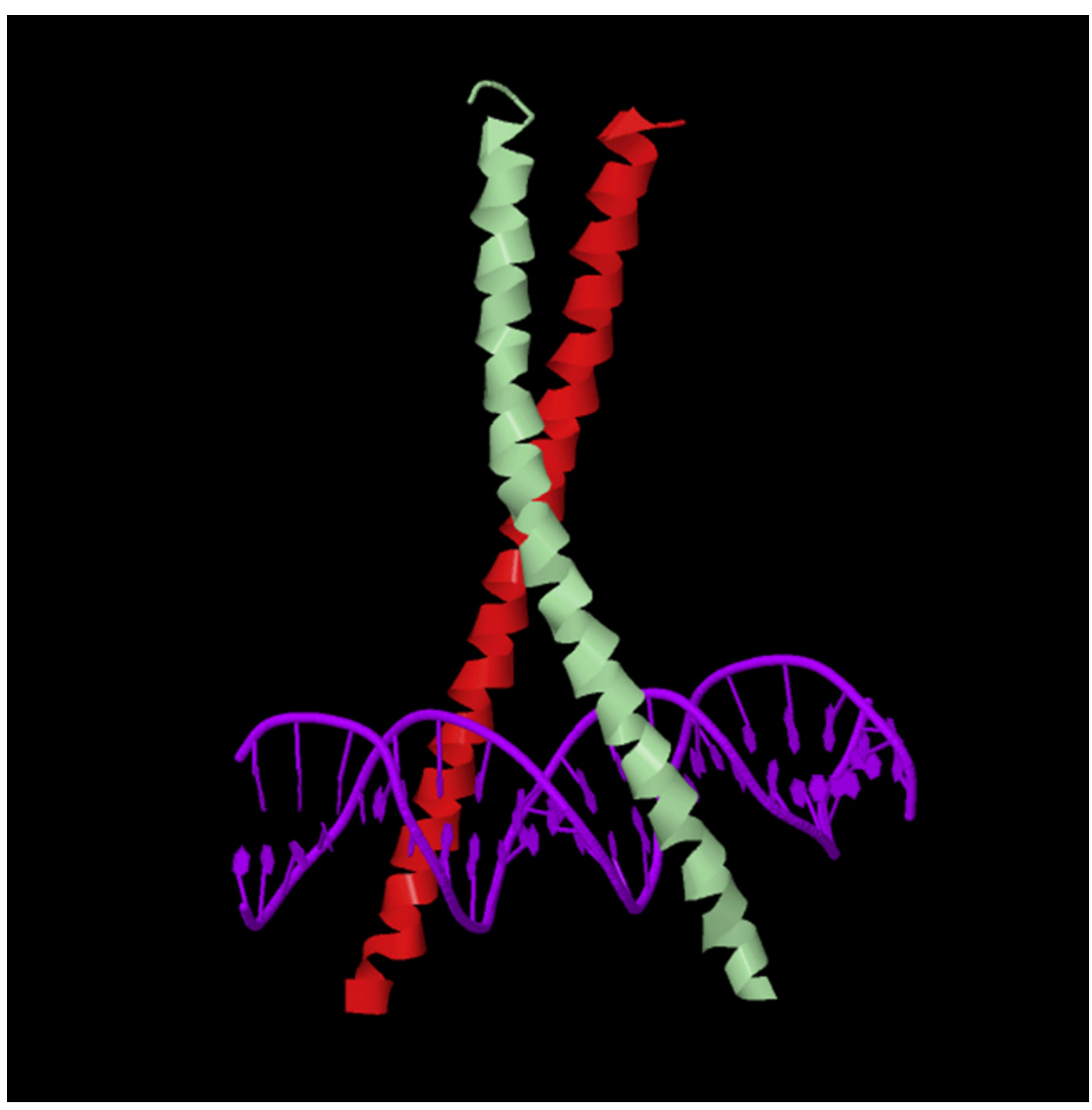

Fig. 6- Estructura del dominio bZIP de CEBPA unido a ADN. Las dos regiones básicas alfa-hélice (abajo) homo-dimerizan a través del cierre de leucina (arriba) para formar una $\mathrm{Y}$ invertida. La estructura fue obtenida de Protein Data Bank(PDB), acceso 1NWQ, y visualizada en Jmol.

La región $\mathrm{N}$-terminal muestra mayor variabilidad que la $\mathrm{C}$-terminal, posee tres subregiones que contienen los dominios de activación, los cuales interactúan con los miembros del aparato basal de transcripción para incrementarla (Nerlov et al., 1994). El N-terminal de CEBPA contiene, además, una región regulatoria negativa cuya función aún es poco conocida (Pei et al., 1991) (Fig. 7). 


\begin{tabular}{|c||c|c|c|l|l|l|l|}
\hline AF & AF & & RF & AF & & B & 7IP \\
\hline
\end{tabular}

Fig. 7. Modelo esquemático de $C E B P A . A F=$ función activadora; $R F=$ función reguladora negativa; $B=$ región básica; ZIP= Cierre de leucina.

CEBPA está compuesto por 353 aminoácidos (Taniguchi et al., 1996) y se expresa justo antes de la transcripción de muchos genes específicos de adipocitos, los cuales poseen sitios de unión para este factor. El gen CEBPA también se expresa en queratinocitos basales y se desregula coordinada y positivamente cuando los queratinocitos abandonan la capa basal y entran en diferenciación terminal (Lopez et al., 2009). Se conocen dos variantes polipeptídicas debido al uso de codones de iniciación alternativos, cuyas proporciones varían durante la diferenciación de adipocitos y el desarrollo de los hepatocitos. Se cree que estas variantes juegan un papel importante en la regulación de la diferenciación debido a que la variante más corta presenta una capacidad transactivadora reducida y carece de actividad antimitótica (Lin et al., 1993; Ossipow et al., 1993). Se ha observado que muchos de los genes a los que se une PPARG poseen sitios de unión a CEBPA en las proximidades (Lefterova et al., 2008). Estos dos factores trabajan en conjunto para guiar los procesos biológicos de los adipocitos mediante unión adyacente de una manera interesante. La co-expresión de CEBPA y PPARG en células NIH-3T3 tiene efectos sinérgicos en la conversión adipocítica y evita la necesidad de estimulación hormonal (Tontonoz et al., 1994b). Esto sugiere que la cooperación entre PPARG y los miembros de la familia C/EBP es necesaria para una diferenciación óptima, aunque el mecanismo preciso de esta cooperación es aún desconocido. Se ha determinado que el sitio de $A D N$ óptimo para la unión de C/EBPs es una repetición dual simétrica RTTGCGYAAY, donde R es A o G, e Y es C o T (Osada et al., 1997), sin embargo, se toleran algunas variaciones. El gen CEBPA (Gene ID: 281677) se encuentra en el cromosoma bovino 18, no posee intrones y consta de $1231 \mathrm{pb}$. Los polimorfismos reportados en CEBPA hasta el momento se detallan en la tabla 2. 


\begin{tabular}{|c|c|c|c|c|c|c|c|}
\hline Identificación & $\begin{array}{l}\text { Posición } \\
\text { (UMD 3.1) }\end{array}$ & Evidencias & Alelos & Secuencia 5' & Secuencia 3' & Región & Efecto \\
\hline rs110793792 & 43929570 & 6 & $\mathrm{C} / \mathrm{A}$ & gggcggggggctgcgaggggeccgcgcccc & gggaaagccgaaagcggcgctgctgggcgc & Exón & Sinónimo \\
\hline rs210446561 & 43929080 & 1 & $\mathrm{G} / \mathrm{C}$ & tgtgcgatctggaactgcaggtgcggggcg & ccaggtgagcgggcggcgggtgcgagtgc & Exón & Ala/Gly (198) \\
\hline rs132753520 & $\begin{array}{c}\text { 43929080:4 } \\
3929081\end{array}$ & 1 & $-/ C$ & gtgcgatctggaactgcaggtgcggggcgg & ccaggtgagcgggcggcgggtgcgagtgcg & Exón & $\begin{array}{c}\text { Cambio en el } \\
\text { marco }\end{array}$ \\
\hline rs136562922 & 43928910 & 2 & $\mathrm{~T} / \mathrm{G}$ & cgccgccgcccgcacggaggtcggggtgcg & ggcggccagccccttgagcgcgccgccggg & Exón & Thr/Pro (255) \\
\hline rs135049579 & 43928889 & 1 & $\mathrm{C} / \mathrm{G}$ & acttcttggctttgccgccgccgccgccgc & cgcacggaggtcggggtgcgtggcggccag & Exón & Gly/Arg (262) \\
\hline rs210841446 & 43928755 & 1 & $\mathrm{C} / \mathrm{T}$ & attgtcactggtcagctccagcaccttctg & tgcgtctccacgttgcgctgcttggccttg & Exón & Sinónimo \\
\hline rs135315610 & $\begin{array}{c}43928668: 4 \\
3928669\end{array}$ & 1 & $-/ \mathrm{C}$ & agggagctctcgggcagctgacggaagatg & ccccgcagcgtgtccagttcgcggctcagt & Exón & $\begin{array}{c}\text { Cambio en el } \\
\text { marco }\end{array}$ \\
\hline
\end{tabular}

Tabla 2. Polimorfismos reportados enel gen bovino CEBPA.

Hasta el momento, se han realizado escasos estudios acerca de la asociación de variantes genéticas en CEBPA y caracteres productivos. El polimorfismo rs110793792 fue asociado a peso a la faena y a peso de carcasa en la raza china Qinchuan (He et al., 2011), y a espesor de grasa dorsal y marmoleo en un conjunto de razas chinas (Wang et al., 2011). El SNP rs41883451, ubicado unos 4,4 kpb downstream de CEBPA, fue asociado de manera sugestiva a marmoleo en una población compuesta por ganado taurino y cebuino (Barendse, 2011), a pesar de no haber resultado significativo en otro estudio previo de similares características (Barendse et al., 2009).

\subsubsection{Receptor $X$ Retinoide Alpha (RXRA)}

Los receptores $X$ retinoide $(R X R)$ son miembros esenciales de la superfamilia de receptores nucleares de hormona tiroidea/esteroidea (NRs), que actúan como factores de transcripción en el desarrollo, la diferenciación, el metabolismo y la muerte celular. El ligando natural de los RXRs no está determinado con claridad. Si bien el ácido 9-cis retinoico fue inicialmente propuesto como ligando, los investigadores no han sido capaces de detectarlo en células cultivadas in-vivo, salvo cuando su isómero trans estaba ya presente o se había añadido (Mic et al., 2003; Wolf et al., 2006). Ácidos grasos polinsaturados, como el ácido docosahexanoico y un metabolito saturado de la clorofila, el ácido fitánico, también fueron identificados como ligandos. RXR posee tres isoformas, $\alpha, \beta$ y $\gamma$, las cuales poseen diferentes niveles de expresión según el tejido (Nohara et al., 2009). 
En el núcleo, RXR funciona como factor de transcripción, unido a otra molécula de RXR como homodímero o a otro NR como heterodímero. Generalmente, la unión del ligando del otro NR define el elemento de respuesta, el cual está compuesto por dos secuencias de seis bases separadas por un número de bases: 5'-PuG(G/T)TCA(X)n-PuG(G/T)TCA-3' (Chambon, 1996). Esta secuencia puede estar repetida, invertida, desordenada, o estar como palíndromo, dependiendo del dímero formado. $\mathrm{RXR} \alpha$ forma heterodímeros con PPARy (descripto anteriormente) y este dímero actúa como factor de transcripción adipocítico (Tontonoz et al., 1994a). El heterodímero con PPAR se une a dos repeticiones directas de la secuencia separadas por una base. El homodímero RXR reconoce preferencialmente dos sitios 5'-(A/G)GGTCA-3' separados por una base.

Como otros receptores nucleares, los RXRs poseen seis dominios funcionales importantes. Empezando desde el extremo $\mathrm{N}$-terminal, estos son: un dominio $\mathrm{A} / \mathrm{B}$, que tiene una función activadora independiente de ligando (AF-1) y al cual se unen proteínas co-activadoras; un dominio de unión a ADN (DBD), por el cual se une a los elementos de respuesta en los promotores; una región bisagra; un dominio de unión a ligando (LBD) que contiene la función dependiente AF-2 y al cual se unen proteínas co-represoras y co-activadoras y por último un dominio extra cuya función está aún poco clara (Mangelsdorf et al., 1992) (Fig. 8). En general, la estructura es similar a la de PPAR. EI DBD del RXR humano (residuos 130-209) posee dos dominios "dedo de zinc" (residuos 135-155 y 171-190), cada uno de los cuales está formado por un ión de Zn coordinado con cuatro cisteínas (Zhao et al., 2000). La estructura cristalina de dos homodímeros RXRa (DBD) unidos a sus elementos de respuesta revela que el oligómero ocupa $15 \mathrm{pb}$, los dos dedos de zinc están separados por 14 aminoácidos que contienen el C-terminal de la hélice de reconocimiento (residuos 152-164). Los residuos Lys160 y Arg164 del DBD interactúan con el surco mayor del ADN. Los residuos Arg182, Arg186, Glu207, Gln208 participan en la estabilización de los oligómeros con el ADN y del homodímero. En la figura 5 se aprecia la estructura tridimensional formada por RXR $\alpha$ en forma de heterodímero. 


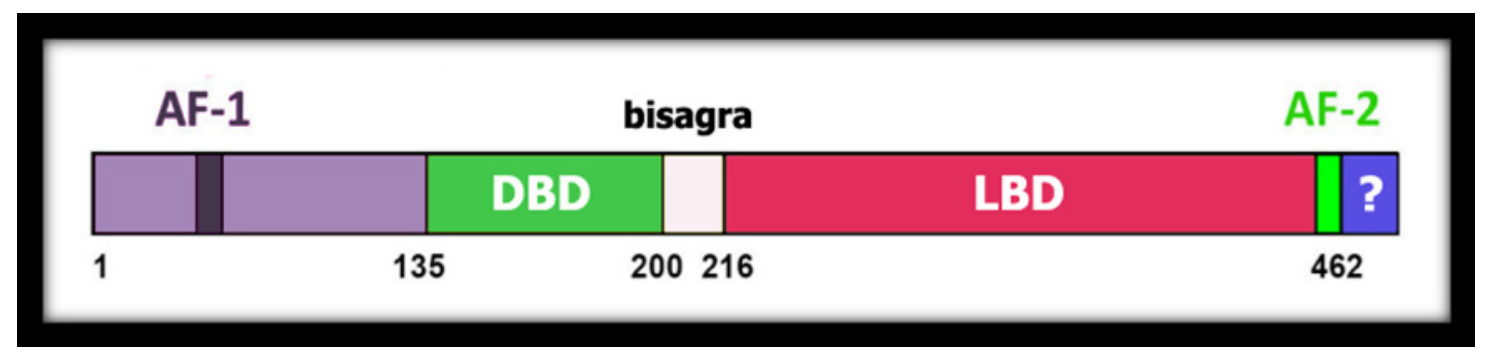

Fig.8. Estructura y dominios del RXRa. AF-1: función activadora independiente de ligando; DBD: dominio de unión a ADN; LBD: dominio de unión a ligando; AF-2: función activadora dependiente de ligando; ?: dominio de función desconocida.

La exportación del RXRa desde el núcleo está mediada por la unión de la hélice de reconocimiento del DBD a la proteína de unión a calcio Calreticulina. Mutaciones presentes en las fenilalaninas ubicadas en las posiciones 158 y 159 en esta hélice inhiben la exportación. La señal de localización nuclear (NLS) (Lys-Arg-TyrVal-Arg-Lys) está localizada en esta región, entre los residuos 160 y 165 (Prüfer et al., 2002). A diferencia de otros NRs, RXRa no tiene secuencias NLS en su región bisagra o en su LBD. EI LBD está conservado entre los miembros de la familia de receptores, y está conformado por 12 alfa-hélices y una pequeña lámina $\beta$ entre las hélices 5 y 6 . Las hélices están dispuestas en una conformación que se denomina "barril" o "sandwich helicoidal anti-paralelo".

RXRa está codificado por el gen bovino RXRA (Gene ID: 507554, ENSBTAG00000017851), el cual se localiza en el cromosoma 11 y por predicción presenta cuatro variantes de splicing. Estas supuestas variantes difieren en los primeros residuos (aproximadamente 30 ) del extremo N-terminal. El gen está formado por 13 exones (considerando las variantes de splicing), su región codificante comprende unas 1600 pb y la proteína resultante consta de entre 464 y 539 residuos, dependiendo de la variante. Los SNPs disponibles en SNPdb se detallan en la tabla 3. 


\begin{tabular}{|c|c|c|c|c|c|c|c|}
\hline Identificación & $\begin{array}{c}\text { Posición (UMD } \\
\text { 3.1) }\end{array}$ & Evidencias & Alelos & Secuencia $5^{\prime}$ & Secuencia 3' & Región & Efecto \\
\hline rs385551168 & $\begin{array}{c}\text { 105981659:1059 } \\
81660\end{array}$ & 1 & $-/ \mathrm{C}$ & $\begin{array}{c}\text { cccgcgttccacgacagagctgggtggc } \\
\text { gg }\end{array}$ & $\begin{array}{c}\text { ccctgagcctgcggagcggcgtggc } \\
\text { tcaaa }\end{array}$ & UTR5' & - \\
\hline rs207528468 & 105981704 & 5 & $\mathrm{G} / \mathrm{A}$ & $\begin{array}{c}\text { agcggcgtggctcaaaatgaaacaagc } \\
\text { atc }\end{array}$ & $\begin{array}{c}\text { cttctttcctgttgaagagaaaccgcc } \\
\text { tc }\end{array}$ & UTR5' & - \\
\hline rs136824840 & 105981816 & 3 & $A / G$ & $\begin{array}{c}\text { cagcccaggtggcggaggaggggaca } \\
\text { cggg }\end{array}$ & $\begin{array}{l}\text { agtgggggaattcctgatgaaaccc } \\
\text { cgcct }\end{array}$ & UTR5' & - \\
\hline rs209839910 & 105990470 & 3 & $\mathrm{C} / \mathrm{T}$ & $\begin{array}{c}\text { cgcagctccatggecgecccctcgctgca } \\
\text { C }\end{array}$ & $\begin{array}{l}\text { cctccctggggeccagcatcggetcc } \\
\text { tcgc }\end{array}$ & Exon 1 & Pro/Ser (33) \\
\hline rs137184653 & 105997426 & 1 & $\mathrm{~A} / \mathrm{C}$ & $\begin{array}{c}\text { aggactgcctgattgacaagcggcagcg } \\
\text { ca }\end{array}$ & $\begin{array}{c}\text { ccgctgccagtactgccgctaccag } \\
\text { aagtg }\end{array}$ & Exón 3 & Asn/Tre (167) \\
\hline rs136289117 & 106012748 & 1 & $\mathrm{~T} / \mathrm{C}$ & $\begin{array}{l}\text { ctcaaacccagccgaggtggaggcgctt } \\
\text { cg }\end{array}$ & $\begin{array}{l}\text { gagaaggtctatgcgtccctggagg } \\
\text { cgtac }\end{array}$ & Exón 8 & Sinónimo (345) \\
\hline rs209862076 & 106014892 & 5 & C/A & $\begin{array}{l}\text { ggaggecccgcaccagatgacttaggcc } \\
\mathrm{cg}\end{array}$ & $\begin{array}{l}\text { ggttcccggeccgeccegecctctgc } \\
\text { ccgc }\end{array}$ & UTR3' & - \\
\hline rs134910781 & 106015066 & 2 & $\mathrm{~T} / \mathrm{C}$ & $\begin{array}{l}\text { gggttcccccetcccggggetcacaccg } \\
\text { gc }\end{array}$ & $\begin{array}{l}\text { cctgccgctccggcggecgccccgg } \\
\text { gatgc }\end{array}$ & UTR3' & - \\
\hline rs133856660 & 106015072 & 2 & $\mathrm{~A} / \mathrm{C}$ & $\begin{array}{c}\text { ccgeccgggttcccccctcccggggetca } \\
\text { C }\end{array}$ & $\begin{array}{l}\text { ccggetcctgecgetccggcggecg } \\
\text { ccccg }\end{array}$ & UTR3' & - \\
\hline rs135888528 & 106015074 & 2 & $\mathrm{~A} / \mathrm{C}$ & $\begin{array}{c}\text { gcccgcccgggttcccccetcccgggget } \\
\text { C }\end{array}$ & $\begin{array}{l}\text { caccggctcctgccgctccggeggc } \\
\text { cgccc }\end{array}$ & UTR3' & - \\
\hline rs134496936 & 106015085 & 2 & $\mathrm{~T} / \mathrm{C}$ & $\begin{array}{c}\text { gtaccccgtgagcccgeccgggttccccc } \\
\mathrm{C}\end{array}$ & $\begin{array}{l}\text { cccggggetcacaccggetcctgcc } \\
\text { gctcc }\end{array}$ & UTR3' & - \\
\hline rs136850659 & 106015129 & 2 & $\mathrm{~A} / \mathrm{C}$ & $\begin{array}{c}\text { gcccagccgccctctgaacgctgcgget } \\
\text { cc }\end{array}$ & $\begin{array}{l}\text { ggggcggaggcgtgtaccccgtga } \\
\text { gcccgc }\end{array}$ & UTR3' & - \\
\hline rs377800777 & $\begin{array}{c}106015312: 1060 \\
15313\end{array}$ & 3 & $-/ C$ & $\begin{array}{c}\text { ggaggggacaggtgggggagetgcca } \\
\text { aaga }\end{array}$ & $\begin{array}{l}\text { cccccccgacccgectcccgggag } \\
\text { gacggg }\end{array}$ & UTR3' & - \\
\hline rs379993345 & 106015449 & 2 & $\mathrm{G} / \mathrm{T}$ & $\begin{array}{l}\text { ggtcagattgggagccgacctctgccetg } \\
\text { g }\end{array}$ & $\begin{array}{l}\text { tttgggggtcacttaaggctgcaggg } \\
\text { acac }\end{array}$ & UTR3' & - \\
\hline rs383580217 & 106015604 & 2 & $\mathrm{C} / \mathrm{G}$ & $\begin{array}{l}\text { cagcctgtgcagagggctgaggctggcc } \\
\text { CC }\end{array}$ & $\begin{array}{l}\text { actcctgcagggcgcgcctgatctct } \\
\text { agtg }\end{array}$ & UTR3' & - \\
\hline rs208047051 & 106015647 & 5 & $\mathrm{C} / \mathrm{G}$ & $\begin{array}{c}\text { cccgtcaccgtgggectcctgggtgggea } \\
\mathrm{g}\end{array}$ & $\begin{array}{l}\text { aggcctccggtccactagagatcag } \\
\text { gcgcg }\end{array}$ & UTR3' & - \\
\hline rs109676994 & 106015758 & 2 & $\mathrm{G} / \mathrm{A}$ & $\begin{array}{c}\text { ggcccoggccagctgtccgctcccogca } \\
\text { gc }\end{array}$ & $\begin{array}{c}\text { gagtgcccacaggtcccgccagctc } \\
\text { tggac }\end{array}$ & UTR3' & - \\
\hline rs135746226 & 106015852 & 1 & $\mathrm{~T} / \mathrm{C}$ & $\begin{array}{c}\text { ccccatcccagggtgcggacactcggec } \\
\text { gc }\end{array}$ & $\begin{array}{l}\text { ccccacctcaggggcccatgagac } \\
\text { gcctgc }\end{array}$ & UTR3' & - \\
\hline rs210659488 & 106015866 & 5 & $\mathrm{C} / \mathrm{A}$ & $\begin{array}{l}\text { ggccctgaggtggggagcggccgagt } \\
\text { gtc }\end{array}$ & $\begin{array}{c}\text { gcacctgggatggggetgtcgtcgt } \\
\text { gtgt }\end{array}$ & UTR3' & - \\
\hline rs137242181 & 106015890 & 3 & $\mathrm{G} / \mathrm{A}$ & $\begin{array}{c}\text { cctgaccagagagggtgcggacggaca } \\
\text { cac }\end{array}$ & $\begin{array}{l}\text { acgacagccccatcccagggtgcg } \\
\text { gacact }\end{array}$ & UTR3' & - \\
\hline rs109586765 & 106015935 & 5 & $\mathrm{C} / \mathrm{T}$ & $\begin{array}{l}\text { gagagacccagcccaggacgctgggec } \\
\operatorname{tgc}\end{array}$ & $\begin{array}{c}\text { gggccgggcgggaccctgaccaga } \\
\text { gagggt }\end{array}$ & UTR3' & - \\
\hline rs209751075 & 106015992 & 6 & $\mathrm{G} / \mathrm{A}$ & $\begin{array}{c}\text { cgtgagacagaaaaacggaccggagg } \\
\text { gagc }\end{array}$ & $\begin{array}{c}\text { cacgacggtgcagaggccttcaccc } \\
\text { tgaga }\end{array}$ & UTR3' & - \\
\hline rs110064982 & 106016058 & 11 & $\mathrm{~T} / \mathrm{C}$ & $\begin{array}{c}\text { cgggggtagcaggaccccacgcaccca } \\
\text { gtt }\end{array}$ & $\begin{array}{c}\text { cggetcccccagccgacaaacgct } \\
\text { gggttt }\end{array}$ & UTR3' & - \\
\hline rs133345826 & 106016066 & 2 & $\mathrm{~A} / \mathrm{C}$ & $\begin{array}{c}\text { gccgctgacgggggtagcaggacccca } \\
\text { cgc }\end{array}$ & $\begin{array}{c}\text { cccagtttcggctcccccagccgaca } \\
\text { aacg }\end{array}$ & UTR3' & - \\
\hline rs137557888 & 106016132 & 2 & $\mathrm{~A} / \mathrm{C}$ & $\begin{array}{c}\text { caccccccacggggagacaggcttgg } \\
\text { ggg }\end{array}$ & $\begin{array}{c}\text { gcagccacaacgctgacccccactc } \\
\text { ctgct }\end{array}$ & UTR3' & - \\
\hline rs211428760 & 106016134 & 4 & $\mathrm{G} / \mathrm{T}$ & $\begin{array}{c}\text { tgcaccccccacggggagacaggettg } \\
\text { gg }\end{array}$ & $\begin{array}{c}\text { gagcagccacaacgetgaccccca } \\
\text { ctcctg }\end{array}$ & UTR3' & - \\
\hline rs134891835 & 106016482 & 2 & $\mathrm{~T} / \mathrm{C}$ & $\begin{array}{c}\text { aggggtaccgcagggggaggaccacc } \\
\text { aggg }\end{array}$ & $\begin{array}{c}\text { gcctgcttcactctgctgacaccacc } \\
\text { acgc }\end{array}$ & UTR3' & - \\
\hline rs381783899 & 106016570 & 3 & $\mathrm{C} / \mathrm{T}$ & $\begin{array}{c}\text { accccacacccagtgccttctgcagctgg } \\
\text { a }\end{array}$ & $\begin{array}{c}\text { acaccccgtccacgcccagcccgc } \\
\text { cccget }\end{array}$ & UTR3' & - \\
\hline rs132979090 & 106016579 & 2 & $A / G$ & $\begin{array}{c}\text { gtccagggcagcggggcgggctgggcg } \\
\text { tgg }\end{array}$ & $\begin{array}{l}\text { cggggtgtgtccagctgcagaaggc } \\
\text { actgg }\end{array}$ & UTR3' & - \\
\hline rs209109531 & 106016767 & 6 & $\mathrm{C} / \mathrm{T}$ & $\begin{array}{l}\text { tcaaacacagcaaggacgttacgatggc } \\
\text { ag }\end{array}$ & $\begin{array}{l}\text { gcccgaggagaagaagggggget } \\
\text { cggeccc }\end{array}$ & UTR3' & - \\
\hline rs379045016 & 106017070 & 4 & $\mathrm{G} / \mathrm{T}$ & $\begin{array}{c}\text { caggcggggctcccgaggccgaggaat } \\
\text { gaa }\end{array}$ & $\begin{array}{l}\text { acgactgtgtctcaggttcggaagttg } \\
\operatorname{ttg}\end{array}$ & UTR3' & - \\
\hline rs110293800 & 106017171 & 5 & $\mathrm{C} / \mathrm{A}$ & $\begin{array}{l}\text { agggccagcggetgacgcgggtgccctc } \\
\operatorname{tg}\end{array}$ & $\begin{array}{c}\text { acggacgtccccgagcaggccagc } \\
\text { ttccaa }\end{array}$ & UTR3' & - \\
\hline rs385601475 & 106017294 & 3 & $\mathrm{C} / \mathrm{T}$ & $\begin{array}{c}\text { acccccoggggcaagtgctggagacca } \\
\text { cgc }\end{array}$ & $\begin{array}{c}\text { gcactccctgctccgcggaagccct } \\
\text { ggttg }\end{array}$ & UTR3' & - \\
\hline
\end{tabular}

Tabla 3. SNPs reportados para el gen bovino $R X R A$. 
El gen RXRA dispone de una amplia región UTR3'. Según la base de datos, esta región abarca 3433 pb y presenta una gran cantidad de SNPs (27). Además, cuenta con tres SNPs en regiones UTR5', dos SNPs responsables de cambio de aminoácidos (missense) y un SNP sinónimo.

Hasta el momento, no se conocen estudios de asociación a caracteres productivos llevados a cabo en este gen, lo que lo vuelve interesante desde el punto de vista innovador.

\subsubsection{Proteína de Unión a Ácido graso 4 (FABP4)}

Las proteínas de unión a ácido graso (Fatty acid binding proteins, FABPs) son una familia de proteínas transportadoras de ácidos grasos y otras sustancias lipofílicas, como los eicosanoides y los retinoides. Se cree que estas proteínas facilitan el paso de los ácidos grasos a través de membranas extra e intracelulares (Weisiger, 2002). Existen dos tipos principales: asociadas a membrana y citoplasmáticas. Estas últimas son pequeñas y altamente conservadas y se unen a ácidos grasos de cadena larga y a otros ligandos hidrofóbicos con gran afinidad (Kaikaus et al., 1990). Principalmente captan ácidos grasos y los transportan a los diferentes compartimientos celulares según convenga, por ejemplo, al retículo endoplásmico para señalización y síntesis de membranas, a la mitocondria o peroxisoma para su oxidación, a las gotas de grasa para su almacenamiento o al núcleo para regular la transcripción (Furuhashi et al., 2008). Se estima que ante la baja solubilidad de los ácidos grasos en ambientes acuosos como el citoplasma, las FABPs facilitan el transporte aumentando su solubilidad (Hertzel et al., 2000).

Las FABPs poseen estructuras terciarias similares, compuestas por diez hojas $\beta$ antiparalelas que conforman una estructura llamada "barril- $\beta$ " (Fig. 9). En el interior de este barril se aloja el ligando (ácido graso, colesterol o retinoide), el cual se une de manera reversible y no covalente (Fig. 10). Normalmente se encuentra un solo ligando por proteína, a pesar del tamaño del barril. Hacia el extremo $\mathrm{N}$-terminal de FABP se observa un motivo hélice-loop-hélice que, según se estima, actúa a modo de tapa permitiendo la entrada y salida del ligando (Hertzel et al., 2000). 


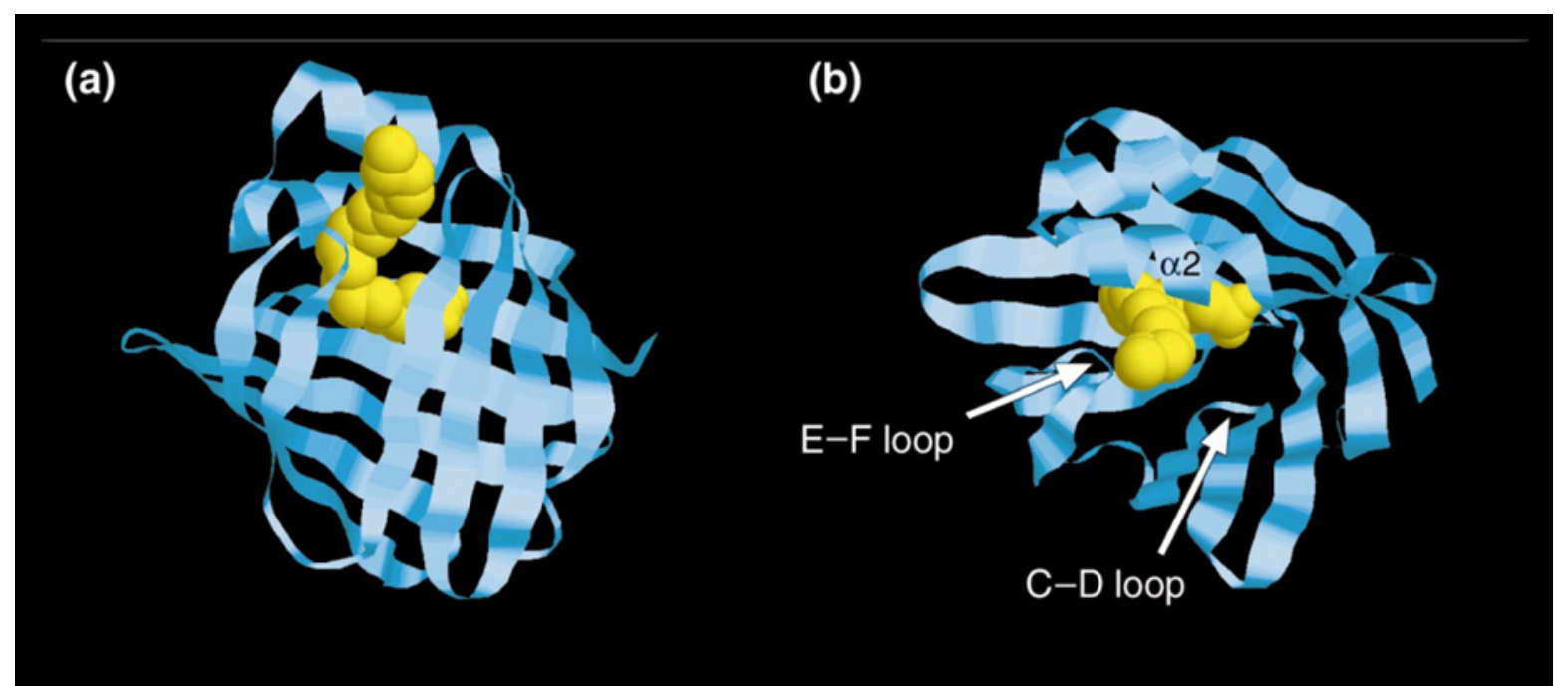

Fig. 9.Estructura cristalográfica de FABP4 unida a ácido oleico (amarillo). (a) Acido oleico unido a la cavidad de FABP4 con el motivo hélice-loop-hélice en la parte superior de la figura. (b) VIsta desde arriba de FABP4, observando la región portal. El portal está rodeado por la segunda $\alpha$ - hélice ( $\alpha 2)$, y loops. 

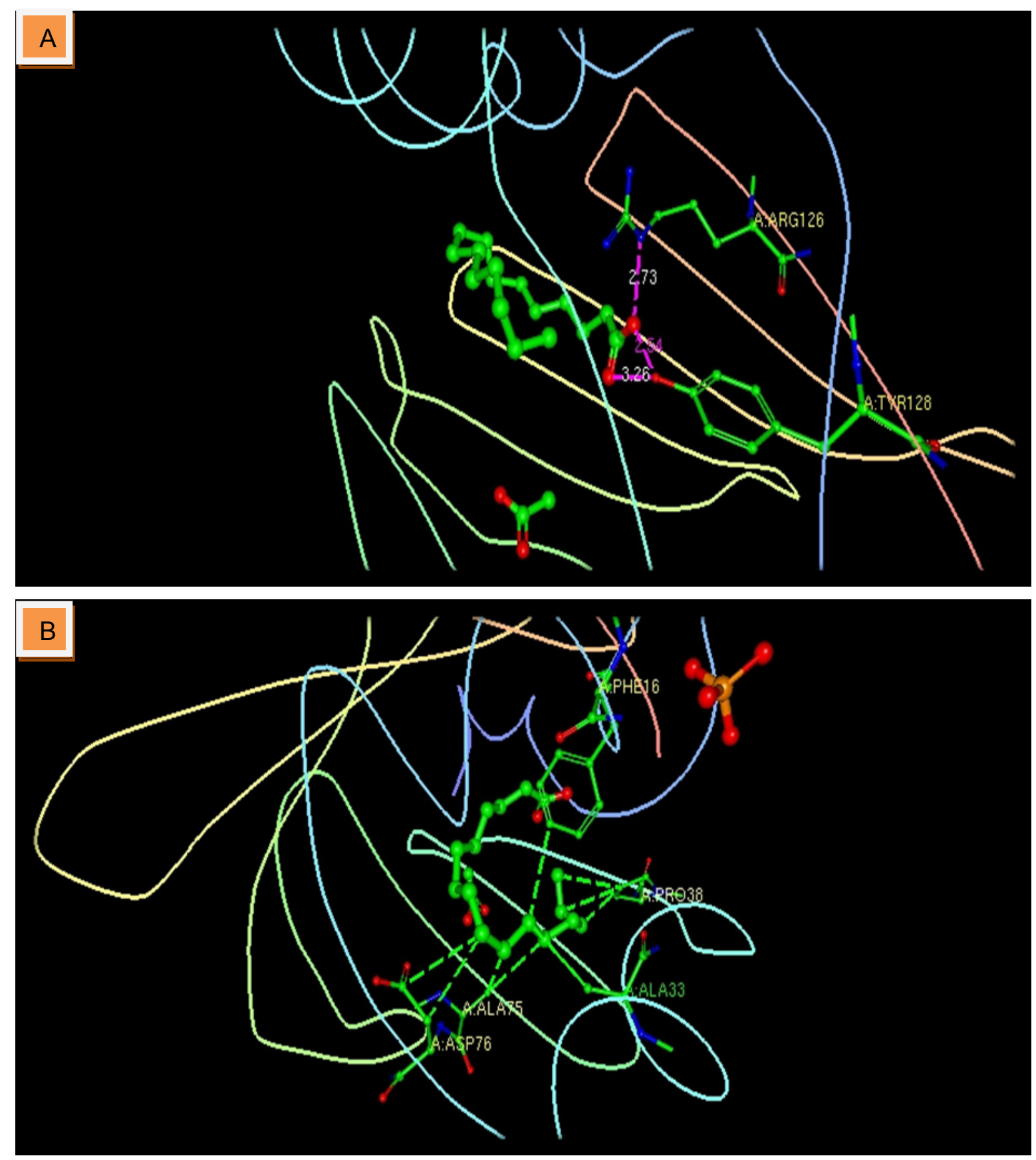

Fig. 10. Modelo de interacción entre aminoácidos específicos de FABP4 y el ácido palmítico. (A) Puentes de hidrógeno entre Arg127, Tyr129 y el ácido palmítico. (B) Interacciones hidrofóbicas entre Phe17, Ala34, Pro39, Ala76, Asp77 y el ácido palmítico.

Se conocen por lo menos nueve tipos de FABPs en mamíferos (Damcott et al., 2004), cuyos niveles de expresión dependen del tejido a pesar de no ser 
necesariamente exclusivos: FABP1 (hígado), FABP2 (intestino), FABP3 (músculo y corazón), FABP4 (adipocitos), FABP5 (epidermis), FABP6 (íleon), FABP7 (cerebro), FABP8 (tejido nervioso periférico), FABP9 (testículo). FABP4 (también llamada aP2 o ALBP) se expresa solo en tejido adiposo y en macrófagos y desempeña un rol importante en la homeostasis de lípidos y glucosa a través de la interacción con los PPARs. El complejo FABP4-ácido graso activa a PPARy, el cual, a su vez, regula la transcripción de FABP4 a modo feedback (Tan et al., 2002; Damcott et al., 2004) (Fig. 11).

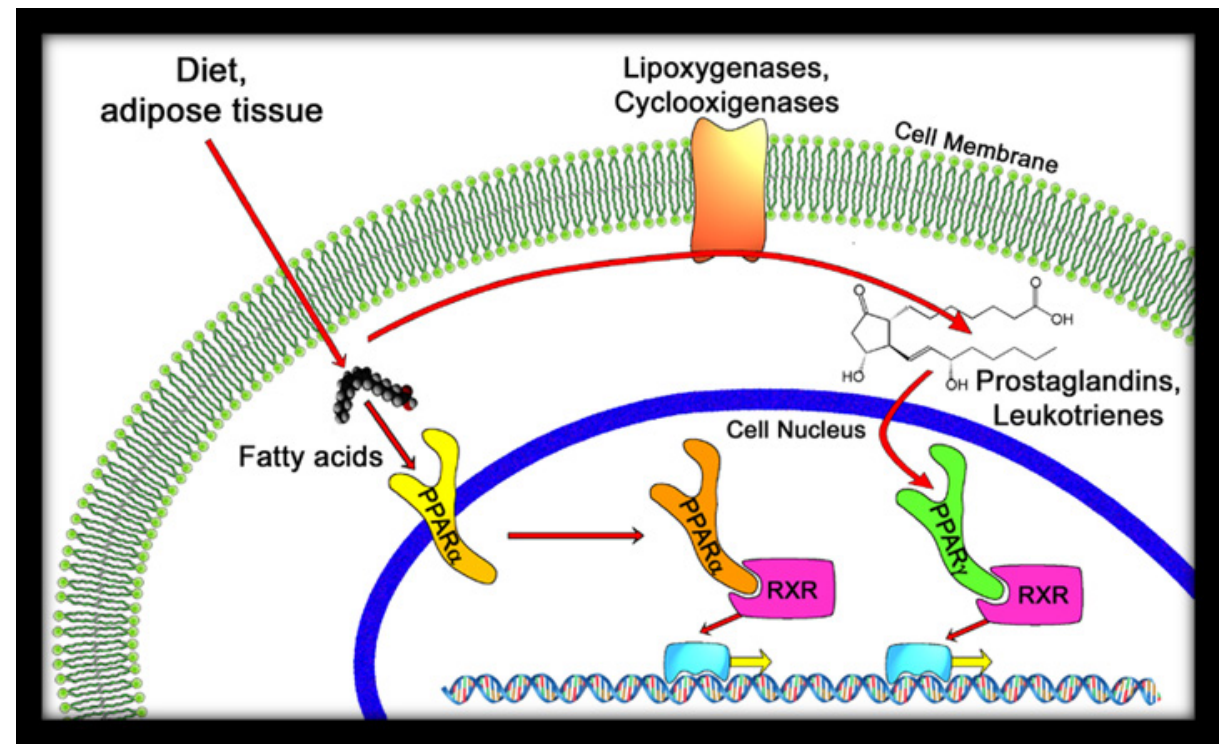

Fig. 11. Activación de PPARs por incorporación de ácidos grasos. (Extraído de http://en.wikipedia.org/wiki/PPAR_agonist)

FABP4 también parece estar involucrada en la hidrólisis de lípidos al interactuar de manera directa con LIPE, una enzima de gran importancia en la hidrólisis de lípidos y que se tratará en la próxima sección (Fig. 12). 


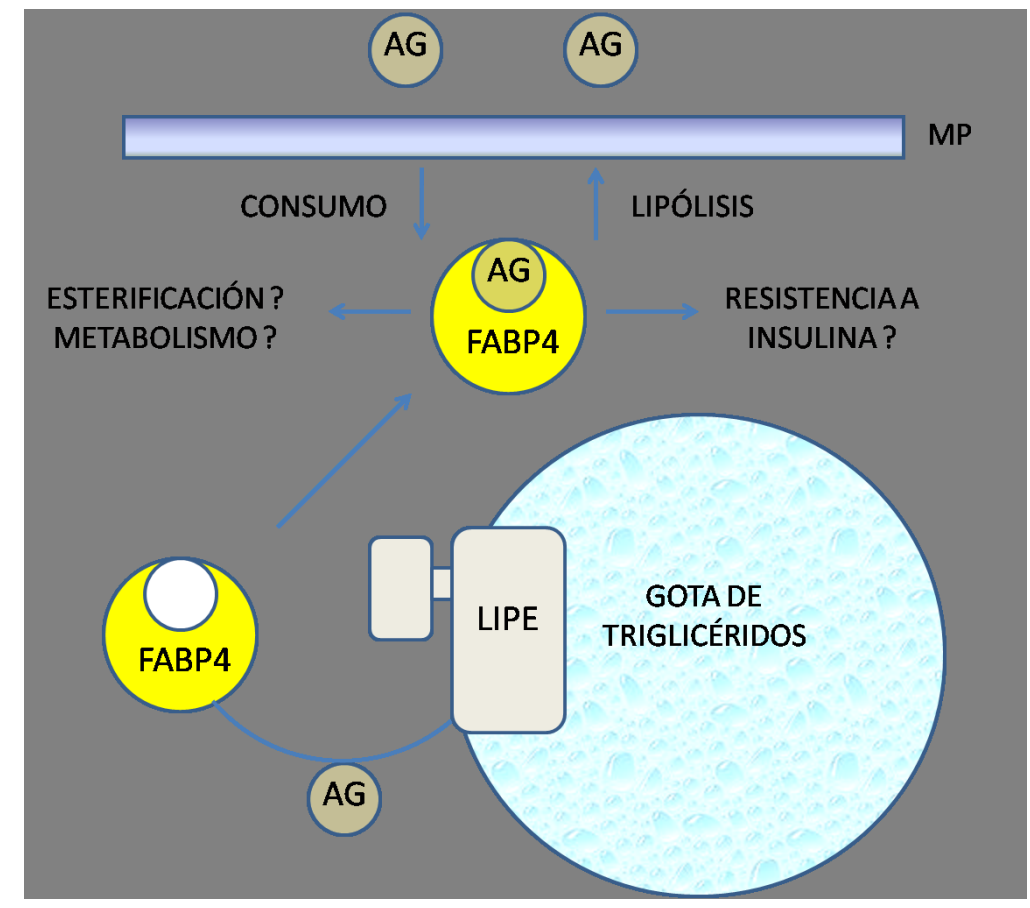

Fig. 12. Modelo esquemático del transporte de ácidos grasos (AG) por FABP4. Las funciones incluyen la unión de ácidos grasos, la interacción con LIPE (HSL), la entrega de ácidos grasos para esterificación y/o otros procesos metabólicos, la liberación de ácidos grasos de la lipólisis, entre otras. (Adaptado de Hertzel et al., 2000)

Se ha detectado una serie de dominios funcionales en FABP4 que incluyen la señal de localización nuclear (NLS) con su respectivo sitio de regulación, la señal de exportación nuclear (NES) y el sitio de unión a LIPE (HSL). La NLS no se distingue observando la estructura primaria de la proteína, pero en la estructura terciaria se observan tres residuos básicos (K22, R31 y K32), localizados en el motivo hélice-loophélice, cuyas cadenas laterales cambian de orientación ante la unión del ligando y conforman un NLS activo. La NES está formada por tres residuos de leucina (L67, L87 y L92) (Furuhashi et al., 2008) (Fig. 13).

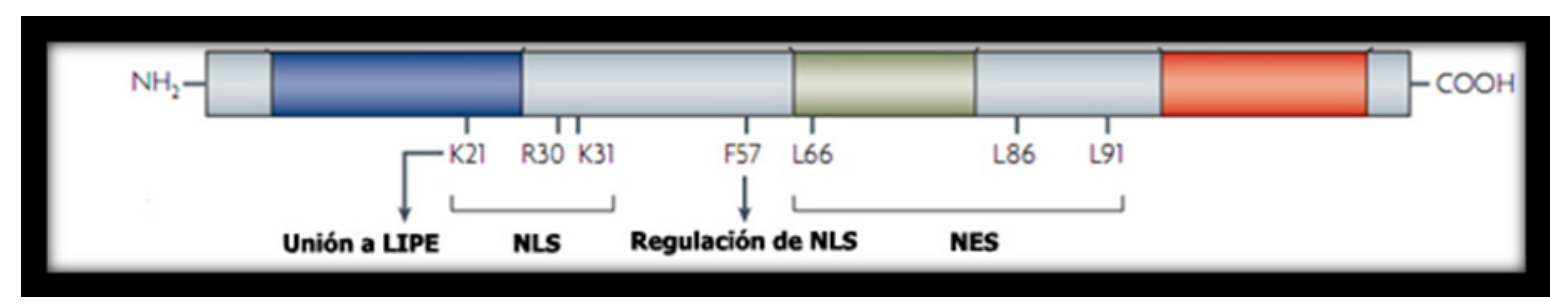

Fig. 13. Dominios funcionales de FABP4 humana. NLS = señal de localización nuclear; NES = señal de exportación nuclear. 
El gen bovino FABP4 (Gene ID: 281759, ENSBTAG00000037526) se encuentra en el cromosoma 14, su ADNc es de 625 pb y está constituido por cuatro exones. Posee una región promotora de 3331 pb (GenBank: FJ884068.1), sobre la que se han detectado varios SNPs. La lista de polimorfismos del promotor y de las zonas codificantes disponible en la base de datos SNPdb se resumen en la tabla 4. El gen presenta veintiún SNPs en la zona promotora, cuatro SNPs en el exón 2, cuatro SNPs en el exón 3 (uno de los cuales involucra a la región de splicing), un SNP en el exón 4 y dos SNPs en la región UTR3'.

El gen FABP4 fue propuesto inicialmente como potencial candidato regulador de la obesidad por estar localizado en un loci de carácter cuantitativo (QTL) para los niveles de leptina en suero de ratones (Ogino et al., 2003). La leptina es una proteína de 16 kDa secretada por los adipocitos blancos y que está involucrada en el balance energético. Desde entonces, diversos autores han demostrado que el cromosoma bovino 14 contiene un QTL para marmoleo (Casas et al., 2003, Pannier et al., 2010) y varios estudios de asociación han sido llevados a cabo. El polimorfismo rs110757796 fue asociado a contenidos de ácido palmítico (C16:0) y palmitoleico (C16:1), y espesor de grasa dorsal en razas asiáticas por Cho et al. (2007), Hoashi et al. (2008) y Narukami et al. (2011). En ganado coreano Hanwoo, este último SNP fue asociado con espesor de grasa dorsal (EGD), AGMI, porcentaje de ácido oleico y ácidos insaturados (Oh et al., 2012). El SNP rs110652478 fue asociado con marmoleo, porcentaje de ácidos insaturados totales, AGMI, y ácido oleico (Oh et al., 2012). El rs110383592 fue asociado con porcentaje de ácido palmítico y AGS (Oh et al., 2012). Maharani et al. (2012) también asoció el SNP rs110652478 con porcentaje de ácido mirístico y palmítico. El SNP rs110383592 fue asociado también con marmoleo en un ganado mixto de Angus, Hereford, Murray Grey, Shorthorn, Brahman, Belmont Red y Santa Gertrudis (Barendse et al., 2009). En Hanwoo, el SNP g 46835280 C>G (rs no disponible) del intrón 1 fue asociado con peso de carcasa y marmoleo; el SNP g 46834583 T>A del intrón 2 con peso de carcasa y el polimorfismo rs110652478 con marmoleo (Lee et al., 2010; Shin et al., 2012). 


\begin{tabular}{|c|c|c|c|c|c|c|c|}
\hline Identificación & $\begin{array}{l}\text { Posición } \\
\text { (UMD 3.1) }\end{array}$ & Evidencias & Alelos & Secuencia 5' & Secuencia 3' & Región & Efecto \\
\hline rs41729203 & 46842425 & 4 & $\mathrm{~A} / \mathrm{C}$ & $\begin{array}{c}\text { tctttcccagcatcaggagct } \\
\text { tttcaaatg }\end{array}$ & $\begin{array}{c}\text { Gtcagctcttcacatcaggt } \\
\text { ggccaaagta }\end{array}$ & Promotor & - \\
\hline rs133335460 & 46842376 & 3 & $\mathrm{G} / \mathrm{A}$ & $\begin{array}{c}\text { cagtcctaagtgttcattgga } \\
\text { aggactgat }\end{array}$ & $\begin{array}{c}\text { Ctgaagctgaaactccaat } \\
\text { actttggccac }\end{array}$ & Promotor & - \\
\hline rs380478068 & 46842353 & 2 & $A / G$ & $\begin{array}{c}\text { aaccagtccatcctaaagg } \\
\text { agatcagtcct }\end{array}$ & $\begin{array}{c}\text { Agtgttcattggaaggactg } \\
\text { atgctgaagc }\end{array}$ & Promotor & - \\
\hline rs135348681 & 46842226 & 1 & $\mathrm{~A} / \mathrm{C}$ & $\begin{array}{c}\text { tcttcagcactcagctttctgc } \\
\text { acagtcca }\end{array}$ & $\begin{array}{c}\text { Ctctcacatccatacatgac } \\
\text { tactggaaaa }\end{array}$ & Promotor & - \\
\hline rs134807551 & 46842134 & 3 & $\mathrm{C} / \mathrm{T}$ & $\begin{array}{c}\text { catatgaaaagctatgacc } \\
\text { aacctagacag }\end{array}$ & $\begin{array}{c}\text { Atattttaaaaagcagattca } \\
\text { ttattttgc }\end{array}$ & Promotor & - \\
\hline rs133214097 & 46842051 & 3 & $\mathrm{~T} / \mathrm{C}$ & $\begin{array}{c}\text { acgagaaactacatttttattt } \\
\text { tacttaat }\end{array}$ & $\begin{array}{c}\text { Ttaattaaaattttaaaaatg } \\
\text { gtcttgatt }\end{array}$ & Promotor & - \\
\hline rs385468921 & 46841880 & 2 & $G / A$ & $\begin{array}{c}\text { tatgttgacattttattctagta } \\
\text { acaaact }\end{array}$ & $\begin{array}{c}\text { Tctcaaatagattttcaaatg } \\
\text { agtatcaca }\end{array}$ & Promotor & - \\
\hline rs209355856 & 46841794 & 4 & $G / A$ & $\begin{array}{c}\text { gtacatttgggtagcagttgt } \\
\text { ctatcaaat }\end{array}$ & $\begin{array}{l}\text { Tgtttttgcaaatattttctccc } \\
\text { agtctat }\end{array}$ & Promotor & - \\
\hline rs208953840 & 46841299 & 3 & C/A & $\begin{array}{c}\text { aaatattccgttgtctggatgt } \\
\text { actacagt }\end{array}$ & $\begin{array}{c}\text { Cattcatacattcaccttctg } \\
\text { aaggacatc }\end{array}$ & Promotor & - \\
\hline rs207576897 & 46841150 & 4 & $A / G$ & $\begin{array}{c}\text { tccatagctctggcttttcctc } \\
\text { aatgtcat }\end{array}$ & $\begin{array}{l}\text { Taacgggaataatataatat } \\
\text { gtgccttgtc }\end{array}$ & Promotor & - \\
\hline rs134271870 & 46841148 & 5 & $A / G$ & $\begin{array}{l}\text { tctccatagctctggettttcct } \\
\text { caatgtc }\end{array}$ & $\begin{array}{c}\text { Tataacgggaataatataat } \\
\text { atgtgccttg }\end{array}$ & Promotor & - \\
\hline rs379533852 & 46841091 & 2 & $\mathrm{C} / \mathrm{T}$ & $\begin{array}{c}\text { cccttccatgctcccaccact } \\
\text { gtcccacaa }\end{array}$ & $\begin{array}{c}\text { Cctgccaaccactgtcatttt } \\
\text { tactgtctc }\end{array}$ & Promotor & - \\
\hline rs384407249 & 46840277 & 2 & $\mathrm{~A} / \mathrm{C}$ & $\begin{array}{c}\text { attctgtcgttttgagattgca } \\
\text { tccaagt }\end{array}$ & $\begin{array}{c}\text { Ctgcatttcggactcttttgttg } \\
\text { accgtga }\end{array}$ & Promotor & - \\
\hline rs381125889 & 46840242 & 1 & $A / G$ & $\begin{array}{c}\text { tattgaatggtttgccttggaa } \\
\text { acgaacag }\end{array}$ & $\begin{array}{c}\text { Gatcattctgtcgttttgaga } \\
\text { ttgcatcc }\end{array}$ & Promotor & - \\
\hline rs377979308 & 46840019 & 1 & $\mathrm{C} / \mathrm{T}$ & $\begin{array}{c}\text { aactctattagcctttgecctg } \\
\text { cttcattc }\end{array}$ & $\begin{array}{c}\text { Gtattccaaggccaaatttg } \\
\text { cctgttactc }\end{array}$ & Promotor & - \\
\hline rs383954773 & 46839976 & 2 & $A / G$ & $\begin{array}{c}\text { ttcgaagagggtgtttgctat } \\
\text { gaccagtgc }\end{array}$ & $\begin{array}{l}\text { Ttctcttggcaaaactctatt } \\
\text { agcctttgc }\end{array}$ & Promotor & - \\
\hline rs382086198 & 46839948 & 3 & $\mathrm{C} / \mathrm{G}$ & $\begin{array}{l}\text { tccatgtgtagagtcacctctt } \\
\text { gtgttgtt }\end{array}$ & $\begin{array}{l}\text { Gaagagggtgtttgctatga } \\
\text { ccagtgcatt }\end{array}$ & Promotor & - \\
\hline rs136650454 & 46839735 & 6 & $\mathrm{G} / \mathrm{A}$ & $\begin{array}{c}\text { acatgttgttgttgttttgattta } \\
\text { ggtcat }\end{array}$ & $\begin{array}{c}\text { Cctgaatggtctagtggttttc } \\
\text { cctgcttt }\end{array}$ & Promotor & - \\
\hline rs135393861 & 46839696 & 7 & $A / G$ & $\begin{array}{c}\text { tatatgttccatgtgtttggac } \\
\text { aaagtatt }\end{array}$ & $\begin{array}{c}\text { Atataatgacatgttgttgttg } \\
\text { tttgatt }\end{array}$ & Promotor & - \\
\hline rs41729170 & 46839537 & 9 & $\mathrm{C} / \mathrm{G}$ & $\begin{array}{c}\text { atattgataatgggggaggc } \\
\text { tatccatatg }\end{array}$ & $\begin{array}{c}\text { Gggaacagggagtacatg } \\
\text { agaaatctctgt }\end{array}$ & Promotor & - \\
\hline rs136334850 & 46839307 & 1 & -/TAT & $\begin{array}{c}\text { gatcattcagtctgaactgtt } \\
\text { gcatagaca }\end{array}$ & $\begin{array}{l}\text { Tatagactgtgggtgatgta } \\
\text { ccattcaggg }\end{array}$ & Promotor & - \\
\hline rs110244878 & 46835164 & 1 & $\mathrm{~T} / \mathrm{G}$ & $\begin{array}{c}\text { aggaaagtggctggcatgg } \\
\text { ccaaacccact }\end{array}$ & $\begin{array}{c}\text { Tgatcatcagtktraatggg } \\
\text { grtgtggtca }\end{array}$ & Exón 2 & Leu/Val (41) \\
\hline rs110373374 & 46835152 & 1 & $\mathrm{~T} / \mathrm{G}$ & $\begin{array}{c}\text { ggcatggccaaacccactk } \\
\text { tgatcatcagt }\end{array}$ & $\begin{array}{c}\text { Traatggggrtgtggtcam } \\
\text { cattaaatcag }\end{array}$ & Exón 2 & Leu/Val (45) \\
\hline rs110228822 & 46835133 & 1 & $\mathrm{C} / \mathrm{A}$ & $\begin{array}{c}\text { tgatcatcagtktraatgggg } \\
\text { rtgtggtca }\end{array}$ & $\begin{array}{c}\text { Cattaaatcagaaagcacc } \\
\text { tttaaaaatac }\end{array}$ & Exón 2 & Thr/Asn (51) \\
\hline rs110757796 & 46835065 & 9 & $A / G$ & $\begin{array}{c}\text { tccttcaaattgggccagga } \\
\text { atttgatgaa }\end{array}$ & $\begin{array}{c}\text { Tcactccagatgacagga } \\
\text { aagtcaag }\end{array}$ & Exón 2 & Ile/Val (74) \\
\hline rs135425060 & 46834401 & 1 & $\mathrm{~A} / \mathrm{C}$ & $\begin{array}{l}\text { ttctctttatggtggttgattttc } \\
\text { catccc }\end{array}$ & $\begin{array}{c}\text { Gttttgtacttgtaccagagc } \\
\text { accttcatc }\end{array}$ & Exón 3 & Trp/Gly (98) \\
\hline rs136912574 & 46834389 & 1 & $A / G$ & $\begin{array}{c}\text { catccacgagtttctctttatg } \\
\text { gtggttg }\end{array}$ & $\begin{array}{c}\text { Ttttccatcccagtttgtactt } \\
\text { gtaccag }\end{array}$ & Exón 3 & Ser/Pro (102) \\
\hline rs110652478 & 46834365 & 9 & $G / A$ & $\begin{array}{c}\text { ggaaaatcaaccaccataa } \\
\text { agagaaaactc }\end{array}$ & $\begin{array}{l}\text { Tggatgataagatggtgcts } \\
\text { gtgagtatct }\end{array}$ & Exón 3 & Val/Met (110) \\
\hline rs110383592 & 46834345 & 11 & $\mathrm{G} / \mathrm{C}$ & $\begin{array}{c}\text { gagaaaactcrtggatgata } \\
\text { agatggtgct }\end{array}$ & $\begin{array}{c}\text { Gtgagtatcttctcactactta } \\
\text { attctaga }\end{array}$ & $\begin{array}{l}\text { Exón } 3 \text { - Sitio } \\
\text { de splicing }\end{array}$ & Sinónimo (116) \\
\hline rs110370032 & 46833834 & 11 & $A / G$ & $\begin{array}{c}\text { tgtcactgccaccagagttta } \\
\text { tgagagagc }\end{array}$ & $\begin{array}{c}\text { Taagccaagggatattgaa } \\
\text { atggatgacgt }\end{array}$ & Exón 4 & Sinónimo (132) \\
\hline rs109077068 & 46833778 & 13 & $\mathrm{G} / \mathrm{A}$ & $\begin{array}{c}\text { ataacaatatatgttggaca } \\
\text { acgtatcca }\end{array}$ & $\begin{array}{c}\text { Cagaaagtcatggagttcg } \\
\text { atgcaaacgtc }\end{array}$ & UTR3' & - \\
\hline rs110266999 & 46833693 & 9 & $\mathrm{~T} / \mathrm{C}$ & $\begin{array}{c}\text { ataaatctaaaaagttttattt } \\
\text { aaccaaca }\end{array}$ & $\begin{array}{c}\text { Aaccatatcaaaatcagtct } \\
\text { ggaagaaaat }\end{array}$ & UTR3' & - \\
\hline
\end{tabular}

Tabla 4. SNPs reportados para el gen bovino FABP4 (Gene ID: 281759, ENSBTAG00000037526). 


\subsubsection{Lipasa Sensible a Hormona (LIPE)}

Como ya se ha mencionado en la sección anterior, LIPE es una enzima clave en la movilización de ácidos grasos desde los acilgliceroles (Lampidonis et al., 2011). Actúa como lipasa neutral intracelular y es capaz de hidrolizar una variedad de ésteres (Holm, 2003). Hasta hace poco, era considerada la lipasa principal y casi exclusiva de la lipólisis estimulada por hormona (Yeaman, 2004). Los adipocitos de ratones a los que se les inactivó el gen LIPE (ratones knockout) fueron incapaces de liberar glicerol y presentaron una acumulación masiva de diacilglicerol en las células, demostrando que la mayor importancia de LIPE como diglicérido lipasa que como triglicérido lipasa (Haemmerle et al., 2002). LIPE exhibe una fuerte actividad diglicérido hidrolasa que es 10 veces más alta que su actividad contra sustratos triglicéridos y 5 veces más alta que su actividad contra monoglicéridos (Belfrage et al., 1978). Este modelo de LIPE como protagonista exclusivo quedó atrás cuando se descubrió una nueva lipasa diferente a todas, la triacilglicerol lipasa adiposa (ATGL), también llamada desnutrina o iPLA2 (Jenkins et al., 2004; Villena et al., 2004; Zimmermann et al., 2004).Esta enzima es responsable del $75 \%$ de la actividad acilhidrolasa citoplasmática en tejido adiposo blanco de ratones deficientes en LIPE, por lo que se le atribuye un rol complementario al de LIPE en los procesos lipolíticos (Zimmermann et al., 2004) (Fig. 14).

LIPE está altamente expresada en tejido adiposo, pero también se expresa en glándula adrenal, ovario, testículo, corazón y músculo esquelético (Qiao et al., 2007; Wang et al., 2004). Se ha observado que esta enzima está altamente conservada entre especies de mamíferos como el cerdo, el humano, los ratones y las ratas (Yajima et al., 2007). 


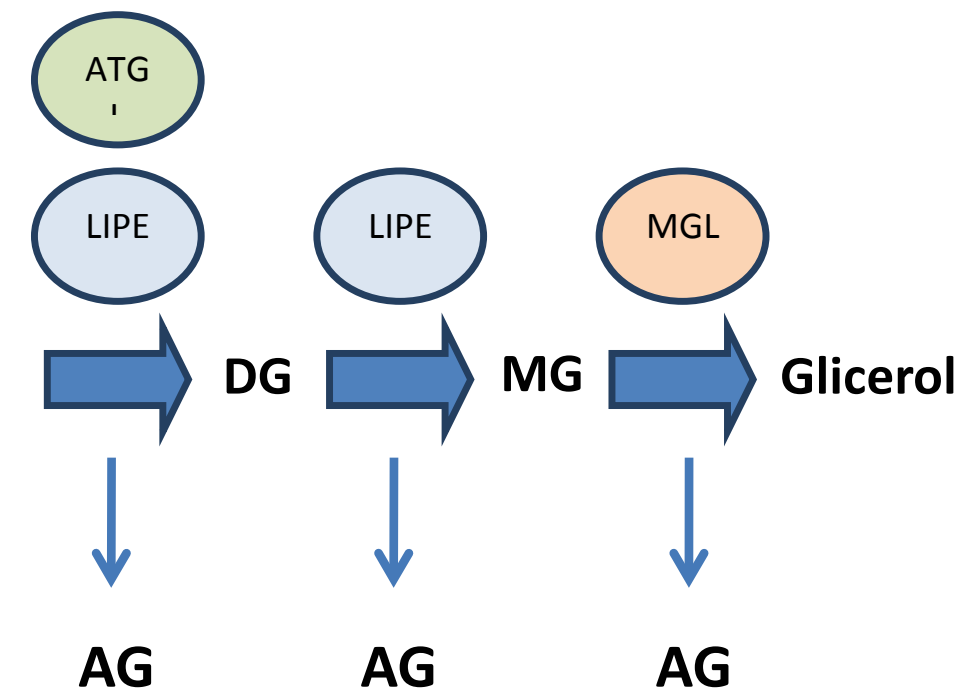

Fig. 14. Representación esquemática de la degradación coordinada de triglicérido (TG) a diacilglicérido (DG) y monoglicérido (MG). Las actividades de ATGL, HSL y MGL son absolutamente necesarias para la liberación de ácidos grasos y glicerol.

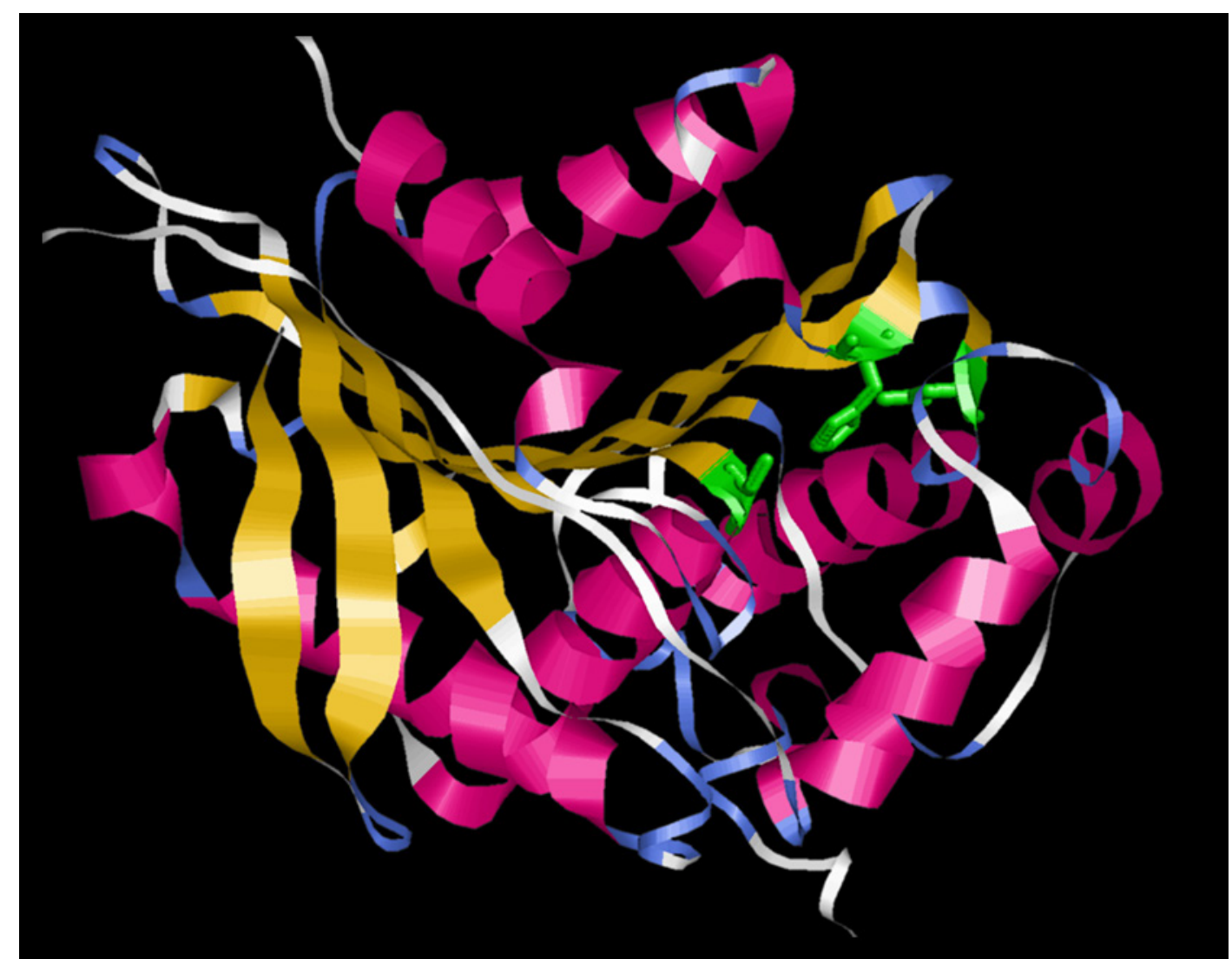

Fig. 15. Estructura del dominio catalítico de LIPE. Las a-hélices se indican con color fucsia, las hojas $\beta$ con amarillo y la triada de aminoácidos que conforman el sitio catalítico con verde. 
LIPE está formada por 756 aminoácidos (NP_001073689.1) y los análisis de estructura indican que es una enzima multi-dominio (Osterlund et al., 1996; Smith et al., 1996; Osterlund et al., 1999). La porción N-terminal, de unos 280 residuos, no posee un rol claro hasta ahora. Se ha sugerido que posiblemente actúe como sitio de unión a otras proteínas, como FABP4, que aumenta la actividad de la enzima al unirse a lípidos y también como sitio de dimerización (Shen et al., 2000; Shen et al., 2001; Smith et al., 2007). Esta región se encuentra bastante conservada en las LIPE de todos los mamíferos. Luego se encuentra la región C-terminal, que presenta un plegamiento $\alpha / \beta$ hidrolasa común entre las lipasas (Contreras et al., 1996; Osterlund et al., 1996; Osterlund et al., 1997). Esta estructura está interrumpida por un módulo regulatorio $(R)$ que contiene sitios de fosforilación involucrados en la activación de la enzima (Anthonsen et al., 1998). El dominio catalítico está compuesto por los fragmentos Ct-1 y Ct-2 y contiene el motivo Gly-X-Ser-X-Gly, existente en muchas de las esterasas y lipasas. Este dominio se encuentra junto con los otros dos miembros de la triada catalítica que caracteriza a estas enzimas (Holm, 2004). La triada está compuesta por la serina del motivo anterior, un residuo de ácido carboxílico (Asp o Glu) y una histidina, en este orden. Además de la triada catalítica hay un sitio catalítico putativo de histidina (familia G_D_X_G) (Fig. 15).

El gen bovino LIPE (Gene ID: 286879) tiene un ADNc de $2647 \mathrm{pb}$ (NM_001080220.1, ENSBTAT00000043890) y está compuesto por 10 exones. Varios SNPs han sido reportados en vacas, cerdos y otras especies pero pocos de ellos han sido estudiados en con más detalle (Lei et al., 2005). Los polimorfismos en zonas codificantes reportados en la base de datos SNPdb para el gen bovino LIPE se presentan en la tabla 5 . 


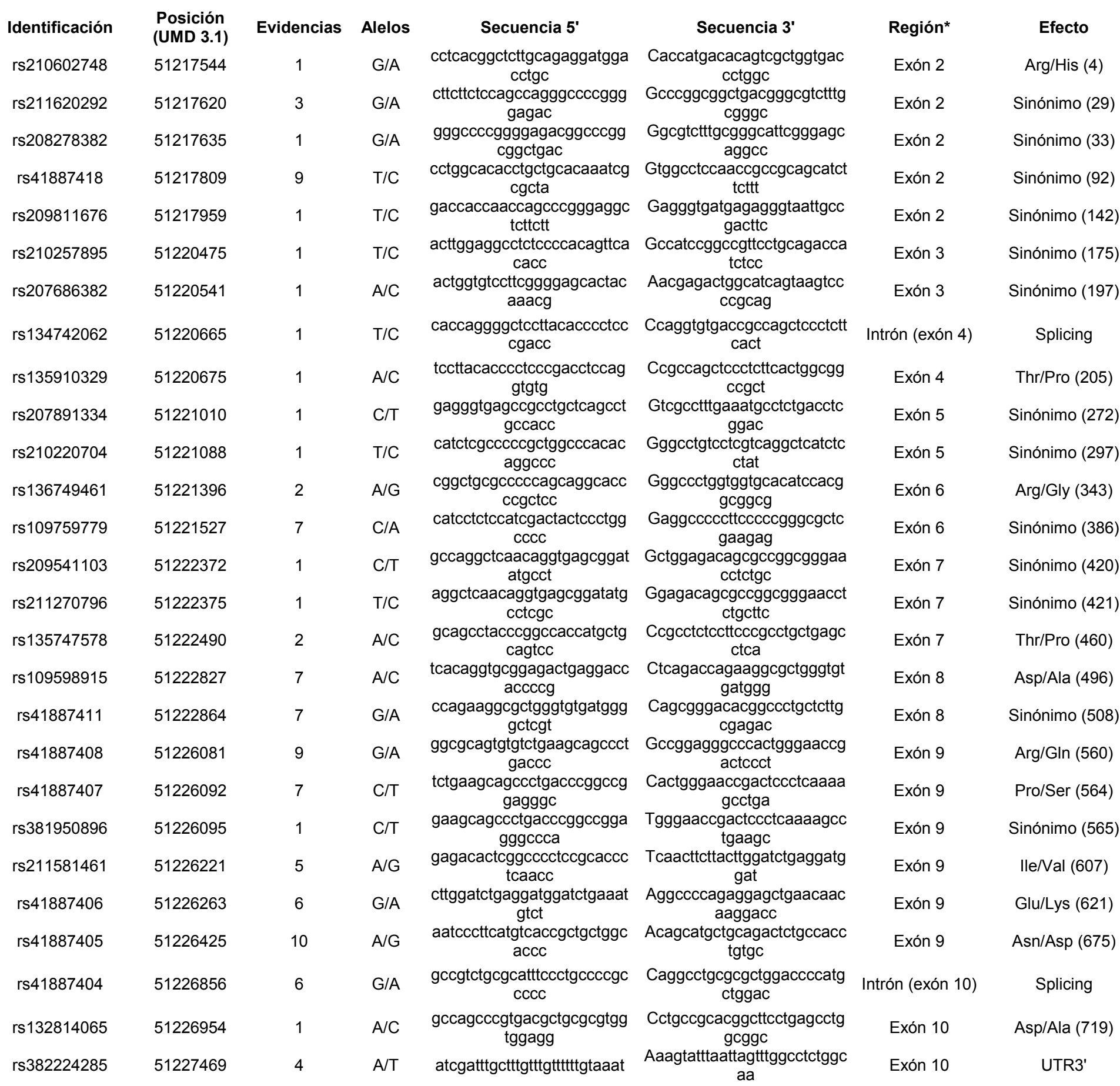

*Los paréntesis indican cercanía relativa

Tabla 5. SNPs reportados en las zonas codificantes del gen bovino LIPE (Gene ID: 286879) 
LIPE es importante porque provee ácidos grasos al cuerpo de manera directa y las mutaciones en su gen podrian afectar a todos los caracteres productivos que involucren a los ácidos grasos como precursores metabólicos además de afectar a la calidad de la carne (Hermo et al., 2008; Wang et al., 2014). Pocos trabajos de asociación han sido realizados para este gen. Fang et al. (2013) reportó asociaciones de los SNPs rs41887418 y rs41887407 con caracteres de carcasa y calidad carnicera en razas chinas con cruza Simmental. EI SNP rs41887418 fue asociado a rendimiento de la canal, tasa neta de carne, circunferencia de patas traseras, tasa de cobertura grasa, grasa mesentérica, grasa de riñonada, $\mathrm{pH}$ del bife y contenido de ácido araquídico (C20:0), ácido dohono-c-linolénico (C20:3n-6) yácido eicosenoico(C20:1). El SNP rs41887407 fue asociado con circunferencia y ancho de patas traseras, profundidad de la canal, espesor de lomo, cobertura de grasa, color de grasa, $\mathrm{pH}$ del bife y composición de ácidos grasos: ácido margárico (C17:0), ácido esteárico (C18:0), ácido linoleico (C18:2c912), ácido a-linolénico (C18:3c91215) y ácido araquidónico (C20:4) (Fang et al., 2013).

Por lo expuesto anteriormente y considerando la importancia de cada uno de los genes descriptos dentro de vías específicas asociadas a la adipogénesis y al metabolismo lipídico, en el presente trabajo de tesis se propuso caracterizarlos en razas bovinas de diferente calidad carnicera. La selección de estos genes candidatos siguió un criterio particular dado que se tuvo en cuenta la interrelación de los mismos dentro de las vías metabólicas, de manera que todos ellos interactúan entre sí a diversos niveles. Para la realización de este trabajo es fundamental la integración de todas las herramientas y la información disponible en las bases de datos de la web. Esto es primordial para poder llevar a cabo la identificación de "genes candidatos", que como se mencionó anteriormente, son genes cuyas variaciones genéticas son responsables de la variación fenotípica. El conocimiento de aquellas variaciones responsables de cambios fenotípicos es de gran utilidad para complementar los métodos tradicionales de selección de ganado, dado que puede incrementarse la frecuencia de los alelos favorables de acuerdo a las preferencias de los consumidores en el contexto de cada sociedad (Hocquette et al., 2006). 


\section{HIPÓTESIS}

La hipótesis general del presente proyecto sostiene que la presencia de mutaciones en algunos de los genes que participan en el metabolismo lipídico en bovinos altera su funcionamiento, y por lo tanto modifica el contenido y la composición de ácidos grasos de la carne. Las mutaciones en los genes PPARG, CEBPA, RXRA, FABP4 y LIPE actúan sobre el metabolismo lipídico a través de diferentes mecanismos: variaciones en los niveles de expresión por modificaciones en las secuencias reguladoras, variaciones en la estabilidad y el plegamiento de las moléculas de ARNm, o cambios estructurales en la proteína por cambios de splicing o aminoácidos, los cuales causan diferente grado de afinidad por otros factores proteicos, ligandos o ADN. 


\section{OBJETIVO}

El objetivo general del presente proyecto de Tesis Doctoral consiste en caracterizar la variabilidad genética presente en los genes PPARG (cromosoma 22), CEBPA (cromosoma 18), RXRA (cromosoma 11), LIPE (cromosoma 18) y FABP4 (cromosoma 14).

\subsection{Objetivos específicos}

El presente plan incluye los siguientes objetivos particulares:

$\checkmark$ Detectar SNPs en las regiones promotora-proximal, regiones no traducidas y regiones codificantes de los genes PPARG, CEBPA, $R X R A$, LIPE y FABP4 en un panel mixto de razas bovinas mediante PCR-secuenciación directa.

$\checkmark$ Determinar las fases y bloques de ligamiento en los genes mencionados.

$\checkmark$ Desarrollar métodos de tipificación de alta performance para validar algunos de los SNPs a nivel poblacional.

$\checkmark$ Evaluar la posible asociación entre los SNPs analizados y el contenido y la composición lipídica de la carne.

$\checkmark$ Evaluar del efecto teórico de los SNPs sobre las estructuras proteicas, las moléculas de ARNm, los sitios putativos de splicing, y la unión de factores de transcripción y otros factores proteicos mediante herramientas bioinformáticas. 


\section{MATERIALES Y MÉTODOS}

\subsection{Material animal}

En el presente trabajo se emplearon dos grupos de muestras para cumplir con los distintos objetivos propuestos. El primer grupo, denominado grupo "A", consistió en 43 muestras de sangre de animales pertenecientes a razas bovinas con diferente capacidad carnicera criadas alrededor del mundo (Angus $n=5$, Hereford $n=5$, Criollo Argentino $n=5$, Wagyu $n=5$, Holstein $n=5$, Limousin $n=4$, Shorthorn $n=5$, Nelore $n=4$ y Brahman $n=5$ ). Este panel de muestras se empleó para identificar polimorfismos genéticos (SNPs o INDELs) mediante la estrategia de re-secuenciación de genes candidatos.

El grupo "B" estuvo constituido por 260 muestras de carne de novillos que provenían de un proyecto previo de evaluación de sistemas de cruza bajo pastura con suplementación estratégica realizado en la Estación Experimental Agropecuaria Balcarce del Instituto Nacional de Tecnología Agropecuaria (INTA Balcarce, Villareal et al., 2006). Este grupo de muestras se empleó para la validación a nivel poblacional de los SNPs detectados en el grupo "A" y para los análisis de asociación con caracteres de contenido y composición de la carne. El muestreo del grupo "B" se realizó durante ocho faenas de novillos nacidos entre 2006 y 2010 que tenían entre 15 y 29 meses de edad. Estos novillos pertenecían a los siguientes grupos genéticos: Angus puros (A) $n=44$, Hereford puros $(H) n=26$, cruzas recíprocas $F 1$ ( $A x H$ y sus retrocruzas) $n=110$, cruzas $\mathrm{F} 2$ (AHxAH y HAxHA) n=39 y un grupo de novillos obtenidos del apareamiento de toros Limousin con vacas cruza F1 (LX) n=41 (Tabla 6). La decisión de usar esta población en lugar de otras poblaciones comerciales se basó en la disponibilidad de información confiable en términos de datos fenotípicos, de manejo y del contexto genético de los animales. 

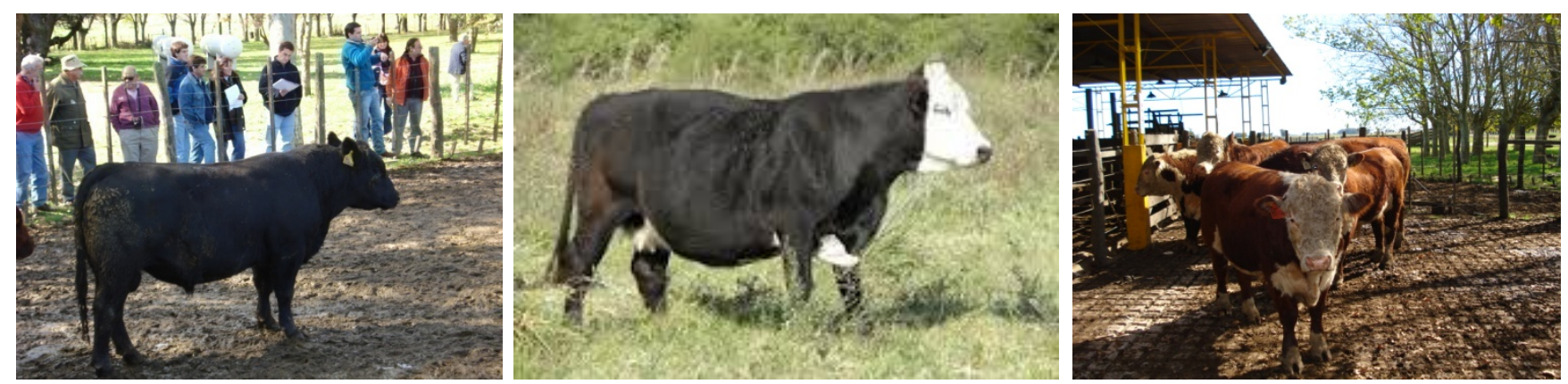

\begin{tabular}{|c|c|c|c|c|c|c|c|c|}
\hline $\begin{array}{c}\text { Raza } \\
\text { padre }\end{array}$ & $\begin{array}{c}\begin{array}{c}\text { Raza } \\
\text { madre }\end{array} \\
A\end{array}$ & $\begin{array}{c}\begin{array}{c}\text { Raza } \\
\text { novillo }\end{array} \\
\mathrm{A}\end{array}$ & $\begin{array}{c}\begin{array}{c}\text { Grupo } \\
\text { genético }\end{array} \\
\text { A }\end{array}$ & 44 & Faena & Fecha de faena & $\mathbf{N}$ & Grupos genéticos \\
\hline $\mathrm{H}$ & $\mathrm{H}$ & $\mathrm{H}$ & $\mathrm{H}$ & 26 & 1 & 27 de Octubre, 2008 & 50 & $\begin{array}{c}A(6), H(3), 75 A(7), 75 H(6) \\
50 A H(23), \operatorname{LX~(5)~}\end{array}$ \\
\hline A & $\mathrm{H}$ & $\mathrm{AH}$ & & & 2 & 4 de Enero, 2011 & 55 & $\begin{array}{c}\text { A (8), H (7), } 75 \mathrm{~A}(5), 75 \mathrm{H}(10), \\
50 A H(19), \operatorname{LX}(6)\end{array}$ \\
\hline $\begin{array}{c}\mathrm{H} \\
\mathrm{AH}\end{array}$ & $\begin{array}{c}\mathrm{A} \\
\mathrm{AH}\end{array}$ & $\begin{array}{c}\mathrm{HA} \\
\mathrm{AHAH}\end{array}$ & $50 \mathrm{AH}$ & 95 & 3 & 22 de Septiembre, 2011 & 29 & $\begin{array}{c}\mathrm{A}(3), 75 \mathrm{~A}(12), 75 \mathrm{H}(4), 50 \mathrm{AH} \\
(10)\end{array}$ \\
\hline $\mathrm{HA}$ & $\mathrm{HA}$ & НАНА & & & 4 & 18 de Octubre, 2011 & 29 & $\begin{array}{c}\mathrm{A}(9), \mathrm{H}(3), 75 \mathrm{~A}(3), 75 \mathrm{H}(3) \\
50 \mathrm{AH}(8), \mathrm{LX}(3)\end{array}$ \\
\hline $\begin{array}{l}A \\
A\end{array}$ & $\begin{array}{l}\mathrm{AH} \\
\mathrm{HA}\end{array}$ & $\begin{array}{l}\mathrm{AAH} \\
\mathrm{AHA}\end{array}$ & $75 \mathrm{~A}$ & 30 & 5 & 3 de Enero, 2012 & 30 & $\begin{array}{c}\mathrm{A}(6), \mathrm{H}(2), 75 \mathrm{~A}(2), 75 \mathrm{H}(1), \\
50 \mathrm{AH}(8), \mathrm{LX}(11)\end{array}$ \\
\hline $\begin{array}{l}\mathrm{H} \\
\mathrm{H}\end{array}$ & $\begin{array}{l}\mathrm{AH} \\
\mathrm{HA}\end{array}$ & $\begin{array}{l}\mathrm{HAH} \\
\mathrm{HHA}\end{array}$ & $75 \mathrm{H}$ & 24 & 7 & 17 de Septiembre, 2012 & 28 & $\begin{array}{c}\text { A (6), H (3), 50AH (10), LX (6) } \\
\begin{array}{c}\text { A (6), H (3), } 75 A(1), 50 A H(15), \\
\text { LX (3) }\end{array}\end{array}$ \\
\hline $\begin{array}{l}\mathrm{L} \\
\mathrm{L}\end{array}$ & $\begin{array}{l}\mathrm{AH} \\
\mathrm{HA}\end{array}$ & $\begin{array}{l}\text { LAH } \\
\text { LHA }\end{array}$ & $L X$ & 41 & 8 & 16 de Octubre, 2012 & 14 & $\mathrm{H}(5), 50 \mathrm{AH}(2), \mathrm{LX}(7)$ \\
\hline
\end{tabular}

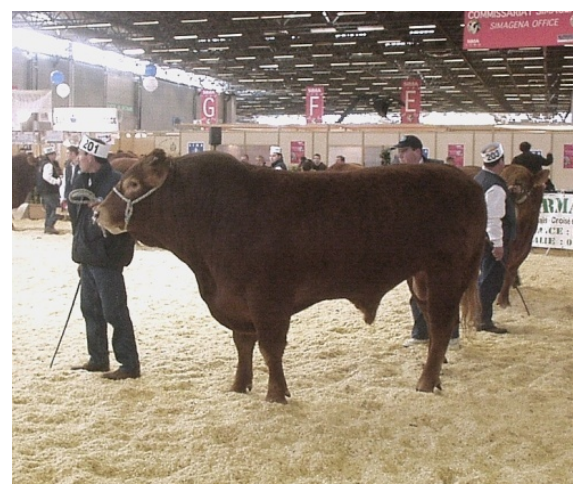

Tabla 6.Estructura del panel de muestras "B". (A) Estructura genética de la población usada para llevar a cabo los estudios de validación ( $n=260)$ y asociación $(n=177)$.(B) Composición del panel "B" por faena. 


\subsection{Extracción de ADN}

El ADN total se extrajo de las muestras de sangre con el kit de purificación de ADN genómico Wizard $\AA$ (Promega, Madison, WI, USA), de acuerdo a las instrucciones del proveedor (Ver Anexo). La extracción de ADN a partir de las muestras de carne se realizó según el método modificado de extracción orgánica sugerido por Wagner et al. (1994) (Ver Anexo).

\subsection{Estudio de re-secuenciación: amplificación, secuenciación y análisis de las secuencias}

Con el fin de caracterizar la variabilidad genética de las regiones codificantes de los genes PPARG, CEBPA, RXRA, LIPE y FABP4 mediante PCR-secuenciación, se diseñaron pares de cebadores (Tabla 7) en base a las secuencias de ADN disponibles en Genbank (Gene IDs: 281993, 281677, 507554, 286879 y 281759 , respectivamente). Las reacciones de PCR se llevaron a cabo en un volumen total de $25 \mu \mathrm{l}$ de una solución de reacción que contenía $20 \mathrm{mM}$ de Tris- $\mathrm{HCl}(\mathrm{pH}=8,4), 50 \mathrm{mM}$ de $\mathrm{KCl}, 1,5 \mathrm{mM}$ de $\mathrm{MgCl}$, $200 \mu \mathrm{M}$ de dNTPs, 0,5 $\mathrm{U}$ de Taq polimerasa (Invitrogen, Carlsbad, CA), 0,4 $\mu \mathrm{M}$ de cada primer y entre 25-50 ng de ADN. En el caso particular del gen CEBPA, que contaba con una composición elevada de CG, se debió implementar el uso de DMSO (2 $\mu \mathrm{l})$ para desestabilizar las estructuras secundarias, ya que estas impedían la amplificación en condiciones normales. Las condiciones de reacción fueron: 1 ciclo de 3 minutos a $94^{\circ} \mathrm{C}, 35$ ciclos de 30 segundos a $94^{\circ} \mathrm{C}, 40$ segundos a la temperatura de annealing correspondiente (Tabla 7), 40 segundos a $72^{\circ} \mathrm{C}$ y una elongación final de 10 minutos a $72^{\circ} \mathrm{C}$. 


\begin{tabular}{|c|c|c|c|c|}
\hline Gen & Secuencias $\left(5^{\prime}-3^{\prime}\right)$ & Tamaño (pb) & $\operatorname{Tm}\left({ }^{\circ} \mathrm{C}\right)$ & Región \\
\hline \multirow{16}{*}{ PPARG } & TCAACCAAGGGTGGGCAGA & 299 & 67,5 & Promotor \\
\hline & TGTGACAGCGAAGGGCTCA & & & \\
\hline & GACGCAACAGCTTGTCACAGC & 471 & 63 & Promotor + Exón 1 \\
\hline & CGCAAGAGCAGCAAGTTAAGC & & & \\
\hline & TCAGGGCTAACGTCACAGCTGGT & 364 & 63 & Exón 2 \\
\hline & CCACAGCCATTAGTCCTGGGAGC & & & \\
\hline & TCCTGTGATGATTGTCTGCTCCTGT & 211 & 62 & Exón 3 \\
\hline & ACCTTGCATCCTTCACAAGCATGA & & & \\
\hline & СССTCGCCCATATTCCTTTGTAGGG & 199 & 62 & Exón 4 \\
\hline & GAGAAGCGTCGAGTGCGGGC & & & \\
\hline & GCACTCATTCATCCTGCCCTTTCTC & 273 & 62 & Exón 5 \\
\hline & ACCCGGCCACCCCAAATGAA & & & \\
\hline & CAGGAGCCCAGCAAAGAGGT & 304 & 62 & Exón 6 \\
\hline & CAGCAAACTCGAACTTGGGC & & & \\
\hline & CAGGTTTGCTGAACGTGAAGC & 838 & 64 & Exón 7 \\
\hline & GCTGCTGCTGGTGAGTGAGA & & & \\
\hline \multirow{4}{*}{ CEBPA } & GCAGGAGGTAGTAGGCGTTG & 492 & 61 & Promotor + Exón \\
\hline & GTCGATGGACGTCTCGTGTT & & & \\
\hline & GCGGCAACGACTTTGACTAC & 360 & 61 & Exón \\
\hline & CCGGTACTCGTTGCTGTTCT & & & \\
\hline \multirow{12}{*}{ LIPE } & GTGGAGCCAGGGGTGACCCAG & 669 & 60 & Exón 2 \\
\hline & TATGTGACTGAGCCTGGTTGGGC & & & \\
\hline & TCCCCACAGTTCACACCTGCCAT & 723 & 60 & Exones 3,4 y 5 \\
\hline & TGCTCCTCAGCTCTGCGTCTGTTC & & & \\
\hline & CAGAACAGACGCAGAGCTGAGGA & 506 & 60 & Exón 6 \\
\hline & TTGTGGCTCTTTGCCCCTGCTG & & & \\
\hline & CCCAAATAGGTCCAGATCCСTGCCT & 837 & 60 & Exones 7 y 8 \\
\hline & ACCTTCTGGTGCTAGGCTGTCC & & & \\
\hline & ССАСССАСАСАСТСAАСCCACAGA & 826 & 60 & Exón 9 \\
\hline & CAGCAGCGGTGACATGAAGGGAT & & & \\
\hline & GCTGGACGACTCGGTCATGT & 505 & 60 & Exón 10 \\
\hline & AGTGATCCCGTGCAAGTCC & & & \\
\hline \multirow{8}{*}{ FABP4 } & ACTGCTGTCTAGATTCCTGGTGGA & 824 & 58 & Promotor + Exón 1 \\
\hline & CATGTCAGACCAATGCTTCCAGAG & & & \\
\hline & TGAAGCTGGCTGCTCTCATGG & 665 & 59 & Exón 2 \\
\hline & TGGTTTGCTATAGGCAGCAGTC & & & \\
\hline & GACTGCTGCCTATAGCAAACCA & 857 & 58 & Exón 3 \\
\hline & ACGGTTCACATTGAGAGGGA & & & \\
\hline & AGGTATACTGTGCCCCCAGCAGT & 818 & 58 & Exón 4 \\
\hline & CAACACGGGCCAGCCG & & & \\
\hline
\end{tabular}


Tabla 7. Cebadores diseñados para amplificar las regiones codificantes de los genes PPARG, CEBPA, RXRA, LIPE y FABP4 mediante PCR-secuenciación.

Los productos de amplificación se verificaron en geles de poliacrilamida $6 \%$, se revelaron mediante la tinción con bromuro de etidio y se visualizaron en un transiluminador UV (ver Anexo). Posteriormente, los productos de PCR se purificaron mediante la técnica de precipitación diferencial con polietilenglicol 8000 (ver Anexo) y se secuenciaron mediante el método de Sanger en un secuenciador automático de ADN MegaBACE 1000 (GE Healthcare, USA) usando el kit DYEnamic ET Terminator (GE Healthcare) (Ver Anexo). Las secuencias crudas fueron editadas mediante el software Sequence Analyzer (GE Healthcare).

Las secuencias de ADN obtenidas se alinearon utilizando el software CLUSTAL-X 2.1 (Larkin et al., 2007). Las variaciones se definieron por comparación directa con las secuencias reportadas en Genbank. En el caso de los sitios heterocigotas se realizó el control individual de las secuencias de ADN con el software Chromas Lite v2.1.1 (Technelysium, http://technelysium.com.au/?page_id=13). El desequilibrio de ligamiento (fase de ligamiento) entre los SNPs detectados por resecuenciación se determinó con el software PHASE (Li et al., 2003) y se visualizó mediante el programa HAPLOVIEW (Barrett et al., 2005) con los métodos "cuatro gametas" y "sólido".

\subsection{Validación poblacional de polimorfismos: selección y genotipificación de SNPs}

Con el fin de realizar estudios de validación a nivel poblacional, se seleccionó algunas de las variantes detectadas por re-secuenciación en el panel de muestras "A" para llevar a cabo los ensayos de genotipificación. Estos se llevaron a cabo en el panel de muestras "B" ( $n=260)$ mediante diferentes métodos, los cuales se mencionan en la siguiente sección. Las mutaciones fueron seleccionadas en base a diferentes características:

- Tipo de cambio (sinónimo/no sinónimo): las mutaciones no sinónimas (missense) eran preferibles ya que al cambiar residuos específicos podrían alterarse la estructura, las propiedades y la función de la proteína. 
- Posición en el gen (región regulatoria, codificante, no-codificante): las mutaciones en las regiones regulatorias (promotoras o no-traducidas) y en zonas traducidas son preferibles a las mutaciones en zonas nocodificantes por el rol biológico que desempeñan.

- Raza de detección: solo valía la pena seleccionar las mutaciones detectadas en Angus, Hereford o Limousin dada la composición del panel "B". Seleccionar una mutación detectada en otras razas y no en las mencionadas acarreaba el riesgo de no presentar variabilidad en el panel.

- Reportes previos de asociación a caracteres de interés productivo: las mutaciones analizadas por otros autores en otras razas bovinas y que presentaban efectos significativos sobre las variables de interés también eran candidatos interesantes a estudiar en nuestra población.

El genotipado de los polimorfismos seleccionados en las muestras del panel "B" se llevó a cabo mediante las técnicas de pirosecuenciación y espectrometría de masas (Ver anexo).

Para tipificar el SNP rs110757796 (I74V) del gen FABP4 se diseñó un método basado en la técnica de pirosecuenciación. Con este fin se diseñaron un par de cebadores externos de amplificación y un cebador interno de secuenciación. En primer lugar, se amplificó por PCR un fragmento de 295 pb correspondiente al exón 2, que incluía el polimorfismo rs110757796, utilizando los primers externos: FABP4-F-biot 5'TCATCAGTTTGAATGGGGGT-3' y FABP4-R 5'AATGGGAGAAAATTCACCAGC 3'.EI primer forward estaba biotinilado para ser utilizado en la etapa posterior de purificación. Además, se diseñó un cebador interno complementario a la cadena forward: FABP4-int 5'-TGTCATCTGGAGTGA-3' (Fig. 16). 
ATTTTTCTTTTCCCAACTATAGGCGTGGGCTTTGCTACCAGGAAAGTGGCTGGCATGGC CAAACCCACTTTGATCATCAGTTTGAATGGGGGTGTGGTCACCATTAAATCAGAAAGCA CCTTTAAAAATACTGAGATTTCCTTCAAATTGGGCCAGGAATTTGATGAAATCACTCCAG ATGACAGGAAAGTCAAGGTGAGAAATAAAGAACTGGAGCAGAGTAAAAAACCTGATTTA TAAATGACTGCTGCCTATAGCAAACCATTTTGTAGAAGGAGGAAAGCCATTCCATTATAA GCCAAAAATCTCAGATTGCTAGATCTGAACCATGTTACCTTTGATATTTAGCTGGTGAAT TTTCTCCCATTTAATAAAATTGTCCTTATTACTTTAAAAATGTTTAACATAATAATTTACTT G

Fig. 16. Distribución de los cebadores para la pirosecuenciación del SNP rs110757796 del exón 2 del gen FABP4. La región codificante se muestra en color naranja, el sitio polimórfico en amarillo, el rojo indica la región de pegado del primer externodirecto (biotinilado), el azul la del primer externo reverso y el subrayado la del primer interno de pirosecuenciación.

La reacción de PCR se llevó a cabo en un volumen final de 25 l. La mezcla de reacción contenía buffer $1 \mathrm{X}$ (Invitrogen), 0,15 $\mu \mathrm{M}$ de cada primer, $200 \mathrm{mM}$ de cada dNTP, $2 \mathrm{mM}$ de $\mathrm{MgCl} 2$, 0,5 unidades de Taq polimerasa (Invitrogen) y $90 \mathrm{ng}$ de ADN. Se utilizó un termociclador Maxygene Gradient (MJResearch - BioRad Laboratories Inc.). El perfil de ciclado consistió en 45 ciclos de 45 segundos a $94^{\circ} \mathrm{C}, 45$ segundos a $63^{\circ} \mathrm{C}$ y 45 segundos a $72^{\circ} \mathrm{C}$, seguidos por una extensión final de 10 minutos a $72^{\circ} \mathrm{C}$.

Para tipificar el SNP rs41610552 del gen PPARG también se desarrolló un método basado en pirosecuenciación. Como en el caso anterior, para amplificar por PCR un fragmento de ADN de 153 pb se diseñó un par de primers externos: PPARGeF(B): 5'-AGCTGACCCGATGGTTGCAGA-3' y PPARG-eR: 5'CCACAGCCATTAGTCCTGGGAGC-3'. Además, se diseñó un cebador interno de localizado a dos bases del sitio polimórfico y complementario a la cadena forward: PPARG-iR: 5'-GGAGCATTTACCCTACTGT-3' (Fig. 17). Las condiciones de reacción fueron iguales a las mencionadas para el marcador del FABP4. 
Fig. 17. Cebadores diseñados para la tipificación del SNP rs41610552 del gen PPARG mediante la técnica de pirosecuenciación. El color verde indica la posición del SNP, el naranja indica el final del exón, el rojo indica la posición del primer externo directo (biotinilado), el azul la del primer externo reverso y el subrayado la del primer interno de pirosecuenciación.

En el caso de los dos métodos de tipificación antes mencionados, los productos de amplificación obtenidos se purificaron mediante la captura de las cadenas de ADN biotiniladas con perlas de sefarosa cubiertas de streptavidina (Streptavidin Sepharose High Performance, GE Healthcare), utilizando la plataforma de purificación PyroMark Prep Workstation (Biotage $A B$ ). Posteriormente, las cadenas simples de ADN purificadas se utilizaron como molde para la reacción de pirosecuenciación. Las reacciones de pirosecuenciación se realizaron utilizando dichos moldes de ADN y 0,3 $\mu \mathrm{M}$ del primer interno diluido en buffer de annealing usando el kit Pyro Gold Reagent Kit (Biotage AB, Uppsala, Sweden). Las muestras fueron corridas en un sistema PSQTM96 y los resultados fueron analizados usando el Pyrosequencing Software (Biotage AB) (Ver anexo para más información).

El resto de los SNPs seleccionados fue tipificado mediante MALDI-TOF de espectrometría de masa, utilizando la plataforma MassARRAYTM de Sequenom (www.sequenom.com). Esta tecnología de genotipificación contempla una primera etapa de amplificación por PCR de las regiones "target" que contienen los SNPs, y para esto se diseñaron 18 pares de cebadores específicos correspondientes a los genes PPARG, CEBPA, RXRA, LIPE y FABP4 que fueron agrupados en dos ensayos multiplex (Ver anexo). Posteriormente los productos de amplificación fueron capturados y purificados mediante el uso de perlas magnéticas para ser utilizados como moldes en la reacción de extensión de cebadores. El producto de la reacción es corrido en la plataforma SEQUENOM y los alelos son discriminados mediante el tiempo de vuelo (time of flight, TOF). El análisis fue realizado en el servicio de GeneSeek, Inc. (Lincoln, NE, USA,www.neogen.com). 


\subsection{Análisis Estadístico Poblacional}

Para poder realizar los análisis estadísticos poblacionales correspondientes a las muestras de carne del panel "B" se definieron, de acuerdo a su raza o composición racial, los siguientes grupos: Angus puros $(A) n=44$, Hereford puros $(H) n=26$, novillos $75 \%$ Angus $(75 \mathrm{~A}) \mathrm{n}=30,75 \%$ Hereford $(75 \mathrm{H}) \mathrm{n}=24,50 \%$ Angus-50\% Hereford $(50 \mathrm{AH})$, $\mathrm{n}=95$ y cruzas con Limousin $(L X) n=41$. La estructura poblacional se muestra en la tabla 6.

Las frecuencias alélicas para cada SNP, dentro de cada subpoblación, se calcularon con el software GENEPOP 4.0 (Rousset et al., 1997; Rousset, 2007). La heterocigosidad observada (ho) y esperada (he) para cada locus y la heterocigosidad promedio esperada sobre todos los locus $(\mathrm{He})$ se estimaron de acuerdo a Nei (1978) usando el software de análisis genéticos poblacionales ARLEQUIN 3.5 (Schneider et al., 2000). Las posibles desviaciones del equilibrio de Hardy-Weinberg (HWE) se estimaron para cada locus y subpoblación mediante el test exacto incluido en el programa GENEPOP. Las fases de ligamiento se reconstruyeron por el método bayesiano implementado en el software Phase v2.1.1 (Li y Stephens, 2003; Crawford et al., 2004) utilizando las opciones predeterminadas. Las fases y el desequilibrio de ligamiento entre los SNPs se visualizaron por medio del programa Haploview (Barrett et al., 2005).

\subsection{Medición de las variables fenotípicas de calidad de carne}

Con el fin de caracterizar la carne de los novillos pertenecientes al grupo "B" se evaluaron las siguientes variables relacionadas con contenido y composición de grasa: espesor de grasa dorsal, contenido de grasa intramuscular y la composición de ácidos grasos. Estas variables se utilizaron posteriormente para llevar a cabo los estudios de asociación con los marcadores genéticos correspondientes a los genes candidatos para contenido y composición grasa. Las mediciones fueron llevadas a cabo en la mayoría de los animales de las primeras cinco faenas (177 animales), al momento de desarrollo de este trabajo de tesis el resto de las mediciones no se encontraban disponibles. 
Previo a la faena se midió el peso de los animales y el espesor de grasa dorsal (EGD_PRE). Las medidas ecográficas de espesor de grasa dorsal se realizan entre las $12^{\circ}$ y $13^{\circ}$ costillas con un ecógrafo Aquila Pro Vet (Esaote), con transductor lineal de 3,5 Mhz y una guía de siliconas que adapta el transductor a la curvatura del dorso del animal, utilizando aceite vegetal como acoplante. Veinticuatro horas después de la faena se extrajeron de la carcasa bloques de carne correspondientes al músculo Longissimus dorsi (13ava costilla), se midió el espesor de grasa dorsal del bife (EGD_BIFE) perpendicular a la superficie exterior en un punto a las tres cuartas partes de la longitud del músculo longissimus desde el extremo del hueso del lomo y luego la grasa subcutánea se removió de cada muestra. El total de lípidos se extrajo de las muestras de acuerdo a la técnica de Folch (1957), la que consiste en la purificación por metilación alcalina y su posterior recuperación mediante hexano. La composición de ácidos grasos se determinó con un cromatógrafo gaseoso GC14B (Shimadzu). La separación de metil-ésteres de ácidos grasos (FAMEs) se llevó a cabo utilizando una columna capilar $100 \mathrm{~m}$ x 0,25mm (Restek). El cromatógrafose programó a una temperatura de $140^{\circ} \mathrm{C}$ durante un minuto, incrementado la temperatura desde $140^{\circ} \mathrm{C}$ hasta $240^{\circ} \mathrm{C}$ a $4^{\circ} \mathrm{C}$ por minuto. Luego se mantuvo a $240^{\circ} \mathrm{C}$ durante 20 minutos. El inyector y el detector se mantuvieron a $260^{\circ} \mathrm{C}$. Los datos se obtuvieron mediante el software GCSolution (Shimadzu). La cantidad de cada ácido graso se determinó por la técnica de estándar interno (Supelco 37 FAME MIX) y se expresó como porcentaje sobre ácidos grasos totales. Los ácidos grasos cuantificados fueron los siguientes: ácido miristoleico (C14:1), ácido palmítico (C16:0); ácido palmitoleico (C16:1), ácido esteárico (C18:0), ácido oleico (C18:1c9), ácido vaccénico (C18:1c11), ácido linoleico (C18:2c912), ácido linolelaídico (C18:2t912), ácido Y-linolénico (C18:3c6912), ácido araquídico (C20:0), ácido eicosenoico (C20:1), ácido eicosadienoico (C20:2), ácido eicosatriinoico (C20:3c81114), ácido araquidónico (C20:4), ácido heneicosílico (C21:0), ácidos grasos saturados (AGS), ácidos grasos monoinsaturados (AGMI), ácidos grasos polinsaturados (AGPI), ácidos grasos Omega-6 ( $\omega-6)$ y ácidos grasos Omega-3 ( $\omega-3)$. El contenido de grasa intramuscular, expresado como extracto etéreo, se determinó como la cantidad de grasa en 100 gramos de músculo fresco excluyendo el tejido adiposo externo.

\subsection{Análisis de asociación entre los marcadores genéticos y las variables de contenido y composición de grasa de la carne}


La asociación entre los SNPs de los genes candidatos y los caracteres evaluados de contenido y composición de la carne se estimó por medio de modelos mixtos. Las variables de carcasa (EGD_PRE y EGD_BIFE) y el contenido de grasa intramuscular fueron analizados según el siguiente modelo:

$$
Y_{i j k l m}=\mu+R_{i}+F_{j}+G_{k}+W_{l}+P_{m}+e_{i j k l m}
$$

Donde Yijklm = valor observado de la variable fenotípica; $\mu$ = media global para la variable dependiente; $R_{i}=$ efecto fijo del grupo racial $i^{\text {th }} ; F_{j}=$ efecto fijo de la faena $j^{\text {th }} ; G_{k}=$ efecto fijo del genotipo del SNP $k^{\text {th }} ; W_{1}=$ regresión para la covariable peso prefaena; $\mathrm{P}_{\mathrm{m}}=$ efecto aleatorio del toro $\mathrm{m}^{\mathrm{th}} ; \mathrm{e}_{\mathrm{ijklm}}=$ error aleatorio.

El modelo consideró como efectos fijos las siguientes variables: grupo racial, fecha de faena, la que incluía el grupo contemporáneo -año de nacimiento y momento de faena dentro de año de nacimiento-, y marcador molecular. El padre del novillo estuvo anidado dentro de grupo racial y fue considerado como efecto aleatorio. En el caso de las variables relacionadas a la composición lipídica, el extracto etéreo (grasa intramuscular) se incluyó como covariable en lugar del peso pre-faena.

Todos los análisis se llevaron a cabo usando el procedimiento MIXED del programa SAS (SAS Inst. Inc., Cary, NC, 1998). Cuando los resultados fueron estadísticamente significativos $(p<0,05)$, se reportaron las medias de mínimos cuadrados y las diferencias entre genotipos fueron determinadas por la prueba de separación de medias de Bonferroni. La tasa de descubrimientos falsos (False Discovery Rate, FDR) se aplicó para controlar la proporción de hipótesis rechazadas incorrectamente debido a comparaciones múltiples. Estos procedimientos se realizaron mediante el método de Benjamini \& Hochberg (1995). Los efectos aditivos se estimaron mediante la diferencia entre los dos genotipos homocigotas y los efectos de dominancia se calcularon restando la media de soluciones de los genotipos homocigotas a la de los heterocigotas. Las pruebas de contraste entre medias de genotipos se realizó de acuerdo a Boldman et al. (1993).

\subsection{Modelado estructural y predicción de efectos}

Con el fin de analizar los efectos de los SNPs estudiados sobre la estructura proteica y los sitios de regulación se utilizaron una serie de herramientas bioinformáticas disponibles en la web.

- RBPDB (Base de Datos de Proteínas de Unión a ARN): RBPDB es una colección de proteínas de unión de ARN vinculada a una base de datos 
curada de observaciones publicadas de unión a ARN. Uno puede buscar a través de esta base de datos los sitios de unión más probables para proteínas de unión a ARN en caso de mutaciones codificantes en zonas no traducidas. (http://rbpdb.ccbr.utoronto.ca/)

- Mfold Web Server (Zuker, 2003): es un servidor web que predice las estructuras secundarias de menor energía libre de secuencias de ARN o ADN de cadena sencilla. Es una manera de evaluar el plegado de secuencias cortas, útil para analizar regiones no traducidas de ARN. (http://mfold.rna.albany.edu/?q=mfold)

○ HHpred (Söding et al., 2005): es uno de los mejores de entre 81 servidores de predicción estructural de proteínas (Mariani et al., 2011). Trabaja por medio de homología estructural con otras estructuras conocidas, realizando comparaciones de a pares entre perfiles de Modelos Ocultos de Markov. Genera modelos 3D que deben ser analizados en plataformas como Rasmol, Pymol, Jmol, entre otros. (http://toolkit.tuebingen.mpg.de/hhpred)

- PhysBinder (Hooghe et al., 2012): Esta es una herramienta en línea que se basa en un algoritmo flexible y extensible para la predicción de sitios de unión de factores de transcripción (FTs). El algoritmo hace uso de características directas (la secuencia) e indirectas (propiedades biofísicas tales como la capacidad de flexión del ADN) de los complejos proteína-ADN. Los usuarios pueden elegir entre más de 60 modelos diferentes de unión a FTs. Estas cualidades la convierten en una herramienta útil en el análisis de regiones promotoras.(http://bioit.dmbr.ugent.be/physbinder/)

Los modelos obtenidos por el servidor HHpred fueron visualizados, alineados y editados por medio del software Swiss-PdbViewer v4.1 (Guex et al., 1997), también conocido como DeepView (http://www.expasy.org/spdbv/). 


\title{
5. RESULTADOS
}

\subsection{Estudio de re-secuenciación de genes candidatos para contenido y composición grasa de la carne.}

\author{
5.1.1. PPARG (Receptor Gamma Activado por el Proliferador de \\ Peroxisomas)
}

Con el fin de caracterizar la variabilidad genética y detectar nuevos polimorfismos en el gen PPARG, se analizaron mediante la estrategia de resecuenciación diferentes regiones de dicho gen en las muestras pertenecientes al panel "A". Este análisis evidenció la presencia de 7 SNPs para el gen PPARG (Tabla 8 , Fig 18). Todos los polimorfismos detectados en las muestras analizadas ya habían sido reportados en la base de datos SNPdb e incluían casi la totalidad de la variación genética, con más de una evidencia, depositada en dicha base de datos. No se detectaron razas homocigotas para el alelo alternativo entre las muestras.

\begin{tabular}{|c|c|c|c|c|c|}
\hline Identificación & $\begin{array}{c}\text { Crom Pos (UMD } \\
3.1 \text { ) }\end{array}$ & Región & Razas AA & Razas AB & Razas BB \\
\hline rs207671117 & 57432251 & $\begin{array}{l}\text { Exón } 1 \text { - } \\
\text { UTR5' }\end{array}$ & $\begin{array}{c}\text { Brahman, Criollo, } \\
\text { Holstein, Limousin, } \\
\text { Nelore, Shorthorn, } \\
\text { Wagyu }\end{array}$ & Angus, Hereford & - \\
\hline rs207739706 & 57432040 & Intrón 1 & $\begin{array}{c}\text { Angus, Criollo, } \\
\text { Hereford, Holstein, } \\
\text { Wagyu }\end{array}$ & Brahman & - \\
\hline rs41610552 & 57412725 & Intrón 2 & - & $\begin{array}{c}\text { Angus, Brahman, } \\
\text { Criollo, Hereford, } \\
\text { Holstein }\end{array}$ & - \\
\hline rs211388309 & 57367181 & $\begin{array}{l}\text { Exón } 7 \text { - } \\
\text { UTR3' }\end{array}$ & $\begin{array}{c}\text { Angus, Criollo, } \\
\text { Hereford, Holstein, } \\
\text { Nelore, Wagyu }\end{array}$ & Brahman & - \\
\hline rs207724742 & 57367099 & $\begin{array}{l}\text { Exón } 7 \text { - } \\
\text { UTR3' }\end{array}$ & $\begin{array}{c}\text { Angus, Criollo, } \\
\text { Hereford, Holstein, } \\
\text { Wagyu }\end{array}$ & Brahman, Nelore & - \\
\hline rs110194439 & 57366957 & $\begin{array}{l}\text { Cercanía } \\
3^{\prime}\end{array}$ & $\begin{array}{l}\text { Angus, Brahman, } \\
\text { Criollo, Hereford, } \\
\text { Holstein, Nelore }\end{array}$ & Wagyu & - \\
\hline rs42661651 & 57366920 & $\begin{array}{l}\text { Cercanía } \\
3^{\prime}\end{array}$ & $\begin{array}{c}\text { Criollo, Holstein, } \\
\text { Nelore }\end{array}$ & $\begin{array}{c}\text { Angus, Brahman, } \\
\text { Hereford, Wagyu } \\
\left(^{*}\right)\end{array}$ & - \\
\hline
\end{tabular}

*Muestras de Wagyu media sangre 
Tabla 8- Polimorfismos en el gen bovino PPARG detectados por re-secuenciación en el panel "A". Se detalla las razas donde se encontró cada una de los genotipos para cada SNP detectados.

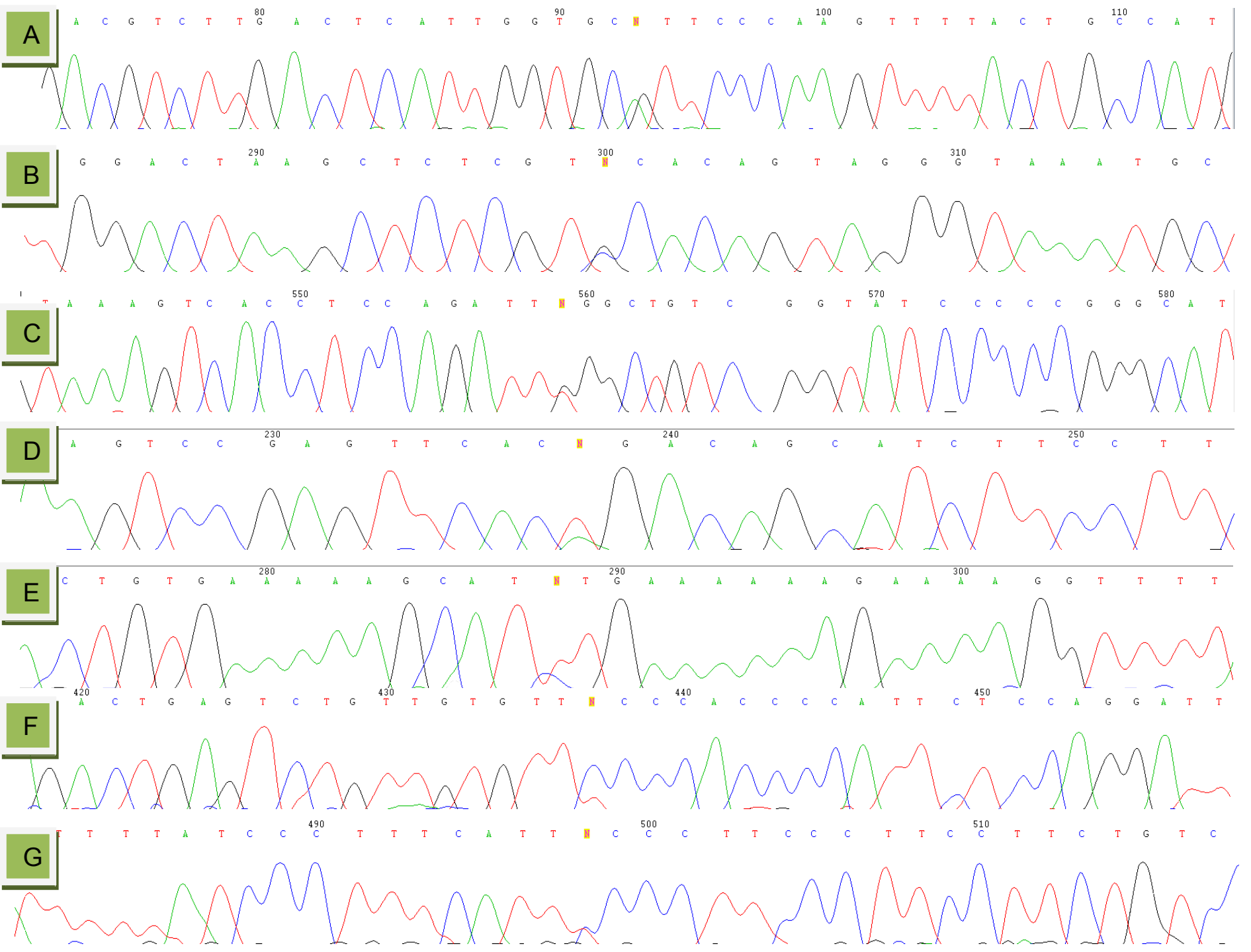

Fig. 18. Secuencias de $A D N$ obtenidas mediante el análisis de muestras del panel "A" donde se observan los diferentes SNPs detectados en el gen PPARG en estado heterocigota. A. rs207671117, B. rs207739706, C. rs41610552, D. rs211388309, E. rs207724742, F. rs110194439, y G. rs42661651 de PPARG. Las posiciones de los SNPs se indican con color amarillo sobre la base nucleotídica.

De los siete SNPs detectados en el gen PPARG, tres polimorfismos se localizaron en las regiones no traducidas (UTR) de los exones: rs207671117 (UTR5'), rs211388309 (UTR3') y rs207724742 (UTR3'). El primero de ellos se detectó en las razas Angus y Hereford, mientras que los otros dos se encontraron en razas cebuinas. 
Los otros cuatro SNPs (rs207739706, rs41610552, rs110194439 y rs42661651) se encontraron en regiones no-codificantes y se detectaron en diferentes razas bovinas. (Tabla 8).

Los trabajos de estudio de variabilidad genética usualmente incluyen dos etapas sucesivas: 1 . detección de SNPs por secuenciación en una muestra reducida y 2. Validación de los SNPs detectados mediante la genotipificación de diferentes poblaciones. El hecho que los polimorfismos no se detectaran en algunas razas no necesariamente significa que no estuvieran presentes, sino que su ausencia puede deberse a que la cantidad de muestras empleadas en esta etapa del trabajo fue limitada y su objetivo estuvo enfocado principalmente a la búsqueda de SNPs en un panel mixto de razas. Es por esta razón que en la segunda etapa del presente trabajo se validaron parte de estos polimorfismos a nivel poblacional utilizando diferentes técnicas de genotipificación.
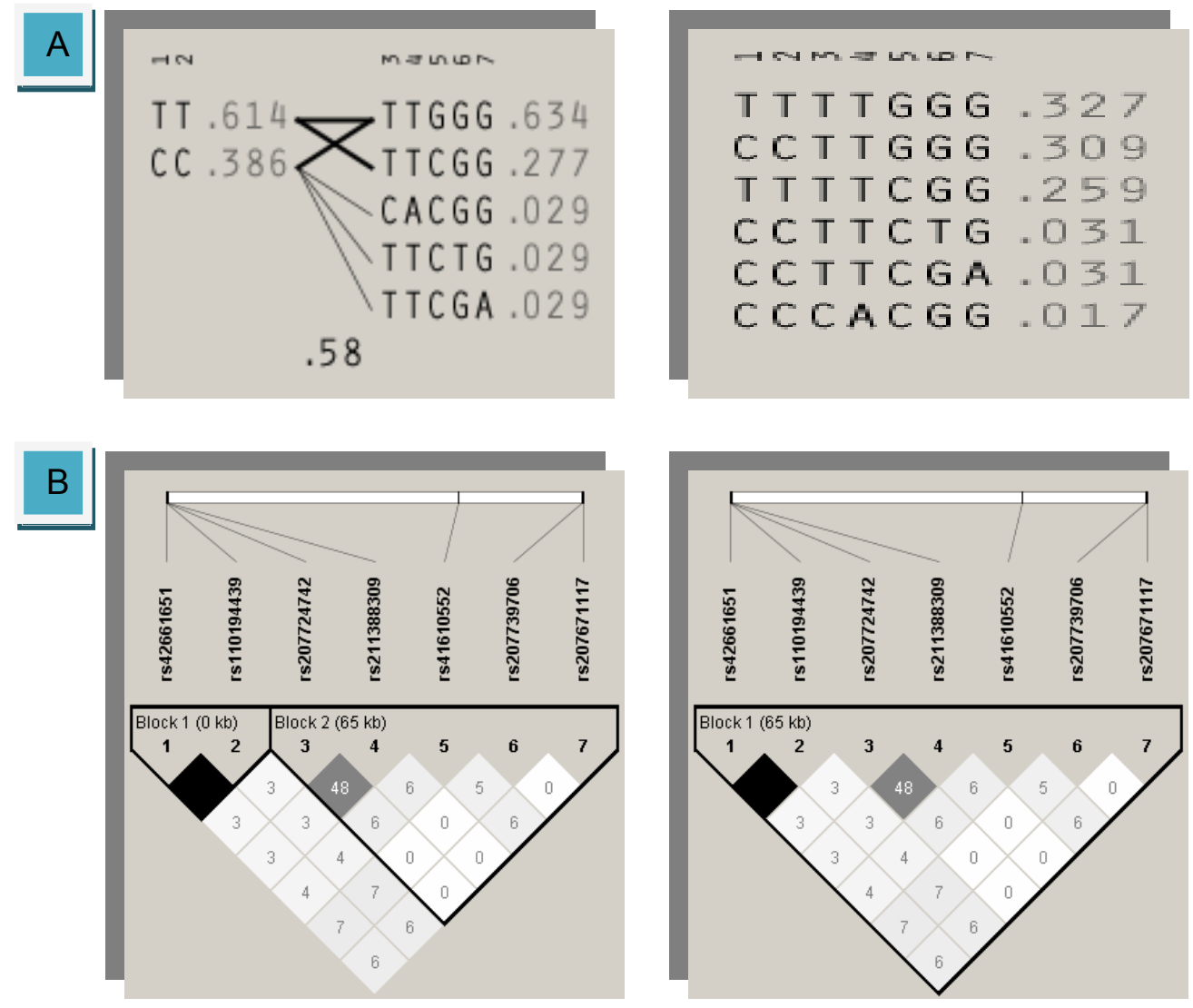

Fig. 19. Haplotipos $(A)$ y bloques de ligamiento $(B)$ detectados por re-secuenciación del gen bovino PPARG y obtenidos con el programa Haploview 3.31 con los métodos de cuatro gametas (izquierda) y sólido (derecha). 
El análisis de ligamiento y la reconstrucción de las fases realizadas por el método de "cuatro gametas" mostraron dos bloques (Fig. 19), uno de menor tamaño localizado en el extremo 3' del gen y compuesto por dos SNPs (rs42661651 y rs110194439) y otro de tamaño mayor y que incluyó a los 5 SNPs restantes. El bloque pequeño constaba de dos haplotipos (CC y TT) y el grande de cinco. Tres de estos cinco haplotipos se encontraron en muy baja frecuencia (Fig. ). El análisis por el método "sólido", evidenció un gran bloque compuesto por todos los SNPs, con tres haplotipos en muy baja frecuencia.

\subsubsection{CEBPA (Proteína de Unión al Amplificador CCAAT Alfa)}

Mediante el estudio de re-secuenciación de las muestras del grupo "A" se detectaron 2 SNPs en el gen CEBPA. Los dos polimorfismos se localizaban en regiones codificantes y uno de ellos no había sido reportado previamente (Tabla 9, Fig.20). Este nuevo SNP, al que se denominó SNPC, fue detectado en las razas cebuinas y en la raza japonesa Wagyu, y causaba un cambio aminoacídico entre dos residuos neutros y polares, serina por asparagina en la posición 139 de la proteína. El otro SNP detectado en el gen CEPBA es el número rs110793792, siendo un SNP de carácter sinónimo con amplia distribución entre la mayoría de las razas, con la excepción de las razas Nelore y Shorthorn, las que solo portaban las variantes homocigotas alternativas (Tabla 9). En el caso de Nelore solo se observaba la variante GG y en Shorthorn la variante TT considerando la secuencia AC_000175.1 como referencia.

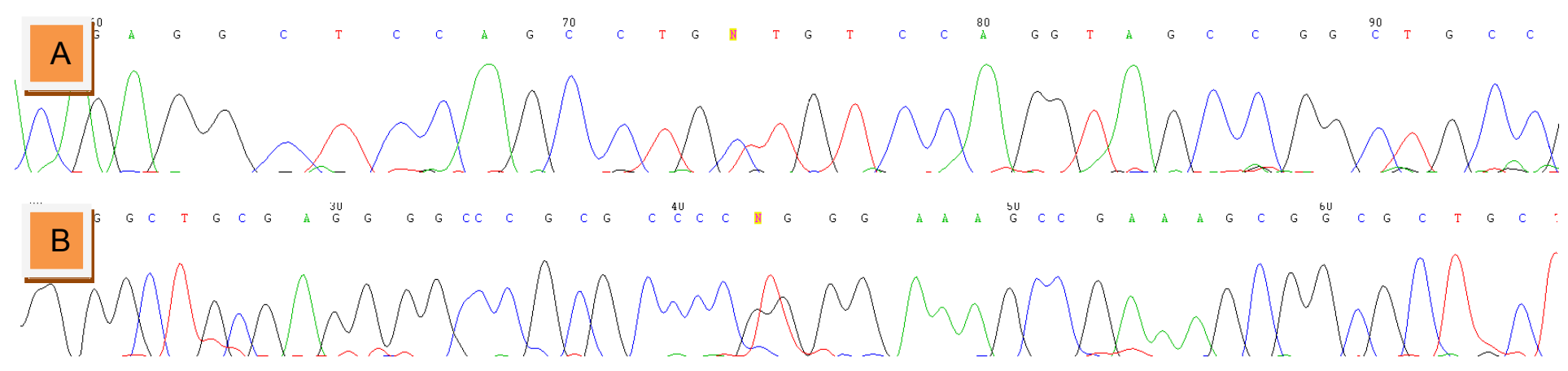

Fig. 20. Secuencias de ADN obtenidas mediante el análisis de muestras del panel "A" donde se observan los SNPs detectados en el gen CEPBA en estado heterocigota. A. SNPC, y B. rs110793792. Los sitios mutados se indican con amarillo. 


\begin{tabular}{|c|c|c|c|c|c|c|c|c|}
\hline Identificación & $\begin{array}{l}\text { Pos Crom } \\
\text { (UMD 3.1) }\end{array}$ & $\begin{array}{l}\text { Alel } \\
\text { os }\end{array}$ & Cambio & Razas AA & Razas AB & $\begin{array}{c}\text { Razas } \\
\text { BB }\end{array}$ & $\begin{array}{c}\text { Secuencia } \\
5^{\prime}\end{array}$ & $\begin{array}{c}\text { Secuencia } \\
3^{\prime}\end{array}$ \\
\hline SNPC & 43929257 & $\mathrm{C} / \mathrm{T}$ & $\begin{array}{l}\text { Ser x Asn } \\
\quad(139)\end{array}$ & $\begin{array}{l}\text { Angus, } \\
\text { Creole, } \\
\text { Hereford, } \\
\text { Holstein, } \\
\text { Limousin, } \\
\text { Shorthorn }\end{array}$ & $\begin{array}{c}\text { Brahman, Nelore, } \\
\text { Wagyu }\end{array}$ & - & $\begin{array}{c}\text { CAGAGGC } \\
\text { TCCAGCC } \\
\text { TG }\end{array}$ & $\begin{array}{l}\text { TGTCCAG } \\
\text { GTAGCCG } \\
\text { GC }\end{array}$ \\
\hline rs110793792 & 43929570 & $\mathrm{G} / \mathrm{T}$ & Sinónimo & Nelore & $\begin{array}{c}\text { Angus, Brahman, } \\
\text { Creole, Hereford, } \\
\text { Holstein, Limousin, } \\
\text { Wagyu }\end{array}$ & $\begin{array}{l}\text { Shorth } \\
\text { orn }\end{array}$ & $\begin{array}{c}\text { GAGGGGC } \\
\text { CCGCGCC } \\
\text { CC }\end{array}$ & $\begin{array}{l}\text { GGGAAAG } \\
\text { CCGAAAG } \\
\text { CG }\end{array}$ \\
\hline
\end{tabular}

Tabla 9. Polimorfismos en el gen CEBPA detectados por re-secuenciación en las muestras del panel "A". Se detalla las razas donde se encontró cada uno de los genotipos para cada SNP detectado.

\subsubsection{LIPE (Lipasa Sensible a Hormona)}

Mediante el estudio de re-secuenciación se detectaron 21 SNPs en el gen LIPE, cinco de los cuales no habían sido reportados previamente (Fig. 21, Tabla 10). De los veintiún SNPs detectados, dieciséis eran transiciones y cinco eran transversiones. El primer SNP inédito (ss974514528) se encontró a 62 pb corriente arriba del segundo exón y se detectó en la raza Holstein. Dos de los SNPs no reportados previamente (ss974514534 y ss974514535) se detectaron en el cuarto intrón, separados entre sí por 61 pb. Los dos últimos polimorfismos inéditos (ss974514541 y ss974514543) se localizaron en el octavo exón y son responsables de cambios de carácter sinónimo en la proteína. Estos últimos cuatro SNPs se detectaron en las razas cebuinas.

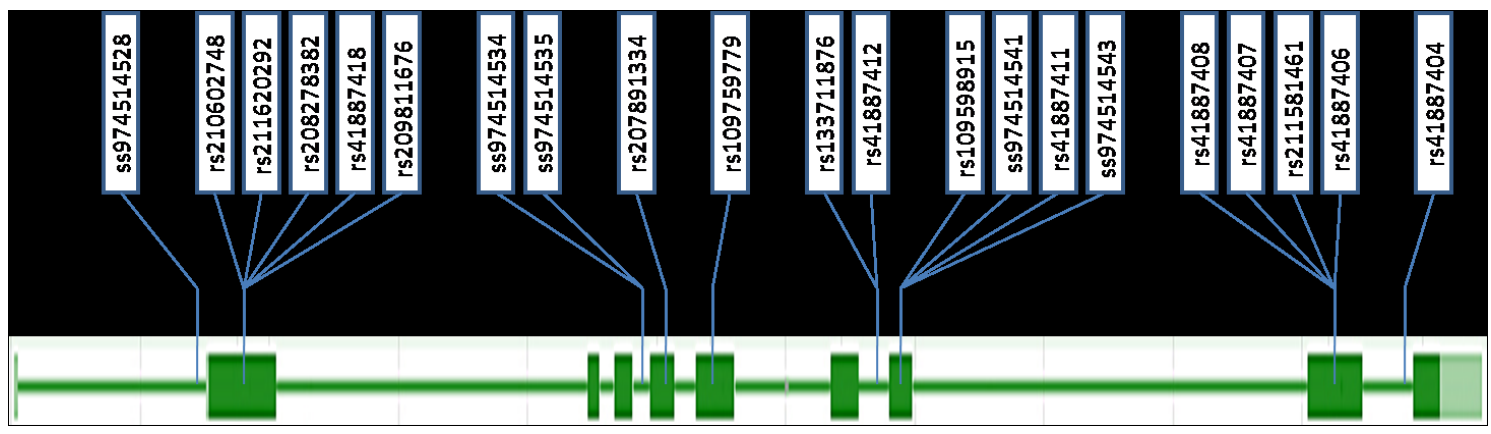

Fig. 21. Polimorfismos detectados en el gen bovino LIPE por re-secuenciación de las muestras del panel "A". Los exones del gen se indican con bloques verdes. 
Con respecto a los dieciséis SNPs restantes, cinco se observaron en el segundo exón del gen (rs210602748, rs211620292, rs208278382, rs41887418, rs209811676), uno en el quinto exón (rs207891334), otro en el sexto exón (rs109759779), dos en el séptimo intrón (rs133711876, rs41887412), dos en el octavo exón (rs109598915, rs41887411), cuatro en el noveno exón (rs41887408, rs41887407, rs211581461, rs41887406) y uno en el noveno intrón (rs41887404) (Fig. 21).

Uno de los SNPs detectados en el segundo exón era de carácter missense (Arg4His) y las otras cuatro mutaciones resultaron ser sinónimas. Las mutaciones del quinto y sexto exón también eran sinónimas. Uno de los SNPs del octavo exón era una mutacion missense (Asp497Ala), mientras que los otros SNPs de este exón fueron sinónimos. Por último, los cuatro SNPs del noveno exón eran mutaciones missense (Arg560GIn, Pro564Ser, lle607Val, Glu621Lys).

El análisis de ligamiento y la reconstrucción de las fases del gen LIPE permitieron la identificación de tres bloques de ligamiento. Uno de ellos estaba formado por nueve SNPs y abarcaba desde el extremo $5^{\prime}$ hasta un poco más de un tercio de la región total analizada. El segundo bloque estuvo compuesto por siete SNPs y abarcaba otro tercio, mientras que el tercer bloque incluyó cinco SNPs y abarcó el segmento restante hacia el extremo 3' (Figura 23). Estos bloques fueron consistentes con el análisis de conservación a nivel proteico, en el que se observaron tres bloques principales (Nt, Ct-1 y Ct-2). 


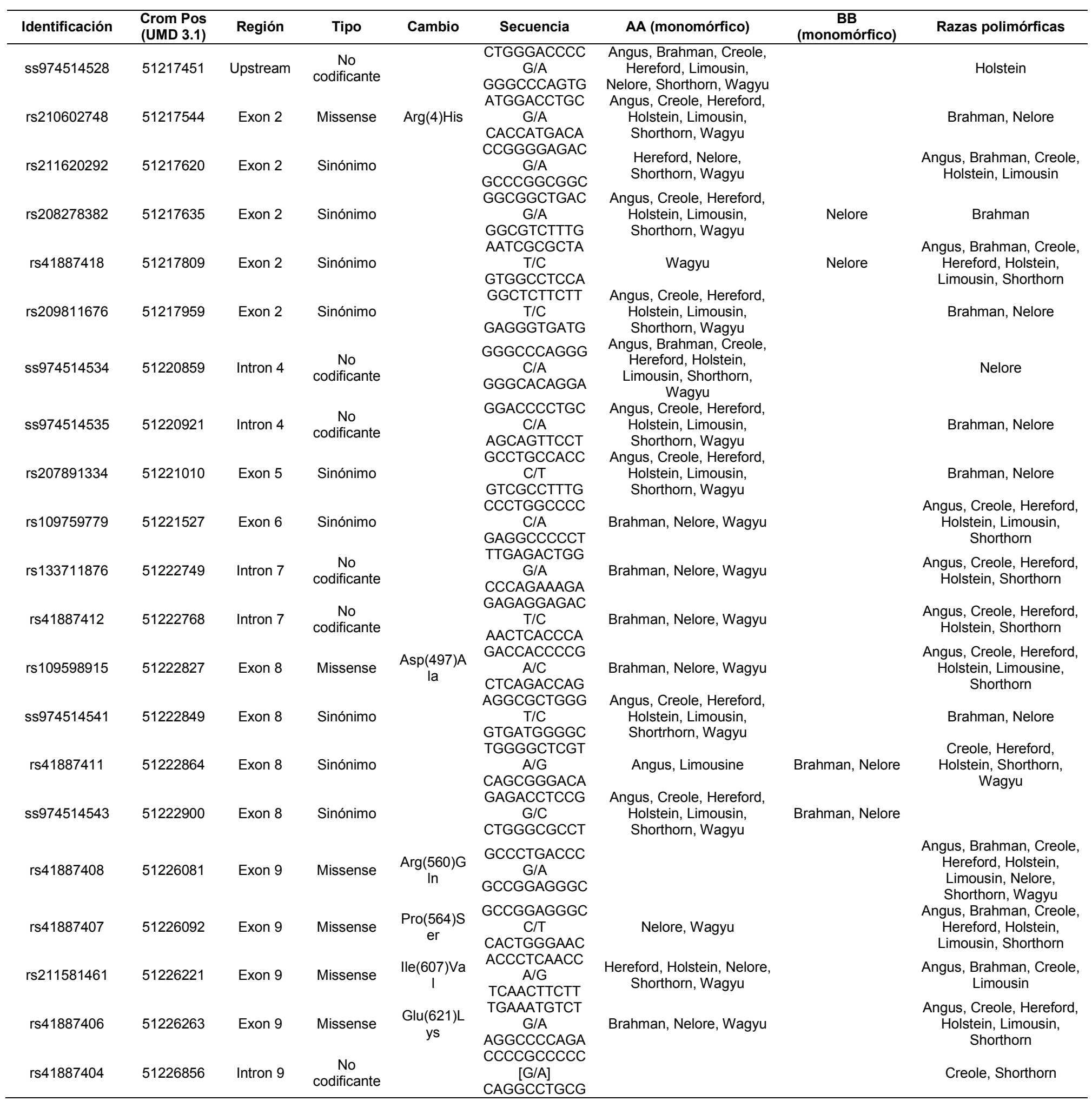

Tabla 10. Polimorfismos detectados por re-secuenciación del gen bovino LIPE en el panel de muestras "A". Se detalla las razas donde se encontró cada una de los genotipos para cada SNP detectados. 

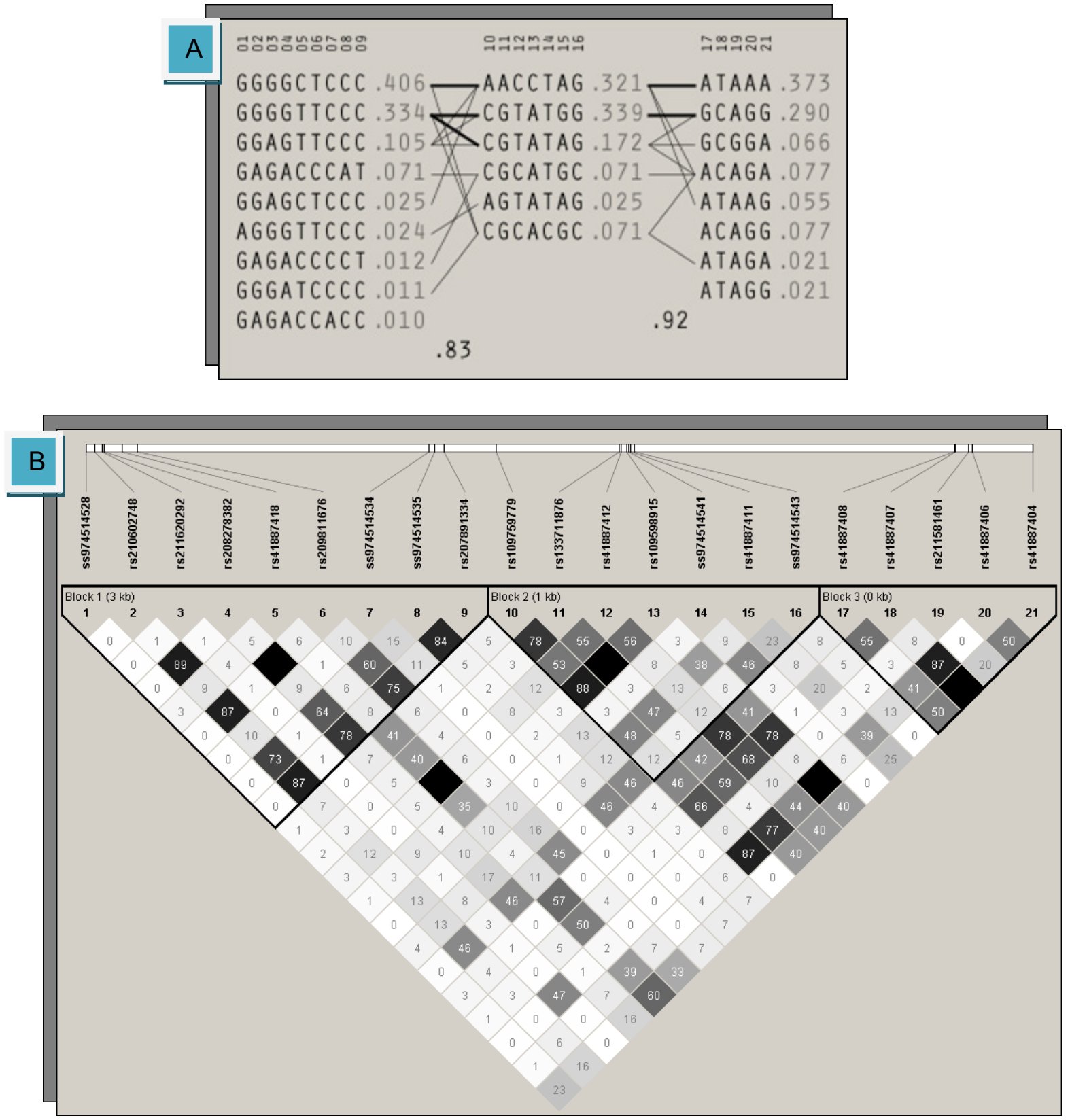

Fig. 22. Haplotipos (A) y bloques de ligamiento (B) detectados en el gen bovino LIPE a partir de los datos del análisis de re-secuenciación y obtenidos por medio del programa Haploview 3.31. Los valores de $r^{2}$ se indican dentro de las cajas. 


\subsubsection{FABP4 (Proteína de Unión a Ácidos Grasos 4)}

En el caso del gen bovino FABP4, el estudio de re-secuenciación permitió detectar un total de 22 mutaciones y cuatro de ellas resultaron ser inéditas (Fig. 23, Tabla 11). Dos de los SNPs no reportados previamente (denominados en el presente trabajo SNP1 y SNP4) se encontraban en la región promotora del gen. El SNP1 se detectó en la raza Angus y el SNP4 en las razas cebuinas Brahman y Nelore. El tercer SNP inédito (SNP7) se detectó en la región UTR5' en las razas Criollo, Nelore y Limousin. El cuarto SNP (SNP20) se localizó en la región UTR3' en las razas Angus y Holstein.

El resto de los SNPs (18), previamente reportado, estuvo distribuido entre las diferentes razas, pero llamativamente todos ellos presentaban variabilidad en ganado taurino. Solo dos variantes causantes de cambios aminoacídicos y dos variantes de carácter sinónimo fueron detectadas entre las mutaciones reportadas, y las mutaciones en zonas regulatorias (6) e intrónicas (8) fueron las más numerosas. Globalmente, seis de las veintidós mutaciones fueron encontradas en la región promotora del gen, una en la región UTR5', cuatro en regiones traducidas, tres en la región UTR3', y ocho en zonas intrónicas. Doce de las mutaciones eran transiciones, nueve eran transversiones y una de ellas era una inserción. 


\begin{tabular}{|c|c|c|c|c|c|c|c|c|}
\hline Identificación & $\begin{array}{l}\text { Pos Crom } \\
\text { (UMD 3.1) }\end{array}$ & Región & Tipo & Cambio & Secuencia & $\begin{array}{l}\text { Razas monomórficas } \\
\text { (AA) }\end{array}$ & $\begin{array}{c}\text { Razas } \\
\text { monomórficas } \\
\text { (BB) }\end{array}$ & $\begin{array}{c}\text { Razas } \\
\text { polimórficas }\end{array}$ \\
\hline SNP1 & 46838537 & Promotora & $\begin{array}{c}\text { No } \\
\text { codificante }\end{array}$ & & $\begin{array}{c}\text { ACTTATTTT/GG } \\
\text { TTTTAAT }\end{array}$ & $\begin{array}{c}\text { Brahman, Criollo, } \\
\text { Hereford, Holstein, } \\
\text { Limousin, Shorthorn, } \\
\text { Wagyu }\end{array}$ & & Angus \\
\hline rs133198078 & 46838452 & Promotora & $\begin{array}{c}\text { No } \\
\text { codificante }\end{array}$ & & $\begin{array}{l}\text { TAATTCTTACA/ } \\
\text { GTTCCTCAATT }\end{array}$ & Holstein & $\begin{array}{l}\text { Brahman, } \\
\text { Limousin, } \\
\text { Shorthorn }\end{array}$ & $\begin{array}{c}\text { Angus, Criollo, } \\
\text { Hereford, Nelore, } \\
\text { Wagyu }\end{array}$ \\
\hline rs132781285 & $\begin{array}{l}46838333- \\
46838334\end{array}$ & Promotora & $\begin{array}{l}\text { Inserción - } \\
\text { /G }\end{array}$ & & $\begin{array}{l}\text { TAAATATGTATA } \\
\text { AAAAAAAATA }\end{array}$ & & & $\begin{array}{l}\text { Angus, Criollo } \\
\text { Hereford, } \\
\text { Shorthorn, } \\
\text { Wagyu }\end{array}$ \\
\hline SNP4 & 46838296 & Promotora & $\begin{array}{c}\text { No } \\
\text { codificante }\end{array}$ & & $\begin{array}{l}\text { ATTTTAAGC/GT } \\
\text { GTCAAAA }\end{array}$ & $\begin{array}{l}\text { Angus, Criollo, Hereford, } \\
\text { Holstein, Limousin, } \\
\text { Shorthorn, Wagyu }\end{array}$ & $\begin{array}{l}\text { Brahman, } \\
\text { Nelore }\end{array}$ & \\
\hline rs110055647 & 46838288 & Promotora & $\begin{array}{c}\text { No } \\
\text { codificante }\end{array}$ & & $\begin{array}{l}\text { AGCTGTCAAAA } \\
\text { GCAAGATTATT }\end{array}$ & Holstein & Limousin & $\begin{array}{l}\text { Angus, Criollo, } \\
\text { Hereford }\end{array}$ \\
\hline rs109682576 & 46838280 & Promotora & $\begin{array}{c}\text { No } \\
\text { codificante }\end{array}$ & & $\begin{array}{l}\text { AAACAAGATTAI } \\
\text { GTTGAAATATT }\end{array}$ & Holstein & Limousin & $\begin{array}{l}\text { Angus, Criollo, } \\
\text { Hereford }\end{array}$ \\
\hline SNP7 & 46837996 & UTR5' & $\begin{array}{c}\text { No } \\
\text { codificante }\end{array}$ & & $\begin{array}{c}\text { AAGCTCACA/CA } \\
\text { AATGTGT }\end{array}$ & $\begin{array}{l}\text { Angus, Brahman, } \\
\text { Hereford, Holstein }\end{array}$ & $\begin{array}{l}\text { Criollo, } \\
\text { Limousin, } \\
\text { Shorthorn }\end{array}$ & Nelore, Wagyu \\
\hline rs382376907 & 46835368 & Intrón 1 & $\begin{array}{c}\text { No } \\
\text { codificante }\end{array}$ & & $\begin{array}{l}\text { ATAAACTCA/GC } \\
\text { TGGAGTA }\end{array}$ & $\begin{array}{c}\text { Brahman, Criollo, } \\
\text { Holstein, Nelore, Wagyu }\end{array}$ & & $\begin{array}{l}\text { Angus, Hereford, } \\
\text { Limousin }\end{array}$ \\
\hline rs109316505 & 46835220 & Intrón 1 & $\begin{array}{c}\text { No } \\
\text { codificante }\end{array}$ & & $\begin{array}{l}\text { TTTCTTTTCCC/ } \\
\text { GAACTATAGGC }\end{array}$ & Brahman, Wagyu, Nelore & Limousin & $\begin{array}{l}\text { Angus, Criollo, } \\
\text { Hereford, } \\
\text { Holstein }\end{array}$ \\
\hline rs110757796 & 46835065 & Exón 2 & Missense & I/V & $\begin{array}{l}\text { ATTTGATGAAA/ } \\
\text { GTCACTCCAGA }\end{array}$ & $\begin{array}{c}\text { Brahman, Nelore, Criollo, } \\
\text { Limousin }\end{array}$ & & $\begin{array}{l}\text { Angus, Hereford, } \\
\text { Holstein, Wagyu }\end{array}$ \\
\hline rs134173517 & 46834560 & Intrón 2 & $\begin{array}{l}\text { No } \\
\text { codificante }\end{array}$ & & $\begin{array}{l}\text { TCATTGTTTTA/ } \\
\text { CTTTTGCAACA }\end{array}$ & Criollo, Holstein, Wagyu & & $\begin{array}{l}\text { Brahman, } \\
\text { Hereford, } \\
\text { Limousin }\end{array}$ \\
\hline rs109014985 & 46834523 & Intrón 2 & $\begin{array}{c}\text { No } \\
\text { codificante }\end{array}$ & & $\begin{array}{l}\text { AATTGCTAAGA/ } \\
\text { TACCTCAAAAT }\end{array}$ & Limousin, Wagyu & Criollo & $\begin{array}{l}\text { Brahman, } \\
\text { Hereford, } \\
\text { Holstein }\end{array}$ \\
\hline rs110652478 & 46834365 & Exón 3 & Missense & $\mathrm{V} / \mathrm{M}$ & $\begin{array}{l}\text { GAGAAAACTCG/ } \\
\text { ATGGATGATAA }\end{array}$ & $\begin{array}{l}\text { Criollo, Hereford, } \\
\text { Limousin, Brahman }\end{array}$ & & Holstein, Wagyu \\
\hline rs110383592 & 46834345 & $\begin{array}{l}\text { Exón 3- } \\
\text { Región } \\
\text { Splicing }\end{array}$ & Sinónima & $\mathrm{L}$ & $\begin{array}{l}\text { AGATGGTGCTG } \\
\text { ICGTGAGTATCT }\end{array}$ & Holstein, Wagyu & $\begin{array}{l}\text { Criollo, } \\
\text { Hereford }\end{array}$ & $\begin{array}{l}\text { Brahman, } \\
\text { Limousin }\end{array}$ \\
\hline rs109388335 & 46834311 & Intrón 3 & $\begin{array}{c}\text { No } \\
\text { codificante }\end{array}$ & & $\begin{array}{l}\text { TTCTAGATTTT/ } \\
\text { CAGTGCTAGGT }\end{array}$ & Brahman & $\begin{array}{l}\text { Criollo, } \\
\text { Limousin, } \\
\text { Wagyu }\end{array}$ & $\begin{array}{l}\text { Hereford, } \\
\text { Holstein }\end{array}$ \\
\hline rs109346428 & 46834289 & Intrón 3 & $\begin{array}{c}\text { No } \\
\text { codificante }\end{array}$ & & $\begin{array}{l}\text { ATCCCATAATT/ } \\
\text { CGTTATCCTAC }\end{array}$ & Criollo, Wagyu & $\begin{array}{l}\text { Limousin, } \\
\text { Brahman }\end{array}$ & $\begin{array}{l}\text { Hereford, } \\
\text { Holstein }\end{array}$ \\
\hline rs111014258 & 46834042 & Intrón 3 & $\begin{array}{c}\text { No } \\
\text { codificante }\end{array}$ & & $\begin{array}{l}\text { GATCTTTGTGT/ } \\
\text { CCTCCCTAGTT }\end{array}$ & Nelore, Brahman & $\begin{array}{l}\text { Holstein, } \\
\text { Shorthorn, } \\
\text { Wagyu }\end{array}$ & $\begin{array}{l}\text { Angus, Criollo, } \\
\text { Hereford, } \\
\text { Limousin }\end{array}$ \\
\hline rs110370032 & 46833834 & Exón 4 & Sinónima & $A$ & $\begin{array}{c}\text { ATGAGAGAGCA } \\
\text { /GTAAGCCAAG } \\
\text { G }\end{array}$ & $\begin{array}{l}\text { Nelore, Limousin, } \\
\text { Shorthorn }\end{array}$ & & $\begin{array}{l}\text { Angus, Brahman, } \\
\text { Criollo, Hereford, } \\
\text { Holstein, Wagyu }\end{array}$ \\
\hline rs109077068 & 46833778 & UTR3' & $\begin{array}{c}\text { No } \\
\text { codificante }\end{array}$ & & $\begin{array}{l}\text { TGACTTTCTGC/ } \\
\text { TTGGATACGTT }\end{array}$ & $\begin{array}{l}\text { Angus, Criollo, Holstein, } \\
\text { Nelore, Shorthorn }\end{array}$ & & $\begin{array}{c}\text { Brahman, } \\
\text { Hereford, } \\
\text { Limousin,Wagyu }\end{array}$ \\
\hline SNP20 & 46833756 & UTR3' & $\begin{array}{c}\text { No } \\
\text { cofidicante }\end{array}$ & & $\begin{array}{c}\text { GTCCAAACA/CT } \\
\text { ATATTGT }\end{array}$ & $\begin{array}{l}\text { Brahman, Criollo, } \\
\text { Hereford, Limousin, } \\
\text { Nelore, Shorthorn, } \\
\text { Wagyu }\end{array}$ & & Angus, Holstein \\
\hline rs110266999 & 46833693 & UTR3' & $\begin{array}{c}\text { No } \\
\text { codificante }\end{array}$ & & $\begin{array}{l}\text { TGATATGGTTA/ } \\
\text { GTGTTGGTTAA }\end{array}$ & $\begin{array}{c}\text { Nelore, Shorthorn, } \\
\text { Wagyu }\end{array}$ & & $\begin{array}{c}\text { Angus, Brahman, } \\
\text { Criollo, Hereford, } \\
\text { Holstein, } \\
\text { Limousin }\end{array}$ \\
\hline rs109593774 & 46833649 & Downstream & $\begin{array}{c}\text { No } \\
\text { codificante }\end{array}$ & & $\begin{array}{l}\text { GCTATGTAATC/ } \\
\text { GATTTATTCAT }\end{array}$ & $\begin{array}{l}\text { Holstein, Nelore, } \\
\text { Shorthorn, Wagyu }\end{array}$ & Brahman & $\begin{array}{l}\text { Angus, Criollo, } \\
\text { Hereford, } \\
\text { Limousin }\end{array}$ \\
\hline
\end{tabular}

Tabla 11. Polimorfismos detectados por re-secuenciación del gen bovino FABP4 en el panel de muestras "A". Se detalla las razas donde se encontró cada uno de los genotipos para cada SNP detectado. 


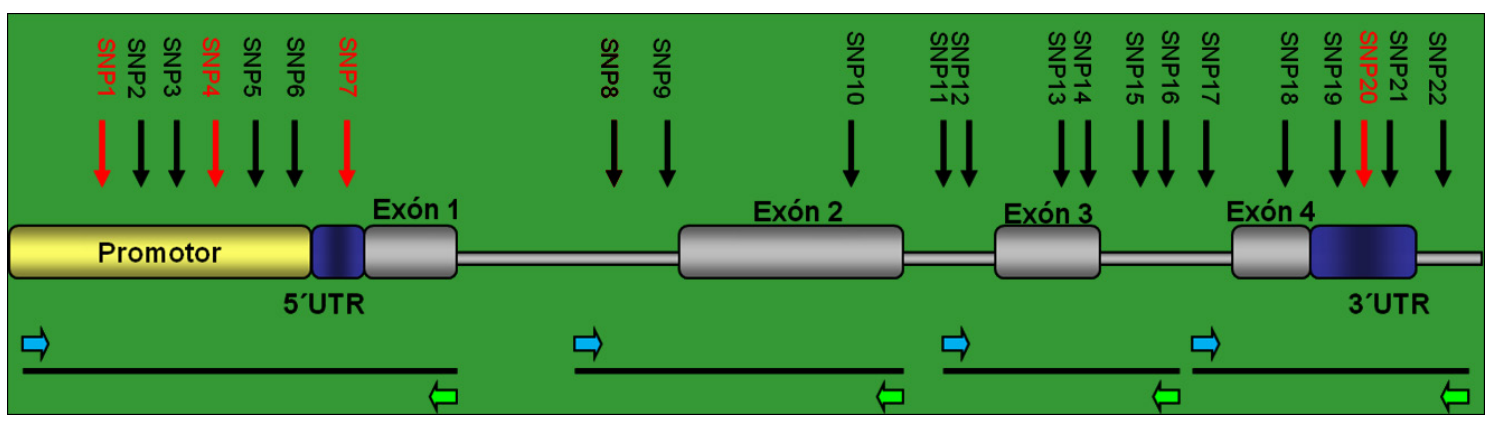

Fig. 23. Distribución de los SNPs detectados en el gen bovino FABP4 por re-secuenciación. Los primers se indican con flechas junto a los fragmentos amplificados. Los SNPs no-reportados se indican con color rojo.
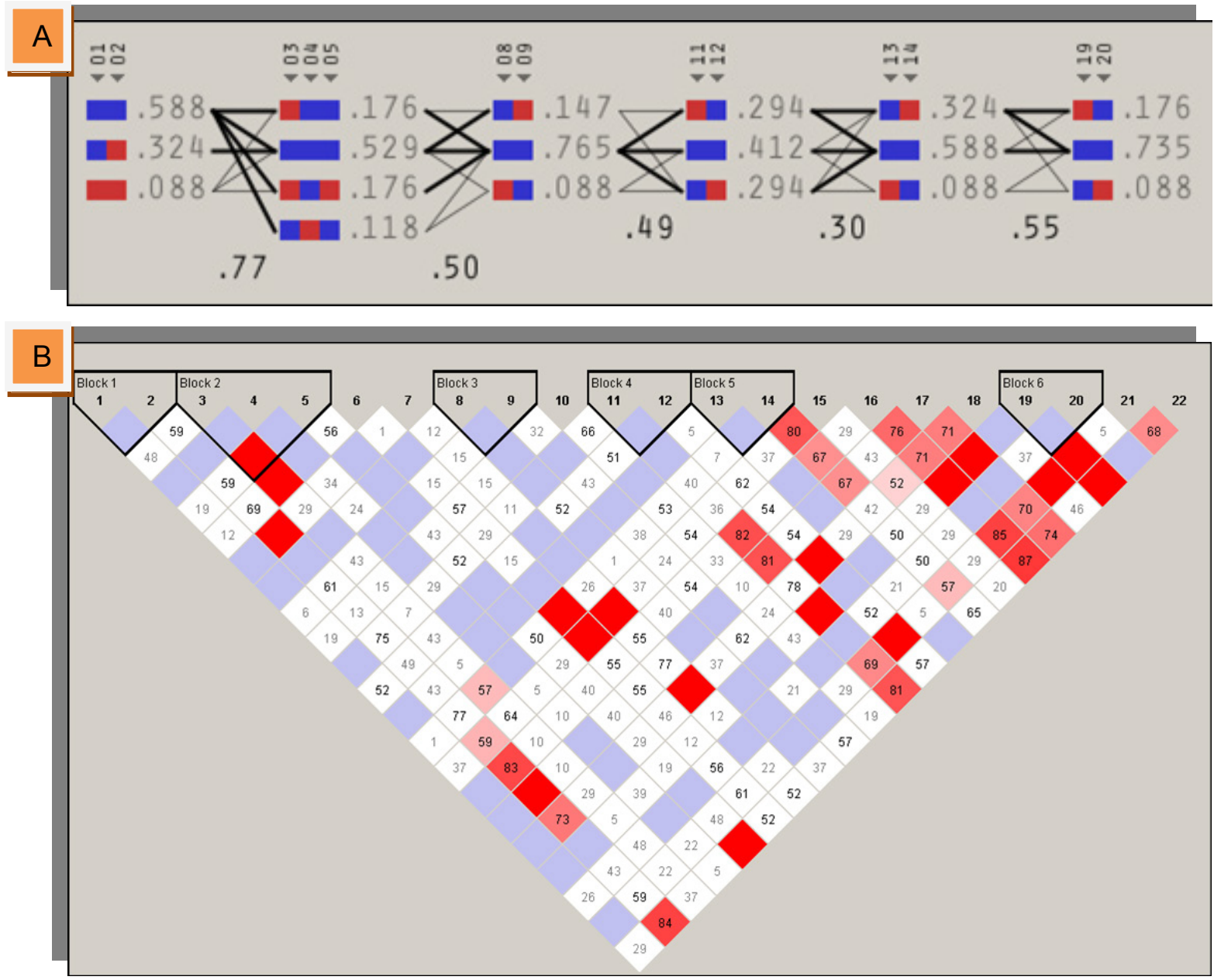

Fig. 24. Haplotipos y desequilibrio de ligamiento en el gen bovino FABP4 obtenidos por re-secuenciación y con el programa Haploview 3.31 (A). Haplotipos de los seis bloques identificados. (B). Plot del desequilibrio de ligamiento (coeficiente $D^{\prime}$ ).

El análisis de los haplotipos y del desequilibrio de ligamiento realizado a partir del estudio de re-secuenciación del gen FABP4 utilizando el programa Haploview evidenció un esquema de alta variabilidad. Se observaron 6 bloques pequeños, 
compuestos en su mayoría por 2 SNPs, que se encontraban dispersos a lo largo del gen (Fig. 24A), y diversos haplotipos (Fig. 24B). Esto podría deberse al elevado polimorfismo que presentó el gen FABP4 bovino y al hecho que en el estudio se incluyeron tanto razas taurinas como cebuinas con diferentes orígenes históricos y geográficos (europeas continentales, europeas británicas, taurinas asiáticas, criollas americanas y cebuinas).

\subsection{Selección y validación de SNPs a nivel poblacional}

\subsubsection{PPARG (Receptor Gamma Activado por el Proliferador de Peroxisomas)}

La selección de SNPs para ser genotipados en la etapa de validación a nivel poblacional se vió simplificada por la baja variabilidad detectada en el gen PPARG bovino durante el análisis de re-secuenciación. Como la población del panel de muestras "B", que sería utilizada para la validación, estaba compuesta por animales de las razas Angus, Hereford y Limousin y sus cruzas, se priorizó la selección de SNPs que habían sido detectados en alguna de estas razas o en razas taurinas históricamente relacionadas. Los candidatos disponibles se reducían a los SNPs rs207671117, rs41610552 y rs42661651. El primero de ellos corresponde a un SNP ubicado en el UTR5', una región potencialmente regulatoria, y que había sido detectado en muestras de las razas Angus y Hereford; el segundo polimorfismo se localizaba al comienzo del intrón 2 y presentaba amplia variabilidad entre las razas; y el tercero era un SNP localizado fuera del gen, cercano al extremo 3' del PPARG y moderadamente distribuido.

En un principio, la idea fue seleccionar uno de los SNPs y tipificarlo por pirosecuenciación en la población $\mathrm{B}$, y ante la probabilidad de que el marcador rs207671117, a pesar de su localización y posible rol biológico, pudiese estar en muy pequeña frecuencia dadas las pocas muestras en las que se encontraba, se decidió seleccionar al SNP rs41610552 y se diseñó el método de tipificación para este marcador. Luego, las posibilidades nos permitieron seleccionar otros tres SNPs para tipificar por medio de la plataforma Sequenom, y se seleccionó al marcador rs207671117, el primer candidato, como uno de ellos. Aún restaba seleccionar dos SNPs, y las opciones eran tomarlos de entre los detectados o elegirlos de entre los reportados por distintos proyectos de secuenciación en SNPdb. Como el resto de los SNPs detectados no presentaba variabilidad en las razas de interés ni se encontraban en zonas interesantes desde el punto de vista molecular, se procedió a seleccionar los 
SNPs rs42016945 y rs109613657. El primero fue localizado en la zona UTR5' de la isoforma 1 de PPARG de la base de datos, el cual presentaba evidencias confiables de existir en las razas del panel $\mathrm{B}$; el segundo contaba con siete observaciones y causaba un cambio Q448H en el exón 7 .

\subsubsection{CEBPA (Proteína de Unión al Amplificador CCAAT Alfa)}

Este caso fue similar al anterior dado que el gen CEPA presentó un bajo nivel de variabilidad en la etapa de re-secuenciación, detectándose solo dos SNPs. Como se mencionó anteriormente, el SNP1 no presentaba variabilidad en las razas que componían el panel "B". Por esta razón, solo se escogió al SNP rs110793792 para tipificar la muestras de validación. Esto se complementó con la selección de otro SNP de la lista de polimorfismos previamente reportados en la base de datos SNPdb. Ninguno de los polimorfismos reportados en dicha base de datos, a excepción del rs110793792, contaban con múltiples evidencias de observación que garantizaran a priori la variabilidad en las razas del panel "B". Finalmente, se seleccionó para su validación el SNP rs210446561 debido a que había sido reportado en un proyecto de secuenciación de Angus y causaba un cambio aminoacídico de los más comunes en la naturaleza, alanina por glicina. Un vez seleccionados los SNPs rs110793792 y rs210446561 se genotipificaron mediante la técnica de espectrometría de masa utilizando la plataforma Sequenom.

\subsubsection{LIPE (Lipasa Sensible a Hormona).}

Contrariamente a lo observado en los genes bovinos PPARG y CEPBA, el gen LIPE mostró un alto grado de polimorfismo durante el estudio de re-secuenciación, detectándose un total de veintiún variantes en las muestras del panel "A". Esto permitió tener más opciones para la selección de polimorfismos para la etapa de validación. Es por esta razón que previo a la selección se llevó a cabo un análisis de conservación de residuos, con el fin de identificar las áreas o dominios más importantes de la enzima a nivel biológico. El estudio se realizó considerando todas las secuencias de mamíferos disponibles en ENSEMBL, y los residuos se colorearon según el grado de conservación (Fig. 25). Básicamente se observaron cuatro regiones conservadas a partir de la comparación: una región $\mathrm{N}$-terminal (Nt) de aproximadamente 280 residuos; una región intermedia de aproximadamente 290 
residuos y compuesta por dos segmentos; y una región C-terminal de unos 100 residuos. Esto es consistente con los trabajos de secuenciación y modelado estructural realizados hace algunos años, lo que sugiere una estructura enzimática multi-dominio. La porción Nt no posee un rol claro hasta ahora y se cree que es sitio de unión para otras proteínas como FABP4 y lípidos, y también se ha propuesto su rol como sitio de dimerización. La porción intermedia es la que exhibe el plegamiento $\alpha / \beta$ hidrolasa, común entre lipasas, y el módulo regulatorio $(R)$ que contiene los sitios de fosforilación involucrados en la activación de la enzima. El dominio catalítico está compuesto por dos fragmentos interrumpidos (Ct-1 y Ct-2) y contiene la triada catalítica de la enzima. Considerado este análisis, se procedió a seleccionar tres SNPs en base a la naturaleza de la mutación (cambio de residuo) y a su localización dentro de la enzima, es decir, la pertenencia a zonas conservadas. EI SNP rs109759779 era de carácter sinónimo, pero se localiza en una posición altamente conservada en mamíferos (mayor a 80\%). EI SNP rs109759779 involucraba un residuo de prolina (386) localizado dentro del domino catalítico, a 27 aminoácidos de distancia de la serina catalítica. Todas las especies de mamíferos que presentaban una región homóloga a la bovina tenían una prolina en esta posición, y por esa razón el rs109759779 parecía un buen candidato para estudio el estudio de validación. EI SNP rs109598915 causaba un cambio aminoacídico, aspartato por alanina, al final de Ct-1. Este SNP se localiza en una región de unos 12 residuos que no estaban tan conservados, pero estaban en medio de un área ampliamente conservada y la naturaleza de la mutación (residuo polar de carga negativa por no-polar neutro) resultaba bastante interesante para seleccionarlo. EI SNP rs41887406 se ubicaba en una región pobremente conservada entre $\mathrm{R}$ y Ct-2, pero causaba un cambio aminoacídico de glutamato por lisina (polar negativo a polar positivo). Además, este SNP había sido asociado recientemente a composición de ácidos grasos y otras características en novillos Simmental chinos (Fang et al., 2013). Dadas estas características, el polimorfismo rs41887406 también se seleccionó para su tificación en la población "B". En resumen, durante el proceso de selección de SNPs para su validación se priorizó la elección de mutaciones que ubicaran dentro o cerca del dominio catalítico, que es la región del gen LIPE con el rol más claro y definido hasta momento. 


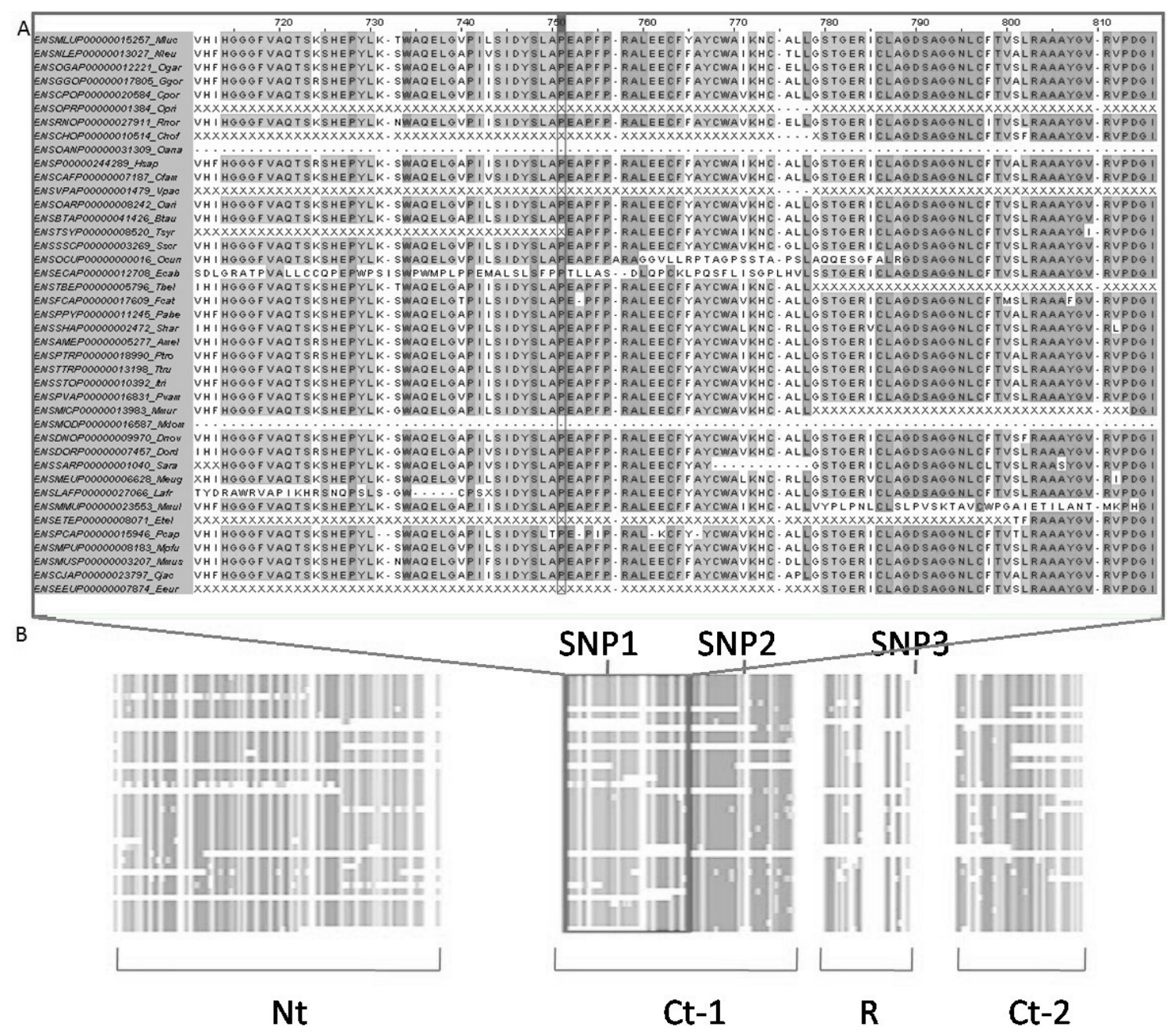

Fig. 25. Análisis de conservación de residuos a nivel evolutivo en el gen bovino LIPE. Las columnas con los residuos que superaban el $75 \%$ de identificación fueron coloreadas con gris claro, y aquellas que superaban el 80\% con gris oscuro. (A) El área que rodea a rs109759779 (SNP1). (B) Vista general de la enzima, incluyendo a los SNPs rs109598915 (SNP2) y rs41887406 (SNP3). El marco indica la región mostrada en la figura $A$.

5.2.4. FABP4 (Proteina de unión a ácidos grasos 4)

El gen bovino FABP4 ha sido extensamente estudiado, tanto en lo que respecta a su variabilidad genética como a su rol en la determinación de las variables de composición y contenido graso de la carne. Es por esta razón que para la selección de los SNPs de este gen para la etapa de validación se tuvo en cuenta como criterio de selección no solo los polimorfismos detectados en las razas de interés en el análisis de re-secuenciación sino también los estudios de asociación previos entre marcadores genéticos del FABP4 y caracteres de calidad carnicera en otras razas. 
El polimorfismo rs110757796 (I74V, exón 2) se seleccionó debido a que había sido asociado a contenidos de ácido palmítico (C16:0) y palmitoleico (C16:1), y espesor de grasa dorsal en razas asiáticas por Cho et al. (2007), Hoashi et al. (2008) y Narukami et al. (2011). Este SNP se tipificó en el panel de muestras "B" mediante una técnica especialmente diseñada en el presente estudio para tal fin. Además, se eligieron otros cuatro SNPs, los que se tipificaron por la técnica de espectrometría de flujo utilizando la plataforma Sequenom. Estos últimos cuatro SNPs fueron: el rs41729173 (UTR3') asociado por Michal et al. (2006) con marmoleo y grasa subcutánea en cruzas Wagyu-Limousin, el rs110652478 (V110M, exón 3) asociado por Hoashi et al. (2008), Lee et al. (2010), Oh et al. (2012) y Shin et al. (2012) con marmoleo en razas japonesas y coreanas, y ácidos grasos insaturados (AGI), monoinsaturados (AGMI) y ácido oleico (C18:1c9) en la raza coreana Hanwoo; el rs110383592 (variante de splicing, exón 3) asociado por Hoashi et al. (2008) y Barendse et al. (2009) con marmoleo en ganado australiano, también fue asociado con porcentaje de ácido palmítico y AGS (Oh et al., 2012); y por último el rs111014258 (intrón 3) que fue asociado con EGD en ganado coreano por Cho et al. (2008).

\subsubsection{RXRA (Receptor X Retinoide Alfa)}

El gen bovino RXRA no se incluyó en la etapa de re-secuenciación. Por otra parte, no existen estudios previos que evalúen el efecto de los polimorfismos de este gen sobre caracteres de calidad de carne. Sin embargo, el gen RXRA fue incluido como gen candidato en las etapas de validación y asociación del presente trabajo de Tesis Doctoral debido a su importante rol en el metabolismo lipídico. Dada la ausencia de otro tipo de información, los SNPs del RXRA se seleccionaron directamente de las bases públicas de polimorfismos. Al no estar del todo determinado el extremo $\mathrm{N}$ terminal de la proteína, ya que el exón 1 presentaba cuatro opciones hipotéticas por predicción bioinformática, solo restaban como candidatos los tres SNPs presentes enlas zonas codificantes (mencionados previamente en la introducción de este trabajo) y los SNPs detectados en la región predicha de la UTR3'. Dado que el tamaño de esta zona es llamativamente grande, y considerando la posibilidad de que se tratara de un error predictivo de la base de datos, se descartó a los SNPs detectados en esta región entre los candidatos. Finalmente, se seleccionaron los SNPs rs209839910 (P108S, exón 2), el cual causaba un cambio de residuo de prolina por serina y contaba con 3 detecciones o evidencias, y el rs136289117 (exón 9), el cual poseía una sola evidencia y producía un cambio de carácter sinónimo, lo cual le otorgaba cierto mérito 
a su supuesta existencia en las razas del panel "B". Además, se escogieron como candidatos los SNPs rs133517803 y rs207774429, localizados posiblemente en el primer intrón o en el promotor de la variante 3 , los cuales contaban con 10 y 2 observaciones, respectivamente.

\subsection{Análisis estadístico de los polimorfismos estudiados}

5.3.1. Caracterización de los polimorfismos analizados en el gen PPARG (Receptor Gamma Activado por el Proliferador de Peroxisomas)

Los SNPs rs41610552 y rs42016945 presentaron frecuencias génicas relativamente balanceadas entre las poblaciones (Alelo de Menor Frecuencia, $M A F>0,12)$. El marcador rs207671117 presentó una baja variabilidad en las poblaciones $\mathrm{A}, 75 \mathrm{H}, 50 \mathrm{AH}$ y $\mathrm{LX}(\mathrm{MAF}>0,02)$ y no presentó variabilidad en las poblaciones $\mathrm{H}$ y 75A (Tabla 12). Finalmente, la mutación rs109613657 resultó ser monomórfica en la totalidad del panel "B".

\begin{tabular}{cccccccc} 
& \multicolumn{8}{c}{ Poblaciones } \\
N & 44 & 26 & 30 & 24 & 95 & 41 & 260 \\
Locus & & & & & & & \\
rs41610552 & $\mathrm{A}$ & $\mathrm{H}$ & $75 \mathrm{~A}$ & $75 \mathrm{H}$ & $50 \mathrm{AH}$ & $\mathrm{LX}$ & Global \\
\cline { 2 - 8 } C & 68,18 & 82,00 & 76,67 & 87,50 & 76,84 & 60,00 & 74,22 \\
G & 31,82 & 18,00 & 23,33 & 12,50 & 23,16 & 40,00 & 25,78 \\
& & & & & & & \\
rs207671117 & $\mathrm{A}$ & $\mathrm{H}$ & $75 \mathrm{~A}$ & $75 \mathrm{H}$ & $50 \mathrm{AH}$ & $\mathrm{LX}$ & Global \\
\cline { 2 - 9 } A & 4,55 & - & - & 2,08 & 3,16 & 6,10 & 3,08 \\
G & 95,45 & 100,00 & 100,00 & 97,92 & 96,84 & 93,90 & 96,92 \\
& & & & & & & \\
rs42016945 & $\mathrm{A}$ & $\mathrm{H}$ & $75 \mathrm{~A}$ & $75 \mathrm{H}$ & $50 \mathrm{AH}$ & $\mathrm{LX}$ & Global \\
\cline { 2 - 8 } C & 68,18 & 78,85 & 68,33 & 81,25 & 75,79 & 65,85 & 72,88 \\
T & 31,82 & 21,15 & 31,67 & 18,75 & 24,21 & 34,15 & 27,12
\end{tabular}

Tabla 12. Frecuencias alélicas de los polimorfismos seleccionados de PPARG tipificados en el panel de muestras $\mathrm{B}$. $\mathrm{A}=$ Angus; $\mathrm{H}=$ Hereford; $75 \mathrm{~A}=$ novillos $75 \%$ Angus; $75 \mathrm{H}=$ novillos $75 \%$ Hereford; $50 \mathrm{AH}=$ novillos $50 \%$ Angus $50 \%$ Hereford; LX = novillos cruza Limousin. 
La prueba de equilibrio de Hardy-Weinberg no evidenció desviaciones significativas de las proporciones teóricas, a excepción del SNP rs42016945 en la población LX $(p<0,05)$ (Tabla 13). La heterocigosidad esperada de los dos marcadores balanceados, rs41610552 y rs42016945, varió entre 0,223 (75H) y 0,486 (LX). La heterocigosidad observada presentó valores entre $0,250(75 \mathrm{H})$ y $0,550(\mathrm{LX})$. Para el caso del rs207671117, y en las poblaciones que presentaron variabilidad, los valores de heterocigosidad esperada fueron $0,042(75 \mathrm{H}), 0,061(50 \mathrm{AH}), 0,088(\mathrm{~A})$ y 0,116 $(L X)$.

\begin{tabular}{|c|c|c|c|c|c|c|c|c|c|c|c|c|}
\hline \multirow{3}{*}{ SNP } & \multicolumn{12}{|c|}{ Poblaciones } \\
\hline & \multicolumn{3}{|c|}{$A$} & \multicolumn{3}{|r|}{$\mathrm{H}$} & \multicolumn{3}{|r|}{$75^{a}$} & \multicolumn{3}{|c|}{$75 \mathrm{H}$} \\
\hline & $h_{e}$ & $h_{\circ}$ & HWE $p$ value & $h_{e}$ & $\mathrm{~h}_{\mathrm{o}}$ & HWE $p$-value & $\mathrm{h}_{\mathrm{e}}$ & $\mathrm{h}_{\mathrm{o}}$ & HWE $p$-value & $\mathrm{h}_{\mathrm{e}}$ & $\mathrm{h}_{\mathrm{o}}$ & HWE $p$-value \\
\hline rs41610552 & 0,44 & 0,50 & 0,49 & 0,30 & 0,36 & 0,56 & 0,36 & 0,33 & 0,63 & 0,22 & 0,25 & 1,00 \\
\hline rs207671117 & 0,09 & 0,09 & 1,00 & 0,00 & 0,00 & - & 0,00 & 0,00 & - & 0,04 & 0,04 & - \\
\hline rs42016945 & 0,44 & 0,41 & 0,73 & 0,34 & 0,42 & 0,55 & 0,44 & 0,30 & 0,10 & 0,31 & 0,29 & 1,00 \\
\hline
\end{tabular}

\begin{tabular}{|c|c|c|c|c|c|c|c|c|c|}
\hline \multirow[t]{2}{*}{ SNP } & \multicolumn{3}{|c|}{$50 \mathrm{AH}$} & \multicolumn{3}{|c|}{$\mathrm{LX}$} & \multicolumn{3}{|c|}{ Global } \\
\hline & $h_{e}$ & $\mathrm{~h}_{\mathrm{o}}$ & HWE $p$-value & $h_{e}$ & $\mathrm{~h}_{\mathrm{o}}$ & HWE $p$-value & $h_{e}$ & $h_{\circ}$ & HWE $p$-value \\
\hline rs41610552 & 0,36 & 0,42 & 0,14 & 0,49 & 0,55 & 0,51 & 0,38 & 0,42 & 0,72 \\
\hline rs207671117 & 0,06 & 0,06 & 1,00 & 0,12 & 0,12 & 1,00 & 0,06 & 0,06 & 1,00 \\
\hline rs42016945 & 0,37 & 0,32 & 0,17 & 0,45 & 0,29 & $0,03^{*}$ & 0,40 & 0,33 & 0,16 \\
\hline
\end{tabular}

Tabla 13. Heterocigosidad esperada (he), heterocigosidad observada (ho) y p-value del Equilibrio de Hardy-Weinberg (HWE) para los SNPs de PPARG en las subpoblaciones y en la población del panel "B". $\mathrm{A}=$ Angus; $\mathrm{H}=$ Hereford; $75 \mathrm{~A}=$ novillos $75 \%$ Angus; $75 \mathrm{H}=$ novillos $75 \%$ Hereford; $50 \mathrm{AH}=$ novillos $50 \%$ Angus $50 \%$ Hereford; $L X=$ novillos cruza Limousin.

5.3.2. Caracterización de los polimorfismos analizados en el gen CEBPA (Proteína de Unión al Amplificador CCAAT Alfa)

El SNP rs110793792 del gen CEBPA no pudo ser tipificado por la plataforma Sequenom en el panel de muestras. Solo pudieron tipificarse un número pequeño de animales y por este motivo el SNP fue descartado del análisis. EI SNP rs210446561 solo pudo ser tipificado en 143 animales. En el análisis se observó que el alelo C era el mayoritario, y que este SNP presentaba un $M A F \geq 0,087$ en todas las poblaciones analizadas (Tabla 14). 


\section{Poblaciones}

$\begin{array}{llllllll}\mathbf{N} & 30 & 14 & 20 & 14 & 42 & 23 & 143\end{array}$

\section{Locus}

\begin{tabular}{cccccccc} 
rs210446561 & $\mathrm{A}$ & $\mathrm{H}$ & $75 \mathrm{~A}$ & $75 \mathrm{H}$ & $50 \mathrm{AH}$ & $\mathrm{LX}$ & Global \\
\cline { 2 - 7 } & & & & & & & \\
C & 25,00 & 10,71 & 12,50 & 14,29 & 10,71 & 8,70 & 13,99 \\
G & 75,00 & 89,29 & 87,50 & 85,71 & 89,29 & 91,30 & 86,01
\end{tabular}

Tabla 14. Frecuencias alélicas del SNP rs210446561 de CEBPA tipificado en el panel de muestras "B". A = Angus; $\mathrm{H}=$ Hereford; $75 \mathrm{~A}=$ novillos $75 \%$ Angus; $75 \mathrm{H}=$ novillos $75 \%$ Hereford; $50 \mathrm{AH}=$ novillos $50 \%$ Angus $50 \%$ Hereford; LX = novillos cruza Limousin.

La prueba del equilibrio de Hardy-Weinberg no mostró desviaciones significativas de las proporciones teóricas. Los valores de heterocigosidad esperada variaron entre $0,162(L X)$ y $0,381(A)$, y la heterocigosidad observada entre $0,174(L X)$ y 0,500 (A) (Tabla 15).

\begin{tabular}{|c|c|c|c|c|c|c|c|c|c|c|c|c|}
\hline \multirow{3}{*}{ SNP } & \multicolumn{12}{|c|}{ Poblaciones } \\
\hline & \multicolumn{3}{|c|}{$A$} & \multicolumn{3}{|r|}{$\mathrm{H}$} & \multicolumn{3}{|r|}{$75^{a}$} & \multicolumn{3}{|c|}{$75 \mathrm{H}$} \\
\hline & $\mathrm{h}_{\mathrm{e}}$ & $\mathrm{h}_{\mathrm{o}}$ & HWE $p$ value & $\mathrm{h}_{\mathrm{e}}$ & $\mathrm{h}_{\mathrm{o}}$ & HWE p-value & $\mathrm{h}_{\mathrm{e}}$ & $\mathrm{h}_{\mathrm{o}}$ & HWE $p$-value & $\mathrm{h}_{\mathrm{e}}$ & $h_{0}$ & HWE $p$-value \\
\hline rs210446561 & 0,38 & 0,50 & 0,15 & 0,2 & 0,21 & 1,00 & 0,22 & 0,25 & 1,00 & 0,25 & 0,29 & 1,00 \\
\hline
\end{tabular}

\begin{tabular}{|c|c|c|c|c|c|c|c|c|c|}
\hline & \multicolumn{3}{|c|}{$50 \mathrm{AH}$} & \multicolumn{3}{|c|}{$L X$} & \multicolumn{3}{|c|}{ Global } \\
\hline & $\mathrm{h}_{\mathrm{e}}$ & $\mathrm{h}_{\mathrm{o}}$ & HWE $p$-value & & $\mathrm{h}_{\mathrm{o}}$ & HWE $p$-value & $\mathrm{h}_{\mathrm{e}}$ & $\mathrm{h}_{0}$ & HWE p-value \\
\hline rs210446561 & 0,19 & 0,21 & 1,00 & 0,16 & 0,17 & 1,00 & 0,24 & 0,28 & 0,99 \\
\hline
\end{tabular}

Tabla 15. Heterocigosidad esperada (he), heterocigosidad observada (ho) y p-value del Equilibrio de Hardy-Weinberg (HWE) para el SNP rs210446561 de CEBPA en las subpoblaciones y la población entera del panel $\mathrm{B}$. $\mathrm{A}=$ Angus; $\mathrm{H}=$ Hereford; $75 \mathrm{~A}=$ novillos $75 \%$ Angus; $75 \mathrm{H}=$ novillos $75 \%$ Hereford; $50 \mathrm{AH}=$ novillos $50 \%$ Angus $50 \%$ Hereford; LX = novillos cruza Limousin. 
5.3.3. Caracterización de los polimorfismos analizados en el gen LIPE (Lipasa Sensible a Hormona)

Las frecuencias alélicas observadas estaban bien balanceadas en todos los grupos poblacionales para los tres SNPs analizados para el gen LIPE (MAF $\geq 0,225$ ). Los valores variaron entre 0,225 y 0,775 (Tabla 16). La heterocigosidad observada y esperada para cada SNP de este gen y cada grupo estudiado se indican en la Tabla 17. Se observaron valores altos de diversidad genética para cada SNP dentro de cada grupo (he $>0,35)$ y en la población total(he $=0,44)$. Los valores de heterocigosidad esperada variaron entre 0,35 (LX) y 0,50 (75A). Además, la prueba de equilibrio de Hardy-Weinberg no mostró desviaciones significativas de las proporciones teóricas en ninguna de las pruebas realizadas (SNP por grupo) (Tabla 17).

\begin{tabular}{|c|c|c|c|c|c|c|c|}
\hline & & & & blacior & nes & & \\
\hline $\mathbf{N}$ & 44 & 26 & 30 & 24 & 95 & 41 & 260 \\
\hline Locus & & & & & & & \\
\hline rs109759779 & A & $\mathrm{H}$ & $75^{a}$ & $75 \mathrm{H}$ & $50 \mathrm{AH}$ & $L X$ & Global \\
\hline A & 66,25 & 71,74 & 57,69 & 76,09 & 63,89 & 77,50 & 67,77 \\
\hline C & 33,75 & 28,26 & 42,31 & 23,91 & 36,11 & 22,50 & 32,23 \\
\hline rs109598915 & A & $\mathrm{H}$ & $75 \mathrm{~A}$ & $75 \mathrm{H}$ & $50 \mathrm{AH}$ & $L X$ & Global \\
\hline A & 39,77 & 42,00 & 48,28 & 35,42 & 45,21 & 28,05 & 40,66 \\
\hline C & 60,23 & 58,00 & 51,72 & 64,58 & 54,79 & 71,95 & 59,34 \\
\hline rs41887406 & A & $\mathrm{H}$ & $75 \mathrm{~A}$ & $75 \mathrm{H}$ & $50 \mathrm{AH}$ & LX & Global \\
\hline A & 60,23 & 55,77 & 51,67 & 64,58 & 53,72 & 71,95 & 58,69 \\
\hline G & 39,77 & 44,23 & 48,33 & 35,42 & 46,28 & 28,05 & 41,31 \\
\hline
\end{tabular}

Tabla 16. Frecuencias alélicas de los polimorfismos seleccionados de LIPE tipificados en el panel de muestras $\mathrm{B}$. $\mathrm{A}=$ Angus; $\mathrm{H}=$ Hereford; $75 \mathrm{~A}=$ novillos $75 \%$ Angus; $75 \mathrm{H}=$ novillos $75 \%$ Hereford; $50 \mathrm{AH}=$ novillos $50 \%$ Angus $50 \%$ Hereford; $L X=$ novillos cruza Limousin. 


\begin{tabular}{|c|c|c|c|c|c|c|c|c|c|c|c|c|}
\hline \multirow{3}{*}{ SNP } & \multicolumn{12}{|c|}{ Poblaciones } \\
\hline & \multicolumn{3}{|c|}{$A$} & \multicolumn{3}{|r|}{$\mathrm{H}$} & \multicolumn{3}{|c|}{$75^{a}$} & \multicolumn{3}{|c|}{$75 \mathrm{H}$} \\
\hline & $\mathrm{h}_{\mathrm{e}}$ & $\mathrm{h}_{\circ}$ & HWE $p$ value & & $\mathrm{h}_{\mathrm{o}}$ & HWE $p$-value & & $\mathrm{h}_{\mathrm{o}}$ & HWE $p$-value & $h_{e}$ & $h_{0}$ & HWE p-value \\
\hline rs109759779 & 0,45 & 0,53 & 0,48 & 0,41 & 0,48 & 0,63 & 0,50 & 0,54 & 0,71 & 0,37 & 0,39 & 1,00 \\
\hline rs109598915 & 0,48 & 0,52 & 0,76 & 0,50 & 0,52 & 1,00 & 0,51 & 0,55 & 0,72 & 0,47 & 0,46 & 1,00 \\
\hline rs41887406 & 0,48 & 0,52 & 0,76 & 0,50 & 0,50 & 1,00 & 0,51 & 0,57 & 0,72 & 0,47 & 0,46 & 1,00 \\
\hline
\end{tabular}

\begin{tabular}{c|ccc|ccc|ccc}
\multicolumn{4}{c|}{$50 A H$} & \multicolumn{4}{c|}{$L X$} & \multicolumn{3}{c}{ Global } \\
\cline { 2 - 9 } & $h_{e}$ & $h_{\circ}$ & HWE p-value & $h_{e}$ & $h_{\circ}$ & HWE p-value & $h_{e}$ & $h_{\circ}$ & HWE p-value \\
rs109759779 & 0,46 & 0,50 & 0,50 & 0,35 & 0,40 & 0,65 & 0,44 & 0,48 & 0,15 \\
rs109598915 & 0,50 & 0,56 & 0,22 & 0,41 & 0,46 & 0,46 & 0,48 & 0,53 & 0,20 \\
rs41887406 & 0,50 & 0,56 & 0,22 & 0,41 & 0,46 & 0,46 & 0,49 & 0,53 & 0,21
\end{tabular}

Tabla 17. Heterocigosidad esperada (he), heterocigosidad observada (ho) y p-value del Equilibrio de Hardy-Weinberg (HWE) para los SNPs de LIPE en las subpoblaciones y la población entera del panel B. $\mathrm{A}=$ Angus; $\mathrm{H}=$ Hereford; $75 \mathrm{~A}=$ novillos $75 \%$ Angus; $75 \mathrm{H}=$ novillos $75 \%$ Hereford; $50 \mathrm{AH}=$ novillos $50 \%$ Angus $50 \%$ Hereford; $L X=$ novillos cruza Limousin.

5.3.4. Caracterización de los polimorfismos analizados en el gen FABP4 (Proteína de Unión a Ácidos Grasos 4)

Las frecuencias alélicas obtenidas para los SNPs del gen FABP4 estuvieron bien balanceadas, con la excepción del marcador rs110652478, el cual resultó ser monomórfico en la población de Angus puros y presentó una baja variabilidad en el grupo $75 \%$ Angus. El resto de los marcadores presentaron valores de MAF mayores a 0,159 (Tabla 18). 


\begin{tabular}{|c|c|c|c|c|c|c|c|}
\hline & oblacion & & & & & & \\
\hline $\mathbf{N}$ & 44 & 26 & 30 & 24 & 95 & 41 & 260 \\
\hline Locus & & & & & & & \\
\hline rs41729173 & A & $\mathrm{H}$ & $75 \mathrm{~A}$ & $75 \mathrm{H}$ & $50 \mathrm{AH}$ & $L X$ & Global \\
\hline C & 84.09 & 59.62 & 71.43 & 70.83 & 71.05 & 68.75 & 0.72 \\
\hline G & 15.91 & 40.38 & 28.57 & 29.17 & 28.95 & 31.25 & 0.28 \\
\hline rs111014258 & A & $\mathrm{H}$ & $75 \mathrm{~A}$ & $75 \mathrm{H}$ & $50 \mathrm{AH}$ & $L X$ & Global \\
\hline C & 63.64 & 26.92 & 40.00 & 41.67 & 40.86 & 30.49 & 0.42 \\
\hline $\mathrm{T}$ & 36.36 & 73.08 & 60.00 & 58.33 & 59.14 & 69.51 & 0.58 \\
\hline rs110383592 & A & $\mathrm{H}$ & $75 \mathrm{~A}$ & $75 \mathrm{H}$ & $50 \mathrm{AH}$ & $L X$ & Global \\
\hline C & 63.64 & 26.92 & 40.00 & 41.67 & 40.96 & 30.49 & 0.42 \\
\hline G & 36.36 & 73.08 & 60.00 & 58.33 & 59.04 & 69.51 & 0.58 \\
\hline rs110652478 & A & $\mathrm{H}$ & $75 \mathrm{~A}$ & $75 \mathrm{H}$ & $50 \mathrm{AH}$ & $L X$ & Global \\
\hline A & - & 23.08 & 5.00 & 14.58 & 13.68 & 25.61 & 0.13 \\
\hline G & 100.00 & 76.92 & 95.00 & 85.42 & 86.32 & 74.39 & 0.87 \\
\hline rs110757796 & A & $\mathrm{H}$ & $75 \mathrm{~A}$ & $75 \mathrm{H}$ & $50 \mathrm{AH}$ & $L X$ & Global \\
\hline$A$ & 31.82 & 74.00 & 58.33 & 58.33 & 54.26 & 65.00 & 0.55 \\
\hline G & 68.18 & 26.00 & 41.67 & 41.67 & 45.74 & 35.00 & 0.45 \\
\hline
\end{tabular}

Tabla 18. Frecuencias alélicas de los polimorfismos seleccionados de FABP4 tipificados en el panel de muestras $\mathrm{B}$. $\mathrm{A}=$ Angus; $\mathrm{H}=$ Hereford; $75 \mathrm{~A}=$ novillos $75 \%$ Angus; $75 \mathrm{H}=$ novillos $75 \%$ Hereford; $50 \mathrm{AH}=$ novillos $50 \%$ Angus $50 \%$ Hereford; $L X=$ novillos cruza Limousin.

Según la prueba de equilibrio de Hardy-Weinberg, tres de los SNPs analizados (rs41729173, rs111014258 y rs110383592) no presentaban desviaciones significativas de las proporciones teóricas. Por el contrario, los marcadores rs110652478 y rs110757796 evidenciaron desviaciones estadísticamente significativas: el SNP rs110652478 en toda la población y el rs110757796 en el grupo poblacional 50\% Angus-50\% Hereford (Tabla 19). Los valores de heterocigosidad esperada, excluyendo el caso del rs110652478, se encontraron entre 0,271 (rs41729173 en A) y 0,499 (rs110757796 en 50AH). La heterocigosidad observada varió entre 0,273 (rs41729173 en A) y 0,600 (rs111014258 y rs110383592 en 75A). 


\begin{tabular}{|c|c|c|c|c|c|c|c|c|c|c|c|c|}
\hline \multirow[b]{2}{*}{ SNP } & \multicolumn{3}{|r|}{ A } & \multicolumn{3}{|r|}{$\mathrm{H}$} & \multicolumn{3}{|c|}{$75^{a}$} & \multicolumn{3}{|c|}{$75 \mathrm{H}$} \\
\hline & $\mathrm{h}_{\mathrm{e}}$ & $\mathrm{h}_{\mathrm{o}}$ & HWE p-value & $\mathrm{h}_{\mathrm{e}}$ & $h_{0}$ & HWE p-value & $\mathrm{h}_{\mathrm{e}}$ & $\mathrm{h}_{\mathrm{o}}$ & HWE p-value & $\mathrm{h}_{\mathrm{e}}$ & $\mathrm{h}_{\mathrm{o}}$ & HWE p-value \\
\hline rs41729173 & 0,27 & 0,27 & 1,00 & 0,49 & 0,50 & 1,00 & 0,42 & 0,50 & 0,38 & 0,42 & 0,33 & 0,34 \\
\hline rs111014258 & 0,47 & 0,41 & 0,51 & 0,40 & 0,38 & 1,00 & 0,49 & 0,60 & 0,26 & 0,50 & 0,42 & 0,67 \\
\hline rs110383592 & 0,47 & 0,41 & 0,52 & 0,40 & 0,38 & 1,00 & 0,49 & 0,60 & 0,26 & 0,50 & 0,42 & 0,67 \\
\hline rs110652478 & - & - & - & 0,36 & 0,15 & $0,01^{*}$ & 0,10 & 0,03 & 0,05 & 0,25 & 0,12 & $0,04^{*}$ \\
\hline rs110757796 & 0,44 & 0,32 & 0,08 & 0,39 & 0,36 & 0,64 & 0,49 & 0,50 & 1,00 & 0,50 & 0,33 & 0,20 \\
\hline
\end{tabular}

\begin{tabular}{c|ccc|ccc|ccc|} 
& \multicolumn{4}{|c|}{50 AH } & \multicolumn{4}{|c|}{ LX } & \multicolumn{4}{c|}{ Global } \\
\cline { 2 - 9 } & $h_{e}$ & $h_{\circ}$ & HWE p-value & $h_{e}$ & $h_{\circ}$ & HWE p-value & $h_{e}$ & $h_{\circ}$ & HWE p-value \\
rs41729173 & 0,41 & 0,43 & 0,80 & 0,43 & 0,52 & 0,27 & 0,41 & 0,42 & 0,85 \\
rs111014258 & 0,49 & 0,47 & 0,83 & 0,43 & 0,46 & 0,72 & 0,49 & 0,46 & 0,93 \\
rs110383592 & 0,49 & 0,47 & 1,00 & 0,43 & 0,46 & 0,72 & 0,49 & 0,46 & 0,94 \\
rs110652478 & 0,24 & 0,06 & $<0,01^{*}$ & 0,39 & 0,12 & $<0,01^{*}$ & 0,23 & 0,07 & $<0,01^{*}$ \\
rs110757796 & 0,50 & 0,36 & 0,05 & 0,46 & 0,4 & 0,49 & 0,5 & 0,37 & 0,08
\end{tabular}

Tabla 19. Heterocigosidad esperada (he), heterocigosidad observada (ho) y p-value del Equilibrio de Hardy-Weinberg (HWE) para los SNPs de FABP4 en las subpoblaciones y la población entera del panel $\mathrm{B}$. $\mathrm{A}=$ Angus; $\mathrm{H}=$ Hereford; $75 \mathrm{~A}=$ novillos $75 \%$ Angus; $75 \mathrm{H}=$ novillos $75 \%$ Hereford; $50 \mathrm{AH}=$ novillos $50 \%$ Angus $50 \%$ Hereford; LX = novillos cruza Limousin.

5.3.5. Caracterización de los polimorfismos analizados en el gen $R X R A$ (Receptor X Retinoide Alfa)

Dos de las mutaciones seleccionadas, rs207774429 y rs133517803 del gen $R X R A$ presentaron frecuencias relativamente balanceadas (MAF $\geq 5,77$ ), lo que no ocurrió con las otras dos, rs136289117 y rs209839910, las cuales presentaron un gran desbalance entre las frecuencias génicas de los dos alelos (Tabla 20). EI SNP rs207774429 solo pudo ser tipificado en 153 animales. La mutación rs136289117 resultó ser monomórfica, excepto en las poblaciones de Angus y Hereford puros, en las cuales la variabilidad fue muy pequeña. El SNP rs209839910 también evidenció baja variabilidad $(1,69 \leq \mathrm{MAF} \leq 4,17)$, con un alelo fijado en la población $75 \%$ Angus. 


\begin{tabular}{|c|c|c|c|c|c|c|c|}
\hline & & & & oblacior & nes & & \\
\hline $\mathbf{N}$ & 44 & 26 & 30 & 24 & 95 & 41 & 260 \\
\hline Locus & & & & & & & \\
\hline rs207774429 & A & $\mathrm{H}$ & $75 \mathrm{~A}$ & $75 \mathrm{H}$ & $50 \mathrm{AH}$ & $\mathrm{LX}$ & Global \\
\hline $\mathrm{C}$ & 71,74 & 65,63 & 65,63 & 64,29 & 68,85 & 69,57 & 68,30 \\
\hline $\mathrm{T}$ & 28,26 & 34,38 & 34,38 & 35,71 & 31,15 & 30,43 & 31,70 \\
\hline rs133517803 & $\mathrm{A}$ & $\mathrm{H}$ & $75 \mathrm{~A}$ & $75 \mathrm{H}$ & $50 \mathrm{AH}$ & $\mathrm{LX}$ & Global \\
\hline A & 32,56 & 5,77 & 33,33 & 20,83 & 23,40 & 45,00 & 27,43 \\
\hline G & 67,44 & 94,23 & 66,67 & 79,17 & 76,60 & 55,00 & 72,57 \\
\hline rs136289117 & A & $\mathrm{H}$ & $75 \mathrm{~A}$ & $75 \mathrm{H}$ & $50 \mathrm{AH}$ & $\mathrm{LX}$ & Global \\
\hline C & 1,16 & 1,92 & - & - & - & - & 0,39 \\
\hline $\mathrm{T}$ & 98,84 & 98,08 & 100,00 & 100,00 & 100,00 & 100,00 & 99,61 \\
\hline rs209839910 & A & $\mathrm{H}$ & $75 \mathrm{~A}$ & $75 \mathrm{H}$ & $50 \mathrm{AH}$ & $\mathrm{LX}$ & Global \\
\hline C & 97,67 & 98,08 & 100,00 & 95,83 & 98,31 & 96,15 & 97,81 \\
\hline $\mathrm{T}$ & 2,33 & 1,92 & - & 4,17 & 1,69 & 3,85 & 2,19 \\
\hline
\end{tabular}

Tabla 20. Frecuencias alélicas de los polimorfismos seleccionados de RXRA tipificados en el panel de muestras $\mathrm{B}$. $\mathrm{A}=$ Angus; $\mathrm{H}=$ Hereford; $75 \mathrm{~A}=$ novillos $75 \%$ Angus; $75 \mathrm{H}=$ novillos $75 \%$ Hereford; $50 \mathrm{AH}=$ novillos $50 \%$ Angus $50 \%$ Hereford; LX = novillos cruza Limousin.

Según la prueba de HWE, el SNP rs207774429 presentó desviaciones significativas con respecto a las proporciones teóricas en la población total $(p<0,01)$. El SNP rs133517803 también presentó desviaciones en la subpoblación 75\% Angus. El resto de los polimorfismos del gen RXRA no presentó desviaciones significativas. Los valores de heterocigosidad esperada, excluyendo a rs 136289117 , variaron entre 0,033 (rs209839910 en 50AH) y 0,500 (rs133517803 en LX). La heterocigosidad observada osciló entre 0,034 (rs209839910 en 50AH) y 0,667 (rs133517803 en 75A) (Tabla 21). 


\begin{tabular}{|c|c|c|c|c|c|c|c|c|c|c|c|c|}
\hline \multirow{3}{*}{ SNP } & \multicolumn{12}{|c|}{ Poblaciones } \\
\hline & \multicolumn{3}{|r|}{$A$} & \multicolumn{3}{|r|}{$\mathrm{H}$} & \multicolumn{3}{|c|}{$75 \mathrm{~A}$} & \multicolumn{3}{|c|}{$75 \mathrm{H}$} \\
\hline & $\mathrm{h}_{\mathrm{e}}$ & $\mathrm{h}_{\mathrm{o}}$ & HWE $p$ value & $\mathrm{h}_{\mathrm{e}}$ & $\mathrm{h}_{\mathrm{o}}$ & HWE p-value & $\mathrm{h}_{\mathrm{e}}$ & $\mathrm{h}_{\mathrm{o}}$ & HWE p-value & $\mathrm{h}_{\mathrm{e}}$ & $\mathrm{h}_{\mathrm{o}}$ & HWE p-value \\
\hline rs207774429 & 0,41 & 0,39 & 1,00 & 0,47 & 0,69 & 0.09 & 0,47 & 0,56 & 0.59 & 0,48 & 0,71 & 0.09 \\
\hline rs133517803 & 0,44 & 0,37 & 0,31 & 0,11 & 0,12 & 1,00 & 0,45 & 0,67 & $0,01^{*}$ & 0,34 & 0,42 & 0,54 \\
\hline rs136289117 & 0,02 & 0,02 & - & 0,04 & 0,04 & - & - & - & - & - & - & - \\
\hline \multirow[t]{3}{*}{ rs209839910 } & 0,05 & 0,05 & 1,00 & 0,04 & 0,04 & - & 0 & 0 & - & 0,08 & 0,08 & 1,00 \\
\hline & \multicolumn{3}{|c|}{$\overline{50 A H}$} & \multicolumn{3}{|c|}{$\overline{L X}$} & \multicolumn{3}{|c|}{ Global } & & & \\
\hline & $\mathrm{h}_{\mathrm{e}}$ & $\mathrm{h}_{\mathrm{o}}$ & HWE p-value & $\mathrm{h}_{\mathrm{e}}$ & $\mathrm{h}_{\mathrm{o}}$ & HWE p-value & $\mathrm{h}_{\mathrm{e}}$ & $\mathrm{h}_{\mathrm{o}}$ & HWE p-value & & & \\
\hline rs207774429 & 0,43 & 0,59 & $<0.01^{*}$ & 0,43 & 0,44 & 1,00 & 0,43 & 0,56 & $<0,01^{*}$ & & & \\
\hline rs133517803 & 0,36 & 0,38 & 0,77 & 0,50 & 0,60 & 0,33 & 0,40 & 0,42 & 0,34 & & & \\
\hline rs136289117 & - & - & - & - & - & - & 0,01 & 0,01 & 1,00 & & & \\
\hline rs209839910 & 0,03 & 0,03 & 1,00 & 0,08 & 0,08 & 1,00 & 0,04 & 0,04 & 1,00 & & & \\
\hline
\end{tabular}

Tabla 21. Heterocigosidad esperada (he), heterocigosidad observada (ho) y p-value del Equilibrio de Hardy-Weinberg (HWE) para los SNPs de RXRA en las subpoblaciones y la población entera del panel B. $\mathrm{A}=$ Angus; $\mathrm{H}=$ Hereford; $75 \mathrm{~A}=$ novillos $75 \%$ Angus; $75 \mathrm{H}=$ novillos $75 \%$ Hereford; $50 \mathrm{AH}=$ novillos $50 \%$ Angus $50 \%$ Hereford; $L X=$ novillos cruza Limousin.

\subsection{Determinación de los haplotipos presentes en los genes analizados}

5.4.1. Determinación de haplotipos del gen PPARG (Receptor Gamma Activado por el Proliferador de Peroxisomas)

Dos de los tres marcadores tipificados para el gen PPARG, el rs207671117 (PPARG5UTR) y el rs42016945, formaban parte de un bloque de ligamiento conformado por tres haplotipos, dos de los cuales constituían más del $95 \%$ de las frecuencias haplotípicas (Fig.26). El haplotipo GC mostró una frecuencia de 0,73, el haplotipo GT una frecuencia de 0,24 y el haplotipo AT, bastante raro, una frecuencia de 0,03 . 


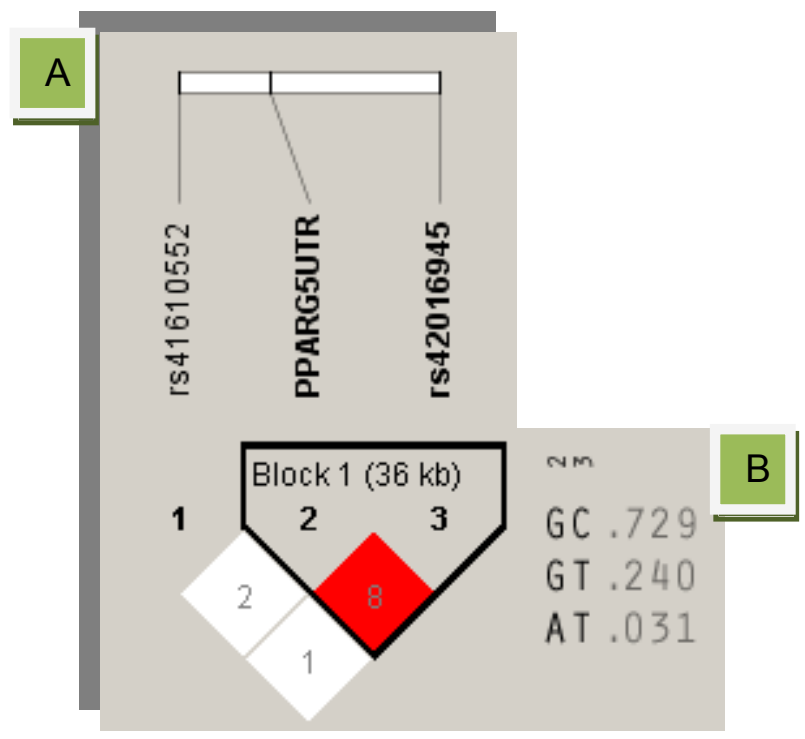

Fig.26. Análisis de ligamiento y haplotipos entre los SNPs seleccionados del gen PPARG, obtenidos mediante el método sólido implementado en el programa Haploview. (A) Bloque de ligamiento detectado. El color rojo indica valores de LOD $\geq 2$.y D' cercano a 1 . El color blanco indica valores de LOD < 2 y D' < 1. Los valores de $r^{2}$ se indican dentro de las cajas. (B) Frecuencias de los haplotipos detectados.

5.4.2. Determinación de haplotipos del gen LIPE (Lipasa Sensible a Hormona)

Los tres SNPs tipificados del gen LIPE conformaban un único bloque de ligamiento que constaba de 4 haplotipos, tres de los cuales constituían más del $98 \%$ de las frecuencias haplotípicas (Fig.27). Los SNPs rs109598915 y rs41887406 se encontraban completamente ligados, por lo tanto, con dos "Tag SNPs" es posible determinar la mayor parte de la variabilidad haplotípica. El haplotipo CCA, la variante recombinante, se encontró en una frecuencia de 0,02. 


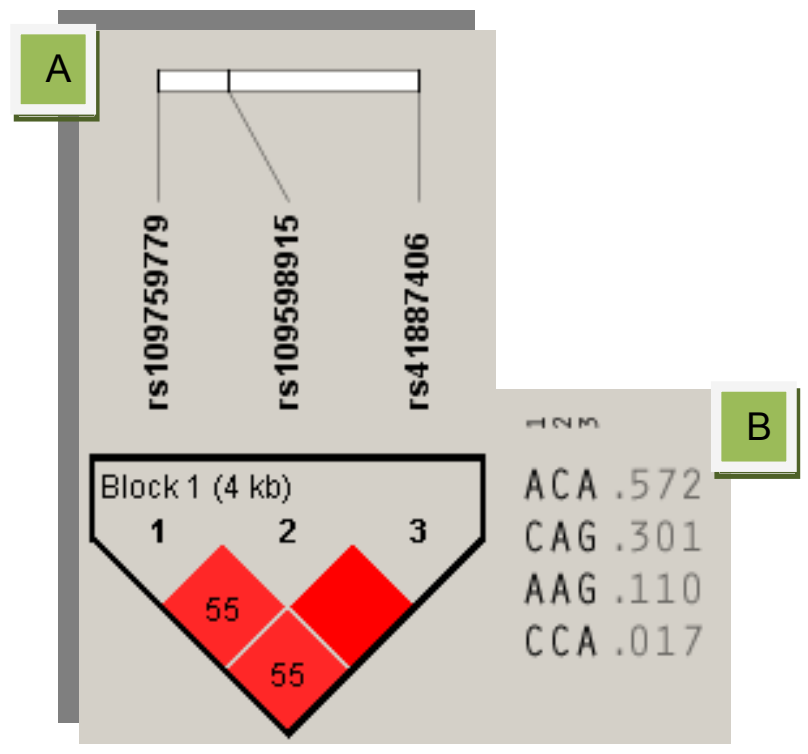

Fig. 27. Análisis de ligamiento y haplotipos entre los SNPs seleccionados de LIPE, obtenidos mediante el método sólido implementado en el programa Haploview. (A) Bloque de ligamiento detectado.El color rojo indica valores de $L O D \geq 2$.y $D^{\prime}$ cercano a 1 . En los casos en que $D^{\prime}=1$ las cajas se muestran vacías. Los valores de $\mathrm{r}^{2}$ se indican dentro de las cajas (B) Frecuencias de los haplotipos detectados.

5.4.3. Determinación de haplotipos del gen FABP4 (Proteina de unión a ácidos grasos 4)

Cuatro de los cinco SNPs analizados del gen FABP4 eran parte de un bloque de ligamiento, el cual estaba representado por cinco haplotipos. Tres de estos haplotipos constituían más del $85 \%$ de las frecuencias haplotípicas (Fig. 28). Los haplotipos detectados presentaron frecuencias entre 0,04 y 0,37 . Los SNPs rs111014258 y rs110383592 se encontraban completamente ligados. 


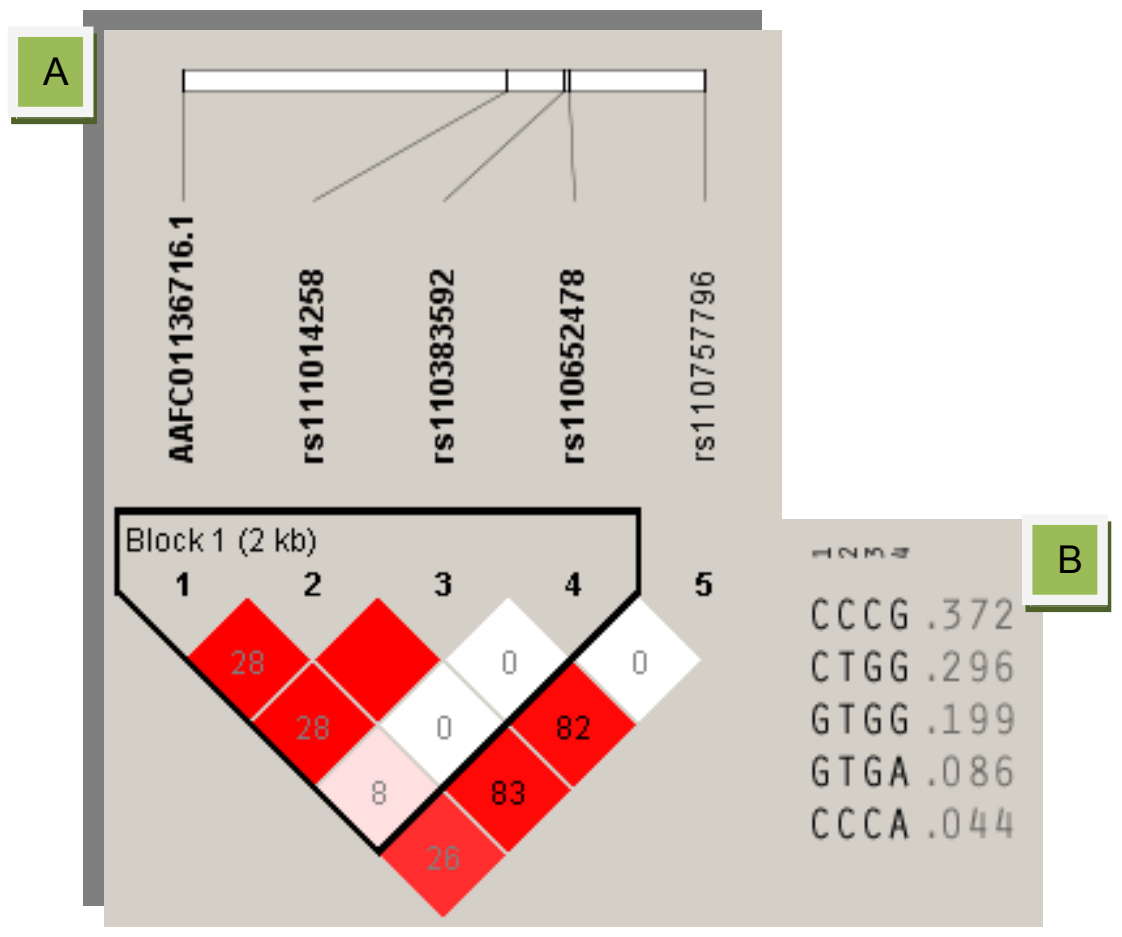

Fig. 28. Estudio de ligamiento y haplotipos entre los SNPs seleccionados de FABP4, bloques obtenidos mediante el método sólido implementado en el programa Haploview. (A) Bloque de ligamiento detectado. El color rojo brillante indica valores de $L O D \geq 2$.y $D^{\prime}=1$, los matices de color rojo indican valores de LOD $\geq 2$ y $D^{\prime}<1$, el blanco indica valores de LOD $<2$ y $D^{\prime}<1$. En los casos en que $D^{\prime}=1$ las cajas se muestran vacías. Los valores de $r^{2}$ se indican dentro de las cajas. (B) Frecuencias de los haplotipos detectados.

\subsubsection{Determinación de haplotipos del gen $R X R A$ (Receptor $X$ Retinoide Alfa)}

Tres de los cuatro SNPs del gen RXRA formaban parte de un bloque de ligamiento, el cual estaba constituido por tres haplotipos. Dos de estos tres haplotipos constituían más del $97 \%$ de las frecuencias haplotípicas (Fig. 29). Por lo tanto, con dos Tag SNPs es posible determinar la mayor parte de la variabilidad haplotípica. 


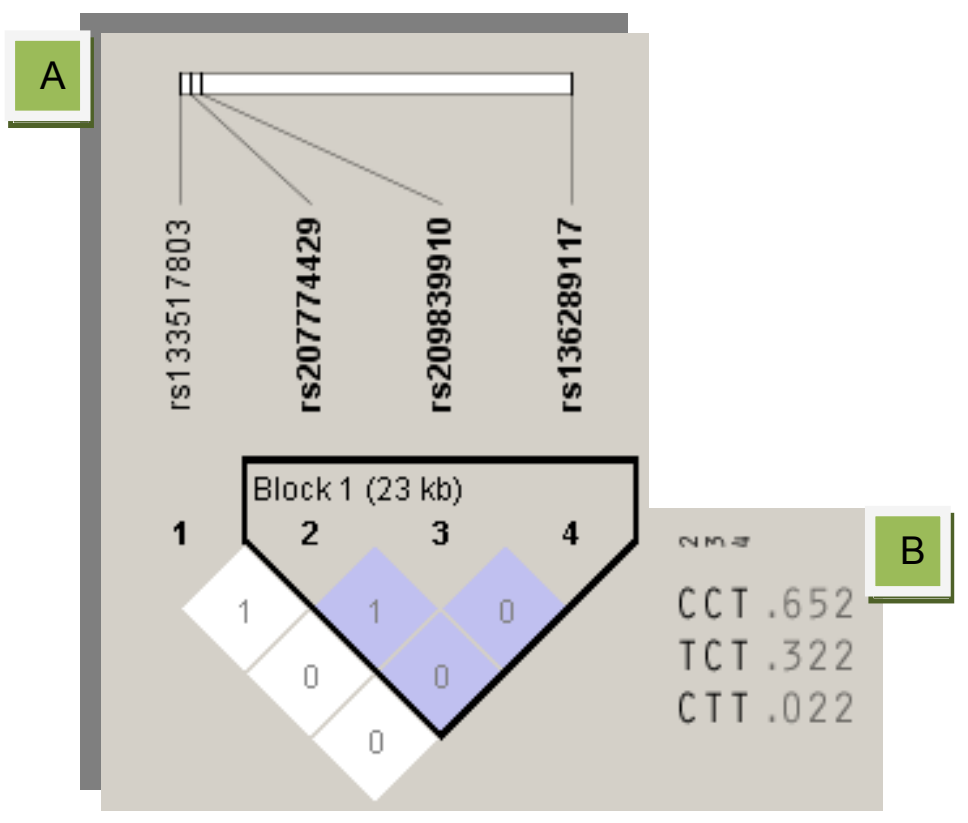

Fig. 29. Estudio de ligamiento y haplotipos entre los SNPs seleccionados de $R X R A$, obtenidos mediante el método sólido implementado en el programa Haploview. (A) Bloque de ligamiento detectado, El color celeste indica valores de LOD $<2$ y $D^{\prime}=1$. Dentro de las cajas se indican los valores de $r^{2}$. (B) Frecuencias de los haplotipos detectados.

\subsection{Estudios de asociación entre los SNPs analizados y caracteres de calidad de carne}

\subsubsection{Asociación de los SNPs del gen PPARG con caracteres de calidad de carne}

Cuando las pruebas individuales de asociación fueron llevadas a cabo, el SNP rs207671117 del gen PPARG mostró efectos significativos $(p<0,05)$ sobre los contenidos de ácido linoleico (C18:2c912, $\mathrm{p}=0,034)$ ácido eicosatriinoico(C20:3c81114, $p=0,030)$ y ácidos grasos Omega-6 $(\omega-6, p=0,023)$. E estudio de este SNP también evidencióefectos sugestivos $(p<0,1)$ sobre los contenidos de ácido araquidónico ( $\mathrm{C} 20: 4, \mathrm{p}=0,087)$ y ácidos grasos polinsaturados totales (AGPI, $p=0,090)$. El genotipo $G G$ presentó valores de $\mathrm{C} 18: 2$ c912 31,04\% más altos que el genotipo AG. El contenido de C20:3c81114 en los individuos con genotipo GG resultó ser un $51,05 \%$ más alto que en los animales de genotipo AG. Sin embargo, cabe destacar que la diversidad genética de este SNP en la población fue muy baja, ya que el alelo minoritario se encontraba en una frecuencia de 0,017. Las medias de cuadrados mínimos se indican en la tabla 22. 
El SNP rs41610552 no mostró asociaciones significativas con ninguna de las variables analizadas. El SNP rs42016945 mostró un efecto significativo y de dominancia sobre el contenido de ácido vaccénico (C18:1c11, $p=0,035)$ y un efecto sugestivo y aditivo sobre el contenido de ácido miristoleico (C14:1, $p=0,092)$. No se observaron efectos significativos sobre el resto de las variables analizadas. A pesar de las asociaciones a nivel individual, cuando se aplicó el método de Benjamini y Hochberg para comparaciones múltiples (69 comparaciones) ninguna alcanzó el umbral de significancia.

\begin{tabular}{|c|c|c|c|c|c|c|}
\hline $\begin{array}{l}\text { SNP/variable } \\
\text { rs207671117 } \\
\end{array}$ & Valor de $p$ & \multicolumn{3}{|c|}{ Medias de cuadrados mínimos de los genotipos ${ }^{1}$} & Efecto de dominancia ${ }^{2}$ & Efecto aditivo $^{3}$ \\
\hline C18_2c912 & $0,034^{*}$ & $3,3483 \pm 0,1337^{a}$ & $2,555 \pm 0,3677^{b}$ & & & \\
\hline C20_3c81114 & $0,030^{*}$ & $0,2299 \pm 0,0102^{a}$ & $0,1522 \pm 0,0344^{b}$ & & & \\
\hline$\omega-6$ & $0,023^{*}$ & $5,1279 \pm 0,1839^{a}$ & $3,8493 \pm 0,5476^{b}$ & & & \\
\hline AGPI & 0,090 & $7,6469 \pm 0,2374$ & $6,3261 \pm 0,7553$ & & & \\
\hline rs42016945 & & $\mathrm{CC}(\mathrm{N}=92)$ & $\mathrm{CT}(\mathrm{N}=63)$ & $\mathrm{TT}(\mathrm{N}=24)$ & & \\
\hline C14_1 & 0,092 & $0,4642 \pm 0,0278$ & $0,5098 \pm 0,0317$ & $0,5893 \pm 0,0510$ & $-0,0169 \pm 0,0407(p=0,679)$ & $0,1251 \pm 0,0580(p=0,033)$ \\
\hline $\mathrm{C} 18$ 1c11 & $0,035^{\star}$ & $0,6214 \pm 0,0751^{a}$ & $0,7932 \pm 0,0828^{b}$ & $0,6482 \pm 0,0998^{\mathrm{ab}}$ & $0,1584 \pm 0,0635(p=0,015)$ & $0,0268 \pm 0,0979(p=0,782)$ \\
\hline
\end{tabular}

\footnotetext{
${ }^{1}$ En la misma fila, las medias de cuadrados mínimos con diferentes letras son significativamente diferentes de acuerdo al test de separación de medias de Bonferroni $(p<0,05)$.

${ }^{2}$ Estimada restando la media de soluciones para los genotipos homocigotas a la de los heterocigotas.

${ }^{3}$ Estimada por la diferencia entre los dos genotipos homocigotas.
}

Tabla 22. Medias de cuadrados mínimos de los valores de ácidos grasos y error estándar (ES) para las clases genotípicas de los polimorfismos rs207671117 y rs42016945 del gen bovino PPARG. N: número de muestras; C18:2c912: contenido de ácido linoleico; C20:3c81114: contenido de ácido eicosatriinoico; w-6: contenido total de ácidos grasos Omega-6; C20:4: contenido de ácido araquidónico; AGPI: contenido total de ácidos grasos polinsaturados; C14:1: contenido de ácido miristoleico; $\mathrm{C} 18: 1 \mathrm{c} 11$ : contenido de ácido vaccénico.

\subsubsection{Asociación de los SNPs del gen CEBPA con caracteres de calidad de carne}

En el análisis individual de asociación se observó una asociación significativa $(p=0,045)$ entre el SNP rs210446561 y el contenido de ácido eicosatriinoico (C20:3c81114) (Tabla 23). El genotipo GC tuvo un valor $28,54 \%$ más alto que el 
genotipo GG. Este análisis solo pudo realizarse con 115 muestras, posiblemente debido a limitaciones de la técnica de tipificación. A pesar de la significancia a nivel individual, el SNP no alcanzó el valor de FDR para comparaciones múltiples (23 comparaciones) estimado por el método de Benjamini y Hochberg.

\begin{tabular}{cccc}
\hline SNP/variable & $\begin{array}{c}\text { Valor de } \\
\mathrm{p}\end{array}$ & $\begin{array}{c}\text { Media de cuadrados mínimos } \\
\text { del genotipo* }\end{array}$ \\
\hline rs210446561 & & $\mathrm{GG}(\mathrm{N}=81)$ & $\mathrm{GC}(\mathrm{N}=34)$ \\
& & $0.2004 \pm$ & $0.2576 \pm$ \\
$\mathrm{C} 20 \_3 \mathrm{c} 81114$ & $0,045^{*}$ & $0.0140^{\mathrm{a}}$ & $0.0262^{\mathrm{b}}$ \\
\hline misma fila, las medias de cuadrados mínimos con diferentes letras son significativamente
\end{tabular}
diferentes de acuerdo a la prueba de separación de medias de Bonferroni $(p<0.05)$

Tabla 23. Medias de cuadrados mínimos de los valores de ácidos grasos y error estándar (ES) para las clases genotípicas del polimorfismo rs210446561 del gen bovino CEBPA. N: número de muestras; C20:3c81114: contenido de ácido eicosatriinoico.

5.5.3. Asociación de los SNPs del gen LIPE con caracteres de calidad de carne

Cuando las pruebas individuales fueron llevadas a cabo, el SNP rs109759779 mostró efectos significativos sobre el contenido total de ácidos grasos monoinsaturados (AGMI) y el contenido de ácido oleico (C18:1c9) ( $p=0,0047$ y 0,0077). El valor de AGMI para el genotipo AC fue 2,19\% más alto que el del genotipo $A A$, pero las muestras con genotipo $C C$ no evidenciaron diferencias significativas con respecto a los otros grupos, posiblemente debido al bajo número de muestras con este genotipo y el alto error estándar. Con respecto al contenido de ácido oleico (C18:1c9), el genotipo CA mostró un valor 2,61\% más alto que el genotipo AA (Tabla 24).

El SNP rs109598915 evidenció un efecto significativo sobre el contenido de ácido heneicosílico $(C 21: 0)(p=0,0116)$, el genotipo $A C$ tuvo un valor $47,83 \%$ más bajo que el genotipo AA. Las muestras con genotipo CC no mostraron diferencias significativas con respecto a los otros grupos. Este SNP también evidenció un efecto sugestivo sobre el contenido de ácidos grasos monoinsaturados ( $A G M I, p=0,0764)$. Un efecto similar fue observado para el SNP rs41887406 ( $p=0,0075 ; p=0,0642)$ con los 
genotipos AG y GG (51,09\%), ya que ambos SNPs se encontraban casi completamente ligados (Tabla 24).

Los tres SNPs mostraron efectos de dominancia significativos $(p<0,05)$ en las pruebas de contraste. Los efectos aditivos no fueron significativos $(p>0,05)$. No se observaron efectos significativos en el resto de las mediciones. A pesar de las asociaciones a nivel individual, ninguna permaneció significativa al aplicar el método de Benjamini y Hochberg para comparaciones múltiples (46 comparaciones) (Tabla 24).

\begin{tabular}{|c|c|c|c|c|c|c|}
\hline SNP/variable & Valor de $p$ & & Media del genotipo ${ }^{1}$ & & Efecto de dominancia ${ }^{2}$ & Efecto aditivo $^{3}$ \\
\hline rs109759779 & & $A A(N=71)$ & $A C(N=80)$ & $\mathrm{CC}(\mathrm{N}=17)$ & & \\
\hline AGMI & $0,005^{*}$ & $47,104 \pm 0,278^{a}$ & $48,137 \pm 0,263^{b}$ & $46,795 \pm 0,539^{a b}$ & $1,188 \pm 0,373(p=0,002)$ & $-0,309 \pm 0,604(p=0,610)$ \\
\hline C18:1c9 & $0,008^{*}$ & $39,483 \pm 0,263^{\mathrm{a}}$ & $40,513 \pm 0,249^{b}$ & $39,594 \pm 0,510^{a b}$ & $0,975 \pm 0,353(p=0,006)$ & $0,111 \pm 0,571(p=0,846)$ \\
\hline rs109598915 & & $A A(N=30)$ & $A C(N=92)$ & $C C(N=53)$ & & \\
\hline $\mathrm{C} 21: 0$ & $0,012^{*}$ & $0,092 \pm 0,014^{a}$ & $0,136 \pm 0,008^{b}$ & $0,115 \pm 0,010^{\mathrm{ab}}$ & $0,033 \pm 0,011(p=0,004)$ & $0,024 \pm 0,017(p=0,162)$ \\
\hline AGMI & 0,076 & $47,148 \pm 0,441^{\mathrm{ab}}$ & $47,937 \pm 0,284^{\mathrm{a}}$ & $47,203 \pm 0,341^{b}$ & $0,761 \pm 0,335(p=0,025)$ & $0,054 \pm 0,512(p=0,916)$ \\
\hline rs41887406 & & $G G(N=30)$ & $A G(N=93)$ & $\mathrm{AA}(\mathrm{N}=52)$ & & \\
\hline $\mathrm{C} 21: 0$ & $0,007^{*}$ & $0,092 \pm 0,014^{\mathrm{a}}$ & $0,139 \pm 0,008^{a}$ & $0,115 \pm 0,010^{\mathrm{ab}}$ & $0,035 \pm 0,011(p=0,002)$ & $-0,022 \pm 0,017(p=0,196)$ \\
\hline AGMI & 0,064 & $47,168 \pm 0,438^{\mathrm{ab}}$ & $47,984 \pm 0,276^{a}$ & $47,221 \pm 0,341^{b}$ & $0,790 \pm 0,336(p=0,020)$ & $-0,053 \pm 0,517(p=0,918)$ \\
\hline
\end{tabular}

${ }^{1}$ En la misma fila, las medias de cuadrados mínimos con diferentes letras son significativamente diferentes de acuerdo al test de separación de medias de Bonferroni $(p<0,05)$.

${ }^{2}$ Estimada restando la media de soluciones para los genotipos homocigotas a la de los heterocigotas.

${ }^{3}$ Estimada por la diferencia entre los dos genotipos homocigotas.

Tabla 24. Medias de cuadrados mínimos de los valores de ácidos grasos y error estándar (ES) para las clases genotípicas de los polimorfismos rs109759779, rs109598915 y rs41887406 del gen bovino LIPE. $\mathrm{N}$ : número de muestras; AGMI: contenido total de ácidos grasos monoinsaturados; C18:1c9: contenido de ácido oleico; C21:0: contenido de ácido heneicosílico. 


\subsubsection{Asociación de los SNPs del gen FABP4 con caracteres de}

calidad de carne

A nivel individual, el SNP rs41729173 evidenció una asociación sugestiva con contenido de ácido $\mathrm{Y}$-linolénico $(\mathrm{C} 18: 3 \mathrm{c6912}, \mathrm{p}=0,056)$. Por otra parte, el SNP rs110757796 tuvo un efecto significativo sobre el espesor de grasa dorsal pre-faena (EGD_PRE, $p=0,010$ ) y un efecto sugestivo sobre el contenido de ácido linolelaídico (C18:2t912, $p=0,055)$. El SNP rs110652478 tuvo efectos significativos sobre los contenidos de ácido linolelaídico (C18:2t912, $p=0,013)$ y ácido eicosatriinoico (C20:3c81114, $p=0,033)$, y efectos sugestivos sobre el contenido de ácido esteárico (C18:0, $p=0,079)$.El SNP rs110383592 mostró efectos sugestivos sobre el contenido de ácido vaccénico $(\mathrm{C} 18: 1 \mathrm{c} 11, \mathrm{p}=0,064)$, el espesor de grasa dorsal pre-faena (EGD_PRE, $p=0,071$ ). El SNP rs111014258 fue asociado sugestivamente con contenido de ácido vaccénico $(\mathrm{C} 18: 1 \mathrm{c} 11, \mathrm{p}=0,074)$ y espesor de grasa dorsal (EGD, $p=0,067$ ) (Tabla 27). El caso particular del SNP rs110652478, en la valoración de los resultados obtenidos debe tenerse en cuenta la baja variabilidad mostrada en la población, solo se detectaron unos pocos individuos con genotípicas de las variantes minoritarias. Ninguno de los SNPs superó el índice FDR al considerar 92 comparaciones. 


\begin{tabular}{|c|c|c|c|c|c|c|}
\hline SNP/variable & $\begin{array}{l}\text { Valor } \\
\text { de p }\end{array}$ & Medias de cu & drados mínimos de I & s genotipos ${ }^{1}$ & Efecto de dominancia ${ }^{2}$ & Efecto aditivo $^{3}$ \\
\hline rs41729173 & & $G G(N=10)$ & $G C(N=63)$ & $\mathrm{CC}(\mathrm{N}=93)$ & & \\
\hline C18_3c6912 & 0,056 & $0,0763 \pm 0,0241$ & $0,0654 \pm 0,0091$ & $0,0387 \pm 0,0088$ & $0,0079 \pm 0,0153(p=0,6052)$ & $0,0375 \pm 0,0253(p=0,141)$ \\
\hline rs110757796 & & $\mathrm{AA}(\mathrm{N}=61)$ & $A G(N=67)$ & $G G(N=48)$ & & \\
\hline EGD_PRE & $0,010^{*}$ & $6,8408 \pm 0,1533^{a}$ & $6,8013 \pm 0,1544^{\mathrm{a}}$ & $7,4579 \pm 0,1942^{b}$ & $-0,3480 \pm 0,1833(p=0,059)$ & $0,6170 \pm 0,2414(p=0,011)$ \\
\hline C18_2t912 & 0,055 & $0,0813 \pm 0,0184$ & $0,0396 \pm 0,0185$ & $0,0877 \pm 0,0213$ & $-0,0449 \pm 0,0184(p=0,016)$ & $0,0064 \pm 0,0242(p=0,791)$ \\
\hline rs110652478 & & $\mathrm{AA}(\mathrm{N}=17)$ & $A G(N=10)$ & $\mathrm{GG}(\mathrm{N}=152)$ & & \\
\hline C18_2t912 & $0,013^{*}$ & $-0,0075 \pm 0,0299^{a}$ & $0,0655 \pm 0,0379^{\mathrm{ab}}$ & $0,0768 \pm 0,0144^{\mathrm{b}}$ & $0,0309 \pm 0,0400(p=0,442)$ & $0,0842 \pm 0,0297(p=0,005)$ \\
\hline C20_3c81114 & $0,033^{*}$ & $0,2851 \pm 0,0286^{a}$ & $0,1650 \pm 0,0373^{b}$ & $0,2234 \pm 0,0111^{\mathrm{b}}$ & $-0,0893 \pm 0,0411(p=0,032)$ & $-0,0617 \pm 0,0302(p=0,044)$ \\
\hline C18_0 & 0,079 & $13,5618 \pm 0,4314^{\mathrm{a}}$ & $14,5833 \pm 0,5596^{\mathrm{ab}}$ & $14,5853 \pm 0,1717^{b}$ & $0,5098 \pm 0,6136(p=0,408)$ & $1,0234 \pm 0,4526(p=0,026)$ \\
\hline rs110383592 & & $\mathrm{CC}(\mathrm{N}=31)$ & CG $(N=88)$ & $G G(N=59)$ & & \\
\hline C18_1c11 & 0,064 & $0,8378 \pm 0,1039^{\mathrm{a}}$ & $0,6109 \pm 0,0717^{b}$ & $0,6753 \pm 0,0749^{\mathrm{ab}}$ & $-0,1456 \pm 0,0650(p=0,028)$ & $-0,1625 \pm 0,1109(p=0,147)$ \\
\hline EGD_PRE & 0,071 & $7,4159 \pm 0,2270^{a}$ & $6,8691 \pm 0,1449^{b}$ & $6,8520 \pm 0,1568^{b}$ & $-0,2648 \pm 0,1849(p=0,154)$ & $.0,5639 \pm 0,2723(p=0,040)$ \\
\hline rs111014258 & & $\mathrm{CC}(\mathrm{N}=31)$ & $\mathrm{CT}(\mathrm{N}=87)$ & TT $(\mathrm{N}=59)$ & & \\
\hline C18_1c11 & 0,074 & $0,8355 \pm 0,1043^{\mathrm{a}}$ & $0,6132 \pm 0,0718^{b}$ & $0,6770 \pm 0,0750^{b}$ & $-0,1430 \pm 0,0656(p=0,032)$ & $-0,1586 \pm 0,1118(p=0,160)$ \\
\hline EGD_PRE & 0,067 & $7,4131 \pm 0,2264$ & $6,8553 \pm 0,1447$ & $6,8509 \pm 0,1564$ & $-0,2767 \pm 0,1845(p=0,135)$ & $-0,5622 \pm 0,2715(p=0,040)$ \\
\hline
\end{tabular}

${ }^{1}$ En la misma fila, las medias de cuadrados mínimos con diferentes letras son significativamente diferentes de acuerdo al test de separación de medias de Bonferroni $(p<0,05)$.

${ }^{2}$ Estimada restando la media de soluciones para los genotipos homocigotas a la de los heterocigotas.

${ }^{3}$ Estimada por la diferencia entre los dos genotipos homocigotas.

Tabla 25. Medias de cuadrados mínimos de los valores de ácidos grasos y error estándar (ES) para las clases genotípicas de los polimorfismos rs41729173, rs110757796, rs110652478, rs110383592 y rs111014258 del gen bovino FABP4. N: número de muestras; C18:3c6912: contenido de ácido Ylinolénico; EGD_PRE: espesor de grasa dorsal pre-faena; C18:2t912: contenido de ácido linolelaídico; C20:3c81114: contenido de ácido eicosatriinoico; C18:0: contenido de ácido esteárico; C18:1c11: contenido de ácido vaccénico. 
5.5.5. Asociación de los SNPs del gen RXRA con caracteres de calidad de carne

Los SNPs rs209839910 y rs136289117 fueron descartados del análisis de asociación dado que presentaron una variabilidad muy baja. EI SNP rs133517803 mostró efectos significativos, sobre el contenido de ácido oleico $(\mathrm{C} 18: 1 \mathrm{c} 9, \mathrm{p}=0,008)$ y el contenido total de ácidos grasos monoinsaturados ( $A G M I, p=0,003$ ). La naturaleza del efecto (aditividad o dominancia) es difícil de determinar ya que ambas fueron significativas. También evidenció un efecto sugestivo y aditivo sobre el espesor de grasa dorsal del bife (EGD_BIFE, p=0,095). Por otro lado, el SNP rs207774429 presentó efectos significativos sobre los contenidos de ácido palmitoleico (C16:1, $p=$ 0,048), ácido esteárico $(C 18: 0, p=0,047)$ y ácido eicosenoico $(C 20: 1, p=0,002)$. Este último análisis debe ser interpretado con precaución debido a que la tipificación fue menos eficiente que en el resto de los casos y solo se utilizaron 92 muestras en el modelo. Ninguno de los dos SNPs superó el índice de significancia por el método de Benjamini y Hochberg (Tabla 26). 


\begin{tabular}{|c|c|c|c|c|c|c|}
\hline SNP/variable & Valor de $p$ & Medias de cua & drados mínimos de & los genotipos ${ }^{1}$ & Efecto de dominancia ${ }^{2}$ & Efecto aditivo $^{3}$ \\
\hline rs133517803 & & $A A(N=12)$ & $A G(N=78)$ & $G G(N=87)$ & & \\
\hline C18_1c9 & $0,008^{*}$ & $41,9457 \pm 0,6380^{\mathrm{a}}$ & $39,8402 \pm 0,2494^{b}$ & $39,9517 \pm 0,2530^{b}$ & $-1,1085 \pm 0,4101(p=0,008)$ & $-1,9940 \pm 0,6812(p=0,004)$ \\
\hline EGD_BIFE & 0,095 & $2,9100 \pm 0,3531$ & $3,4814 \pm 0,1445$ & $3,6832 \pm 0,1409$ & $0,1848 \pm 0,2153(p=0,392)$ & $0,7732 \pm 0,3647(p=0,035)$ \\
\hline rs207774429 & & $\mathrm{CC}(\mathrm{N}=34)$ & $\mathrm{CT}(\mathrm{N}=54)$ & $\mathrm{TT}(\mathrm{N}=4)$ & & \\
\hline C18_0 & $0,047^{*}$ & $13,8937 \pm 0,3394^{\mathrm{a}}$ & $14,9095 \pm 0,2406^{b}$ & $15,1817 \pm 0,8995^{\mathrm{ab}}$ & $0,3718 \pm 0,5259(p=0,483)$ & $1,2880 \pm 0,9815(p=0,196)$ \\
\hline C20_1 & $0,002^{*}$ & $0,0552 \pm 0,0094^{\mathrm{a}}$ & $0,0638 \pm 0,0067^{\mathrm{a}}$ & $0,1576 \pm 0,0250^{b}$ & $-0,0426 \pm 0,0146(p=0,005)$ & $0,1024 \pm 0,0273(p<0,001)$ \\
\hline
\end{tabular}

${ }^{1}$ En la misma fila, las medias de cuadrados mínimos con diferentes letras son significativamente diferentes de acuerdo al test de separación de medias de Bonferroni $(p<0,05)$.

${ }^{2}$ Estimada restando la media de soluciones para los genotipos homocigotas a la de los heterocigotas.

${ }^{3}$ Estimada por la diferencia entre los dos genotipos homocigotas.

Tabla 26. Medias de cuadrados mínimos de los valores de ácidos grasos y error estándar (ES) para las clases genotípicas de los polimorfismos rs133517803 y rs207774429 del gen bovino RXRA. N: número de muestras; C18:1c9: contenido de ácido oleico; AGMI: contenido total de ácidos grasos monoinsaturados; EGD_BIFE: espesor de grasa dorsal del bife; C16:1: contenido de ácido palmitoleico; C18:0: contenido de ácido esteárico; C20:1: contenido de ácido eicosenoico. 


\subsection{Análisis in sílicode los polimorfismos}

\subsubsection{Análisis in sílico de los polimorfismos del gen PPARG}

En la región UTR 5' de la isoforma 2 del gen PPARG se encontró el SNP rs207671117. Para analizar sus posibles efectos a nivel regulatorio-traduccional se realizó una búsqueda de sitios reconocidos por proteínas de unión a ARN a través de la base de datos RBPDB (RNA-Binding Proteins Database) con un umbral de 0,8 (Fig. 30). Si bien el SNP no se localizó sobre ninguno de los sitios de unión predichos, estaba ubicado a una base de distancia de un sitio de unión a la Proteína Fusionada en Sarcoma (FUS), una proteína de unión a ADN que jugaría un importante rol en el mantenimiento de la integridad genómica.

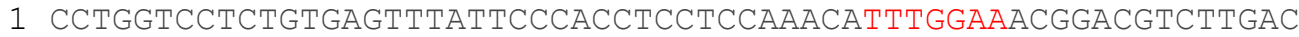 \\ 61 TCATTGGTGCGTTCCCAAGTTTAATGCCATGCATCTTTTTCTTTGAACGGAACTGGCCT}

\section{TTTGCAAGAAATAGACCAAATATCGGTGGGAGTCGTGGCAAATCCCTGTTCCGTGCTGTG}

Fig. 30. Secuencia UTR5' de la isoforma 2 de PPARG y algunos de sus sitios de unión a factores de unión a ARN (predichos por RBPDB, RNA-Binding Proteins Database, con umbral de score 0.8). El color rojo indica sitio de unión a EIF4-B (factor de iniciación de la traducción eucariota 4-B), el color violeta indica sitio de unión a FUS (proteína fusionada en sarcoma), el azul indica sitio de unión a YTHDC1 (proteína con dominio YTH 1) y el naranja sitio de unión a MBNL1 (muscleblind-like Drosophila), las cuales son proteínas reguladoras de splicing. Con color gris se indica un uORF presente en la secuencia.

Además, se realizó una búsqueda de marcos abiertos de lectura upstream (uORFs) que pudieran cumplir papeles regulatorios en la traducción y se encontró un uORF en la secuencia analizada. Sin embargo, el SNP rs207671117 no formaba parte de este motivo (Fig. 30). Luego, se analizó la estructura secundaria de la región UTR 5 ' por medio del Mfold Web Server (Zuker, 2003), para comprobar si el polimorfismo era parte de algún plegamiento de la molécula de ARN, y se observó que formaba parte de una estructura tipo hairpin (Fig. 31). El cambio G/A extendería un par de bases la región adyacente que no se encuentra hibridada, afectando tal vez la unión de factores regulatorios o la estabilidad de la molécula. 


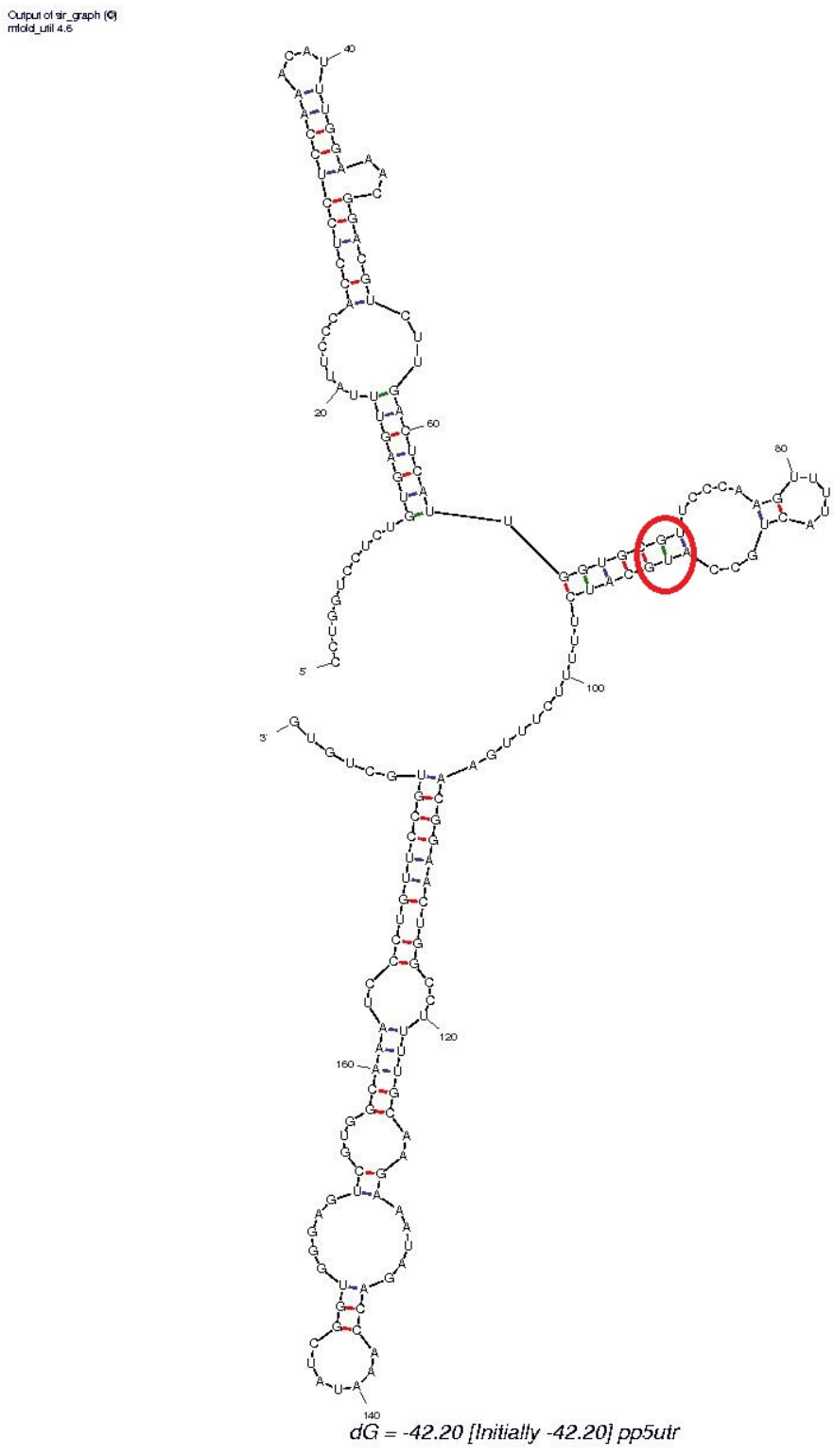

Fig. 31. Estructura secundaria de la región UTR $5^{\prime}$ de la isoforma 2 del gen bovino PPARG predicha con mfold Web Server. Con rojo se indica la localización del SNP rs207671117.

EI SNP rs42016945, que forma parte de la región UTR 5' de la isoforma 1 de PPARG, fue analizado de la misma manera que el rs207671117. La base de datos ENSEMBL dispone de dos transcriptos alternativos para la isoforma 1 del gen PPARG (ENSBTAT00000001760, ENSBTAT00000044042), las cuales difieren en las primeras bases de sus regiones UTR 5', por lo que ambas versiones fueron consideradas para el análisis del SNP (Fig. 32). Según RBPDB, ningún sitio de unión se localizaba sobre la posición del SNP, pero contiguo a él se encontró un sitio de unión a NONO (Non- 
POU domain-containing octamer-binding protein, SCORE=8,95), una proteína involucrada en numerosos procesos nucleares como el desenrollado, la recombinación, la unión de ADN y la regulación del splicing, entre otros.

1 CTTTACCTCCGCCGGTGATCAGAAGCCTGCGTCTCTAAATTCTTAAGTCCCCTTGCTTAG

61 TTGTTCAGGTTTGAAAGAAGCCACAACATACAACTCTAAGCCAGAGACATACAAGAGGGA

121 CGTTTCCGTAAACAAGTGTCATTCCTGAACAGTAGGTAAACT

1 AgAAgCCTGCGTCTCTAAATTCTTAAgTCCCCTTGCTTAGTTGTTCAgGTTTGAAAgAAG

61 CCACAACATACAACTCTAAGCCAGAGACATACAAGAGGGACGTTTCCGTAAACAAGTGTC

121 ATTCCTGAACAAAATTACC

Fig. 32. Secuencias UTR5' de la isoforma 1 de PPARG (ENSBTAT00000044042, arriba, y ENSBTAT00000001760, abajo) y algunos de los sitios de unión a factores de unión a ARN predichos por RBPDB, (RNA-Binding Proteins Database), con umbral de 0.8. Con color azul se indica un sitio de unión a ZRANB2 (SCORE $=10,30$ ), con naranja se indica un sitio de unión a NONO (SCORE $=8,95$ ), con rojo a RBMY1A1 (SCORE = 7,66 y 7,65), con violeta a FUS (SCORE = 7,37), con verde a MBNL1 (SCORE = $6,23)$.

Al analizar la estructura del fragmento UTR 5' del transcripto ENSBTAT00000044042, la plataforma mfold arrojó varias estructuras posibles, de manera que se continuó analizando la de menor energía libre $(-38.40 \mathrm{kcal} / \mathrm{mol})$. La posición del SNP sobre la estructura predicha se indica en la figura 33. En el caso del transcripto ENSBTAT00000001760, la plataforma arrojó dos estructuras, y también se tomó la de menor energía libre $(-27.70 \mathrm{kcal} / \mathrm{mol})$. La posición del SNP se indica en la figura 34. En ambas variantes el SNP parece formar parte de la misma estructura tipo hairpin. 


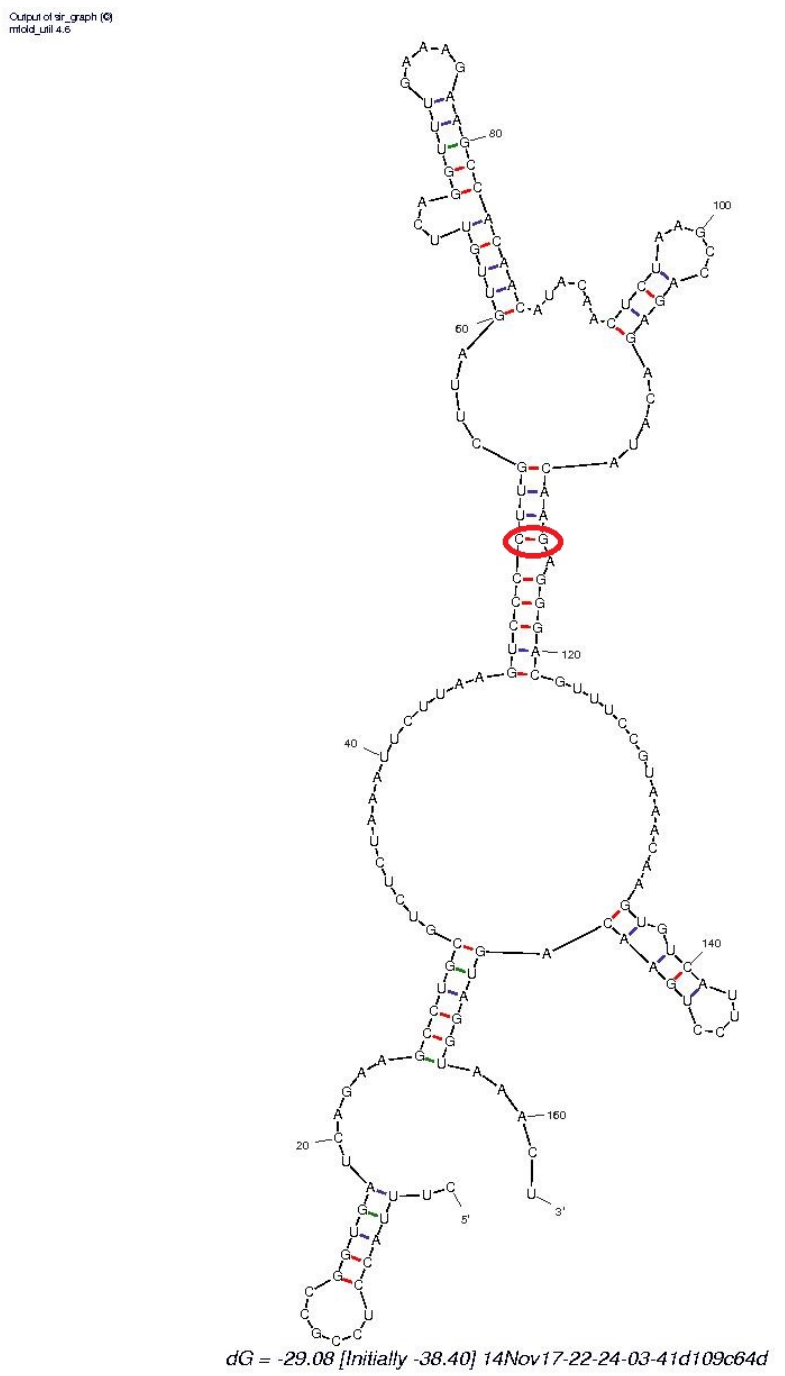

FIg. 33. Estructura secundaria de la región UTR 5' del transcripto ENSBTAT00000044042 de la isoforma 1 del gen bovino PPARG predicha con mfold Web Server. Con rojo se indica la localización del SNP rs42016945. 


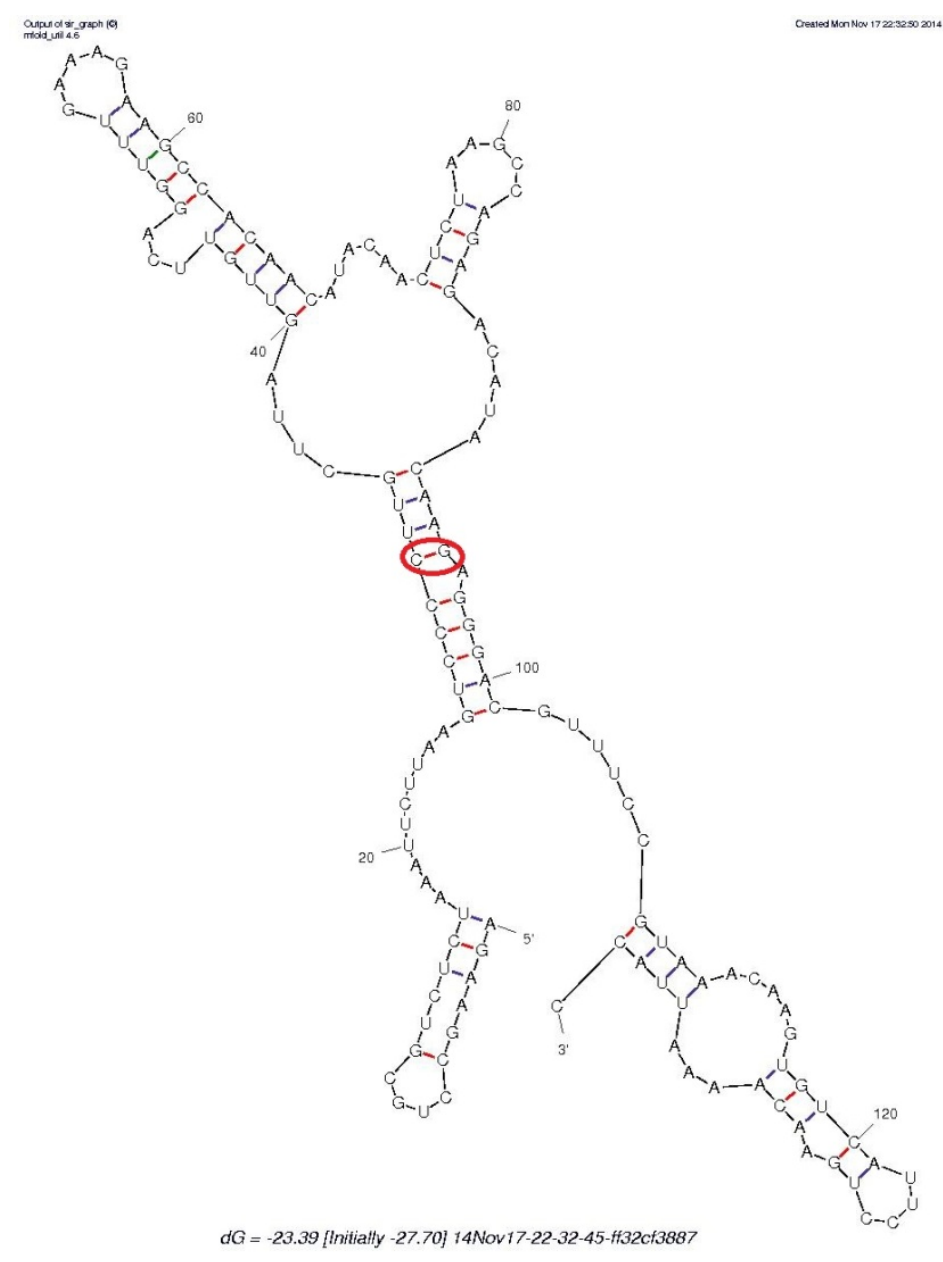

FIg. 34. Estructura secundaria de la región UTR 5' del transcripto ENSBTAT00000001760 de la isoforma 1 del gen bovino PPARG predicha con mfold Web Server. Con rojo se indica la localización del SNP rs42016945.

5.6.2. Análisis in sílico del polimorfismo del gen CEBPA

Para el gen CEBPA se realizó el análisis in sílico del SNP rs21044656, que causaba un cambio de alanina por glicina en la posición 198 de la proteína. A pesar de tratarse de dos residuos bastante similares, se analizaron los efectos del cambio aminoacídico sobre su estructura terciaria por medio de la aplicación HHPred (Söding et al., 2005). Desafortunadamente, los modelos disponibles (1jhb_A, 1gu4_A) para predecir la estructura eran del complejo CEBPB-ADN, los cuales abarcaban desde el residuo 265 al 352 (bZIP) y no incluían al residuo polimórfico. 
5.6.3. Análisis in sílico de los polimorfismos del gen LIPE

En el caso del gen LIPE, se intentó generar modelos estructurales de la enzima usando la aplicación HHPred para evaluar los efectos de los SNPs missense sobre la estructura proteica. Sin embargo, la disponibilidad limitada de estructuras homólogas resueltas no permitió un modelado confiable de las zonas en las que se encontraban los SNPs. Solo fue posible modelar el dominio catalítico (residuos 316-497, 620-756), el cual era compartido por varias esterasas y lipasas de otros organismos. La estructura 3D de este dominio fue predicha de manera constreñida usando el modelo 1jji_A, una Carboxilesterasa Hiper-termofílica de Archaeon Archaeoglobus fulgidus, la cual era la proteína homóloga más similar disponible en la base de datos (Fig. 35). El modelo consistió en un plegamiento $\alpha / \beta$ hidrolasa que consiste en ocho láminas $\beta$ rodeadas por a hélices y una cercanía particular entre los tres residuos catalíticos (Ser424, Asp692 and His722), la cual era el tipo de estructura esperada. Los SNPs missense que se intentaron analizar se encontraban en los bordes de las regiones homólogas, casi fuera del plegado. 

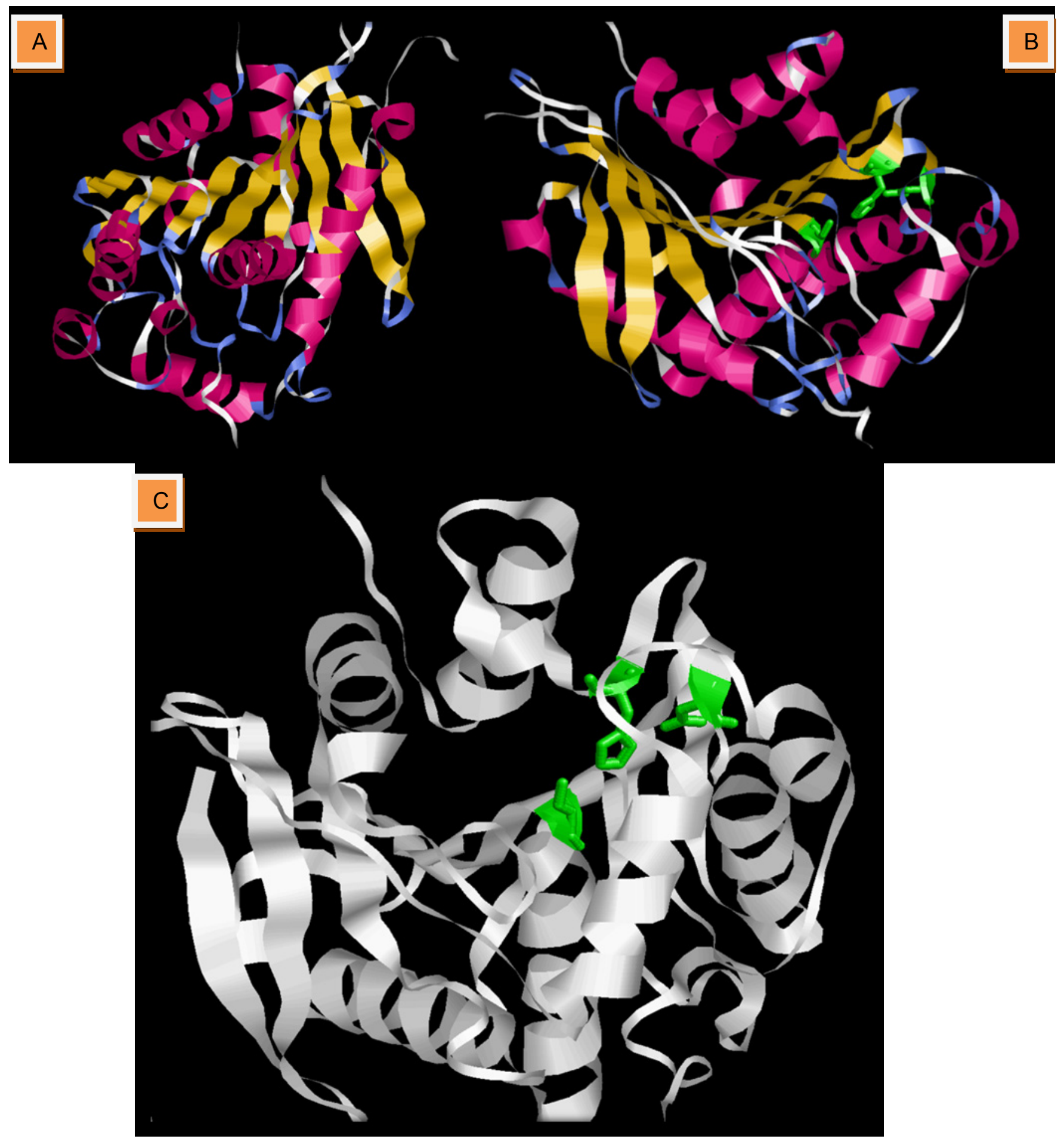

Fig. 35. Modelado molecular del dominio catalítico putativo de LIPE. (A) El modelo contiene los residuos 316-497 y 620-756, y muestra ocho láminas $\beta$ conectadas por $\alpha$-hélices, las cuales representan los elementos estructurales principales del plegamiento $\alpha$ / $\beta$ hidrolasa. (B) La triada de residuos catalíticos (coloreados con verde) ilustrados con palillos. (C) Vista alternativa de la triada catalítica coloreada con verde. 
5.6.4. Análisis in sílico de los polimorfismos del gen FABP4

Se predijo la estructura terciaria de la proteína bovina del gen FABP4 a partir de un modelo de alta resolución (1.4 Å) de FABP4 humana (3q6I_A). A partir de los modelos generados para las variantes polimórficas se analizó la conformación estructural. Se utilizó la opción "computar puentes de hidrógeno" del software SwissPdbViewer para comparar las posibles interacciones entre los residuos de la estructura.

EI SNP rs110652478 (Val110Met) causaba pequeños desplazamientos entre algunos residuos cercanos al SNP, como Asp112 y Lys113, con quienes interactúa por medio de uniones puente-hidrógeno (Fig. 36C). Este reordenamiento pareció originar un nuevo puente-hidrógeno entre los residuos Lys108 y Glu117 (Fig. 36A). Tambien se vieron pequeños cambios en la disposición de los residuos cercanos a Arg127, que cumple un rol fundamental en la estabilización del ligando. Por ejemplo, el grupo ceto del residuo Leu116 se vió desplazado 5,5 con respecto al grupo NH de Arg127 (Fig. 36B), con quien forma uniones puente-hidrógeno. A pesar de esta observación, lo más interesante es un cambio en la disposición de su cadena lateral, crucial en la unión del ligando ya que forma uniones puente-hidrógeno con el grupo polar del lípido (Fig. $36 \mathrm{C})$. 


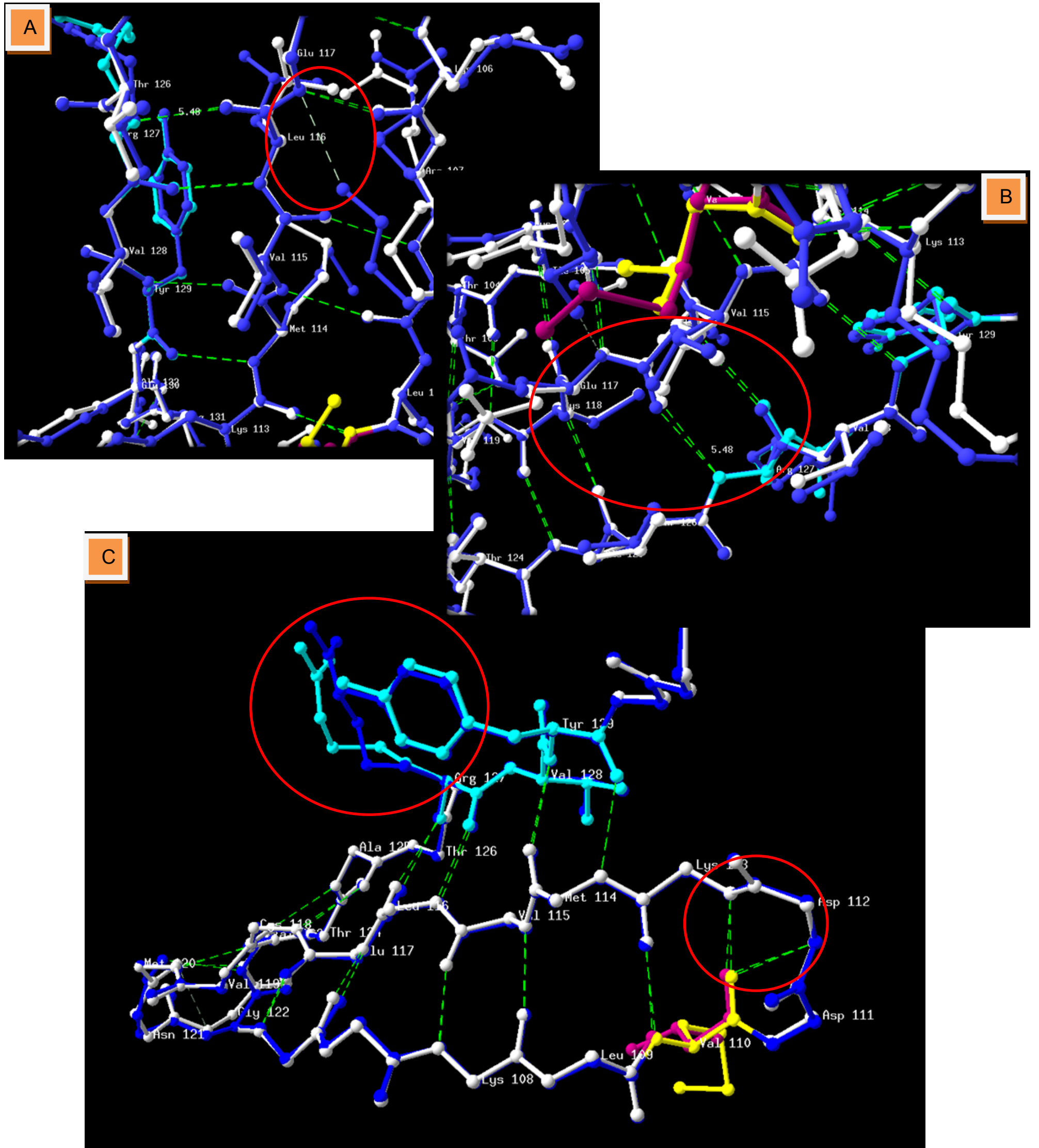

Fig. 36. Posibles efectos de la mutación rs110652478 (Val110Met) sobre la estructura proteica de FABP4, predicha a partir de la estructura de FABP4 humana por HHPred. Los residuos de unión a ligando se indican con color celeste y las uniones puente-H con verde. (A) Puente-H adicional entre la 
cadena lateral de Lys108 y Glu117. (B) Pequeños desplazamiento en las cercanías del residuo de unión a ligando Arg127. (C) Desplazamiento notorio de la cadena lateral de Arg127 y pequeños desplazamientos adyacentes a la mutación.

El SNP rs110757796 (lle74Val) involucraba residuos cuyas cadenas laterales se orientaban hacia la superficie de la molécula. Causaba pequeños desplazamientos en las cercanías del sitio mutado, los cuales causaban reordenamientos en las interacciones puente-hidrógeno entre los residuos. Esto se observó en las interacciones entre los residuos Thr75, Asp78 y Arg79, y entre las cadenas laterales de Asp77 y Arg79 (Fig. 37).Esta zona se encontraba involucrada en la interacción con la cola hidrofóbica de los ligandos en humanos por medio del residuo 76. Otro punto interesante es que el cambio de aminoácido pareció bloquear el sitio de unión al grupo carboxilo del ligando, acercando las cadenas laterales de Arg127 y Tyr129 y permitiendo una interacción puente-hidrógeno entre estos dos aminoácidos responsables de interactuar con el grupo polar del ligando (Fig. 38). Este bloqueo, sin embargo, no fue observado al considerar como modelo homólogo a la Proteína Periférica de Membrana P2 de la Mielina Humana (4bvm_A), la cual mostraba el score más alto (528.0) en el alineamiento de perfiles de Modelos Ocultos de Markov efectuado por la aplicación. 


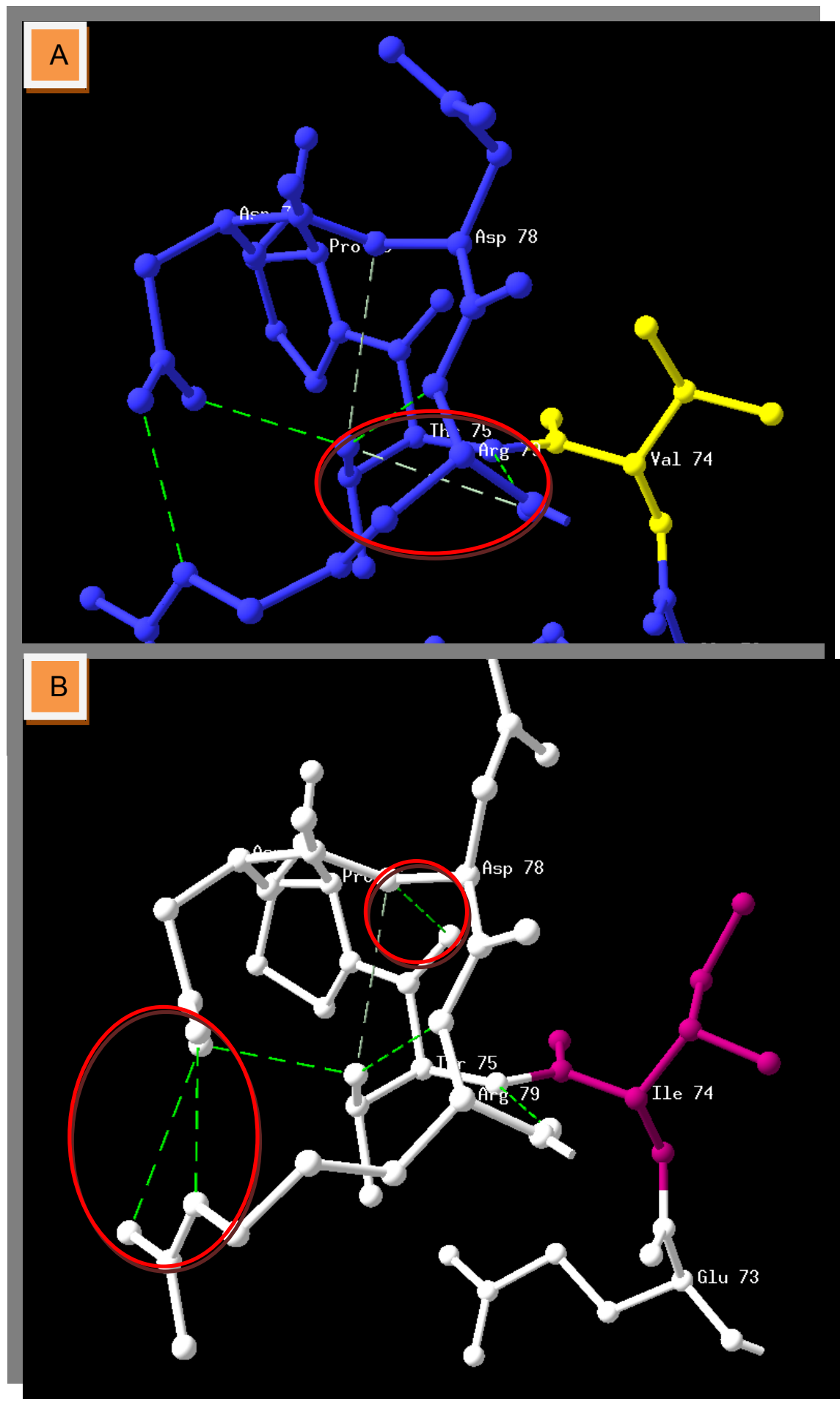

Fig. 37. Efectos de la mutación rs110757796 (lle74Val) sobre la estructura proteica de FABP4, predicha a partir de la estructura de FABP4 humana por HHPred. La cadena mutada (A) se indica con color azul, la normal (B) con blanco. El color verde indica las uniones puente-hidrógeno computadas por SwissPdbViewer. 


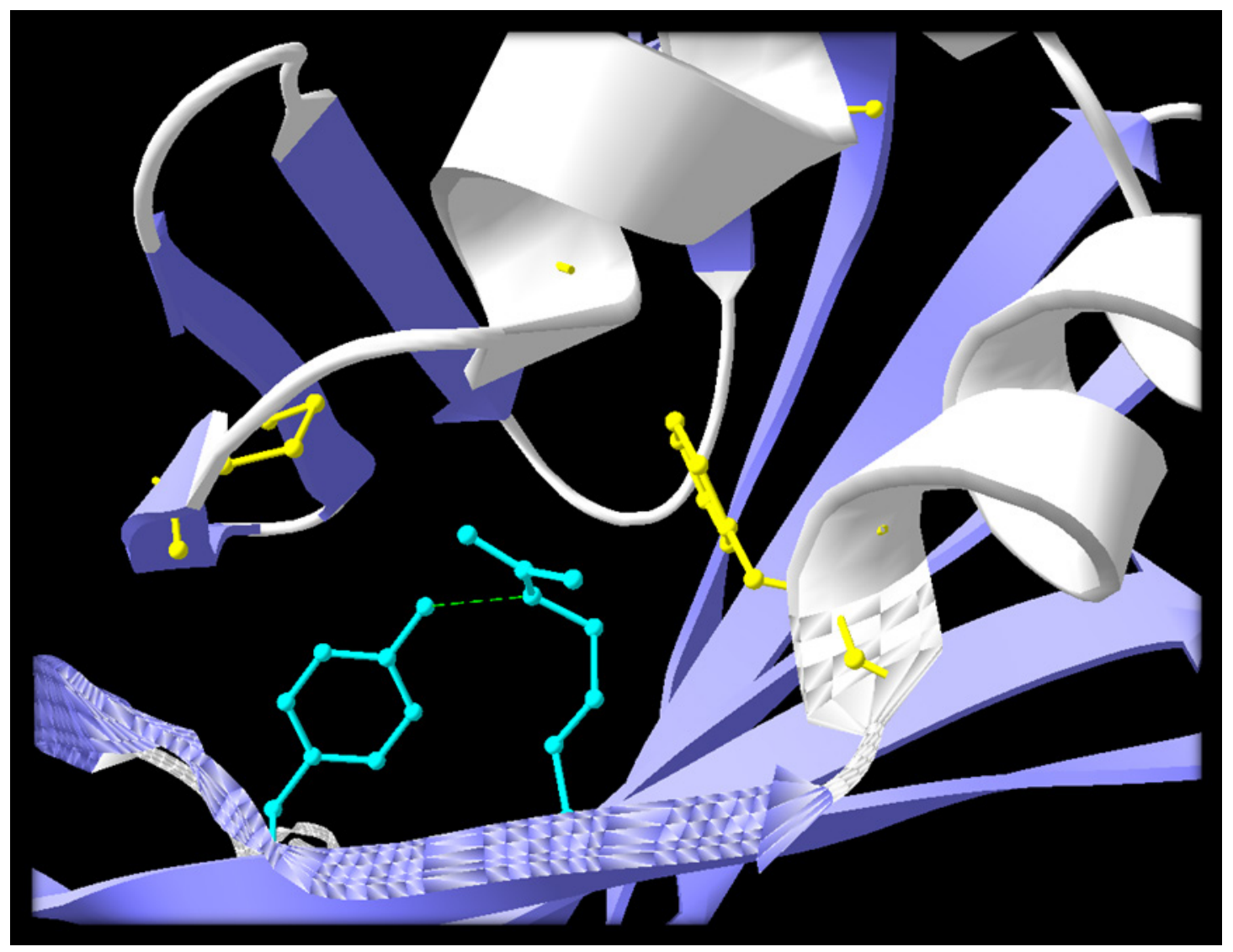

Fig. 38. Efectos de la mutación rs110757796 (lle74Val) sobre los aminoácidos de unión a ligando de FABP4, predicha a partir de la estructura de FABP4 humana por HHPred. Los residuos de unión a ligando se indican con color celeste y las uniones puente-H con verde. Desplazamiento de la cadena lateral de Arg127 (celeste) y bloqueo del sitio de unión a ligando por formación de un puente-H entre las cadenas laterales de Arg127 y Tyr129 (celeste). El color amarillo señala los residuos encargados de estabilizar la región hidrofóbica del ligando. 
El SNP rs110383592 se ubicó sobre la última base nucleotídica del exón 3, sobre la región de splicing y su carácter era sinónimo, ya que mantenía el residuo de leucina, y por este motivo no fue necesario realizar un análisis estructural. Lo que se analizó, en cambio, fue la frecuencia de codón en Bos taurus según la lista disponible en http://www.kazusa.or.jp/codon/cgi-bin/showcodon.cgi?species=9913. El codón original, CTG, presentó una frecuencia de 43,5 (por millar), mientras que el codón alternativo, СTC, contaba con una frecuencia de 21,2 (por millar). La frecuencia del nuevo codón fue sin duda menor a la del codón original.

Los SNPs restantes, rs111014258 y rs41729173, se localizaban en zonas no codificantes que carecían de roles claros, por lo que no fueron analizados.

\subsubsection{Análisis in sílico de los polimorfismos del gen $R X R A$}

Los SNPs rs133517803 y rs207774429 del gen $R X R A$ se ubicaban sobre una posible zona promotora alternativa, por lo que se realizó una búsqueda de zonas de unión a factores de transcripción a través de PhysBinder (Fig. 39). De acuerdo con esta herramienta, considerando todos los modelos humanos y murinos disponibles y la opción de umbrales "promedio", el polimorfismo rs133517803 se localizaba con un valor de umbral de 308 sobre un sitio de unión al factor de transcripción ESRRB, una proteína similar al receptor de estrógeno cuyo rol aún no está del todo claro.

EI SNP rs207774429 se localizaba con un umbral de 703 sobre un sitio de unión a TFAP2C, y con un umbral de 763 sobre un sitio de unión TFAP2A. Estos últimos dos son factores involucrados en varios procesos del desarrollo. También se observó, con umbral de 614, un posible sitio de unión a RUNX3, un factor que actúa como supresor de tumores. Los demás factores de transcripción analizados no fueron detectados sobre las posiciones de los SNPs. 


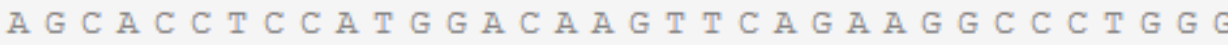
T GA A A G T C G G C T C T G G C CA A A T C G G G C C T G C C

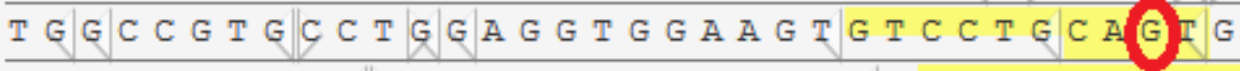
T G T C C C C A G G A C T G T T G G A C T G G T G A C C G A T E T

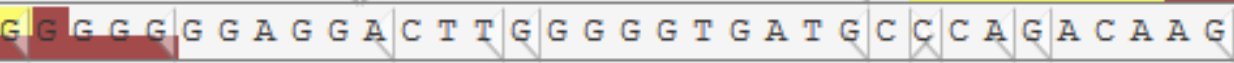
G C T T C T T C C T G T T C T GA G C C T G G C G C T C T G A C A C A G C T G C T G T C A G T T C G G C A C G C A A A T C C T C C T G G G T T G T T G G T C T CA A G C A G A T G T C T C C C CA A C C T G G G G T T T C T G G A G A G G T CA C T G C A T T G C A C C C C T G G C C T G $\mid$ C T C GA C T T G T CA A A A C T T \begin{tabular}{l|l|l|l|l|l|l|l|l|l|l|l|}
\hline &
\end{tabular}

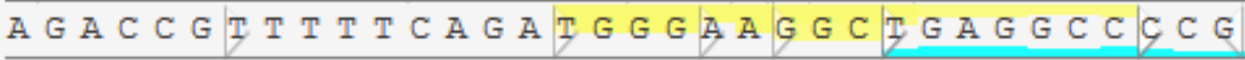
G G C G G G G T G G G G G G T G G G G T T C C T G|G T A T G C T C A G

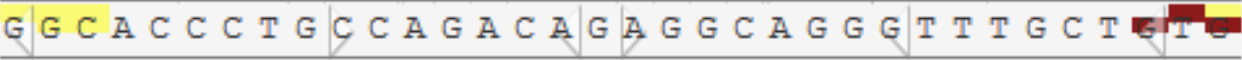
GCCTG C A G C T C T G G C T C C A G C G G C C G T G T T T G G

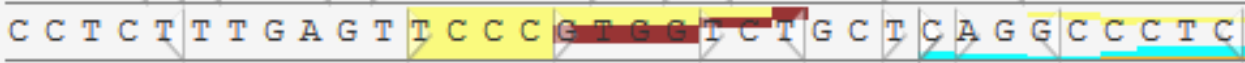
G G G C $\mid$ G $\mid$ G $|\subset| A|G| T \mid T$ T C A C C C C A G A G $A \mid G C$ C T T C C T C C T G TA A A G C T T C T C G C T GA G C C C T C G G G T G G G A

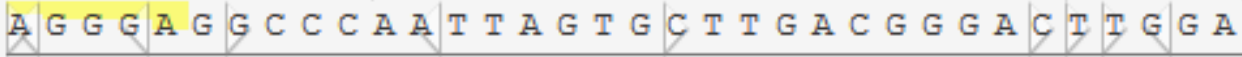
A A A C C C T G G G T GAAAGAC C G T G T G T G G C C G G G C C T C T C A C C G C A G C C T C T G TA G G C T G C C T

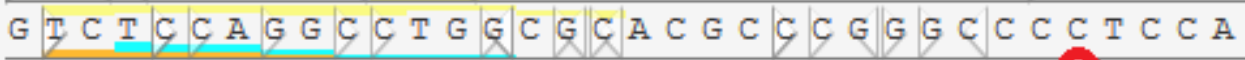
c C A G G C G C A

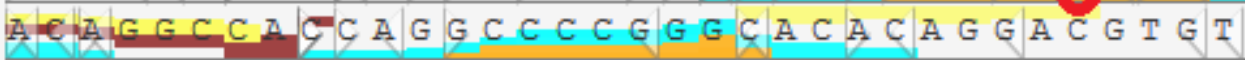
A C C T C T C CA A G C C C C G T G T G T T A G A G G G C C T G

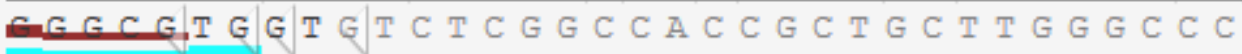
C T G A CA A C C T T T CGGTGTGCGGG

Fig. 39. Sitios de unión a los factores de transcripción ESRRB (amarillo), TFAP2A (celeste), TFAP2C (naranja) y RUNX3 (marrón) detectados en la región promotora de la variante 3 de RXRA. Las posiciones de los polimorfismos rs133517803 (arriba) y rs207774429 (abajo) se indican con círculos. 


\section{DISCUSION}

\subsection{Análisis de la variabilidad presente en los genes estudiados}

Los resultados obtenidos a partir de la re-secuenciación de los genes estudiados fueron diversos, mientras que algunos genes evidenciaron una variabilidad baja o moderada, otros resultaron ser altamente variables comparados con las medias reportadas en bovinos. Hace unos años, los resultados del Consorcio Bovino HapMap (Bovine HapMap Consortium 2009) expusieron una densidad de un SNP cada 714 pb para las razas Angus y Holstein, y de un SNP cada 285 pb para la raza Brahman. Además, solo el $22 \%$ de los SNPs detectados eran compartidos por ambas subespecies, y el $47,4 \%$ eran exclusivos de la raza Brahman.

En este trabajo se detectaron 7 SNPs en el gen PPARG, sobre una longitud analizada de aproximadamente 2.959 pb por animal, lo que resultó en la presencia de un SNP cada $423 \mathrm{pb}$ considerando todas las razas incluidas en el panel "A". Sin embargo, tres de los siete SNPs (43\%) fueron detectados solo en razas cebuinas, valor que coincide con los valores reportados anteriormente. El resultado, considerando la distribución, sería de un SNP cada 740 pb en Bos taurus y de un SNP cada $592 \mathrm{pb}$ en Bos indicus. Estos resultados evidenciaron que el gen PPARG presenta un grado de polimorfismo similar al promedio reportado para los bovinos (BovineHapMapConsortium, 2009).

El gen CEBPA presentó dos SNPs sobre un total de 852 pbanalizadas por animal, lo que se traduce en un SNP cada $426 \mathrm{pb}$. En este caso, uno de los dos SNPs se detectó principalmente en las muestras de razas cebuinas. Por lo tanto, si se considera cada tipo bovino en forma independiente, el gen CEBPA evidenció un SNP cada $852 \mathrm{pb}$ en taurinos y uno cada $426 \mathrm{pb}$ en razas cebuinas. Como en el caso anterior, los valores obtenidos se corresponden con los previamente reportados.

Con respecto al gen LIPE se detectaron 21 SNPs al analizar 2.600 pb por animal, lo que representaun SNP cada $123 \mathrm{pb}$. Cuando se consideró a $B$. taurus y $\mathrm{B}$. indicus en forma separada, se observó que los dos tipos bovinos presentaban valores similares de polimorfismos, con un SNP cada 200 pb en los primeros y uno cada 217 
pb en los cebuinos. Siete SNPs eran exclusivos de ganado cebuino. Los resultados obtenidos mostraron que el gen LIPE presentaría niveles de variabilidad genética superiores al observado para la especie, especialmente en las razas taurinas.

En el caso del gen bovino FABP4, se detectaron 22 mutaciones, lo cual redundóen la presencia de un SNP cada $144 \mathrm{pb}$ al analizar $3.164 \mathrm{pb}$. El alto nivel de variabilidad genética observado en este gen fue similar a la detectada para el gen LIPE. Los resultados obtenidos concuerdan con los reportados por Cho et al. (2007) que detectaron un total 15 SNPs analizando solo el ganado coreano. Cuando se evaluaron $B$. taurus y $B$. indicus en forma separada, se observó un SNP cada 151 pb en el grupo taurino y uno cada 452 pb en el índico. Ambos tipos compartían 7 de los 22 SNPs (32\%).

En conclusión, los estudios de re-secuenciación de genes involucrados en metabolismo lipídico estudiados en el presente trabajo permitieron detectar 52 polimorfismos al secuenciar un total de 9575 pb, lo que resultó en un promedio de un SNP cada 184 pb, variando entre uno en 123 y uno en 486 . Estos resultados son concordantes con los valores previamente reportados en la bibliografía. Por otra parte, la comparación del grado de polimorfismo entre los dos tipos bovinos mostró que las razas índicas evidenciaban mayor, o al menos igual, variabilidad que las taurinas, dependiendo del gen analizado.

Cabe mencionar que el hecho de que algunos polimorfismos no fueran detectados en ciertas razas no significa que no se encontraran presentes en las mismas, sino que no pudieron ser identificados. Este hecho sería consecuencia del bajo número de muestras empleadas en esta etapa del trabajo de Tesis, ya que en esta fase del estudio el objetivo no era validar SNPs, sino detectar variabilidad entre las razas. Por otra parte, las muestras de algunas razas fueron complicadas de amplificar y analizar, y varias de las secuencias obtenidas no alcanzaban la misma extensión, por este motivo no se las incluyó en las tablas. Lo mismo ocurre en sentido inverso, la detección de los SNPs en este estudio no garantiza que sean informativos en todas las razas, ya que en algunas de ellas podrían encontrarse en baja frecuencia o estar ausentes. Así, por ejemplo,en esta etapa de re-secuenciación no se detectó ninguna de las mutaciones 200 A>G (D7G, exón 1), 42895 C>T (sinónimo, exón 5) y 72472 G>T (Q448H, exón 7) del gen PPARG, reportadas por Fan et al. (2011) en razas chinas. Esto puede deberse a que estos polimorfismos se encuentren limitados principalmente a razas del extremo oriente. 
Los genes PPARG y CEBPA mostraron los menores valores de polimorfismo. El grado de conservación observado en estos genes parece estar de acuerdo con la importancia biológica que tienen como factores de transcripción y reguladores maestros de la adipogénesis. Ninguna mutación fue encontrada en las regiones de traducción de la proteína PPARG, y de las dos mutaciones detectadas en el gen CEBPA, solo una causaba un cambio aminoacídico. Por el contrario, en los genes $L I P E$ y $F A B P 4$, que codifican enzimas del metabolismo graso, la variabilidad fue más alta, tal vez por no tener un rol regulatorio del que dependan otros tantos procesos y por cumplir funciones más bien específicas dentro del organismo. Este hecho plantea una comparación interesante entre la conservación de factores reguladores primarios y la de enzimas con roles más específicos y compensables que podría ser abordada en mayor profundidad en el futuro.

La variabilidad genética detectada en los genes durante la etapa de resecuenciación se reflejó en la construcción de los haplotipos y bloques de ligamiento. En el caso de PPARG, las mutaciones detectadas presentaron frecuencias bajas, lo que originó grandes bloques de ligamiento y que pocos haplotipos llevaran casi toda la variabilidad. En el gen LIPE, por el contrario, los bloques de ligamiento fueron consistentes con un criterio de conservación inter-específico, el cual fue analizado por medio de alineamientos proteicos a la hora de seleccionar los SNPs para validación. Los tres bloques de ligamiento observados correspondían con los tres bloques conservados entre especies ( $\mathrm{N}, \mathrm{Ct}-1$ y Ct-2). El estudio del gen FABP4 evidenció una gran variabilidad que se puso de manifiesto mediante la presencia de pequeños bloques de ligamiento y numerosos haplotipos.

Los SNPs del gen CEBPA no fueron tipificados con eficiencia por la plataforma de Genotipificación SEQUENOM, el SNP rs110793792no pudo ser genotipado y el rs210446561 solo fue tipificado en la mitad de las muestras. Este gen también fue difícil de amplificar duranteel estudio de re-secuenciación, debido a la presencia de zonas ricas en GC que imposibilitaban una amplificación eficiente. Este inconveniente fue solucionado mediante el agregado de DMSO a la mezclade reacción. Sin embargo, es posible que estas zonas ricas en GC también hayan interferido con el proceso de genotipificaciónmediante la técnica espectrometría de masa utilizada por la plataforma SEQUENOM.

Los SNPs rs136289117 y rs209839910 del gen RXRA, presentaron una variabilidad muy pequeña y ausencia de variabilidad en ciertos grupos poblacionales. 
Tres de los cuatro SNPs tipificados para este gen formaban parte de un bloque de ligamiento, el cual estaba constituido por tres haplotipos.

Algunos de los SNPs seleccionados para los estudios poblacionales desafortunadamente presentaron una pequeña o ninguna variabilidad en las razas analizadas. Así fue el caso del SNP rs109613657 (PPARG), el cual no presentó variabilidad. Este SNP, elegido entre los reportados en SNPdb y analizado previamente por Fan et al. (2012), contaba con siete observaciones que seguramente correspondían a razas bovinas de otras regiones geográficas. Es difícil saber con certeza en qué razas se observaron esas mutaciones ya que muy pocos remitentes a las bases de datos públicas (por ejemplo, SNPdb) adjuntan la información metodológica completa, como ser la raza analizada, en sus reportes.

En cuanto a las mutaciones que fueron genotipadas eficientemente mediante espectrometría de masa, las frecuencias génicas fueron muy diversas en los diferentes grupos genéticos. En la mayoría de los casos, y como era de esperarse, los valores más diferentes se observaron en la subpoblación LX. Esto coincide con el origen histórico y las características productivas de las tres razas involucradas, mientras que Angus y Hereford provienen de Escocia, Limousin es una raza europea continental.

Cuando se analizó el equilibrio de Hardy-Weinberg se observaron desviaciones significativas de las proporciones teóricas en algunas subpoblaciones. Así fue el caso de los marcadores rs42016945 (PPARG) en la subpoblación LX; rs110652478 (FABP4) en las subpoblaciones $\mathrm{H}, 75 \mathrm{H}, 50 \mathrm{AH}, \mathrm{LX}$ y en la población global; rs110757796 (FABP4) en la subpoblación 50AH; rs2077744429 (RXRA) en la subpoblación $50 \mathrm{AH}$ y en la población global; rs133517803 en la subpoblación 75A. Como era de esperar, la mayoría de los desequilibrios se observaron en los grupos cruza. Además, la presencia de desequilibrio sugeriría la violación de alguno/s de los supuestos de la ley y la existencia de fenómenos como el emparejamiento selectivo, pequeño tamaño poblacional, endogamia y sobre todo migración, teniendo en cuenta el propósito original de la población, que era el de evaluar sistemas de cruza en pasturas con suplementación estratégica.

Los análisis de ligamiento y los haplotipos estuvieron de acuerdo con la composición de la población, ya que a pesar de seguir siendo una mezcla, estaba conformada por tres razas relativamente cercanas desde el punto de vista evolutivo. Por este motivo se obtuvieron grandes bloques de ligamiento con haplotipos muy comunes y otros en muy baja frecuencia. 


\subsection{Asociación entre los SNPs seleccionados con caracteres de calidad de carne y estudios de predicción}

Con el fin deevaluar el efecto de las variantes genéticas seleccionadas sobre caracteres de engrasamiento de la población correspondiente al panel "B", se llevaron a cabo estudios de asociación con variables de contenido y composición grasa. Al estudiar las asociaciones de los marcadores genéticos a nivel individual, el SNP rs207671117 del gen PPARG mostró efectos significativos sobre los contenidos de ácido linoleico, ácido eicosatriinoico y ácidos grasos Omega-6. Por otra parte, se detectaron efectos sugestivos $(p<0,1)$ sobre los contenidos de ácido araquidónico y ácidos grasos polinsaturados totales. El SNP rs42016945 evidenció un efecto significativo sobre el contenido de ácido vaccénico y un efecto sugestivo sobre el contenido de ácido miristoleico, pero ninguno de estos efectos fue significativo luego de aplicar el FDR para controlar los rechazos falsos de hipótesis nulas debidos a comparaciones múltiples. Las posibles asociaciones iniciales del SNP rs42016945 mostraron un efecto aditivo para el contenido de ácido miristoleico $(p<0,05)$ y un efecto de dominancia para el contenido de ácido vaccénico $(p<0,05)$ en las pruebas de contraste. Por el contrario, no se observaron asociaciones con espesor de grasa dorsal, como las reportadas por Fan et al. (2012) en razas chinas, ni con marmoleo.

Las causas de las asociaciones observadas con contenido graso pueden ser varias, dado que PPARG es un factor de transcripción involucrado en la regulación del inicio de los procesos de diferenciación adipocítica y deposición de ácidos grasos, regulando la expresión de todo un grupo de genes involucrado en el metabolismo lipídico (Fig. 2). Dado que los SNPs del PPARG que evidenciaban asociaciones significativas se localizaban en la región UTR5' del gen, estos cambios nucleotídicos podrían modificar la estabilidad del ARNm por alteraciones en el plegado de la molécula o cambios en la afinidad por ciertos factores proteicos de unión a ARN, o simplemente encontrarse en desequilibrio de ligamiento con otras mutaciones no detectadas.

Cualquier cambio que se produzca sobre una molécula tan importante para el metabolismo como PPARG, por pequeño que sea, podría desencadenar efectos notables sobre la expresión de los genes involucrados posteriormente en las rutas metabólicas, como por ejemplo FABP4. Esta hipótesis fue analizada en la etapa de predicción de efectos mediante el uso de herramientas bioinformáticas. Los análisis 
mostraron que las mutaciones se encontraban sobre posibles sitios de unión a factores proteicos y en medio de estructuras tipo hebilla o "hairpin" de la región UTR5' del ARNm.

En el caso del gen CEBPA, la mutación genotipificada evidenció inicialmente un efecto significativo sobre el contenido de ácido eicosatriinoico, pero no alcanzó el umbral de significancia de FDR para comparaciones múltiples. La mutación en cuestión, el SNP rs210446561, causa un cambio de alanina por glicina, dos residuos de cadena lateral pequeña y similar. Como se mencionó anteriormente, y al igual que para el gen PPARG, cada pequeño cambio encontrado en los reguladores maestros de la adipogénesis, como son estos dos genes, que a su vez participan en muchas otras rutas regulatorias del organismo, puede ser importante y es digno de ser estudiado en mayor profundidad. Sin embargo, las técnicas utilizadas en el presente trabajo no dieron buenos resultados para las mutaciones de este gen y la información obtenida fue bastante limitada. Sumada a la pobre eficiencia de la genotipificación poblacional para las dos mutaciones elegidas, se encuentra la escasez de modelos proteicos disponibles que hubieran permitido analizar los efectos a nivel estructural de las mutaciones, razón por la cual no pudo evaluarse la base molecular de la asociación.

Al analizar las mutaciones del gen LIPE a nivel individual, el SNP rs109759779 mostró asociaciones significativas con los contenidos de ácido oleico y ácidos grasos monoinsaturados totales. Los SNPs rs109598915 y rs41887406, que se encontraban ligados, evidenciaron una asociación significativa con el contenido de ácido heneicosílico y una asociación sugestiva con el contenido total de ácidos grasos monoinsaturados. Sin embargo, como en los casos anteriores, ninguno de ellos fue significativo al aplicar el ajuste para comparaciones múltiples. Estas asociaciones iniciales mostraron efectos de dominancia $(p<0,05)$ en las pruebas de contraste, por lo que los genotipos homocigotas y heterocigotas de ciertos alelos parecían comportarse diferente al otro genotipo homocigota. La dominancia es común entre las enzimas, ya que muchas de ellas ejercen sus roles dentro de rutas metabólicas que proveen ciertos márgenes de acción dependiendo de los equilibrios de otras reacciones paralelas y de la disponibilidad de sustrato, de manera que pequeños incrementos en la actividad, causados por genotipos heterocigotas, podrían ser suficientes para saturar las reacciones. En el caso de LIPE, se pueden imaginar varios escenarios en los que la enzima afecte la acumulación de ácido oleico, los ácidos grasos monoinsaturados y el ácido heneicosílico. Estudios previos han reportado que el ácido oleico es esterificado mayormente en las posiciones sn-2 y sn-3 de la molécula de 
glicerol en ganado bovino, mientras que el ácido heneicosílico es esterificado en las posiciones sn-1 y sn-3. Como LIPE hidroliza la posición sn-3 de los diglicéridos (Rodriguezet al., 2010; Eichmannet al., 2012), un simple incremento de la actividad podría afectar a ambos ácidos grasos ya que una gran proporción de ambos se localiza en sn-3. Además, LIPE puede también hidrolizar en sn-1 en menor medida, por lo que los ácidos grasos en sn-2 podrían acumularse gradualmente. Las tasas y la cinética de la hidrólisis de triglicéridos por la enzima ATGL y la re-esterificación desde diglicéridos por DGAT1 y DGAT2 también deberían ser consideradas. El escenario real podría ser mucho más complejo y se requiere un número mayor de estudios para dilucidar completamente los procesos por los cuales los SNPs localizados en las enzimas de esta ruta podrían afectar la regulación de ácidos grasos.

Otros polimorfismos de LIPE han sido asociados previamente con composición lipídica en ganado bovino (Fang et al., 2013), principalmente el rs41887407. Los individuos homocigotas CC para este polimorfismo fueron asociados con mayor contenido de ácido araquídico, dohono-c-Linoleénico y eicosanoico en bife $(p<0,05)$. Este SNP se encuentra a solo 170 pb del SNP rs41887406 que se analizó en este trabajo, el que presentó una asociación significativa con el contenido de ácido heneicosílico y una asociación sugestiva con el contenido total de ácidos grasos monoinsaturados. Dado que LIPE está involucrado directamente en la lipólisis, es de esperarse que los cambios estructurales en la enzima modifiquen la composición de ácidos grasos en los tejidos. Estos cambios estructurales podrían reflejarse en la estereo/regioselectividad de la enzima, los procesos de activación o inhibición, y/o la estabilidad. EI SNP rs109759779, en cambio, era sinónimo, y modificó la frecuencia de codón de 20,4 (por millar) para CCC a 14,6 para CCA, de acuerdo a los datos disponibles en http://www.kazusa.or.jp/codon/cgi-bin/showcodon.cgi?species=9913. Se ha propuesto que los cambios en las frecuencias de codones afectarían el tiempo de plegado pos-traduccional de las proteínas (Kimchi-Sarfatyet al., 2007), especialmente en haplotipos de SNPs sinónimos que disminuyen las frecuencias de codón. Esto podría contribuir a explicar los efectos causados por el SNP rs109759779 en las variables estudiadas de contenido lipídico. Los cambios estructurales en las proximidades del SNP podrían afectar varias de las características como ser la selectividad de sustrato o la unión a otras proteínas como FABP4, que interactúa con LIPE a través el dominio N-terminal y reduce el efecto de inhibición por producto (Shen et al., 2001). Los SNPs rs109598915 y rs41887406 eran de carácter missense, pero sus efectos no pudieron ser evaluados por modelado estructural. Esto ocurrió debido a que desafortunadamente no había estructuras homólogas disponibles que permitieran 
el modelado de las regiones particulares donde se encontraban los SNPs, que flanqueaban las estructuras disponibles del dominio catalítico.

Los polimorfismos del gen FABP4 también evidenciaron asociaciones aparentemente significativas con varias mediciones en primera instancia, pero no superaron el índice de significancia de FDR. Los resultados obtenidos estuvieron parcialmente de acuerdo conlos reportados por otros autores. El SNP rs41729173 (región downstream), había sido asociado por Michal et al. (2006) con marmoleo y grasa subcutánea en cruzas F2 Wagyu-Limousin, pero esta asociación no fue detectada en la población de este trabajo. Por el contrario, este polimorfismo se asoció con contenido de ácido y-linolénico. El SNP rs110757796 había sido asociado a espesor de grasa dorsal por Cho et al. (2007) y este resultado si se repitió en este trabajo, pero la asociación con contenidos de ácidos palmítico y palmitoleico reportadas por Hoashi et al. (2008) y Narukami et al. (2011) no fueron observadas. Sin embargo, se observó una asociación conotro componente graso, el ácido linolelaídico. El SNP rs110652478, que había sido asociado por varios autores con marmoleo en ganado coreano y japonés, no se comportó de la misma manera en la población analizada en el presente trabajo, sin embargo, se observaron asociaciones con variables de composición lipídica (ácido linolelaídico, ácido eicosatriinoico yácido esteárico). Tampoco se observó la asociación reportada con marmoleo del SNP rs110383592 (Hoashi et al., 2008; Barendse et al., 2009), pero por el contrario, este polimorfismo mostró efectos sugestivos sobre el contenido de ácido vaccénico y el espesor de grasa dorsal pre-faena. Cabe destacar que este SNP, rs110383592, se encontró ligado al SNP rs111014258, el cual había sido asociado previamente a espesor de grasa dorsal en ganado coreano por Cho et al. (2008). Los resultados observados para los SNPs rs110383592 y rs110652478 deben ser tomados con cuidado debido a la baja variabilidad mostrada en la población, ya que solo se detectaron unos pocos individuos con las variantes genotípicas alternativas. Las diferencias entre los reportes previos y los resultados obtenidos podrían deberse a diferencias raciales, ambientales entre las poblaciones analizadas, los diseños experimentales y la forma en que se definieron y evaluaron las variables.

Dos de las mutaciones analizadas en el gen FABP4 causaban cambios de aminoácido en el dominio de unión a ligando de la proteína, por lo que se las analizó por medio de modelado estructural. Mediante este análisis se observó que además de causar pequeños cambios en la disposición de residuos en las cercanías del sitio mutado, ambas mutaciones podían desplazar la cadena lateral del aminoácido Arg127, el cual desempeña un rol de unión al grupo carboxílico del ligando por medio de 
uniones puente de hidrógeno (Fig.40). Al desplazarse la cadena lateral, la afinidad por el ácido palmítico y otros ligandos podría verse afectada, sobre todo si sucede algo similar a lo predicho para la mutación rs110757796 (I74V), donde los aminoácidos Arg127 y Tyr129 pasaban a formar puentes de hidrógeno entre sí, dificultando la estabilización del grupo polar del lípido en la enzima. Esto es consistente con los resultados obtenidos por Hoashi et al. (2008) y Narukami et al. (2011), quienes reportaron asociaciones entre este SNP y el contenido de ácido palmítico y palmitoleico particularmente, por lo que los análisis bioinformáticos realizados en el presente trabajo podrían ayudar a explicar dichos resultados.

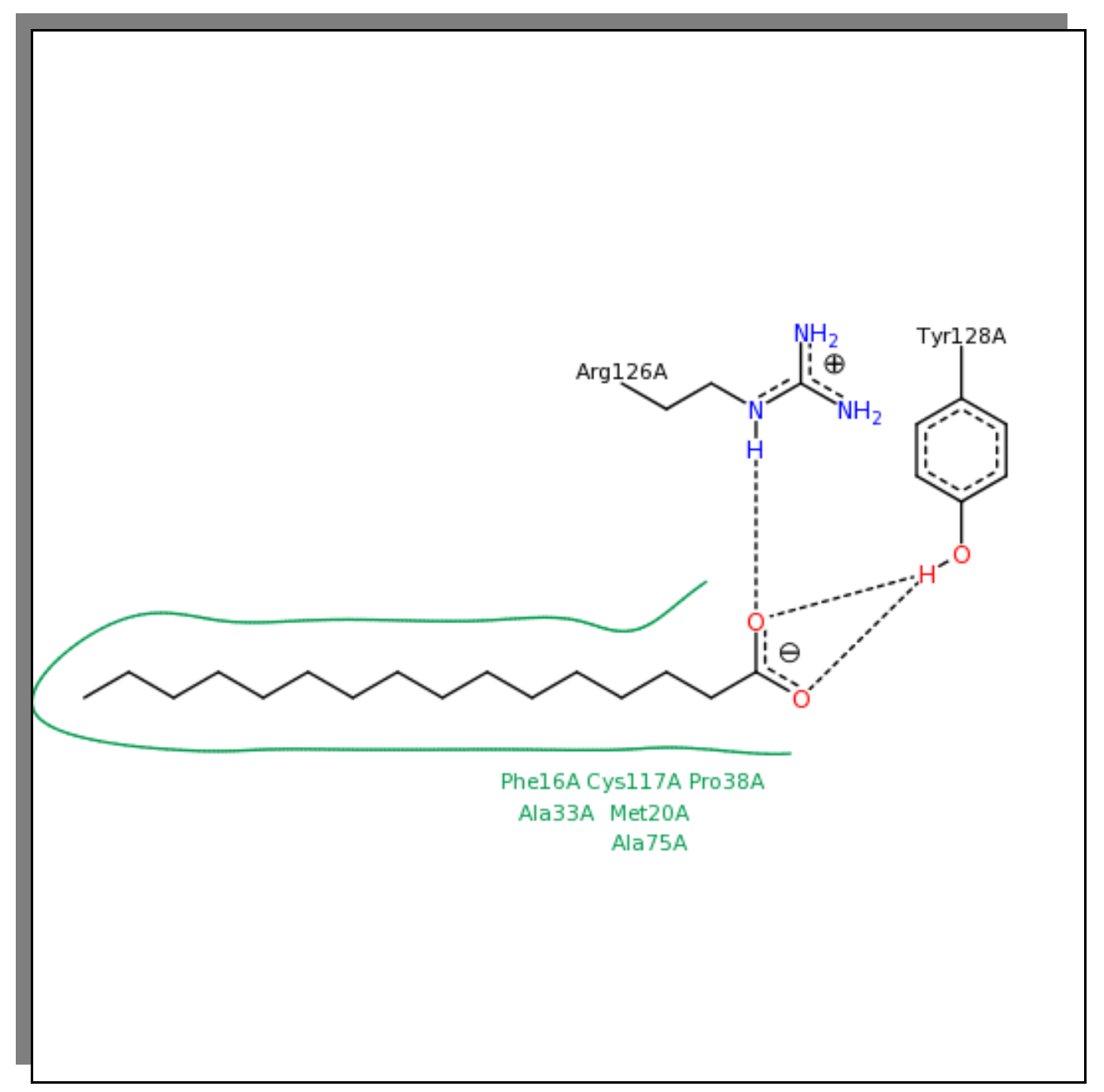

Fig. 40. Representación de la interacción entre los residuos de FABP4 y el ácido palmítico en humanos. La cabeza polar del ácido palmítico interactúa por puentes de hidrógeno con los residuos Arg126 y Tyr128, mientras que la cola hidrocarbonada es estabilizada por uniones hidrofóbicas con otros residuos, entre los que se encuentran Phe16, Cys117, Pro38, Ala33, Met20, Ala75. (Tomada de Protein Data Bank, estructura $2 \mathrm{HNX}$ ) 
Las mutaciones detectadas en elgen RXRA se localizaban en una zona promotora putativa, y según el análisis de predicción se ubicaban sobre posibles sitios de unión a factores de transcripción involucrados en muchos procesos del desarrollo, algo interesante considerando la naturaleza y el rol de RXRA en el organismo. Las variaciones en los niveles de expresión de este gen podrían afectar la expresión de otros genes corriente abajo en la cadena de señales, dado que actúa como heterodímero de PPARG. Al no existir reportes previos de asociación para este gen con caracteres productivos, los resultados obtenidos representan la evidencia de que las mutaciones en este gen podrían servir para el mejoramiento animal a través de programas de selección asistidas por marcadores genéticos (MAS).

En resumen, las asociaciones observadas entre los marcadores de genéticos y las variables de contenido y composición lipídica podrían ser consecuencia, según el tipo y localización del SNP, de diferentes mecanismos, tales como cambios en la estructura tridimensional de la proteína, en los niveles de expresión por mutaciones en sitios de unión a factores de transcripción en las regiones promotoras, en las frecuencias de codones, en la estabilidad del ARNm por alteraciones en el plegado de la molécula, en la afinidad por ciertos factores proteicos de unión a ARN por mutaciones en la regiones UTR, entre otros. Por otra parte, según la función del producto del gen (regulatoria, enzimática) los cambios evaluados tendrían herencias de tipo codominante o dominante. 


\section{CONCLUSIONES}

Los estudios de caracterización genética de genes candidatos mediante la estrategia de re-secuenciación, la validación de SNPs a nivel poblacional, estudios de asociación entre marcadores genéticos y caracteres de contenido y composición lipídica y los análisis predictivos realizados en el presente trabajo de Tesis Doctoral derivaron en las siguientes conclusiones:

a. Los estudios de caracterización de la variabilidad genética mediante re-secuenciación permitieron identificar 10 SNPs inéditos para la especie bovina, uno de ellos perteneciente al gen CEBPA, cinco al gen LIPE y cuatro al gen FABP4. Estos resultados evidencian que a pesar de los estudios de secuenciación masiva que se han llevado a cabo en la especie bovina, la estrategia utilizada aún permite la detección de nueva variabilidad genética.

b. Los genes reguladores maestros (PPARG y CEBPA) presentaron valores de variabilidad menores a los detectados en genes (LIPE y FABP4) con funciones más específicas (transporte y degradación de lípidos) dentro del metabolismo lipídico.

c. Las razas cebuinas mostraron niveles de polimorfismos mayor o igual al observado en las taurinas, siendo este resultado coincidente con lo publicado previamente.

d. Varios de los SNPs detectados fueron validados en una población Angus, Hereford y cruza.

e. Los estudios de asociación sugirieron posibles efectos de los genotipos de los genes PPARG, CEBPA, RXRA, LIPE y FABP4 sobre diferentes variables de contenido y composición lipídica. A pesar que algunas de estas asociaciones coinciden con estudios previos, los resultados obtenidos deberán ser confirmados mediante el análisis de poblaciones independientes para que puedan ser utilizados en programas de selección asistida por marcadores genéticos.

f. Sobre la base de la ubicación de los SNPs, el tipo de cambio ocasionado y de los resultados de los análisis predictivos se puede plantear que las diferentes asociaciones detectadas podrían ser consecuencia de diferentes mecanismos, tales como cambios en los niveles de expresión, modificaciones estructurales o en la afinidad por otros factores proteicos, cambios en la estabilidad de ARNm, entre otros. 


\section{REFERENCIAS}

AGRE, P.; JOHNSON, P. F.; MCKNIGHT, S. L. 1989. Cognate DNA binding specificity retained after leucine zipper exchange between GCN4 and C/EBP. Science 246, 922-926.

ALFAIA, C.; ALVES, S.; MARTINS, S.; COSTA, A.; FONTES, C.; LEMOS, J.; BESSA, R.; PRATE, J. 2009. Effect of the feeding system on intramuscular fatty acids and conjugated linoleic acid isomers of beef cattle, with emphasis on their nutritional value and discriminatory ability. Food Chem. 114, 939-946.

ANTHONSEN, M. W.; RÖNNSTRAND, L.; WERNSTEDT, C.; DEGERMAN, E.; HOLM, C. 1998. Identification of novel phosphorylation sites in hormone-sensitive lipase that are phosphorylated in response to isoproterenol and govern activation properties in vitro. J. Biol. Chem. 273, 215-221.

BARENDSE, W. 1999. Assessing lipid metabolism. International patent application PCT/AU98/00882, international patent publication WO 99/23248.

BARENDSE, W. 2011. Haplotype Analysis Improved Evidence for Candidate Genes for Intramuscular Fat Percentage from a Genome Wide Association Study of Cattle. PLoS ONE 6(12), e29601.

BARENDSE, W.; BUNCH, R. J.; HARRISON, B. E. 2009. Variation at CPE but not CEBPA appears to be associated with intramuscular fat deposition in the longissimus muscle of cattle. Anim Prod Sci 49, 558-562.

BARENDSE, W.; BUNCH, R.; HARRISON, B. E.; THOMAS, M. B. 2006. The growth hormone $1 \mathrm{GH} 1: \mathrm{c} .457 \mathrm{C}>\mathrm{G}$ mutation is associated with intramuscular and rump fat distribution in a large sample of Australian feedlot cattle. Animal Genetics 37 (3), 211-214.

BARENDSE, W.; BUNCH, R.; THOMAS, M.; ARMITAGE, S.; BAUD, S.; DONALDSON, N. 2004. The TG5 thyroglobulin gene test for a marbling quantitative trait loci evaluated in feedlot cattle. Aust J Exp Agric 44(7), 669- 674.

BARKHOUSE K. L., VAN VLECK L. D., CUNDIFF L. V., KOOHMARALE M., LUNSTRA D. D., CROUSE J. D. 1996. Prediction of breeding values for tenderness of market animals from measurements on bulls. J. Anim. Sci. 74, 2612-2621. 
BARRETT, J. C.; FRY, B.; MALLER, J.; DALY, M. J. 2005. Haploview: analysis and visualization of LD and haplotype maps. Bioinformatics 21, 263-265.

BELFRAGE, P.; JERGIL, B.; STRALFORS, P.; TORNQVIS, T. H. 1978. Identification and some characteristics of the enzyme protein of the hormone-sensitive lipase from rat adipose tissue. Adv Exp Med Biol 101, 113-126.

BEN ALI, Y.; CHAHINIAN, H.; PETRY, S.; MULLER, G.; CARRIĖRE, F.; VERGER, R.; ABOUSALHAM, A. 2004. Might the kinetic behavior of hormonesensitive lipase reflect the absence of the lid domain? Biochemistry 43(29), 92989306.

BENJAMINI, Y.; HOCHBERG, Y. 1995. Controlling the false discovery rate: a practical and powerful approach to multiple testing. J. Roy. Stat. Soc. Ser. B 57, 289300.

BENYSHEK L. L., COMERFORD J. W., LITTLE D. E., LUDWIG C. 1988. Estimates of carcass genetic parameters from Hereford field data. J. Anim. Sci. 66 (Suppl. 1), 10 (Abstract).

BERGER, J.; MOLLER, D. E. 2002. The mechanisms of action of PPARs. Annu. Rev. Med. 53, 409-435.

BEUZEN, N.D.; STEAR, M.J.; CHANG, K.C. 2000. Molecular markers and their use in animal breeding. Vet. J. 160, 42-52.

BOLDMAN, K. G.; KRIESE,L. A.; VAN VLECK, L. D.; VAN TASSEL, L. A.; KACHMAN, S. D. 1993. A Manual for Use of MTDFREML, a Set of Programs to Obtain Estimates of Variance and Covariances. USDA, ARS, Washington, DC.

BUCHANAN, F. C.; FITZSIMMONS, C. J.; VAN KESSEL, A. G.; THUE, T. D.; WINKELMAN -SIM, D. C.; SCHMUTZ, S. M. 2002. Association of a missense mutation in the bovine leptin gene with carcass fat content and leptin mRNA levels. Genetics Selection Evolution 34 (1), 105-116.

CAO, Z.; UMEK, R. M.; MCKNIGHT, S. L. 1991. Regulated expression of three C/EBP isoforms during adipose conversion of 3T3-L1 cells. Genes Dev. 5, 1538-1552.

CARRILLO, C.; CAVIA, M. M.; ALONSO-TORRE, S. R. 2012. Antitumor effect of oleic acid; mechanisms of action: a review. Nutr hosp 27, 1860-1865. 
CASAS, E.; SHACKELFORD, S.D.; KEELE, J.W.; KOOHMARAIE, M.; SMITH, T.P.L.; STONE, R.T. 2003. Detection of quantitative trait loci for growth and carcass composition in cattle. J. Anim. Sci. 81: 2976-2983.

CASAS, E.; WHITE, S.N.; RILEY, D.G.; SMITH, T.P.L.; BRENNEMAN, R.A.; OLSON, T.A.; JOHNSON, D.D.; COLEMAN, S.W.; BENNETT, G.L.; CHASE JR.; C.C. 2005. Assessment of single nucleotide polymorphisms in genes residing on chromosomes 14 and 29 for association with carcass composition traits in Bos indicus cattle. J. Anim. Sci. 83, 13-19.

CASAS, E.; WHITE, S. N.; SHACKELFORD, S. D., WHEELER, T. L., KOOHMARAIE, M.; BENNETT, G. L.; SMITH, T. P. 2007. Assessing the association of single nucleotide polymorphisms at the thyroglobulin gene with carcass traits in beef cattle. J. Anim. Sci. 85(11), 2807-14.

CATTLE QTLdb (Cattle Quantitative Trait Locus Database). 2014. <http://www.animalgenome.org/cgi-bin/QTLdb/BT/index>

CHAMBON, P. 1996. A decade of molecular biology of retinoic acid receptors. FASEB J. 10, 940-954.

CHANDRA, V.; HUANG, P.; HAMURO, Y.; RAGHURAM, S.; WANG, Y.; BURRIS, T. P.; RASTINEJAD, F. 2008. Structure of the intact PPAR-gamma-RXR nuclear receptor complex on DNA. Nature 456, 350-356.

CHO, S.; PARK, T. S.; YOON, D. H.; CHEONG, H. S.; NAMGOONG, S.;PARK, B. L.; LEE, H. W.; HAN, C. S.; KIM, E. M.; CHEONG, I. C.; KIM, H.; SHIN, H. D. 2008. Identification of genetic polymorphisms in FABP3 and FABP4 and putative association with back fat thickness in Korean native cattle. BMB Reports 41, 29-34.

CICCRA. 2014. Informe económico mensual. Documento № 163-Agosto 2014. http://www.ipcva.com.ar/files/ciccra/ciccra_2014_08.pdf

CONTRERAS, J. A.; KARLSSON, M.; OSTERLUND, T.; LAURELL, H.; SVENSSON, A.; HOLM, C. 1996. Hormone-sensitive lipase is structurally related to acetylcholinesterase, bile salt-stimulated lipase, and several fungal lipases. J. Biol. Chem. 271, 31426-31430.

CRAWFORD, D. C.; BHANGALE, T.; LI, N.; HELLENTHAL, G.; RIEDER, M. J.; NICKERSON, D. A.; STEPHENS, M. 2004. Evidence for substantial fine-scale variation in recombination rates across the human genome. Nat. Genet. 36, $700-706$. 
DALEY, C.; ABBOTT, A.; DOYLE, P.S.; NADER, G.A.; LARSON, S. 2010. A review of fatty acid profiles and antioxidant content in grass-fed and grain-fed beef. Nutr. J. 9, 10-22.

DAMCOTT, C.M.; MOFFETT, S.P.; FEINGOLD, E.; BARMADA, M.M.; MARSHALL, J. A.; HAMMAN, R. F.; FERRELL, R. E. 2004. Genetic variation in fatty acid-binding protein-4 and peroxisome proliferator-activated receptor gamma interactively influence insulin sensitivity and body composition in males. Metabolism 53, $303-309$.

DEKKERS, J.C.M. 2004. Commercial application of marker and gene assisted selection in livestock: Strategies and lessons. J. Anim. Sci. 82, 313-328.

DEVITT, C. J. B.; WILTON, J. W. 2001. Genetic correlation estimates between ultrasound measurements on yearling bulls and carcass measurements on finished stears. J. Anim. Sci. 79, 2790-2797.

EDWARDS, I. J.; O'FLAHERTY, J. T. 2008. Omega-3 fatty acids and PPARY in cancer. PPAR Research, 1-14.

EGGEN, A.; HOCQUETTE, J-F. 2003. Genomic approaches to economic trait loci and tissue expression profiling: application to muscle biochemistry and beef quality. Meat Sci. 66, 1-9.

EICHMANN, T. O.; KUMARI, M.; HAAS, J. T.; FARESE JR, R. V.; ZIMMERMANN, R.; LASS, A.; ZECHNER, R. 2012. Stereo/Regioselectivity of Adipose Triglyceride Lipase, Hormone-sensitive Lipase, and Diacylglycerol-O-acyltransferases. J. Biol. Chem. 287, 41446-41457.

ESCHER, P.; WAHLI, W. 2000. Peroxisome proliferator-activated receptors: insight into multiple cellular functions. Mutat. Res. 448, 121-138.

EVANS, R. M.; BARISH, G. D.; WANG, Y. X. 2004. PPARs and the complex journey to obesity. Nat. Med. 10, 355-361.

EYNARD, A.R. 2006. Effects of milk and beef lipids on human health. Rev. Arg. Prod. Anim. 26, 169-177.

FAN, Y. Y.; ZAN, L. S.; FU, C. Z.; TIAN, W. Q.; WANG, H. B.; LIU, Y. Y.; XIN, Y. P. 2011. Three novel SNPs in the coding region of PPARY gene and their associations with meat quality traits in cattle. Mol Biol Rep. 38(1), 131-137. 
FANG, X. B.; ZHANG, L. P.; YU, X. Z.; LI, J. Y.; LU, C. Y.; ZHAO, Z. H.; YANG, R. J. 2013. Association of LIPE gene E1-C.276C>T and E8-C.51C>T mutation with economical traits of Chinese Simmental cattle. Mol Biol Rep 41 (1), 105-112.

FAO. 2013. The State of Food and Agriculture 2013: Food systems for better nutrition. Organización de las naciones unidas para la agricultura y la alimentación. <http://www.fao.org/docrep/018/i3300e/i3300e.pdf>

FERNANDES, T. L.; WILTON, J. W.; MANDEL, L. B.; DEVITT, C. J. B. 2002. Genetic parameter estimates for meat quality traits in beef cattle managed under a constant finishing program. In: proceedings of the 7th World Congress on Genetics Applied to Livestock Production. August 19-23, 2002. Montpellier, france, session 02. Breeding rumiants for meat production. Communication No. 02-93.

FERNYHOUGH, M. E.; OKINE, E.; HAUSMAN, G.; VIERCK, J. L.; DODSON, M. V. 2007. PPARY and GLUT-4 expression as developmental regulators/markers for preadipocyte differentiation into an adipocyte. Domest. Anim. Endocrinol. 33, 367378.

FIEMS, L.O.; DE CAMPENEERE, S.; DE SMET, S.; VAN DE VOORDE, G.; VANACKER, J.M.; BOUCQUÉ, C.V. 2000. Relationship between fat depots in carcasses of beef bulls and effect on meat colour and tenderness. Meat Sci. 56(1), 4147.

FOLCH, J.; LEES, M.; SLOANE-STANLEY, H. 1957 - "A simple method for the isolation andpurification of total lipids from animal tissuee". J. Biol. Chem. 226, 497509.

FORMAN, B. M.; TONTONOZ, P.; CHEN, J.; BRUN, R. P.; SPIEGELMAN, B. M.; EVANS, R. M. 1995. 15-Deoxy-delta12,14-prostaglandin J2 is a ligand for the adipocyte determination factor PPAR gamma. Cell 83, 803-812.

FREDRIKSON, G.; STRÅLFORS, P.; NILSSON, N. O.; BELFRAGE, P. 1981. Hormone-sensitive lipase of rat apidose tissue. Purification and some properties. J. Biol.Chem. 256(12), 6311-6320.

FREDRIKSON, G.; TORNQVIST, H.; BELFRAGE, P. 1986. Hormone-sensitive lipase and monoacylglycerol lipase areboth required for complete degradation of adipocyte triacylglycerol. Biochim. Biophys. Acta 876(2), 288-293. 
FROHNERT, B. I.; HUI, T. Y.; BERNLOHR, D. A. 1999. Identification of a functional peroxisome proliferator-responsive element in the murine fatty acid transport protein gene. J. Biol. Chem. 274, 3970-3977.

FURUHASHI, M.; HOTAMISLIGIL, G. S. 2008. Fatty acid-binding proteins: role in metabolic diseases and potential as drug targets. Nat Rev Drug Discov. 7(6), 489503.

GAMPE, R. T. JR; MONTANA, V. G.; LAMBERT, M. H.; MILLER, A. B.; BLEDSOE, R. K.; MILBURN, M. V.; KLIEWER, S. A.; WILLSON, T. M.; XU, H. E. 2000. Asymmetry in the PPARgamma/RXRalpha crystal structure reveals the molecular basis of heterodimerization among nuclear receptors. Mol. Cell. 5, 545-555.

GARCÍA, P.; PENSEL, N.; SANCHO, A.; LATIMORI, N.; KLOSTER, A.; AMIGONE, M.; CASAL, J. 2008. Beef lipids in relation to animal breed and nutrition in Argentina. Meat Sci. 79, 500-508.

GEORGE, M.H. 2001. Managing cattle feeding programs for marbling. Marbling Symposium 2001. pp. 125-128.

GRANT, A. C.; ORTIZ-COLON, G.; DOUMIT, M. E.; BUSKIRK, D. D. 2008. Optimization of in vitro conditions for bovine subcutaneous and intramuscular preadipocyte differentiation. J Anim Sci. 86(1), 73-82.

GREGOIRE, F. M.; SMAS, C. M.; SUL, H. S. 1998. Understanding adipocyte differentiation. Physiol Rev. 78(3), 783-809.

GREGORY, K. E.; CUNDIFF, L. V.; KOCH, R. M. 1995. Genetic and phenotypic (co)variances for growth and carcass traits of purebred and composite populations of beef cattle. Genet. Sel. Evol. 19, 225-248.

GUAN, H. P.; ISHIZUKA, T.; CHUI, P. C.; LEHRKE, M.; LAZAR, M. A. 2005. Corepressors selectively control the transcriptional activity of PPARgamma in adipocytes. Genes Dev. 19, 453-461.

GUEX, N.; PEITSCH, M.C. 1997. SWISS-MODEL and the Swiss-PdbViewer: An environment for comparative protein modeling. Electrophoresis 18, 2714-2723.

HAEMMERLE, G; ZIMMERMANN, R.; HAYN, M.; THEUSSL, C.; WAEG, G.; WAGNER, E.; SATTLER, W.; MAGIN, T. M.; WAGNER, E. F.; ZECHNER, R. 2002. 
Hormone-sensitive lipase deficiency in mice causes diglyceride accumulation in adipose tissue, muscle, and testis. J. Biol. Chem. 277(7), 4806-4815.

HANSON, R. W. 1998. Biological role of the isoforms of C/EBP minireview series. J. Biol. Chem. 273(44), 28543.

HAUSMAN, G. J.; DODSON, M. V.; AJUWON, K.; AZAIN, M.; BARNES, K. M.; GUAN, L. L.; JIANG, Z.; POULOS, S. P.; SAINZ, R. D.; SMITH, S.; SPURLOCK, M.; NOVAKOFSKI, J.; FERNYHOUGH, M. E. BERGEN, W. G. 2009. The biology and regulation of preadipocytes and adipocytes in meat animals. J Anim Sci, 87, 1218-1246.

HE, H.;LIU, X.;GU, Y.;LIU, Y.;YANG, J. 2011. Effect of genetic variation of CEBPA gene on body measurement and carcass traits of Qinchuan cattle. Mol Biol Rep 38, 4965-4969.

HENKE, B. R.; BLANCHARD, S. G.; BRACKEEN, M. F.; BROWN, K. K.; COBB, J. E.; COLLINS, J. L.; HARRINGTON, W. W. JR; HASHIM, M. A.; HULLRYDE, E. A.; KALDOR, I.;KLIEWER, S. A.; LAKE, D. H.; LEESNITZER, L. M.; LEHMANN, J. M.; LENHARD, J. M.; ORBAND-MILLER, L. A.; MILLER, J. F.; MOOK, R. A. JR; NOBLE, S. A.; OLIVER, W. JR; PARKS, D. J.; PLUNKET, K. D.; SZEWCZYK, J. R.; WILLSON, T. M. 1998. N-(2-Benzoylphenyl)-L-tyrosine PPARgamma agonists. 1. Discovery of a novel series of potent antihyperglycemic and antihyperlipidemic agents. J. Med. Chem. 41:5020-5036.

HERMO, L.; CHUNG, S.; GREGORY, M.; SMITH, C. E.; WANG, S. P.; ELALFY, M.; CYR, D. G.; MITCHELL, G. A.; TRASLER, J. 2008. Alterations in the testis of hormone sensitive lipase-deficient mice is associated with decreased sperm counts, sperm motility, and fertility. Mol Reprod Dev. 75(4), 565-577.

HERTZEL, A. V.; BERNLOHR, D. A. 2000. The mammalian fatty acid-binding multigene family: molecular and genetic insights into function. Trends Endocrinol. Metab. 11, 175-180.

HOASHI, S.; HINENOYA, T.; TANAKA, A.; OHSAKI, H.; SASAZAKI, S.; TANIGUCHI, M.; OYAMA, K.; MUKAI, F.; MANNEN, H. 2008. Association between fatty acid compositions and genotypes of FABP4 and LXR-alpha in Japanese Black cattle. BMC Genetics 9, 84-90. 
HOCQUETTE, J.; RENAND, G.; LEVÉZIEL, H.; PICARD, B.; CASSAR-MALEK, I. 2006. The potential benefits of genetics and genomics to improve beef quality - a review. Animal Sci. Papers Rep. 24(3), 173-189.

HOLM, C. 2003. Molecular mechanisms regulating hormone-sensitive lipase and lipolysis. Biochem. Soc. Trans. 31(Pt 6), 1120-1124.

HOOGHE, B.; BROOS, S.; VAN ROY, F.; DE BLESER, P. 2012. A flexible integrative approach based on random forest improves prediction of transcription factor binding sites. Nucleic Acids Res., 40:e106

HUERTA-LEIDENZ, N. O.; CROSS, H. R.; SAVELL, J. W.; LUNT, D. K.; BAKER, J. F.; SMITH, S. B. 1996. Fatty acid composition of subcutaneous adipose tissue from male calves at different stages of growth. J. Anim. Sci. 74, 1256-1264.

HURST, H. C. 1995. Transcription factors 1: bZIP proteins. Protein Profile 2, 101-168

IPCVA. 2011. Evaluacion de los beneficios potenciales de la producción de carne de alta calidad con terneros macho de razas lecheras. Cuadernillo Técnico $\mathrm{N}^{\circ}$ 10. <http://www.ipcva.com.ar/files/ct10.pdf> [consulta: 04 Junio 2013]

ISSEMANN, I.; GREEN, S. 1990. Activation of a member of the steroid hormone receptor superfamily by peroxisome proliferators. Nature 347, 645-650.

ITOH, T.; YAMAMOTO, K. 2008. Peroxisome proliferator activated receptor gamma and oxidized docosahexaenoic acids as new class of ligand. Naunyn Schmiedebergs Arch. Pharmacol. 377, 541-547

JENKINS, C. M.; MANCUSO, D.J.; YAN, W.; SIMS, H.F.; GIBSON, B.; GROSS, R.W. 2004. Identification, cloning, expression, and puri fication of three novel human calcium-independent phospholipase A2 family members possessing triacylglycerol lipase and acylglycerol transacylase activities. J. Biol. Chem. 279, 48968-48975.

KAIKAUS, R. M.; BASS, N. M.; OCKNER, R. K. 1990. Function of fatty acid binding proteins. Experientia 46, 617-630.

KELLY, M.J.; TUME, R.K.; NEWMAN, S.; THOMPSON, J.M. 2013. Genetic variation in fatty acid composition of subcutaneous fat in cattle. Anim. Prod. Sci. 53, 129-133. 
KEMP, D. J.; HERRING, W. O.; KAISER, C. J. 2002. Genetic and environmental parameters for steer ultrasound and carcass traits. J. Anim. Sci. 80, 1489-1496.

KHORASANIZADEH, S.; RASTINEJAD, F. 2001. Nuclear-receptor interactions on DNA-response elements. Trends Biochem. Sci. 26, 384-390.

KIMCHI-SARFATY, C.; OH, J. M.; KIM, I. W.; SAUNA, Z. E.; CALCAGNO, A. M.; AMBUDKAR, S. V.; GOTTESMAN, M. M. 2007. A "silent" polymorphism in the MDR1 gene changes substrate specificity. Science $315,525-528$.

KOKTA,T. A.; DODSON, M. V.; GERTLER, A.; HILL, R. A. 2004. Intercellular signaling between adipose tissue and muscle tissue. Domest. Anim. Endocrinol. 27, 303-331.

KRAEMER, F. B.; SHEN, W. J. 2002. Hormone-sensitive lipase: control of intracellular tri-(di)acylglycerol andcholesteryl ester hydrolysis. J. Lipid Res 43(10), 1585-1594.

KRAFT, J.; KRAMER, J.; SCHOENE, F.; CHAMBERS, J.; JAHREIS, G. 2008. Extensive analysis of Long-chain polyunsaturated fatty acids, CLA, trans-18:1 isomers, and plasmalogenic lipids in different retail beef types. J. Agr. Food Chem. 56, 47754782.

KREY, G.; BRAISSANT, O.; L'HORSET, F.; KALKHOVEN, E.; PERROUD, M.; PARKER, M. G.; WAHLI, W. 1997. Fatty acids, eicosanoids, and hypolipidemic agents identified as ligands of peroxisome proliferator-activated receptors by coactivatordependent receptor ligand assay. Mol. Endocrinol. 11, 779-791.

LAMB, M. A.; ROBISON, O. W.; TESS, M.W. 1990. Genetic parameters for carcass traits in Hereford bulls. J. Anim. Sci. 68, 64-69.

LAMPIDONIS, A. D.; ROGDAKIS, E.; VOUTSINAS, G. E.; STRAVOPODIS, D J. 2011. The resurgence of Hormone-Sensitive Lipase (HSL) in mammalian lipolysis. Gene 477(1-2), 1-11.

LANDSCHULZ, W. H.; JOHNSON, P. F.; MCKNIGHT, S. L. 1989. The DNA binding domain of the rat liver nuclear protein C/EBP is bipartite. Science 243,1681 1688. 
LARKIN, M. A.; BLACKSHIELDS, G.; BROWN, N. P.; CHENNA, R.; MCGETTIGAN, P. A.; MCWILLIAM, H.; VALENTIN, F.; WALLACE, I. M.; WILM, A.; LOPEZ, R.; THOMPSON, J. D.; GIBSON, T. J.; HIGGINS, D. G. 2007. Clustal W and Clustal X version 2.0.Bioinformatics 23, 2947-2948.

LAWLESS, F.; STANTON, C.; L'ESCOP, P.; DEVRY, R.; DILLON, P.; MURPHY, J.J. 1999. Influence of breed on bovine milk cis-9, trans-11-conjugated linoleic acid content. Livest. Prod. Sci. 130, 2285-2291.

LEE, J. W.; CHOI, S. B.; KIM, J. S.; KEOWN, J. F.; VAN VLECK, L. D. 2000. Parameter estimates for genetic effects on carcass traits of Korean native cattle. J. Anim. Sci. 78, 1181-1190.

LEE, S. H.; VAN DER WERF, J. H. J.; PARK, E. W.; OH, S. J.; GIBSON, J. P.; THOMPSON, J. M. 2010. Genetic polymorphisms of the bovine fatty acid binding protein 4 gene are significantly associated with marbling and carcass weight in Hanwoo (Korean Cattle). Anim. Genet. 41(4), 442-444.

LEFTEROVA, M. I.; ZHANG, Y.; STEGER, D. J.; SCHUPP, M.; SCHUG, J.; CRISTANCHO, A.; FENG, D.; ZHUO, D.; STOECKERT, C. J. JR, LIU, X. S.; LAZAR, M. A.2008. PPARgamma and C/EBP factors orchestrate adipocyte biology via adjacent binding on a genome-wide scale. Genes Dev. 22(21), 2941-2952.

LEHMANN, J. M.; MOORE, L. B.; SMITH-OLIVER, T. A.; WILKISON, W. O.; WILLSON, T. M.; KLIEWER, S. A. 1995. An antidiabetic thiazolidinedione is a high affinity ligand for peroxisome proliferator-activated receptor gamma (PPAR gamma). J. Biol. Chem. 270, 12953-12956.

LEI, M. G.; WU, Z. F.; DENG, C. Y.; DAI, L. H.; ZHANG, Z. B.; XIONG, Y. Z. 2005. Sequence and polymorphism analysis of porcine hormone-sensitive lipase gene 5'-UTR and exon I. Yi Chuan Xue Bao 32(4), 354-359.

LEKSTROM, H. J.; XANTHOPOULOS, K. G. 1998. Biological role of CCAAT/enhancer-binding protein family of transcription factors. J. Biol. Chem. 273: 28545-28548.

LENGI, A. J.; CORL, B. A. 2010. Factors influencing the differentiation of bovine preadipocytes in vitro. J Anim Sci. 88(6), 1999-2008.

LI, N., STEPHENS, M. 2003. Modelling linkage disequilibrium, and identifying recombination hotspots using snp data. Genetics 165, 2213-2233. 
LIN, F. T.; MACDOUGALD, O. A.; DIEHL, M. A.; LANE, M. D. 1993. A 30-kDa alternative translation product of the CCAAT/enhancer binding protein alpha message: transcriptional activator lacking antimitotic activity. Proc. Nat. Acad. Sci. USA 90, 96069610.

LOPEZ, R. G.; GARCIA-SILVA, S.; MOORE, S. J.; BERESHCHENKO, O.; MARTINEZ-CRUZ, A. B.; ERMAKOVA, O.; KURZ, E.; PARAMIO, J. M.; NERLOV, C. 2009. C/EBPa and beta couple interfollicular keratinocyte proliferation arrest to commitment and terminal differentiation. Nat. Cell Biol. 11, 1181-1190.

LOPEZ-HUERTAS, E. 2010. Health effects of oleic acid and long chain omega3 fatty acids (epa and dha) enriched milks. A review of intervention studies. Pharmacol res. 61(3), 200-207.

MAC LOUGHLIN, R. J.; GARRIZ, C. A. 2011. Espesor de grasa dorsal como predictor de la composición de la res en bovinos. Sitio argentino de producción animal. $<$ http://www.produccionanimal.com.ar/informacion_tecnica/carne_y_subproductos/127-espesor_grasa.pdf> MACRAE, J.; O'REILLY, L.; MORGAN, P. 2005. Desirable characteristics of animal products from a human health perspective. Livest. Prod. Sci. 94, 95-103.

MAHARANI, D.; JUNG, Y.; J.; RYOO, S. H UNG, W. Y.; JO, C.; LEE, S. H.; YEON, S. H.; LEE, J. H. 2012. Association of five candidate genes with fatty acid composition in Korean cattle. Mol Biol Rep, 39(5), 6113-6121.

MANGELSDORF, D. J.; BORGMEYER, U.; HEYMAN, R. A.; ZHOU, J. Y.; ONG, E. S.; ORO, A. E.; KAKIZUKA, A.; EVANS, R. M. 1992. Characterization of three RXR genes that mediate the action of 9-cis retinoic acid. Genes Dev.6:329-344.

MARIANI, V.; KIEFER, F.; SCHMIDT, T.; HAAS, J.; SCHWEDE, T. 2011. Assessment of template based protein structure predictions in CASP9. Proteins, 79, 37-58.

MARTÍNEZ MARÍN, A. L.; PÉREZ HERNÁNDEZ, M.; PÉREZ ALBA, L.; GÓMEZ CASTRO, G.; CARRIÓN PARDO, D. 2010. Lipid metabolism in ruminants. Redvet 11(08).

MATSUSUE, K.; PETERS, J.; GONZALEZ, F. 2004. PPARß/ס potentiates PPAR- $\gamma$-stimulated adipocyte differentiation. FASEB J. 18, 1477-1479. 
MAY, S.G.; DOLEZAL, H.G.; GILL, D.R.; RAY, F.K.; BUCHANAN, D.S. 1992. Effect of days fed, carcass grade traits, and subcutaneous fat removal on postmortem muscle characteristics and beef palatability. J. Anim. Sci. 70, 444-453.

MIC, F. A.; MOLOTKOV, A.; BENBROOK, D. M.; DUESTER, G. 2003. Retinoid activation of retinoic acid receptor but not retinoid $X$ receptor is sufficient to rescue lethal defect in retinoic acid synthesis. Proc Natl Acad Sci 100, 7135-7140.

MICHAL, J. J.; ZHANG, Z. W.; GASKINS, C. T.; JIANG, Z. 2006. The bovine fatty acid binding protein 4 gene is significantly associated with marbling and subcutaneous fat depth in Wagyu x Limousin F2 crosses. Animal Genet. 37(4), 400-2.

MUELLER, E.; DRORI, S.; AIYER, A.; YIE, J.; SARRAF, P.; CHEN, H.; HAUSER, S.; ROSEN, E. D.; GE, K.; ROEDER, R. G.; SPIEGELMAN, B. M. 2002 Genetic analysis of adipogenesis through peroxisome proliferator-activated receptor gamma isoforms. J. Biol. Chem. 277, 41925-41930.

NARUKAMI, T.; SASAZAKI, S.; OYAMA, K.; NOGI, T.; TANIGUCHI, M.; MANNEN, H. 2011. Effect of DNA polymorphisms related to fatty acid composition in adipose tissue of Holstein cattle. Animal Science Journal = Nihon Chikusan Gakkaihō, 82(3), 406-411.

NEI, M. 1978. Estimation of average heterozygosity and genetic distance from a small number of individuals. Genetics $89,583-590$.

NERLOV, C.; ZIFF, E. B. 1994. Three levels of functional interaction determine the activity of CCAAT/enhancer binding protein- $\alpha$ on the serum albumin promoter. Genes Dev. 8, 350-362.

NGUYEN, P.; LERAY, V.; DIEZ, M.; SERISIER, S.; LE BLOC'H, J.; SILIART, B.; DUMON, H. 2008. Liver lipid metabolism. J Anim Physiol Anim Nutr 92, 272-283.

NKRUMAH, J. D.; LI, C.; BASARAB, J. B.; GUERCIO, S.; MENG, Y.; MURDOCH, B.; HANSEN, C.; MOORE, S. S. 2004. Association of a single nucleotide polymorphism in the bovine leptin gene with feed intake, feed efficiency, growth, feeding behaviour, carcass quality and body composition. Can. J. Anim. Sci. 84 (2), 211-219. 
NOHARA, A.; KOBAYASHI, J.; MABUCHI, H. 2009. Retinoid X receptor heterodimer variants and cardiovascular risk factors. J Atheroscler Thromb 16, 303318.

NOVAKOFSKI, J. 2004. Adipogenesis: Usefulness of in vitro and in vivo experimental models. J. Anim. Sci. 82, 905-915.

NOLTE, R. T.; WISELY, G. B.; WESTIN, S.; COBB, J. E.; LAMBERT, M. H.; KUROKAWA, R.; ROSENFELD, M. G.; WILLSON, T. M.; GLASS, C. K.; MILBURN, M. V. 1998. Ligand binding and co-activator assembly of the peroxisome proliferatoractivated receptor-gamma. Nature 395, 137-143.

NUERNBERG, K.; DANNENBERGER, D.; NUERNBERG, G.; ENDER, K.; VOIGT, J.; SCOLLAN, N. 2005. Effect of a grass-based and a concentrate feeding system on meat quality characteristics and fatty acid composition of longissimus muscle in different cattle breeds. Livest. Prod. Sci. 94, 137-147.

O'CONNOR, S. F.; TATUM, J. D.; WULF, D. M.; GREEN, R. D.; SMITH, G. C. 1997. Genetic effects on beef tenderness in Bos indicus x Bos taurus cattle. J. Anim. Sci. $75,1822-1830$.

OECD-FAO. 2013. Agricultural Outlook 2013-2022. http://www.oecd.org/site/oecd-faoagriculturaloutlook/highlights-2013-EN.pdf

OGINO, T.; MORALEJO, D. H.; KOSE, H.; YAMADA, T.; MATSUMOTO, K. 2003. Serum leptin concentration is linked to chromosomes 2 and 6 in the OLETF rat, an animal model of type 2 diabetes with mild obesity. Mamm Genome 14(12), 839-844.

OH, D. Y.; LEE, Y. S.; LA, B. M.; YEO J. S. 2012. Identification of the SNP (single nucleotide polymorphism) for fatty acid composition associated with beef flavorrelated FABP4 (fatty acid binding protein 4) in Korean cattle. Asian-Aust. J. Anim. Sci. 25, 913-920.

OH, D.; LEE, Y.; LEE, C.; CHUNG, E.; YEO, J. 2011. Association of bovine fatty acid composition with missense nucleotide polymorphism in exon 7 of peroxisome proliferator-activated receptor gamma gene. Anim. Genet. 43(4), 474.

OSADA, S.; YAMAMOTO, H.; NISHIHARA, T.; IMAGWA, M. 1997. DNA binding specificity of the CCAAT/enhancer-binding protein transcription factor family. J. Biol. Chem. 271, 3891-3896. 
OSSIPOW, V.; DESCOMBES, P.; SCHIBLER, U. 1993. CCAAT/enhancer binding protein mRNA is translated into multiple proteins with different transcription activation potentials. Proc. Natl. Acad. Sci. U.S.A. 90, 8219-8223.

OSTERLUND, T.; BEUSSMAN, D. J.; JULENIUS, K.; POON, P. H.; LINSE, S.; SHABANOWITZ, J.; HUNT, D. F.; SCHOTZ, M. C.; DEREWENDA, Z. S.; HOLM, C. 1999. Domain identification of hormone-sensitive lipase by circular dichroism and fluorescence spectroscopy, limited proteolysis, and mass spectrometry. J. Biol. Chem. 274, 15382-15388.

OSTERLUND, T.; CONTRERAS, J. A.; HOLM, C. 1997. Identification of essential aspartic acid and histidine residues of hormone-sensitive lipase: apparent residues of the catalytic triad. FEBS Lett. 403, 259-262.

OSTERLUND, T.; DANIELLSON, B.; DEGERMAN, E.; CONTRERAS, J. A.; EDGREN, G.; DAVIS, R. C.; SCHOTZ, M. C.; HOLM, C. 1996. Domain-structure analysis of recombinant rat hormone-sensitive lipase. Biochem. J. 319, 411-420.

OTTO, T. C.; LANE, M. D. 2005. Adipose development: From stem cell to adipocyte. Crit. Rev. Biochem. Mol. Biol. 40, 229-242.

PANNIER, L.; MULLEN, A. M.; HANILL, R. M.; STAPLETON, P. C.; SWEENEY T. 2010. Association analysis of single nucleotide polymorphism in DGAT1, TG and FABP4 genes and intramuscular fat in crossbred Bos Taurus cattle. Meat Sci. 85, 515518.

PARIACOTE F., VAN VLECK L. D., HUNSLEY R. E. 1998. Genetic and phenotypic parameters for carcass traits of American Shorthorn beef cattle. J. Anim. Sci. 76, 2584-2588.

PEI, D. Q.; SHIH, C. H. 1991. An "attenuator domain" is sandwiched by two distinct transactivation domains in the transcription factor C/EBP. Mol. Cell. Biol. 11, 1480-1487.

PERISSI, V.; ROSENFELD, M.G. 2005. Controlling nuclear receptors: the circular logic of cofactor cycles. Nat. Rev. Mol. Cell Biol. 6, 542-554.

PITCHFORD, W.; DELAND, M.; SIEBERT, B.; MALAU-ADULIAND, A.; BOTTEMA, C. 2002. Genetic variation in fatness and fatty acid composition of crossbred cattle. J. Anim. Sci. 80, 2825-2832. 
POLI, V. 1998. The role of C/EBP isoforms in the control of inflammatory and native immunity functions. J. Biol. Chem. 273, 29279-29282.

PRADO, I.N.; PRADO, R.M.; ROTTA, P.P.; VISANTAINER, J.V.; MOLETTA; J.L.; PEROTTO, D. 2008. Carcass characteristics and chemical composition of the Longissimus muscle of crossbred bulls (Bos taurus indicus vs. Bos taurus taurus) finished in feedlot. J. Anim. Feed Sci. 17, 295-306.

PRÜFER, K.; BARSONY, J. 2002. Retinoid X receptor dominates the nuclear import and export of the unliganded vitamin D receptor. Mol Endocrinol. 16, 17381751.

QIAO, Y.; HUANG, Z.; LI, Q.; LIU, Z.; HAO, C.; SHI, G.; DAI, R,; XIE, Z. 2007. Developmental changes of the FAS and LIPE mRNA expression and their effects on the content of intramuscular fat in Kazak and Xinjiang sheep. J Genet Genomics 34(10), 909-917.

RAMJI, D. P.; FOKA, P. 2002. CCAAT/enhancer-binding proteins: structure, function and regulation. Biochem. J. 365, 561-575.

RODRIGUEZ, J. A.; BEN ALI, Y.; ABDELKAFI, S.; MENDOZA, L. D.; LECLAIRE, J.; FOTIADU, F.; BUONO, G.; CARRIĖRE, F.; ABOUSALHAM, A. 2010. In vitro stereoselective hydrolysis of diacylglycerols by hormone-sensitive lipase. Biochim. Biophys. Acta 1801, 77-83

RODRÍGUEZ-CRUZ, M.; TOVAR, A. R.; DEL PRADO, M.; TORRES, N. 2005. Mecanismos moleculares de los ácidos grasos poliinsaturados y sus beneficios. Rev. Invest. Clín. 57(3), 457-472.

ROSEN, E. D. 2005. The transcriptional basis of adipocyte development. Prostaglandins Leukot. Essent. Fatty Acids 73, 31-34.

ROSEN, E. D.; HSU, C. H.; WANG, X.; SAKAI, S.; FREEMAN, M. W.; GONZALEZ, F. J.; SPIEGELMAN, B. M. 2002. C/EBPalpha induces adipogenesis through PPARgamma: a unified pathway. Genes Dev. 16(1), 22-26.

ROSEN, E. D.; MACDOUGALD, O. A. 2006. Adipocyte differentiation from the inside out. Nat. Rev. Mol. Cell. Bio. 7, 885-896. 
ROSENSON, R. S. 2007. Effects of peroxisome proliferator-activated receptors on lipoprotein metabolism and glucose control in type 2 diabetes mellitus. Am. J. Cardiol. 99(4A), 96B-104B.

ROUSSET, F. 2007. Inferences from spatial population genetics. In: Handbook of statistical genetics. Eds. D. J. Balding, M. Bishop \& C. Cannings, pp. 945-979. Wiley, Chichester, U.K., 3rd edn.

ROUSSET, F.; RAYMOND, M. 1997. Statistical analysis of population genetic data: old tools, new concepts. Trends Ecol. Evol. 12, 313-317.

SCHNEIDER, S.; ROESSLI, D.; EXCOFFIER, L. 2000. Arlequin Version 2.000: A software for population genetics data analysis. Genetics and Biometry Laboratory, University of Geneva, Switzerland.

SCHOONJANS, K.; STARLS, B.; AUWERX, J. 1996. The peroxisome proliferator activated receptors (PPARs) and their effects on lipid metabolism and adipocyte differentiation. Biochim. Biophys. Acta. 1302, 93-109.

SCOLLAN, N.; HOCQUETTE, J-F.; NUERNBERG, K.; DANNENBERGER, D.; RICHARDSON, I.; MOLONEY, A. 2006. Innovations in beef production systems that enhance the nutritional and health value of beef lipids and their relationship with meat quality. Meat Sci. 74, 17-33.

SEVANE, N.; ARMSTRONG, E.; CORTÉS, O.; WIENER, P.; PONG WONG, R.; DUNNER, S.; GEMQUAL CONSORTIUM. 2013. Association of bovine meat quality traits with genes included in the PPARG and PPARGC1A networks. Meat Sci. 94, 328335.

SHEN, W. J.; LIANG, Y.; HONG, R.; PATEL, S.; NATU, V.; SRIDHAR, K.; JENKINS, A.; BERNLOHR, D. A.; KRAEMER, F. B. 2001. Characterization of the functional interaction of adipocyte lipid-binding protein with hormone-sensitive lipase. J. Biol. Chem. 276(52), 49443-49448.

SHEN, W.J.; PATEL, S.; HONG, R.; KRAEMER, F.B. 2000. Hormone sensitive lipase functions as an oligomer. Biochemistry 39, 2392-2398.

SHERMAN, E. L.; NKRUMAH, J. D.; MURDOCH, B. M.; LI, C.; WANG, Z.; FU, A.; MOORE, S. S. 2008. Polymorphisms and haplotypes in the bovine neuropeptide $Y$, growth hormone receptor, ghrelin, insulin-like growth factor 2, and uncoupling proteins 
2 and 3 genes and their associations with measures of growth, performance, feed efficiency, and carcass merit in beef cattle. J. Anim. Sci. 86, 1-16.

SHIN, S. C.; HEO, J. P.; CHUNG, E. R. 2012. Genetic variants of the FABP4 gene are associated with marbling scores and meat quality grades in Hanwoo (Korean cattle). Mol. Biol. Rep. 39(5), 5323-5330.

SMITH, A. J.; THOMPSON, B. R.; SANDERS, M. A.; BERNLOHR, D. A. 2007. Interaction of the adipocyte fatty acid-binding protein with the hormone-sensitive lipase: regulation by fatty acids and phosphorylation. J. Biol. Chem. 282, 32424-32432.

SMITH, G. M.; GARTON, A. J.; AITKEN, A.; YEAMAN, S. J. 1996. Evidence for a multi-domain structure for hormone-sensitive lipase. FEBS Lett. 396, 90-94.

SÖDING, J.; BIEGERT, A.; LUPAS, A. N. 2005. The HHpred interactive server for protein homology detection and structure prediction. Nucleic Acids Res 33, W244-W248.

SORENSEN, B.; KÜHN, C.; TEUSCHER, F.; SCHNEIDER, F.; WESELAKE, R.; WEGNER, J. 2006. Diacyl glycerol acyltransferase (DGAT) activity in relation to muscle fat content and DGAT1 genotype in two different breeds of Bos taurus. Arch. Tierz. Dummerstorf . 49(4), 351-356.

SPLAN, R. K.; CUNDIFF, L. V.; DIKEMAN, M. E.; VAN VLECK, L. D. 2002. Estimates of parameters between direct and maternal genetic effects for weaning weight and direct genetic effects for carcass traits in crossbred cattle. J. Anim. Sci. 80, 3107-3111.

ŠUBRT, J.; RADEK, F.; ZDENĚK, Ž.; MILADA, F.; ELIŠKA, D. 2006. The content of polyunsaturated fatty acids in intramuscular fat of beef cattle in different breeds and crossbreeds. Archiv Tierzucht Dummerstorf 49(4), 340-350.

TAN, N. S.; SHAW, N. S.; VINCKENBOSCH, N.; LIU, P.; YASMIN, R.; DESVERGNE, B.; WAHLI, W.; NOY, N. 2002. Selective cooperation between fatty acid binding proteins and peroxisome proliferator-activated receptors in regulating transcription. Mol. Cell. Biol. 22 (14), 5114-5127.

TANIGUCHI, M.; MANNEN, H.; OYAMA, K.; SHIMAKURA, Y.; WATANABE, H.; KOJIMAE, T.; KOMATSUE, M.; HARPERF, G.S.; TSUJIB, S. 2004a. Differences in stearoyl-CoA desaturase mRNA levels between Japanese Black and Holstein cattle. Livest. Prod. Sci. 87, 215-220. 
TANIGUCHI, M.; UTSUGI, T.; OYAMA, K.; MANNEN, H.; KOBAYASHI, M.; TANABE, Y.; OGINO, A.; TSUJI, S. 2004b. Genotype of stearoyl-CoA desaturase is associated with fatty acid composition in Japanese Black cattle. Mamm. Genome 15, 142-148.

TANIGUCHI, Y.; SASAKI, Y. 1996. Rapid communication: nucleotide sequence of bovine C/EBP alpha gene. J. Anim. Sci. 74, 2554.

TATSUDA, K.; OKA, A.; IWAMOTO, E.; KURODA, Y.; TAKESHITA, H.; KATAOKA, H.; KOUNO, S. 2008. Relationship of the bovine growth hormone gene to carcass traits in Japanese black cattle. J. Anim. Breed. Genet. 125, 45-49.

THALLER, G.; KÜHN, C.; WINTER, A.; EWALD, G.; BELLMANN, O.; WEGNER, J.; ZÜHLKE, H.; FRIES, R. 2003. DGAT1, a new positional and functional candidate gene for intramuscular fat deposition in cattle. Animal Genetics 34, 354-357.

TONTONOZ, P.; GRAVES, R. A.; BUDAVARI, A. I.; ERDJUMENT-BROMAGE, H.; LUI, M.; HU, E.; TEMPST, P.; SPIEGELMAN, B. M. 1994a. Adipocyte-specific transcription factor ARF6 is a heterodimeric complex of two nuclear hormone receptors, PPAR gamma and RXR alpha. Nucleic Acids Research, 22(25), 5628-34.

TONTONOZ, P.; HU, E.; SPIEGELMAN, B. M. 1994b. Stimulation of adipogenesis in fibroblasts by PPARGy 2 , a lipid-activated transcription factor. Cell 79 , 1147-1156.

ULBRICHT, T.L.V.; SOUTHGATE, D.A.T. 1991. Coronary heart disease: seven dietary factors. The Lancet 338, 985-992.

VALENZUELA B., R.; BASCUÑAN G., K.; VALENZUELA B., A. 2008. Docosahexaenoic acid (DHA): A nutritional view for the prevention of Alzheimer's disease. Rev. Chil. Nutr. 35(1), 250-261.

VAN BEEKUM, O.; FLESKENS, V.; KALKHOVEN E. 2009. Posttranslational modifications of PPAR-gamma: fine-tuning the metabolic master regulator. Obesity (Silver Spring) 17(2),213-9.

VAN EENENNAAM, A.L.; DRAKE, D.J. 2012. Where in the beef-cattle supply chain might DNA tests generate value? Anim. Prod. Sci. 52, 185-196. 
VAN VLECK L. D., HAKIM A. F., CUNDIFF L. V., KOCH R. M., CROUSE J. D., BOLDMAN K. G. 1992. Estimated breeding values for meat characteristics of crossbred cattle with an animal model. J. Anim. Sci. 70, 363-371.

VASTA, V.; PRIOLO, A.; SCERRA, M.; HALLETT, K.; WOODB, J.; DORAN, O. 2009. $\Delta 9$-desaturase protein expression and fatty acid composition of longissimus dorsi muscle in lambs fed green herbage or concentrate with or without added tannins. Meat Sci. 82, 357-364.

VILLARREAL, E. L.; MELUCCI, L. M.; MEZZADRA, C. A. 2006. Genetic Components for Slaughter and Meat Quality. Traits in the Angus-Hereford Crossing. 8th World Congress on Genetics Applied to Livestock Production, Belo Horizonte, Brasil.

VILLENA, J.A.; ROY, S.; SARKADI-NAGY, E.; KIM, K.-H.; SUL, H.S. 2004. Desnutrin, an adipocyte gene encoding a novel patatin domain-containing protein, is induced by fasting and glucocorticoids: ectopic expression of desnutrin increases triglyceride hydrolysis. J. Biol. Chem. 279, 47066-47075.

VINSON, C. R.; SIGLER, P. B.; MCKNIGHT, S. L. 1989. Scissors-grip model for DNA recognition by a family of leucine zipper proteins. Science 246, 911-916.

WAGNER, V.; SCHILD, T. A.; GELDERMANN, H. 1994. Application of polymorphic DNA sequences to differentiate the origin of decomposed bovine meat. J. Forensic. Sci. 64, 89-95.

WAKU, T.; SHIRAKI, T.; OYAMA, T.; FUJIMOTO, Y.; MAEBARA, K.; KAMIYA, N.; JINGAMI, H.; MORIKAWA, K. 2009. Structural insight into PPARgamma activation through covalent modification with endogenous fatty acids. J. Mol. Biol. 385, 188-199

WALCZAK, R.; TONTONZ, P. 2002. PPARadigms and PPARadoxe: expanding roles for PPARgamma in the control of lipid metabolism. J. Lipid. Res. 43, 177-186.

WANG, S. P.; CHUNG, S.; SONI, K.; BOURDAGES, H.; HERMO, L.; TRASLER, J.; MITCHELL, G. A. 2004. Expression of human hormone-sensitive lipase (LIPE) in postmeiotic germ cells confers normal fertility to LIPE-deficient mice.

Endocrinology 145(12), 5688-5693. 
WANG, H.; ZAN, L. S.; WANG, H. B.; SONG, F. B. 2011. A novel SNP of the $\mathrm{C} / \mathrm{EBPa}$ gene associated with superior meat quality in indigenous Chinese cattle. Genet. Mol. Res. 10 (3), 2069-2077.

WANG, S. P.; WU, J. W.; BOURDAGES, H.; LEFEBVRE, J. F.; CASAVANT, S.; LEAVITT, B. R.; LABUDA, D.; TRASLER, J.; SMITH, C. E.; HERMO, L.; MITCHELL, G. A. 2014. The Catalytic Function of Hormone-Sensitive Lipase is Essential for Fertility in Male Mice. Endocrinology 155(8), 3047-3053

WARREN, H.E.; SCOLLAN, N.D.; NUTE, G.R.; HUGHES, S.I.; WOOD, J.D.; RICHARDSON, R.I. 2008. Effects of breed and a concentrate or grass silage diet on beef quality in cattle of 3 ages. II: Meat stability and flavour. Meat Sci. 78, 270-278.

WARRISS, P. D. 2000. Meat science: an introductory text. School of Veterinary Science. University of Bristol. Bristol. UK. 321 p.

WEISIGER, R. A. 2002. Cytosolic fatty acid binding proteins catalyze two distinct steps in intracellular transport of their ligands. Mol. Cell. Biochem. 239 (1-2): $35-43$.

WEISS, S. B.; KENNEDY, E. P.; KIYASU, J. Y. 1960. The enzymatic synthesis of triglycerides. J. Biol. Chem. 235, 40-44.

WILLIAMS, S. C.; CANTWELL, C. A.; JOHNSON, P. F. 1991. A family of C/EBP-related proteins capable of forming covalently linked leucine zipper dimers in vitro. Genes Dev. 5, 1553-1567.

WOLF, G. 2006. Is 9-cis-retinoic acid the endogenous ligand for the retinoic acid-X receptor? Nutr Rev. 64, 532-538.

WOOD, I. A.; MOSER, G.; BURRELL, D. L.; MENGERSEN, K. L.; HETZEL, D. J. 2006. A meta-analytic assessment of a thyroglobulin marker for marbling in beef cattle. Genet. Sel. Evol. 38, 479-494.

WU, Z.; ROSEN, E. D.; BRUN, R.; HAUSER, S.; ADELMANT, G.; TROY, A. E.; MCKEON, C.; DARLINGTON, G. J.; SPIEGELMAN, B. M. 1999. Cross-regulation of C/EBP alpha and PPAR gamma controls the transcriptional pathway of adipogenesis and insulin sensitivity. Mol Cell. 3(2), 151-158. 
YAJIMA, H.; KOBAYASHI, Y.; KANAYA, T.; HORINO, Y. 2007. Identification of peroxisome-proliferator responsive element in the mouse HSL gene. Biochem Biophys Res Commun 352(2), 526-531.

YEAMAN, S. J. 2004. Hormone-sensitive lipase—New roles for an old enzyme. Biochem J. 379, 11-22.

YOON, H.B.; SEO, K. S.; KIM, S. D.; CHO, Y. M.; NA, S. H.; PARK, C. J.; JEON, G. J. 2002. Estimation of genetic parameters for direct genetic effect for carcass traits of Hanwoo (Korean Brown cattle) steers. In: Proceedings of the 7th World Congress on Genetics Applied to Livestock Production, August 19-23, 2002, Montpellier, France. Session 02. Breeding ruminants for meat production. Communication No. 02-89.

ZAPLETAL, D.; CHLÁDEK, G.; ŠUBRT, J. 2009. Breed variation in the chemical and fatty acid compositions of the Longissimus dorsi muscle in Czech Fleckvieh and Montbeliarde cattle. Livest. Sci. 123, 28-33.

ZHANG, S.; KNIGHT, T. J.; REECY, J. M.; BEITZ, D. C. 2008. DNA polymorphisms in bovine fatty acid synthase are associated with beef fatty acid composition. Anim. Genet. 39, 62-70.

ZHAO, Q.; CHASSE, S. A.; DEVARAKONDA, S.; SIERK, M. L.; AHVAZI, B.; RASTINEJA,D. F. 2000. Structural basis of RXR-DNA interactions. J Mol Biol. 296, 509-520.

ZIMMERMANN, R.; STRAUSS, J. G.; HAEMMERLE, G.; SCHOISWOHL, G.; BIRNER-GRUENBERGER, R.; RIEDERER, M.; LASS, A.; NEUBERGER, G.; EISENHABER, F.; HERMETTER, A.; ZECHNER, R. 2004. Fat mobilization in adipose tissue is promoted by adipose triglyceride lipase. Science 306, 1383-1386.

ZUKER, M.. 2003. Mfold web server for nucleic acid folding and hybridization prediction. Nucleic Acids Res.31 (13), 3406-3415.

ZUO, Y.; QIANG, L.; FARMER, S. R. 2006. Activation of CCAAT/enhancerbinding protein (C/EBP) alpha expression by C/EBP beta during adipogenesis requires a peroxisome proliferator-activated receptor-gamma-associated repression of HDAC1 at the C/ebp alpha gene promoter. J. Biol. Chem. 281, 7960-7967. 


\section{ANEXO}

Kit de purificación de ADN genómico Wizard $®$ (Promega, Madison, WI, USA)

\begin{tabular}{|c|c|c|c|c|c|}
\hline \multirow{2}{*}{$\begin{array}{l}\text { Sample } \\
\text { Size }\end{array}$} & \multicolumn{2}{|c|}{$\begin{array}{l}\text { Lysis } \\
\text { Solution }\end{array}$} & \multirow{2}{*}{$\begin{array}{c}\text { Protein } \\
\text { Precipitation } \\
\text { Solution }\end{array}$} & \multirow[b]{2}{*}{ Isopropanol } & \multirow{2}{*}{$\begin{array}{c}\text { DNA } \\
\text { Rehydration } \\
\text { Solution } \\
\end{array}$} \\
\hline & Cell & Nuclei & & & \\
\hline $300 \mu l$ & $900 \mu l$ & $300 \mu \mid$ & الر100 & $300 \mu \mathrm{l}$ & $100 \mu \mid$ \\
\hline $1 \mathrm{ml}$ & $3 \mathrm{ml}$ & $1 \mathrm{ml}$ & 330بl & $1 \mathrm{ml}$ & 150 ul \\
\hline $3 \mathrm{ml}$ & $9 \mathrm{ml}$ & $3 \mathrm{ml}$ & $1 \mathrm{ml}$ & $3 \mathrm{ml}$ & 250 \\
\hline $10 \mathrm{ml}$ & $30 \mathrm{ml}$ & $10 \mathrm{ml}$ & $3.3 \mathrm{ml}$ & $10 \mathrm{ml}$ & $800 \mu \mid$ \\
\hline
\end{tabular}

Tabla 27. Volúmenes de reactivos empleados en el kit de extracción de ADN genómico Wizard® (obtenido del manual de instrucciones del kit)

1- Usando los volúmenes de la tabla 27, se combinaron los volúmenes apropiados de sangre y solución de lisis celular y se los mezcló por inversión.

2- Se incubó por 10 minutos a temperatura ambiente.

3- Se centrifugó las muestras según su volumen: $\leq 300 \mu \mathrm{l}$ : 13000-16000 x g (velocidad máxima en micro-centrífuga), 20 segundos; $1-10 \mathrm{ml}: 2000$ x g, 10 minutos.

4- Se descartó el sobrenadante y se vortexeó el pellet.

5- Usando los volúmenes de la tabla 27, se agregó la solución de lisis nuclear y se mezcló por inversión.

6- Se agregó la solución de precipitación proteica y se vortexeó por 20 segundos.

7- Se centrifugó las muestras según su volumen: $\leq 300 \mu \mathrm{l}$ : 13000-16000 x g (velocidad máxima en micro-centrífuga), 3 minutos; 1-10 ml: $2000 \times \mathrm{g}, 10$ minutos.

8- Se transfirió el sobrenadante a un nuevo tubo que contenía isopropanol (volumen según la tabla 27) y se mezcló. 
9- Se centrifugó las muestras según su volúmen: $\leq 300 \mu$ : 13000-16000 x g (velocidad máxima en micro-centrífuga), 1 minuto; 1-10 ml: $2000 \times \mathrm{g}, 1$ minuto.

10- Se descartó el sobrenadante y se agregó etanol $70 \%$ (el mismo volumen que de isopropanol).

11- Se repitió el punto 9 .

12- Se quitó el etanol y se secó el pellet al aire por 10-15 minutos.

13- Se rehidrató el $A D N$ en un volumen apropiado de solución de rehidratación de ADN por 1 hora a $65^{\circ} \mathrm{C}$ u overnight a $4^{\circ} \mathrm{C}$.

\section{Extracción de ADN de las muestras de carne}

1- Se tomó $0,1 \mathrm{~g}$ de cada muestra (congeladas a $-80^{\circ} \mathrm{C}$ ) y fueron cortados en pequeños trozos con un escarpelo.

2- Los trozos fueron suspendidos en $750 \mu \mathrm{l}$ de buffer de digestión (HCl 50 mM, EDTA 25 mM, DTT 20 mM, N-laurosilsarcosina $2 \%)$ con $30 \mu \mathrm{l}$ de proteinasa $\mathrm{K}(10 \mathrm{mg} / \mathrm{ml})$.

3- La suspensión fue incubada overnight a $55^{\circ} \mathrm{C}$.

4- Se agregó $250 \mu \mathrm{l}$ de acetato de amonio $10 \mathrm{M}$

5- Se centrifugó la mix por 5 minutos a máxima velocidad en una microcentrífuga Eppendorf.

6- El ADN fue precipitado con Isopropanol

7- El pellet fue resuspendido en $200 \mu \mathrm{l}$ de agua y almacenado a $-20^{\circ} \mathrm{C}$ hasta su utilización.

\section{Preparación de geles de poliacrilamida $6 \%$}

$\begin{array}{lc}\text { Agua destilada } & 9 \mathrm{ml} \\ \text { TBE 5X } & 3 \mathrm{ml} \\ \text { Poliacrilamida } 30 \% & 3 \mathrm{ml} \\ \text { APS } & 150 \mu \mathrm{l} \\ \text { TEMED } & 15 \mu \mathrm{l}\end{array}$


1. Limpiar los vidrios con alcohol para desengrasarlos.

2. Colocar los separadores $(0,375 \mathrm{~mm})$ sobre el vidrio entero y apoyar encima, con mucho cuidado, el vidrio calado. Sujetar con ganchos o clips.

3. Agregar el TEMED y el APS a la mezcla de poliacrilamida, mezclar bien y proceder (desde el extremo calado) a cargar el gel con una pipeta de vidrio, evitando que se formen burbujas de aire.

4. Una vez que se lleno el molde con el gel, colocar el peine con cuidado.

5. Esperar que polimerice y montar en la cuba electroforética con TBE 1X. No dejar el gel polimerizado mucho tiempo sin montar para evitar la deshidratación.

6. Sembrar las muestras y correr a 170 watts durante el tiempo necesario.

TBE 5X:

$54 \mathrm{~g}$ de Tris base.

27,5 g de Ácido Bórico.

$20 \mathrm{ml}$ de EDTA 0.5M ( $\mathrm{pH}=8$ ).

Completar hasta $1000 \mathrm{ml}$ con agua destilada.

Preparación de las muestras para su siembra

La muestra se siembra en el gel con colorante DYE, permitiendo así su visualización durante la corrida electroforética. Se toman $3 \mu$ del ADN genómico y se le agregan $1 \mu \mathrm{l}$ de DYE, los $4 \mu \mathrm{l}$ resultantes se colocan en los pocillos del gel. La corrida electroforética se realiza a 170 voltios durante 1 hora y cuarto. 


\section{Colorante DYE:}

$0.025 \mathrm{~g}$ de Bromophenol Blue.

$4 \mathrm{~g}$ de sacarosa.

Completar hasta un volumen final de $100 \mathrm{ml}$ con agua destilada.

\section{Revelado de los geles}

1. Se colocan $50 \mu \mathrm{l}$ de Bromuro de etidio en $500 \mathrm{ml}$ de $\mathrm{H} 20$ destilada.

2. Sumergir el gel en la solución por unos segundos.

3. Revelar bajo luz UV.

\section{Purificación de las reacciones de PCR por precipitación con polietilenglicol} (PEG)

Este protocolo está ajustado para reacciones de PCR de $50 \mu \mathrm{l}$. Si el volumen de la PCR es diferente, modificar la escala manteniendo las proporciones.

1. Correr $5 \mu \mathrm{l}$ de la PCR en un gel de agarosa para verificar la amplificación.

2. Al resto de la reacción de PCR agregarle $50 \mu \mathrm{l}$ de una solución de $20 \%$ PEG - $2.5 \mathrm{M}$ $\mathrm{NaCl}$ y mezclar bien.

3. Incubar a $37^{\circ} \mathrm{C}$ por 15 minutos.

4. Centrifugar a alta velocidad $(\sim 15.000 \times \mathrm{g})$ durante 15 minutos a temperatura ambiente.

5. Retirar el sobrenadante con pipeta y descartarlo. El pellet es incoloro y queda adherido a la pared del tubo.

6. Agregar $125 \mu \mathrm{l}$ de etanol $70 \%$. Si se agrega el etanol en el fondo del tubo, centrifugar 2 minutos. Si se agrega el etanol suavemente por la pared del tubo, dejar reposar un minuto. Eliminar el sobrenadante y descartar. Eliminar la mayor cantidad 
posible del etanol.

7. Secar el pellet a $37^{\circ} \mathrm{C}$ durante $10-15$ minutos. Asegurarse de que no queden restos de etanol y que el pellet esté seco. Un exceso en el secado del pellet dificulta la resuspensión.

8. Disolver el producto de PCR en $25 \mu$ de agua bidestilada estéril. Resuspender completamente el pellet (con pipeta o vortex). Ayuda incubar por unos minutos a temperatura ambiente o a $37^{\circ} \mathrm{C}$.

9. Correr de 2 a $4 \mu \mathrm{l}$ en un gel de agarosa durante 10 minutos para tener una idea aproximada del porcentaje de recuperación. Simultáneamente sembrar 20 y 100 ng de un standard de DNA.

\section{Solución 20\% PEG - 2,5 M NaCl}

Para $50 \mathrm{ml}$ mezclar:

10.0 g polietilenglicol 8000 (funciona igualmente con el PEG 6000 u 8000)

$7.3 \mathrm{~g}$ de $\mathrm{NaCl}$

Agregar $45 \mathrm{ml}$ de agua bidestilada. Agitar y dejar disolver el PEG durante al menos 20 minutos. Se puede colocar la solución en un agitador a $37^{\circ} \mathrm{C}$.

Cuando se disolvió el PEG (la solución se vuele incolora), completar el volumen hasta $50 \mathrm{ml}$ con agua bidestilada. Conservar a temperatura ambiente.

\section{Re-secuenciación}

Las muestras fueron analizadas en un secuenciador automático MEGABACE 1000. Que utiliza una mezcla de nucleótidos sin marcar y dideoxinucleótidos marcados fluorescentemente con distintos colores. La ventaja de esta tecnología radica en que la secuenciación se lleva a cabo en una sola reacción, a diferencia de las cuatro necesarias para tecnologías alternativas, como en la utilización de primers marcados. Los fragmentos obtenidos en la reacción se separan en un capilar mediante electroforesis, y el color asociado a cada uno de ellos se detecta utilizando un rayo 
láser. La secuencia de colores registrada por el detector a lo largo de la corrida es indicativa de la secuencia de bases que componen al fragmento, y es informada al usuario a través de un computador.

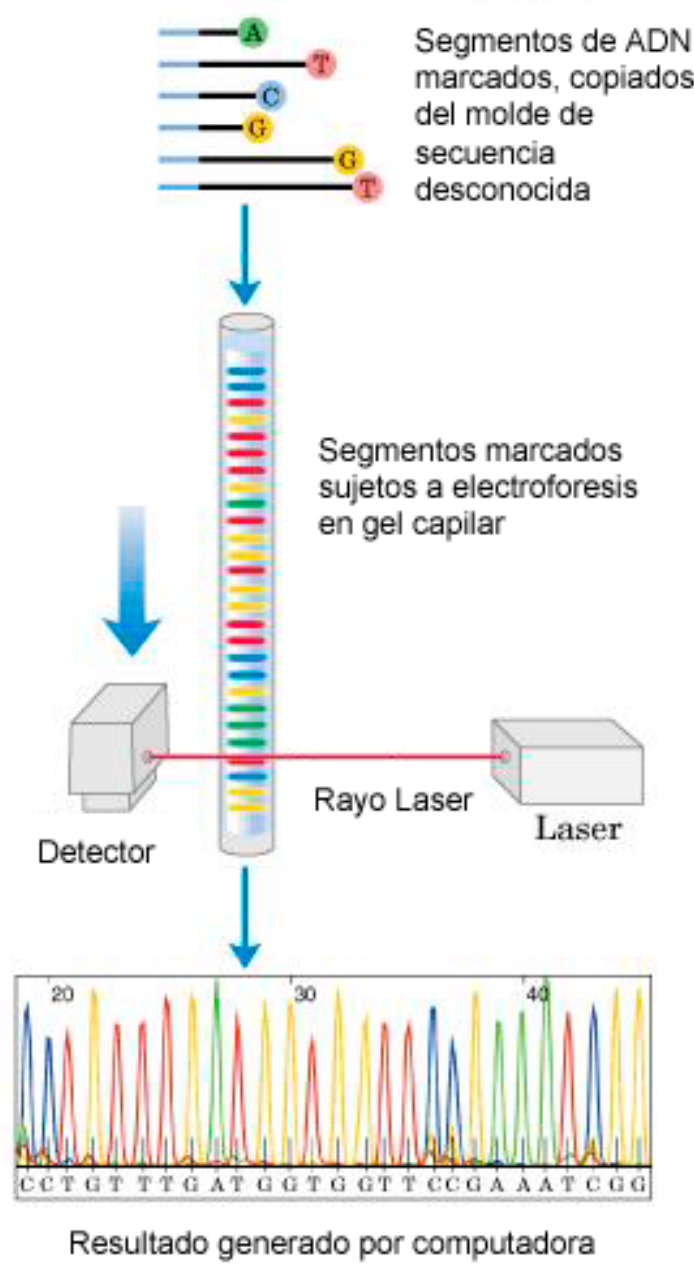

Fig 41. Representación esquemática de un proceso de secuenciación por terminadores fluorescentes

Actualmente este método se ha convertido en uno de los preferidos para secuenciación automática, debido a su capacidad, rapidez y al bajo costo que acarrea cada reacción. Sin embargo, la utilización de terminadores marcados provoca un efecto de desigualdad de altura entre los picos del electroferograma, algo que se ha ido tratando de resolver mediante la implementación de nuevas polimerasas y colorantes, que minimizan la variabilidad de la incorporación. 
Protocolo a seguir para realizar las reacciones de secuenciación

Una reacción standard se realiza en 10 ul finales de acuerdo al siguiente protocolo:

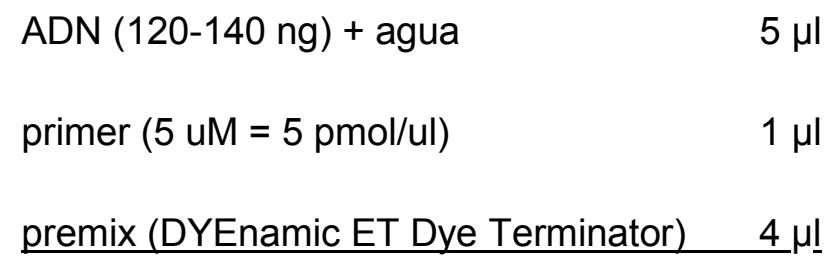

$10 \mu \mathrm{l}$

La mezcla se somete a un ciclado de amplificación poco riguroso: 40 ciclos de 20 segundos a $95^{\circ} \mathrm{C}, 15$ segundos a $50^{\circ} \mathrm{C}$ y 1 minuto a $60^{\circ} \mathrm{C}$.

Luego hay que purificar las reacciones para eliminar los cebadores y los nucleótidos fluorescentes no incorporados, para ello se realiza una precipitación con acetato de amonio y etanol de acuerdo al siguiente protocolo.

Reacción de secuencia

$10 \mu \mathrm{l}$

Acetato de amonio $7.5 \mathrm{M}$

$1 \mu \mathrm{l}$

Etanol absoluto

$30 \mu \mathrm{l}$

1. Centrifugar a $15.000 \mathrm{rpm}$ durante 15 minutos.

2. Descartar el sobrenadante.

3. Lavar con $100 \mu \mathrm{l}$ de etanol $70 \%$, agregando el alcohol con suavidad para no despegar el pellet.

4. Dejar reposar 1 minuto y eliminar tanto etanol como sea posible (si quedaran gotas en las paredes, centrifugar brevemente y eliminarlas con la pipeta). Esto es importante ya que los restos de etanol producen artefactos en la corrida del secuenciador (dye blobs).

5. Secar el etanol a $37^{\circ} \mathrm{C}$ durante aproximadamente 10 minutos. No secar 
excesivamente (dificulta la resuspensión).

6. Disolver el pellet en $10 \mu \mathrm{l}$ de MegaBACE Loading Solution vortexeando vigorosamente durante 20-30 segundos para asegurar una resuspensión completa.

\section{Preparado de muestras para Pirosecuenciación}

Luego de obtener el producto de PCR empleando un primer biotinilado y el otro sin marcar:

A) Preparación de Placa para purificación

1. Preparar la siguiente mezcla multiplicando por el numero de muestras a pirosecuenciar:

$$
\mathrm{x} 1 \text { muestra }
$$

Buffer de "binding" $\quad 40 \mu \mathrm{l}$

Perlas de Sefarosa $\quad 3 \mu \mathrm{l}$

$\mathrm{H} 2 \mathrm{O} \quad 17 \mu \mathrm{l}$

Volumen final $\quad 60 \mu \mathrm{l}$

2. Mezclar muy bien antes de distribuir en la placa de purificación. Evitar la decantación de las perlas de sefarosa. Distribuir en cada fosa de la placa de Purificación:

Mezcla de binding $\quad 60 \mu \mathrm{l}$

Producto de PCR $\quad 20 \mu \mathrm{l}$

3. Tapar la placa con film. Incubar la mezcla por 5-10 minutos a temperatura ambiente mientras se agita a $1400 \mathrm{rpm}$.

4. Durante la incubación preparar la Placa para Pirosecuenciación.

B) Preparación de la Placa para Pirosecuenciación 
1. Preparar la siguiente mezcla multiplicando por el número de muestras a pirosecuenciar:

$\begin{array}{ll} & \text { x1 muestra } \\ \text { Buffer de "annealing" } & 44,865 \mu \mathrm{l} \\ \text { Primer interno de secuenciación } & 0,135 \mu \mathrm{l}\end{array}$

2. Distribuir $45 \mu \mathrm{l}$ en cada fosa de la placa para Pirosecuenciación (PSQ).

C) Purificación

1. Con las perlas de sefarosa en suspensión, aspirar la solución usando la estación de purificación (Vacuum Prep Tool ${ }^{\mathrm{TM}}$ ). De esta forma las perlas de sefarosa se adhieren al filtro de las puntas del soporte de aspiración. Mantener las puntas dentro de la placa de PCR hasta verificar que toda la solución haya sido aspirada.

2. Transferir el soporte de aspiración a la primera cuba y aspirar el etanol $70 \%$ por 5 segundos.

3. Transferir el soporte de aspiración a la segunda cuba y aspirar $\mathrm{NaOH} \mathrm{0,2} \mathrm{M} \mathrm{por} 5$ segundos para desnaturalizar el ADN.

4. Transferir el soporte de aspiración a la tercera cuba y aspirar el buffer de lavado (10 a $20 \mathrm{ml}$ por placa) por 5 segundos.

5. Levantar el soporte de aspiración a una posición vertical para permitir que el líquido drene de las puntas. Retornar a la posición horizontal. Colocar el soporte de aspiración sobre la placa de Pirosecuenciación (introduciendo las puntas en los posillos sin tocar el líquido), apagar la bomba de aspiración y agitar suavemente para permitir que las perlas caigan en la placa $P S Q$.

6. Calentar la placa a $80^{\circ} \mathrm{C}$ por dos minutos para permitir el annealing del primer de secuenciación. Enfriar a temperatura ambiente.

7. Limpiar las puntas del soporte de aspiración agitándolo en la cuarta cuba que contiene agua Milli $\mathrm{Q}$, con el fin de eliminar cualquier perla 
remanente.

8. Cuando todas las placas han sido preparadas, transferir el soporte de aspiración a quinta cuba y aspirar el agua Milli Q por 20-30 seg para lavar el soporte de aspiración.

\section{Pirosecuenciación}

La pirosecuenciación (Ronaghi et. al.1996, 1998), una técnica novedosa de secuenciación, no es utilizada para secuenciar genomas debido a la limitación en la longitud de la lectura, pero sí es muy útil para genotipificación (Ahmadian et. al., 2000; Alderborn et. al., 2000), en re-secuenciación de genes asociados a enfermedades (Garcia et. al., 2000) y en la determinación de secuencias de ADN con estructuras secundarias intrincadas. Resulta mucho más rápida, eficaz y económica que la técnica RFLP, por lo que se diseñó un método de diagnóstico basado en pirosecuenciación para el polimorfismo c.1328 C>T.

La técnica se basa en la detección del pirofosfato (PPi), liberado durante la incorporación de un nucleótido al ADN, que forma parte de una cascada de reacciones cuyo producto final es la generación de luz visible.

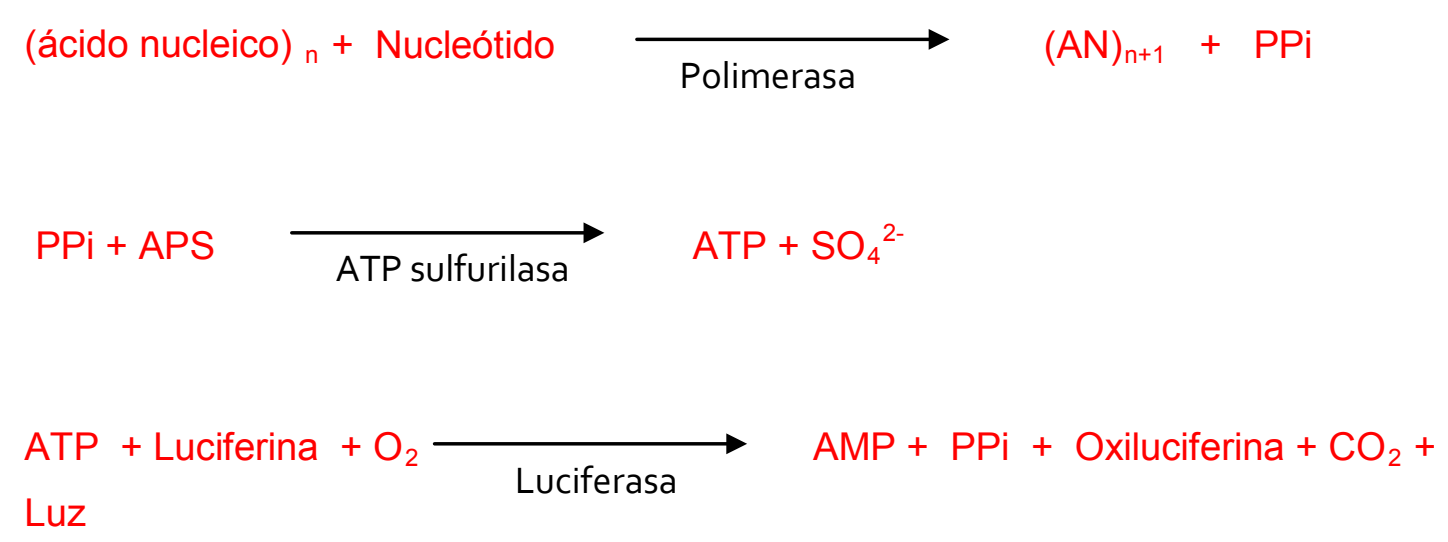

Fig 42. Reacciones involucradas en la generación de luz

La cascada comienza con la incorporación de un nucleótido por la polimerasa, en la cual se libera un PPi como producto. Luego la enzima ATP sulfurilasa genera ATP a partir de APS (adenosina 5' fosfosulfato) y del PPi liberado anteriormente (Fig. 42). El 
ATP provee la energía necesaria para la oxidación de la luciferina y la generación de luz. Como la identidad del nucleótido incorporado se conoce, la secuencia molde puede ser determinada fácilmente.

La pirosecuenciación estándar utiliza el fragmento de Klenow (sin actividad $5^{\prime} \rightarrow 3^{\prime}$ exonucleasa) de la Polimerasa I de Escherichia coli, la cual es una polimerasa relativamente lenta. La ATP sulfurilasa utilizada es una versión recombinante de la levadura Saccharomyces cerevisiae y la luciferasa proviene de la luciérnaga Photinus pyralis.

Las tres reacciones se llevan a cabo en 3-4 seg a temperatura ambiente. Un picomol de ADN en una reacción de pirosecuenciación genera $6 \times 10^{11}$ moléculas de ATP que, a su vez, generan más de $6 \times 10^{9}$ fotones con una longitud de onda de $560 \mathrm{~nm}$. Esta cantidad de luz es fácilmente detectada y se grafica en forma de picos en un pirograma (Fig. 43).

La pirosecuenciación (Fig. 44) puede llevarse a cabo en fase en fase sólida y en fase líquida (Ronaghi , 1998).

En fase sólida (sistema de 3 enzimas) se inmoviliza el ADN en un soporte y se realiza un lavado para remover el exceso de sustrato luego de cada adición de nucleótido. En fase líquida (sistema de 4 enzimas) se utiliza una enzima de la papa, la apirasa, que degrada los nucleótidos no incorporados. La adición de esta enzima elimina la necesidad de un soporte sólido y de la etapa de lavado, lo que le permite a la reacción ser realizada en un sólo tubo. Esta enzima muestra alta actividad catalítica y sólo se necesitan bajas concentraciones para degradar los nucléotidos trifosfato a nucléotidos difosfato y luego a monofosfato que no han sido incorporados.

La pirosecuenciación aprovecha la cooperatividad de varias enzimas para monitorear la síntesis de ADN. La cinética de las enzimas puede ser estudiada en tiempo real observando un pirograma, en donde la pendiente de la curva ascendente está determinada mayormente por las actividades de la Polimerasa y la ATP sulfurilasa; , la altura de la señal por la actividad de la luciferasa y la pendiente de la curva descendente por la eficiencia del lavado. 


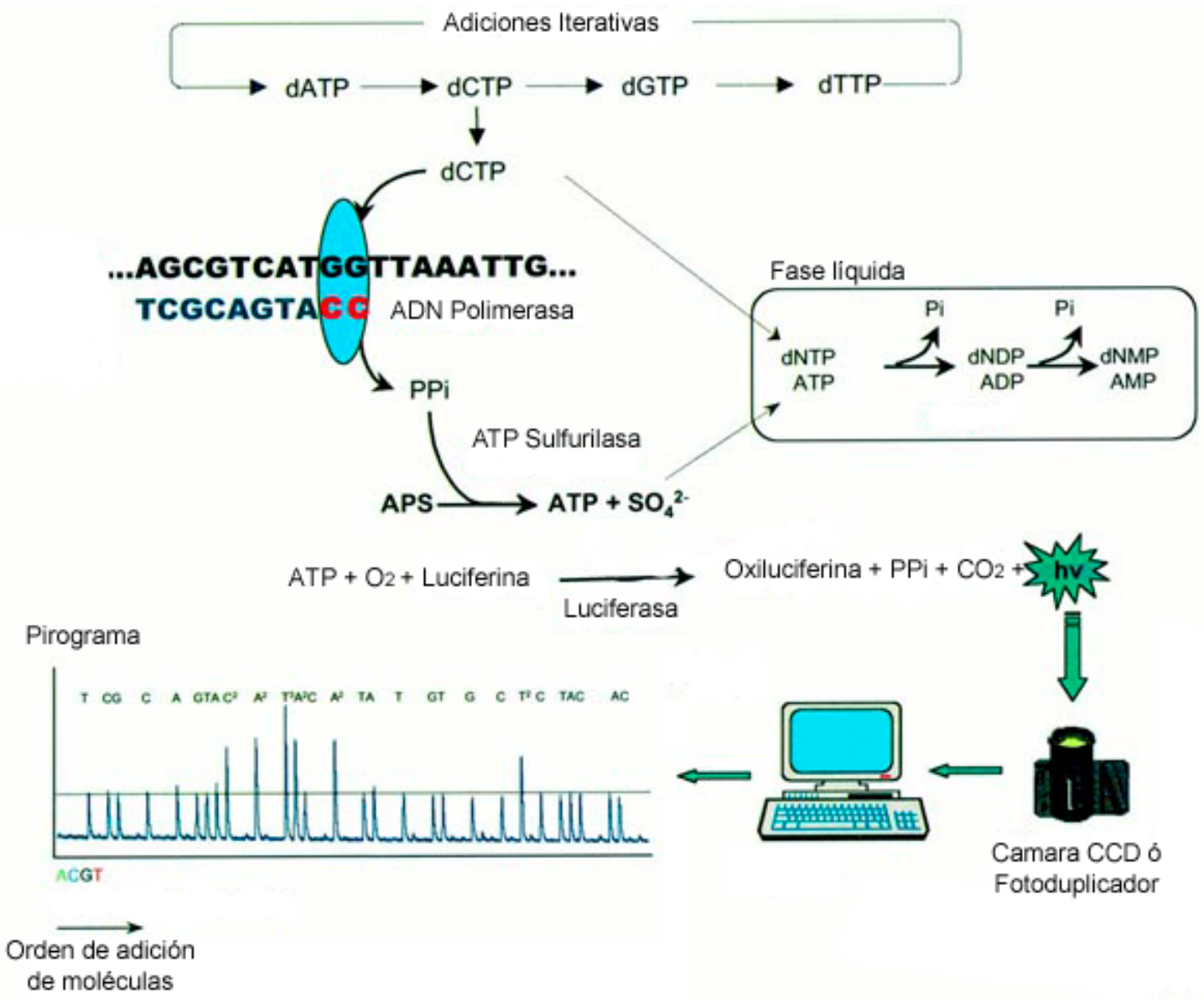

Fig. 43. Pasos de la pirosecuenciación

Para poder realizar la purificación del producto de PCR que se destinará a pirosecuenciación, se amplifica el fragmento de ADN con uno de los cebadores (el forward o el reverse) biotinilado para ser capturado por perlas magnéticas unidas a Streptavidina. Se sedimentan las perlas y los componentes restantes de la reacción de PCR pueden ser removidos con un lavado para obtener DNA doble hebra puro. Luego se utiliza álcali para desnaturalizar el ADN doble hebra y obtener simple hebra. Se agrega el cebador de secuenciación, el cual hibrida con la simple hebra de ADN pura. Esta forma de purificar el molde provee información de alta calidad y bajas señales de fondo. 


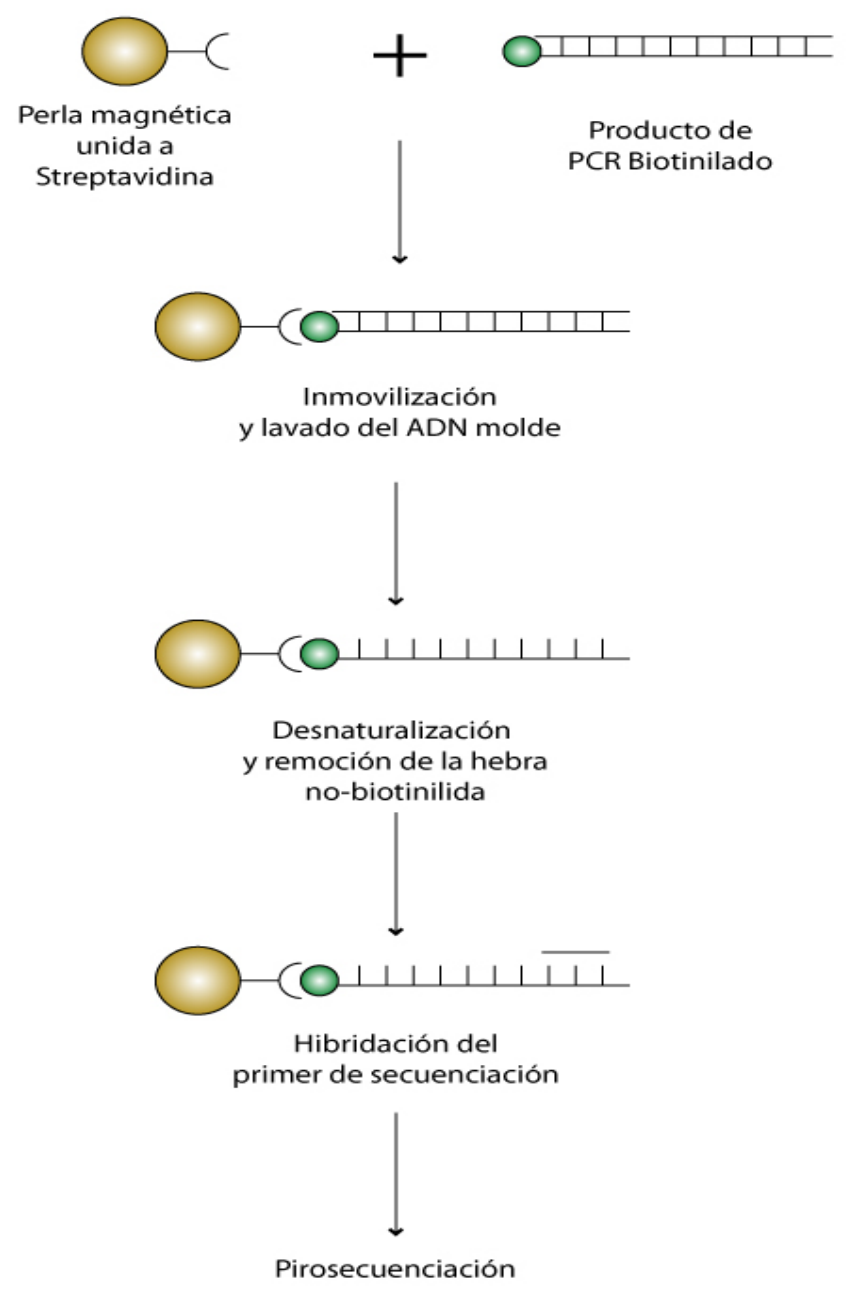

Fig. 44. Preparado del molde en fase sólida.

\section{Genotipificación de SNPs por pirosecuenciación.}

Para el análisis de SNPs por pirosecuenciación, el primer de secuenciación se diseña de forma tal que su extremo 3' hibride de una a tres bases antes de la posición polimórfica. En el pirograma se distinguen claramente los distintos genotipos; cada combinación alélica (homocigota o heterocigota) generará un patrón especifico comparado con las otras dos variantes (Ahmadian et al., 2000; Alderborn et al., 2000). Esta característica hace que la tipificación sea fácil y muy precisa. Por último, la pirosecuenciación permite la detección de haplotipos cuando varios SNPs están cercanos entre sí. 
1. Reconstituir la mezcla de enzimas (ADN polimerasa, ATP sulfurilasa, luciferasa y apirasa) y sustrato (adenosina 5 ' fosfosulfato APS y luciferina) cada una en $620 \mu$ de agua Milli $Q$.

2. Programar la corrida en la computadora del operador.

3. Agregar la mezcla de enzimas, la mezcla de sustrato y los cuatro deoxinucleótidos al cartucho ( $\mathrm{PSQ}^{\mathrm{TM}} 96$ cartridge) como se indica en la siguiente figura. Los volúmenes necesarios son calculados automáticamente por el software del PSQ 96MA.

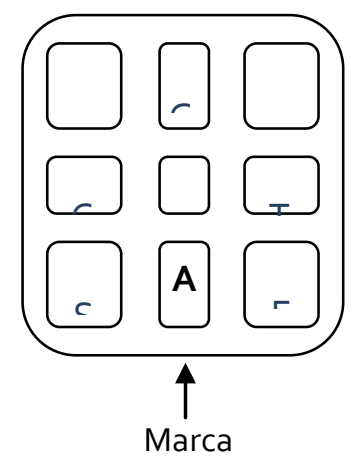

Representación esquemática de los PSO 96 reagent cartridge. EI contenido de los diferentescompartimentos están indicados por: $\mathrm{S}$ "sustrato"; E "mezcla de enzimas"; A, C, G y T para los diferentes nucleótidos.

4. Cargar la placa y el cartucho (cartridge) en el equipo PSQ 96 MA.

5. Iniciar la corrida. 


\section{Genotipificación por SEQUENOM}

amplification

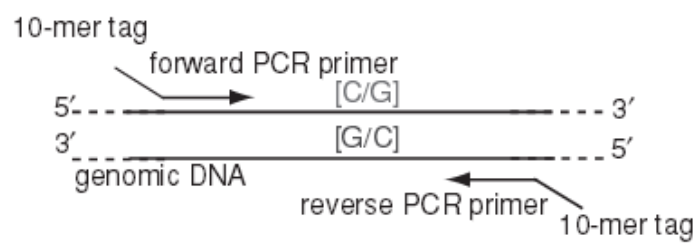

PCR product

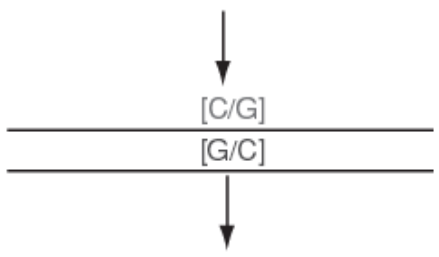

SAP treatment

iPLEX reaction

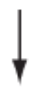

Tratamiento para

neutralizar los dNTPs no

incorporados

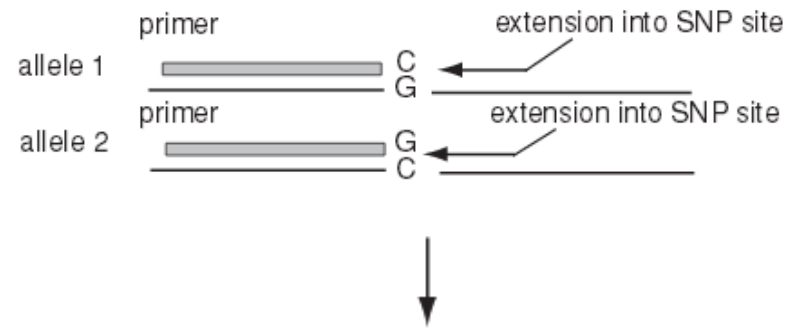

Mezcla que contiene el primer, la enzima, el buffer y nucleótidos de masa modificada

sample conditioning, dispensing, and MALDI-TOF MS

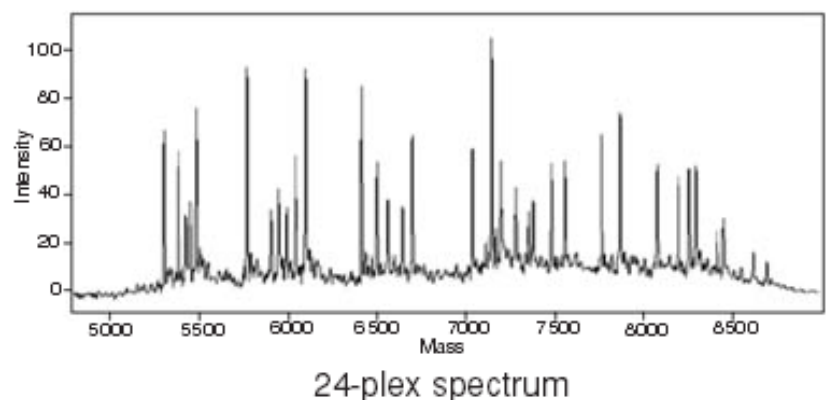

Análisis de

espectrometría de masa MALDI-TOFF

Fig. 45. Genotipificación por la plataforma SEQUENOM (adaptado de https://www.empiregenomics.com/files/store/products/Genotyping/SNP_Genotyping_Using_the\%20Seque nom.pdf) 